\title{
OXALAMIDES AS A HYDROGEN BONDING MOTIF IN THERMOPLASTIC ELASTOMERS
}


The research in this thesis was carried out from 2006 until 2010 in the research group Polymer Chemistry and Biomaterials of the MIRA institute for Biomedical Technology and Technical Medicine, University of Twente, Enschede, The Netherlands. The research was financially supported by the DOW chemical company under research agreement 218193.

\section{Committee}

Chairman: prof. dr. G. van der Steenhoven University of Twente Promotor: prof. dr. J. Feijen University of Twente Assistant promotor: prof. dr. P.J. Dijkstra University of Twente

Members:

\author{
dr. R. Broos \\ prof. dr. J.W.M. Noordermeer \\ prof. dr. V. Subramaniam \\ prof. dr. A.-J. Schouten \\ prof. dr. J.A. Loontjens \\ prof. dr. R.P. Sijbesma
}

\begin{abstract}
DOW Benelux BV
University of Twente

University of Twente

University of Groningen

University of Groningen

University of Eindhoven
\end{abstract}

Oxalamides as a hydrogen bonding motif in thermoplastic elastomers

Niels Sijbrandi

$\mathrm{PhD}$ Thesis with references and summaries in English and Dutch University of Twente, Enschede, The Netherlands

ISBN: 978-90-365-3245-7

DOI: http://dx.doi.org/10.3990/1.9789036532457

Printed by Wöhrmann Print Service, Zutphen, The Netherlands

(C) 2011 by N.J. Sijbrandi, all rights reserved.

Cover design by N.J. Sijbrandi 


\title{
OXALAMIDES AS A HYDROGEN BONDING MOTIF IN THERMOPLASTIC ELASTOMERS
}

\section{PROEFSCHRIFT}

\author{
ter verkrijging van \\ de graad van doctor aan de Universiteit Twente, \\ op gezag van de rector magnificus, \\ prof. dr. H. Brinksma, \\ volgens besluit van het College voor Promoties \\ in het openbaar te verdedigen \\ op donderdag 1 september 2011 om 12:45 uur
}

door

Niels Jurriaan Sijbrandi

geboren op 20 februari 1982

te Franeker 
Dit proefschrift is goedgekeurd door:

\section{Promotor}

prof. dr. J. Feijen

Assistent-promotor

prof. dr. P.J. Dijkstra

Dit werk is auteursrechtelijk beschermd

N.J. Sijbrandi

2011

ISBN: 978-90-365-3245-7 


\section{Contents}

1 General introduction 1

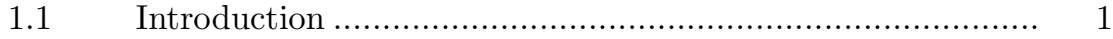

1.2 Aim of the study ...................................................... 3

1.3 Outline of the thesis ............................................. 4

$1.4 \quad$ References .............................................................. 5

2 Oxalamides as a hydrogen bonding motif in thermoplastic elastomers

$2.1 \quad$ Thermoplastic elastomers ....................................... 7

$2.2 \quad$ Oxalamides............................................................. 15

2.3 Polyoxalamides .................................................... 19

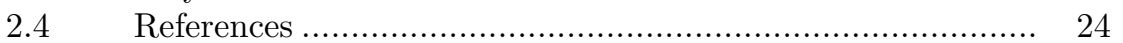

3 Design and properties of segmented poly(ether amide)s with uniform oxalamide based hard segments $\quad 31$

$3.1 \quad$ Introduction ....................................................... 32

Experimental................................................... 34

3.3 Results and Discussion ............................................. 40

3.4 Conclusions ..................................................... 50

3.5 References ....................................................... 50

4 Morphology and mechanical properties of segmented poly(ether amide)s with uniform oxalamide based hard segments $\quad 53$

$4.1 \quad$ Introduction ......................................................... 54

$4.2 \quad$ Experimental .......................................................... 56

4.3 Results and Discussion ........................................... 59

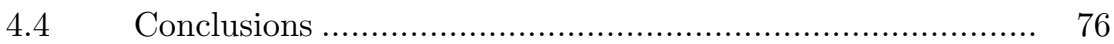

4.5 References ............................................................. 76

5 Effect of polytetrahydrofuran or oxamic acid ethyl ester end groups on the properties of low molecular weight bisoxalamide based segmented poly(ether amide)s $\quad 79$

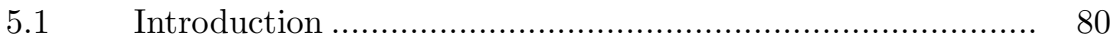

5.2 Experimental ....................................................... 82

5.3 Results and Discussion .......................................... 85

$5.4 \quad$ Conclusions .......................................................... 96

5.5 References ................................................................ 96

6 Conformation and crystal structure of bisester-bisoxalamides $\quad 99$

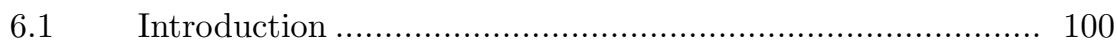

6.2 Experimental ................................................ 104

6.3 Results and Discussion ....................................... 108 


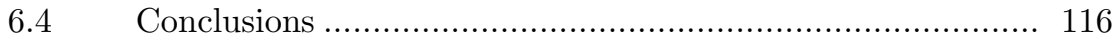

6.5 References ........................................................ 117

7 Synthesis, morphology and properties of segmented poly(ether ester amide)s comprising uniform glycine or $\beta$-alanine extended bisoxalamide hard segments

$7.1 \quad$ Introduction ........................................................... 120

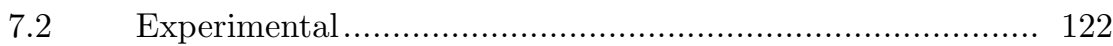

7.3 Results and Discussion ........................................... 128

$7.4 \quad$ Conclusions ........................................................... 150

$7.5 \quad$ References ............................................................... 151

8 The effect of molecular orientation in electrospun fibers of a segmented poly(ether amide) with uniform bisoxalamide hard segments on its mechanical properties 153

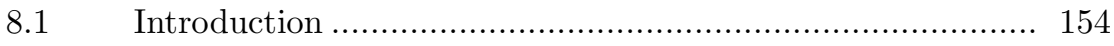

8.2 Experimental .......................................................... 156

8.3 Results and Discussion .......................................... 165

8.4 Conclusions ........................................................ 174

8.5 References ....................................................... 175

$\begin{array}{lr}\text { Summary } & 179\end{array}$

$\begin{array}{lc}\text { Samenvatting } & 183\end{array}$

$\begin{array}{ll}\text { Dankwoord } & 187\end{array}$

$\begin{array}{lc}\text { Curriculum Vitae } & 193\end{array}$ 


\section{Chapter 1}

\section{General introduction}

\subsection{Introduction}

\section{Thermoplastic elastomers}

Thermoplastic elastomers (TPEs) are a class of polymeric materials, which combine the characteristic elastic properties of conventional rubbers and processability of thermoplastics ${ }^{1-3}$. TPEs possess many rubber-like properties like softness, flexibility and elasticity. Unlike conventional rubbers, which are covalently crosslinked and can be regarded as thermoset polymers, TPEs contain thermally reversible physical crosslinks and hence can be melt processed. Due to its easy processing, TPE waste material can be recycled, which has become an important environmental as well as an economic issue in the development of new materials. The world demand of TPEs in 2008 was 3.1 million metric tons and is forecast to rise 5.9 percent per year through 2013 to 4.75 million metric tons ${ }^{4}$. This growth is driven by the intention to replace natural and synthetic rubbers that can not be recycled as well as by the exploration of possible new applications. The automotive industry is the largest market for TPEs at the global level. Other important applications of TPEs can be found in footwear, asphalt and bitumen modification, adhesives, sealants and coatings, consumer and sporting goods, wire and cable jacketing and medical products and equipment. Commercially important TPEs are divided into three groups, of which the styrenic type block copolymers (SBCs) is the largest in volume and is followed by the thermoplastic olefin/elastomer blends (TPOs and TPVs) and finally the segmented block copolymers. This last group is divided in thermoplastic polyurethane-, polyesterand polyamide elastomers (TPE-Us, TPE-Es and TPE-As, respectively).

\section{Segmented block copolymers}

Segmented block copolymers consisting of alternating soft and hard segments are typical examples of TPEs ${ }^{1,2}$. The hard segments form rigid domains, which serve as the thermo reversible crosslinks for the flexible soft matrix. Carbamate (urethane), urea and amide groups are often used as structural units in hard segments. These groups are well known for their ability to self-associate via hydrogen bonding, thereby creating the crosslinks necessary for the polymer matrix. Segmented block copolymers 
based on urethanes/ureas (TPE-Us) are a versatile class of polymers used in a variety of applications like foams, footwear and elastomer fibers ${ }^{2,5,6}$. A disadvantage of TPE-Us is their low thermal stability. As most TPE-Us have melting temperatures above their thermal decomposition temperatures melt processing is limited. Moreover, isocyanates, reagents for the preparation of TPE-Us, are industrially prepared from primary amines by reaction with phosgene, which is a highly toxic agent. Segmented block copolymers with hard segments comprising amide groups (TPE-As) have a much higher thermal stability than TPE-Us ${ }^{1}$. These TPE-As generally have an excellent toughness, chemical resistance, flexibility at low temperatures and elastic recovery. TPE-As are currently used in a wide range of applications from sports to medical equipment (Figure 1.1).

(a)

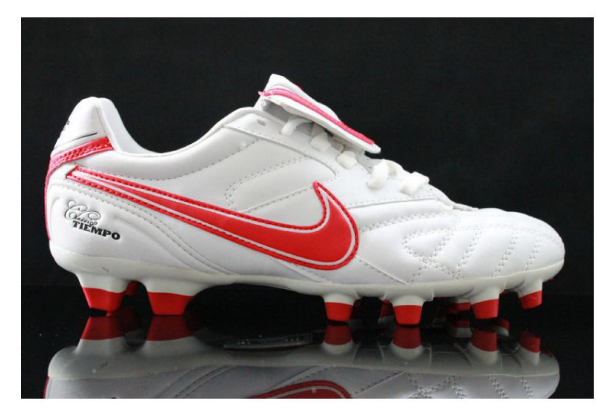

(b)

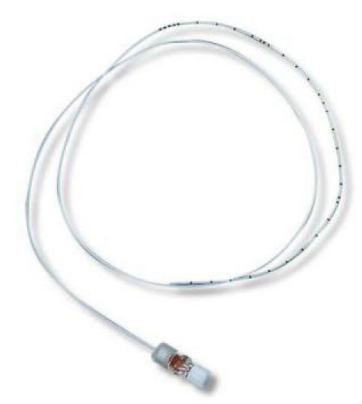

Figure 1.1: Examples of products in which TPE-As are used. (a) Football shoes, the outsole is made of TPE-A (PEBAX $\left.{ }^{\circledR}\right)$. (b) Urinary catheter made from a clear blend of TPE-A (PEBAX $\left.{ }^{\circledR}\right)$.

\section{Oxalamides}

Oxalamides, diamides of oxalic acid, are self-complimentary hydrogen bonding molecules capable of donating and receiving two hydrogen bonds ${ }^{7,8}$. These groups have a high in-plane trans configuration and in many cases their self-assembly results in robust one-dimensional hydrogen bonded arrays. Moreover, polymers comprising oxalamide groups have properties like high moduli, high melting temperatures and limited solubility in organic solvents ${ }^{9,10}$. These properties combined with the persistent selfassembly behavior make oxalamide groups an interesting hydrogen bonding motif to be used in hard segments that are able to physically crosslink a soft polymer matrix (Figure 1.2). 


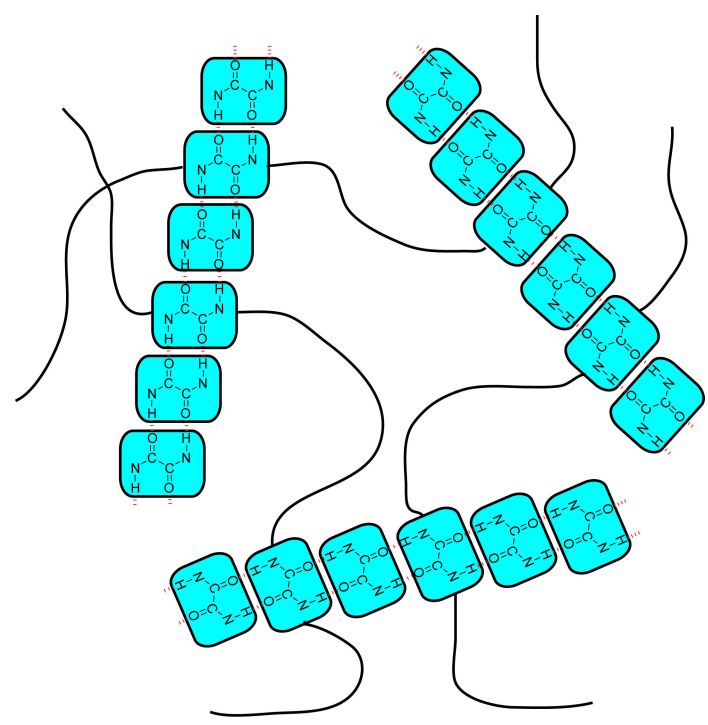

Figure 1.2: Schematic representation of a copolymer composed of hydrogen bonded oxalamide groups and flexible soft segments.

Oxalic acid and its ester derivatives are prepared on an industrial scale and are thus economically accessible monomers ${ }^{11}$. As we describe in this thesis, the hard segments based on oxalamides in TPEs can be prepared from diethyl oxalate, aliphatic diamines and amino acids, compounds based on renewable resources ${ }^{11,12}$.

\subsection{Aim of the study}

The aim of the study was to investigate the oxalamide group as hydrogen bonding motif for use as crosslinker in TPEs. As such, segmented poly(ether amide)s were prepared consisting of alternating polytetrahydrofuran (PTHF) soft segments and uniform oxalamide based hard segments. The number of oxalamide groups, the length of the aliphatic spacer between oxalamide groups and the end groups of the oxalamide hydrogen bonding array were systemically varied in order to find the optimal hydrogen bonding array providing the material with interesting mechanical and thermal properties. The polymers are fully characterized in terms of their physical, thermal and mechanical properties. To understand the structure-property relationship, knowledge of the phase separated morphology and organization of the oxalamide hard segment is of utmost importance. 


\subsection{Outline of the thesis}

In this thesis, segmented block copolymers based on PTHF soft segments and uniform oxalamide based hard segments are described. The synthesis, morphology and properties have been investigated in detail.

In chapter 2 a literature review is presented on segmented poly(ether amide)s, including the synthesis and properties of segmented poly(ether amide)s comprising both polydisperse aliphatic or uniform (semi-)aromatic hard segments. A second topic highlighted is the hydrogen bonding and conformational characteristics of oxalamide units and their use in crystal engineering. Finally, the synthesis, thermal properties and crystal structure of known polyoxalamides is presented.

In chapter 3 the synthesis and structure of segmented poly(ether amide)s composed of PTHF soft segments and uniform oxalamide based hard segments is described. The number of oxalamide groups in the hard segment and aliphatic spacer length between oxalamide groups were systematically varied to determine the effects of an oxalamide based hard segment on the thermal properties of the segmented poly(ether amide)s. Hard segments generated by bis- or trisoxalamides were identified as strong and directional hydrogen bonding segments providing elastic materials with good thermal properties. The phase separated morphology and mechanical properties of these polymers are described in Chapter 4. Emphasis is given on the organization of the oxalamide hard segments in the fiber-like nano-crystals present in the PTHF soft matrix on the basis of X-ray measurements.

In Chapter 5 the effect of PTHF or oxamic ethyl ester end groups on the thermal and mechanical properties of low molecular weight bisoxalamide based segmented poly(ether amide)s is described. These polymers were prepared by melt polycondensation of an $\alpha, \omega$-amino end functionalized PTHF and a bisoxalamide precursor applying different molar feed ratios.

In chapter 6, a series of bisoxalamides end functionalized with glycine or $\beta$-alanine ester groups is presented. A qualitative model of the crystalline structures of these compounds was proposed on basis of X-ray diffraction and FT-IR measurements. High molecular weight segmented poly(ether ester amide)s were prepared by melt condensation of the bisester-bisoxalamide monomers with $\alpha, \omega$-hydroxyl end functionalized PTHF. The effect of the structure of the bisester-bisoxalamide segment and the length of the soft PTHF block on the thermal, physical and mechanical properties of the 
obtained TPEs is discussed in chapter 7. Special attention is given to the influence of the glycine and $\beta$-alanine moiety on the thermal and mechanical properties of the segmented poly(ether ester amide)s.

A segmented poly(ether amide) composed of uniform bisoxalamide hard segments and PTHF soft segments, as described in chapter 3, was electrospun in fibers with diameters ranging from 150 to $2000 \mathrm{~nm}$ (chapter 8). The molecular orientation of the polytetrahydrofuran and the bisoxalamide segments in single electrospun fibers was investigated using polarized Raman microspectroscopy. Tensile tests on single electrospun fibers were performed using an atomic force microscope (AFM) setup. The relation between the molecular orientation in single electrospun segmented poly(ether amide) fibers and the mechanical properties is discussed.

\subsection{References}

[1] Fakirov, S. Handbook of condensation thermoplastic elastomers; Wiley-VCH: Weinheim, 2005.

[2] Holden, G.; Legge, N. R.; Quirk, R.; Schroeder, H. Thermoplastic elastomers, 2nd ed.; Hanser Publishers: Munich, 1996.

[3] Kear, K. Developments in thermoplastic elastomers; Rapra technology LTD: Shawbury, 2003.

[4] http://www.freedoniagroup.com/brochure/25xx/2551smwe.pdf.

[5] Szycher, M. Szycher's handbook of polyurethanes; CRC Press: Boca Raton, 1999.

[6] Thomson, T. Polyurethanes as speciality chemicals "principles and application"; CRC Press: Boca Raton, 2005.

[7] Coe, S.; Kane, J. J.; Nguyen, T. L.; Toledo, L. M.; Wininger, E.; Fowler, F. W.; Lauher, J. W. J Am Chem Soc 1997, 119, 86-93.

[8] Aleman, C.; Casanovas, J. J Mol Struct Theochem 2004, 675, 9-17.

[9] Black, W.; Preston, J. Man-made fibers. science and technology, 2nd ed.; Interscience: New York, 1968.

[10] Shalaby, S. W.; Pearce, E. M.; Frederic, R. J.; Turi, E. A. J Polym Sci Part B Polym Phys 1973, 11, 1-14.

[11] Kirk-Othmer, Encyclopedia of Chemical Technology; John Wiley \& Sons, Inc: New York, 2007.

[12] Naik, S. N.; Goud, V.; Rout, P.; Dalai, A. Renewable and Sustainable Energy Rev 2010, 14, 578-597. 


\section{Chapter 2}

\section{Oxalamides as a hydrogen bonding motif in thermoplastic elastomers}

\subsection{Thermoplastic elastomers}

Thermoplastic elastomers (TPEs) are materials that combine the physical characteristics of conventional elastomers (e.g. vulcanized natural rubber) with the processing characteristics of thermoplastics ${ }^{1-3}$. The principal difference between conventional elastomers and TPEs is the type of crosslinking. Covalent crosslinks in conventional elastomers are created by vulcanization, which is a slow irreversible process. Consequently, once shaped and vulcanized, the material cannot be processed anymore. In contrast, TPEs contain thermally reversible crosslinks generated through phase separation, crystallization, hydrogen bonding or ionic interactions. This gives manufacturers the ability to produce rubber-like materials using fast processing equipment like injection molders, blow molders and extruders, that have been developed for the plastics industry. Moreover, the intensive (and expensive) compounding and vulcanization steps of conventional rubber processing are eliminated and scrap can usually be reground and recycled.

TPEs can be divided in three groups, namely:

- Styrenic triblock copolymers (SBCs)

- Elastomeric blends such as thermoplastic olefins (TPOs) and thermoplastic vulcanisates (TPVs)

- Segmented block copolymers such as thermoplastic polyurethane-, polyester- or polyamide elastomers (TPE-Us, TPE-Es, TPE-As, respectively) 


\subsubsection{Segmented block copolymers}

Segmented block copolymers consisting of alternating flexible soft segments and rigid hard segments are an important class of TPEs. Polyesters and polyethers having a low glass transition temperature are often used as the flexible soft segments, while the hard segments can be either polymers or short chains containing carbamate (urethane), ester, urea or amide groups ${ }^{1-3}$. At ambient temperatures, the hard and soft segments are thermodynamically immiscible and phase separation from the melt by cooling occurs via either liquid-liquid demixing or crystallization. Whereas, carbamate (urethane) based hard segments often phase separate through liquid-liquid demixing followed by partial crystallization, segments consisting of ester or amide groups usually phase separate through crystallization. A schematic morphological representation of segmented block copolymers consisting of fast crystallizable hard segments is depicted in Figure 2.1 ${ }^{4}$. In these segmented block copolymers the hard segments form crystalline domains (A) which are randomly dispersed in a soft polymer matrix (D). These domains act as physical crosslinks providing the material with dimensional stability and reinforcing the soft polymer matrix. The soft phase mainly consists of low $\mathrm{T}_{\mathrm{g}}$ soft segments which provide the material its elastomeric character. The hard segments that do not crystallize (C) mix with the soft phase. When the material is heated above the melting point of the hard domains, the polymer becomes a viscous liquid and can be melt processed.

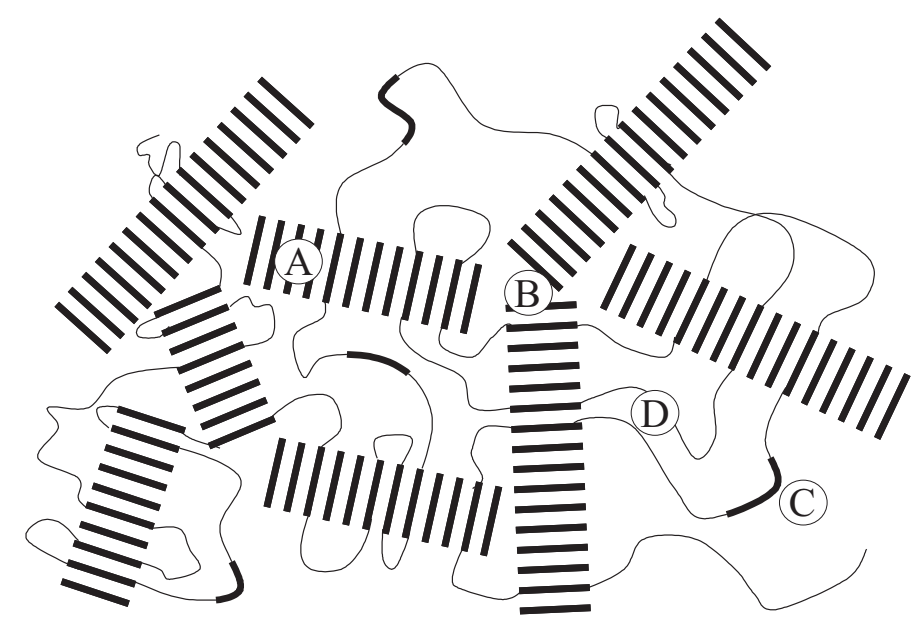

Figure 2.1: Schematic representation of the morphology of a segmented block copolymer with crystallizable hard segments. (A) crystalline domain, (B) junction of crystalline lamellae (C) amorphous hard segment and (D) amorphous phase ${ }^{4}$. 


\subsubsection{Segmented poly(ether amide)s}

A class of segmented block copolymers described above are the segmented poly(ether amide)s consisting of alternating polyether soft segments and rigid amide group containing hard segments. Mostly, the flexible segments applied in these copolymers are poly(tetramethylene oxide) (abbreviated as PTMO, PTMG or PTHF), poly(ethylene oxide) (abbreviated as PEO or PEG) or poly(propylene oxide) (abbreviated as PPO or PPG). The amide segments are mainly based on nylon-6, nylon-11 or nylon-12 although segmented poly(ether amide)s based on nylon-6,6, nylon-6,10, nylon-6,12, nylon-10,10, nylon-11,6 or nylon- 4,6 have also been reported ${ }^{1,2,5-11}$. An overview of commercially available segmented poly(ether amide)s is presented in Table 2.1.

Table 2.1: Suppliers, trade names and structures of commercially available segmented poly(ether amide)s ${ }^{1}$.

\begin{tabular}{llll}
\hline Supplier & Trade name & Soft segment & Hard segment \\
\hline Arkema & PEBAX $^{\circledR}$ & PTMO & nylon-12 \\
& & & nylon-11 \\
& & PEO & nylon-6 \\
& PLATAMID $^{\circledR}$ & PEO & co-polyamide \\
& VESTAMID $^{\circledR}$ E & PTMO & nylon-12 \\
Degussa & GRILAMIDE $^{\circledR}$ ELY & PTMO & nylon-12 \\
EMS-Grivory & PELESTAT $^{\circledR}$ & BEO $^{a}$ & nylon-6 \\
Sanyo & PELI) & & nylon-12 \\
Ube & PAE & PPO & co-polyamide \\
\hline
\end{tabular}

${ }^{\mathrm{a}}$ Bisphenol A ethoxylate (BEO)

In the late 1960s and early 1970s, various research groups explored the possibility of synthesizing segmented poly(ether amide)s by covalently linking polyether blocks to polyamide blocks via amide, carbamate or urea linkages. Several polymerization methods were employed for the synthesis of these segmented poly(ether amide)s, such as thermal polymerization, solution polymerization, interfacial polymerization and anionic polymerization ${ }^{1,2,12}$. However, it was not until the discovery of titanium tetraalkoxide catalysts that the synthesis of sufficiently high molecular weight segmented poly(ether amide)s with ester linkages became possible ${ }^{1,2,6-8,12}$. This discovery resulted in the introduction of the segmented poly(ether amide)s known as PEBAX ${ }^{\circledR}$ by Atochem (now Arkema) who is the leader in the production of segmented poly(ether amide)s. 
PEBAX ${ }^{\circledR}$ is prepared in two steps (Scheme 2.1) $)^{1,2,5-8}$. In the first step, an $\alpha, \omega$ carboxylic acid end functionalized polyamide block is prepared by reacting lactams, amino $\operatorname{acid}(\mathrm{s})$ and/or diacids and diamines, usually under pressure at high temperatures in the presence of a chain terminating di-acid (Scheme 2.1a). The average molecular weight of the polyamide fragment can be tuned by the amount of terminating acid groups relative to the amount of the polyamide forming monomers. Subsequently, this oligomer is reacted with an $\alpha, \omega$-hydroxyl end functionalized polyether in the presence of a suitable catalyst to enhance the reaction rate (Scheme 2.1b). A large range of materials, in which the molecular weight $\left(\mathrm{M}_{\mathrm{n}}\right)$ of the polyether blocks varied from 400 to 3000 g.mol ${ }^{-1}$ and that of the polyamide blocks from 500 to 5000 g.mol ${ }^{-1}$, have been prepared.

(a)

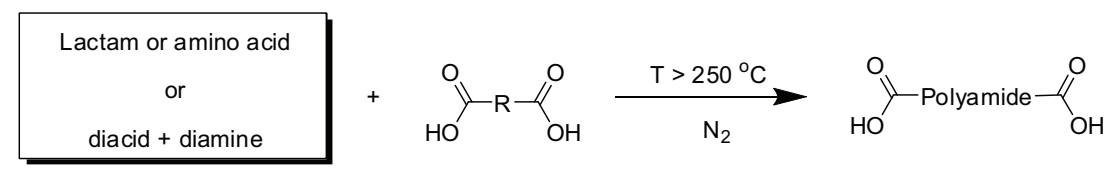

(b)

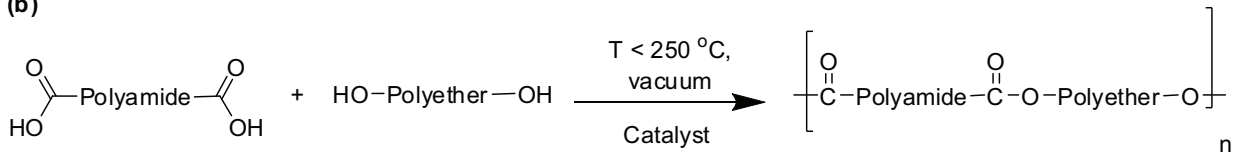

Scheme 2.1: Schematic representation of the preparation of PEBAX ${ }^{\circledR}$. (a) Synthesis of an $\alpha, \omega$-carboxylic acid end functionalized polyamide block, (b) polymerization to a segmented poly(ether amide).

Degussa prepares its range of segmented poly(ether amide)s (under the trade name VESTAMID $^{\circledR}$ E) in a single step by first mixing all monomers and prepolymers together followed by polycondensation ${ }^{1}$. An advantage of this method is that more homogeneous reaction mixtures and higher polymerization rates are obtained. This preparation method leads to a statistical distribution of the monomers in the polymer chain. A main drawback of this method is the potential degradation of the polyether segments due to the rather severe process conditions. Especially when using lactams, which generally require high temperatures for ring-opening, side reactions can easily occur. 
Structural characterization of the poly(ether amide)s described above revealed a well-defined phase separation that depends on the type and molecular weight of the polyether and polyamide macromonomers ${ }^{9,10,12-32}$. The polyamide segments crystallize in a lamellar type structure independent of the polyether/polyamide mass ratio. In polyamide rich polymers the lamellar structures are able to self-organize in larger spherulitic superstructures.

The mechanical behavior of segmented poly(ether amide)s depends on the polyether/ polyamide mass ratio (PE/PA ratio) ${ }^{12}$. The segmented copolymers show typical elastomeric properties if the polyether matrix is the continuous phase in which the crystalline polyamide domains are dispersed $(\mathrm{PE} / \mathrm{PA}>1)$. The moduli of these materials range from 10 to $30 \mathrm{MPa}$, the yield strain is in between 100 and $200 \%$ and strains at break are above $1000 \%$. Furthermore, the materials exhibit good recoverability, low permanent set and low mechanical hysteresis. On the other hand, at low polyether/polyamide mass ratios $(\mathrm{PE} / \mathrm{PA}<1)$, the hard phase becomes more and more interconnected and polymer properties change to those of typical thermoplastics ${ }^{12}$. Materials with a $\mathrm{PA} / \mathrm{PE}$ ratio close or equal to 1 show an intermediate behavior associated to some extent with a co-continuous phase.

\subsubsection{Uniform hard segments}

When the molecular weight distribution of the hard segments in segmented block copolymers is polydisperse incomplete phase separation takes place. The shorter segments mainly dissolve in the soft polymer matrix resulting in an increase in the glass transition temperature and hence reducing the elastomeric behavior at lower temperatures. Another disadvantage of the presence of polydisperse hard segments is broadening of the melting transition resulting in a temperature dependent rubber plateau. Furthermore, a high hard segment concentration in the polymer is needed to obtain good mechanical properties.

To improve material properties several segmented copolymers with uniform urethane, urethane(urea), urea and amide based hard segments were prepared ${ }^{33-50}$. The properties of these segmented block copolymers are significantly affected by the symmetry and type of hydrogen bonding in the hard segment. Segmented block copolymers comprising uniform hard segments showed a better phase separation and a higher degree of hard segment crystallization than their polydisperse analogues. Consequently, segmented block copolymers with uniform hard segments have a low glass transition 
temperature and a sharp melting transition resulting in improved elastomeric behavior at low temperatures and a broad temperature independent rubber plateau. Furthermore, these materials possess good thermal and mechanical properties even at low hard segment concentrations.

Segmented poly(ether amide)s comprising uniform amide based hard segments have been extensively studied by Gaymans and coworkers ${ }^{33,34,46,47,51-70}$. Chemical structures of these segments, such as the di-aramid segment (T $\Phi \mathrm{T}$ ) composed of dimethyl terephthalate $(\mathrm{T})$ and 1,4-phenylenediamine $(\Phi)$ or the tetra-amide segment (T6T6T) composed of dimethyl terephthalate $(\mathrm{T})$ and 1,6-diaminohexane (6), are depicted in Figure 2.2. In the synthesis of these (macro)monomers oligomerization readily occurred and extensive fractionation was necessary. The segmented poly(ether amide)s were generally prepared by reacting the preformed hard segments with $\alpha, \omega$-hydroxyl end functionalized polyethers in a two step solution/melt polycondensation yielding high molecular weight transparent elastic materials. Even at a hard segment concentration of $\sim 3$ wt $\%$ the polymers displayed a highly phase separated morphology of fiber-like nano-crystals randomly dispersed in a soft polymer matrix. Although the hard segments are relatively short $(<3 \mathrm{~nm})$, they crystallize fast and almost completely in the polymer matrix. The materials possess attractive physical properties like a low glass transition temperature, a broad and almost complete temperature independent rubber plateau with a relatively high modulus and a sharp melting transition.
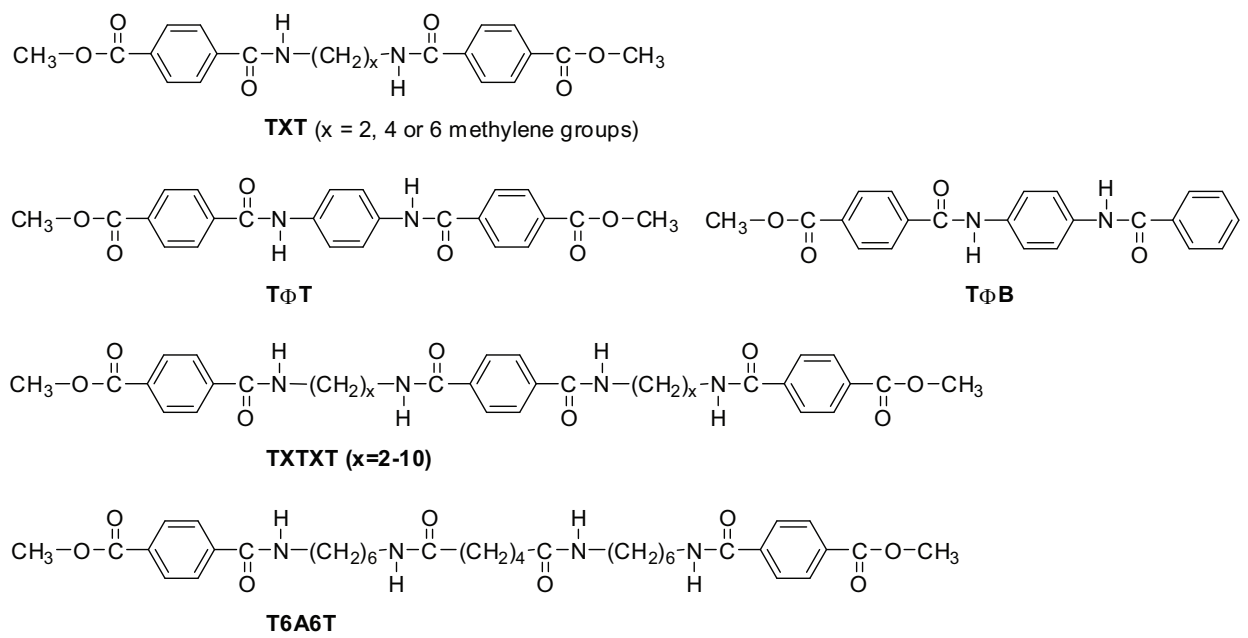

Figure 2.2: Structures of uniform amide based hard segments used in segmented poly(ether amide)s $\mathrm{s}^{33,34,46,47,51-70}$. 


\subsubsection{Hydrogen bonding end-groups}

A relative new concept in materials science is the end functionalization of low molecular weight polymers with groups that are self-complementary in the formation of hydrogen bonds $^{71}$. Due to association of the end-groups, polymer chains are formed with a virtual high molecular weight (Figure 2.3a). These polymers are also referred to as the so-called supramolecular polymers. However, at higher temperatures hydrogen bonds are easily broken and the polymer chains dissociate into their low molecular weight precursors. The resulting decrease in melt viscosity is advantageous for the processability of the material. To allow the formation of supramolecular polymers with significant degrees of polymerization, a high association constant between hydrogen bonding groups is needed. The 2 -ureido-4[1H]-pyrimidinone (UPy) is a well-known quadruple hydrogen bonding motif (Figure 2.3b) and has been extensively used as an end-to-end associating group due to its high association constant $\left(\mathrm{K}_{\text {assoc }}=6.10^{8} \mathrm{M}^{-1}\right.$ in toluene) and synthetic accessibility ${ }^{72-77}$.

(a)

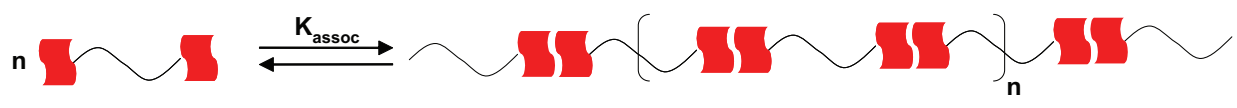

(b)
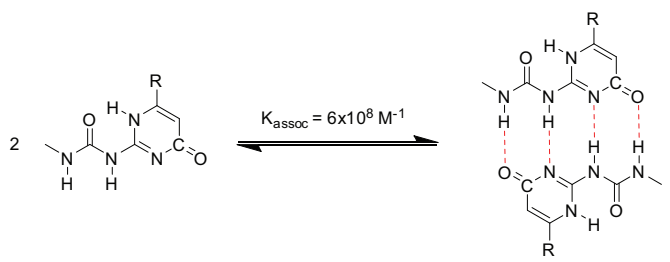

Figure 2.3: (a) Schematic representation of a supramolecular polymer. (b) Dimerization of 2-ureido-4[1H]-pyrimidinone (UPy).

Although dimerization of the UPy moiety allowed the formation of polymers (polyethers, polyesters and polycarbonates) with virtual high molecular weights, the materials lack dimensional stability, have low moduli and as discussed above the properties are highly temperature dependent. Kautz et $a l^{78}$ showed that addition of an additional carbamate (urethane) or urea group leads to lateral aggregation, and formation of fiber-like nano-ribbons in the polymer matrix (Figure 2.4). The formation of the nano-ribbons dramatically improved the mechanical and thermal properties of the corresponding polymers. 

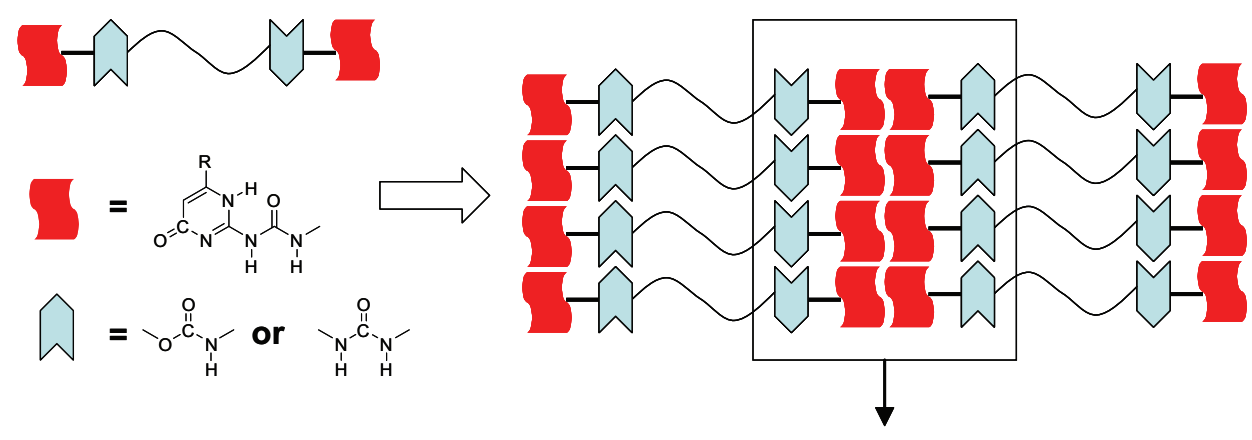

Fiber-like nano-ribbon

Figure 2.4: Schematic representation of a polymer with hydrogen bonding in longitudinal and lateral directions.

\subsubsection{Segmented poly(ether amide)s with oxalamide based hard segments}

To our knowledge, only one patent reports on the use of oxalamides in segmented poly(ether amide)s (Scheme 2.2) ${ }^{79}$. These segmented poly(ether amide)s were prepared by reacting in a first step Jeffamines ${ }^{\circledR}$ (amine terminated PPO - $\mathrm{M}_{\mathrm{n}}=300-3000$ g.mol${ }^{-1}$ ) with diethyl oxalate to convert the amine functional groups to the corresponding amide-ester groups. Subsequently, the amide-ester functionalized Jeffamine ${ }^{\circledR}$ was polycondensated with a variety of aliphatic and aromatic $\alpha, \omega$-diamines. The reaction afforded polymers with mechanical properties varying from though elastic to hard and brittle and melting temperatures ranging from 90 to $250{ }^{\circ} \mathrm{C}$, depending on the polymer composition.

(a)

$\mathbf{x}$
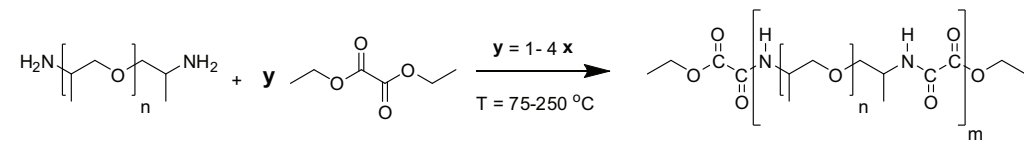

(b)

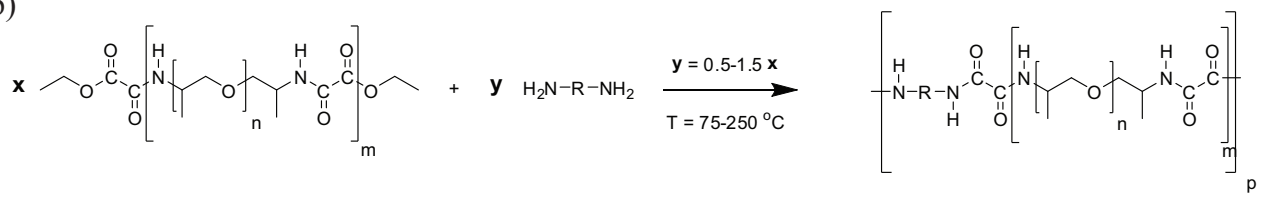

Scheme 2.2: Synthesis of oxalamide based segmented poly(ether amide)s ${ }^{79}$. 


\subsection{Oxalamides}

The oxalamide group as a hydrogen bonding motif has been utilized in various research areas, like crystal engineering ${ }^{80-84}$, protein engineering ${ }^{85-88}$, organic gelators ${ }^{89-92}$ and materials science ${ }^{93}$. Oxalamides, diamides of oxalic acid, are self-complimentary hydrogen bonding molecules capable of donating and receiving two hydrogen bonds (Figure 2.5 $)^{80}$. The solid state structure of N,N'-dimethyl oxalamide (DMO) as determined from X-ray data shows that the molecule has a planar trans configura$\operatorname{tion}^{94}$.

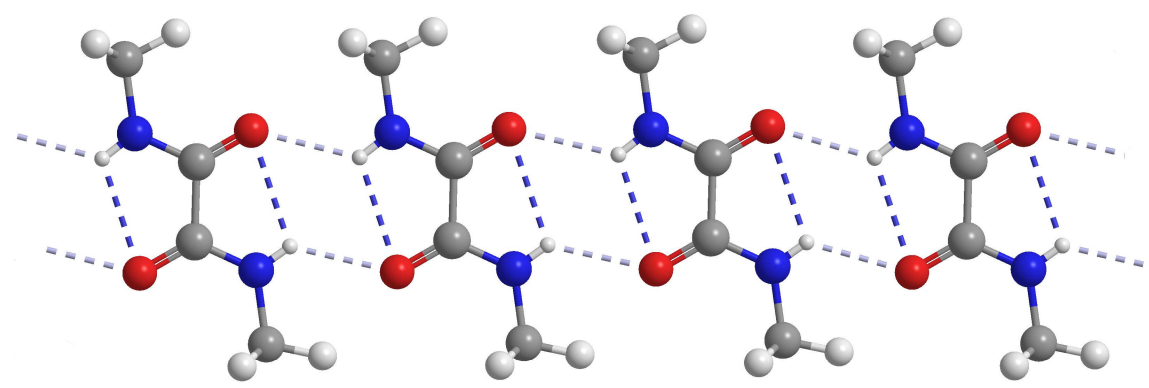

Figure 2.5: The solid state structure of N,N'-dimethyloxalamide ${ }^{94}$.

\subsubsection{Conformation and hydrogen bonding of oxalamides}

The conformation and hydrogen bonding of N,N'-disubstituted oxalamide derivatives was studied by using N,N'-dimethyloxalamide (DMO) as a model compound ${ }^{95,96}$. Gas-phase energy calculations revealed distinct energy minima for three different conformations (Figure 2.6). The conformation with the lowest energy corresponds to the trans-trans-trans ( $t t t$ ) conformation. A second energy minimum was found for the cis-trans-trans (ctt) conformation, which is $6.6 \mathrm{kcal}^{\mathrm{mol}}{ }^{-1}$ less stable than the all trans conformation. The least stable conformation, $12.7 \mathrm{kcal}^{\mathrm{mol}}{ }^{-1}$ higher in energy, corresponds to the csc (cis-skew-cis) conformation. The central dihedral angle $\left(\omega_{2}\right)$ is $144.8^{\circ}$ (skew conformation) and the other groups are in a cis conformation. Similar calculations on N-methylacetamide (NMA) revealed that the trans and the cis conformation differ only $2.1 \mathrm{kcal}^{\mathrm{mol}} \mathrm{m}^{-1}$ in energy, which illustrates the conformational rigidity of the oxalamide group compared to the acetamide group and its preference for a planar $t t t$-conformation. This conformational rigidity also insures its in-plane hydrogen bonding. 
<smiles>CNC(=O)CCCNC(=O)C(C)NC</smiles>

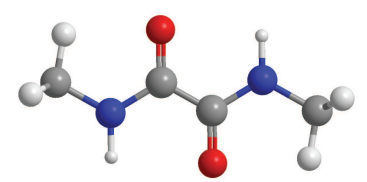

$t t t$

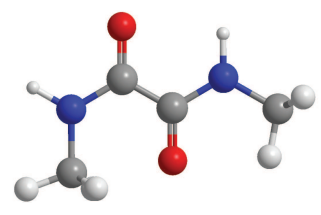

ctt

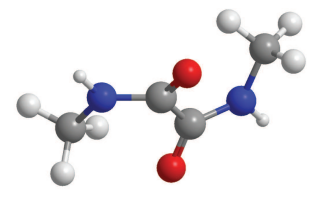

$\csc$

Figure 2.6: Calculated low energy conformations of N,N'-dimethyloxalamide ${ }^{95,96}$.

(a)

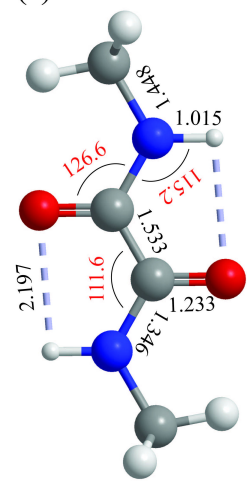

(b)

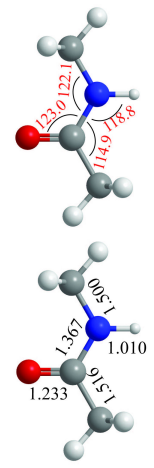

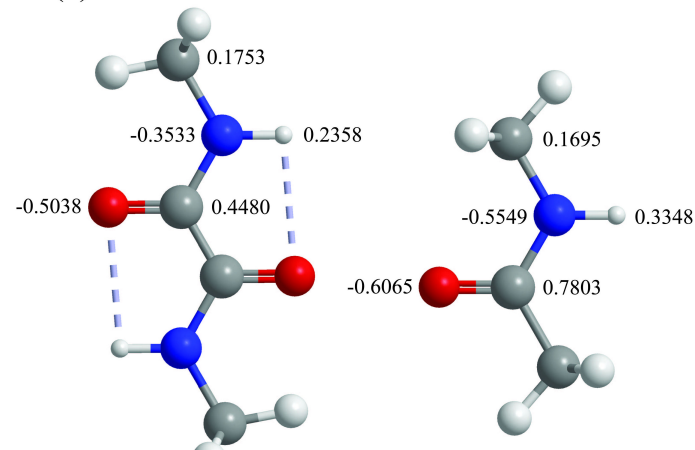

Figure 2.7: Relevant geometrical (a) and electronic (b) parameters for the oxalamide and amide functionality obtained from ab initio calculations on N,N'-dimethyl oxalamide and $\mathrm{N}$-acetamide ${ }^{95}$. The two $\mathrm{C} 5$ intramolecular interactions in the oxalamide group are represented by the dotted lines.

The most relevant bond distances and charge densities of the oxalamide and the amide group, which were obtained from ab initio calculation on DMO and NMA are depicted in Figure $2.7^{95}$. The $\mathrm{N}-\mathrm{C}(\mathrm{O})$ bond length and the $<\mathrm{H}-\mathrm{N}-\mathrm{C}(\mathrm{O})$ angle are $0.021 \AA$ and $3.6^{\circ}$ larger in amides than in oxalamides. Furthermore the $\mathrm{N}-\mathrm{H}$ bond is shorter in amides than in oxalamides. These geometrical features are related to the formation of a C5 conformation with an intramolecular hydrogen bond.

The ability of the oxalamide group to form intramolecular hydrogen bonds has been confirmed by spectroscopic methods like NMR and also X-ray diffraction ${ }^{95,97-101}$. 
The most reliable criterion of hydrogen bond formation is that based on the van der Waals radii. The van der Waals radii that are possibly engaged in amides are 1.55 $\AA(\mathrm{N})$ and $1.52 \AA(\mathrm{O})$. Thus for $\mathrm{N}-\mathrm{O}$ distances shorter than $3.07 \AA$, the presence of a hydrogen bond must be considered. In the trans-planar configuration of DMO, both the inter- and intramolecular N-O distances (2.720 and $2.860 \AA$, respectively) are shorter than the van der Waals radius ${ }^{94}$. This clearly indicates that the hydrogen bonds are bifurcated exhibiting weak intramolecular and stronger intermolecular hydrogen bonds. Moreover, infrared spectra of oxalamides dissolved in $\mathrm{CH}_{2} \mathrm{Cl}_{2}$ at high dilution revealed the presence of hydrogen bonds indicating intramolecular hydrogen bonding ${ }^{98}$. The intra- and intermolecular hydrogen bond interactions also depend highly on substituents. It was shown for N,N'-butyl substituted oxalamides $\left(\mathrm{C}_{4} \mathrm{H}_{9}\right.$, $i$ - $\mathrm{C}_{4} \mathrm{H}_{9}, s-\mathrm{C}_{4} \mathrm{H}_{9}$ and $t$ - $\left.\mathrm{C}_{4} \mathrm{H}_{9}\right)$ that the intramolecular hydrogen bonding character of the oxalamide increases with the amount of methyl groups on the $\alpha$-carbon due to steric hindrance. It appeared that the hydrogen bonding in the $t$ - $\mathrm{C}_{4} \mathrm{H}_{9}$ derivative was almost exclusively intramolecular ${ }^{98}$.

Energy calculations showed that the intermolecular $\mathrm{N}-\mathrm{H} \cdots \mathrm{O}=\mathrm{C}$ hydrogen bond formed by two amide groups in NMA is about $30 \%$ stronger than that involving two oxalamide groups ${ }^{95,98}$. Moreover, the cooperative energy effects generated by formation of multiple hydrogen bonds are almost negligible for oxalamides while these account for about $\sim 17 \%$ in amides. Another important difference in hydrogen bonding between oxalamide groups and amide groups concerns the linearity of the intermolecular hydrogen bonds. The $\mathrm{N}-\mathrm{H} \cdots \mathrm{O}=\mathrm{C}$ angle in oxalamide-oxalamide hydrogen bonding deviates $\sim 30{ }^{\circ} \mathrm{C}$ from linearity whereas the amide-amide hydrogen bonding is close to linearity. The difference in conformation between the oxalamide groups and amide groups is mainly ascribed to the intramolecular hydrogen bonding in the oxalamide. DMO and NMA also exhibit important electronic differences as depicted in Figure 2.7. The charge separation is larger in NMA than in DMO.

\subsubsection{Oxalamides in crystal engineering}

The hydrogen bonding between oxalamides groups has been successfully used to structurally pre-organize diacetylenes necessary for their polymerization ${ }^{81,82,102,103}$. Poly(diacetylene)s (PDAs) are conjugated polymers which are potent multiphoton absorbers that have application in optical limiters, waveguides and thermometric sensors. The only viable synthetic method for the preparation of PDAs is polymer- 
ization in the solid state via a topochemical reaction. If the reactive monomers are preorganized at a distance commensurate with the repeat distance in the final polymer $(\sim 4.9 \AA)$, then the application of thermal or photochemical energy can bring about the polymerization (Figure 2.8a). Most diacetylenes do not crystallize in accordance to these precise structural requirements and hence no polymerization occurs.

Lauher and Fowler demonstrated that substituted oxalamides, allowing hydrogen bonding interactions through carboxylic acids, pyridines or hydroxyl groups form two-dimensional hydrogen bonded layers in a predictable fashion. The oxalamide groups provide like-to-like hydrogen bonding in one direction with a characteristic repeat distance of $\sim 5 \AA$, whereas the end groups dimerize in a second direction through hydrogen bonding ${ }^{80,83,84}$. By functionalizing diacetylenes with complementary endgroups, these monomers can be co-crystallized with the oxalamide host compounds (Figure 2.8b). This so called host-guest approach allows pre-organization of diacetylenes necessary for topochemical polymerization. The result of the polymerization reaction is a single crystal with polymer chains embedded in a lattice of oxalamide host molecules. The crystalline product, with all the diacetylene units in perfect alignment, has highly anisotropic spectroscopic properties.

(a)

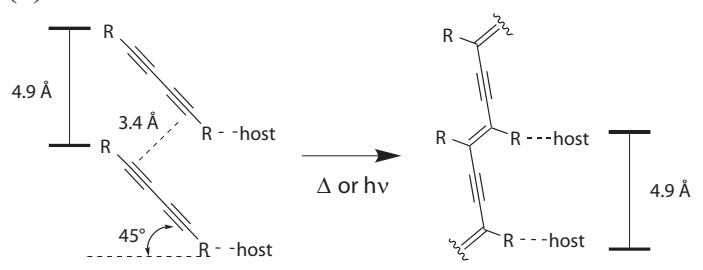

(b)

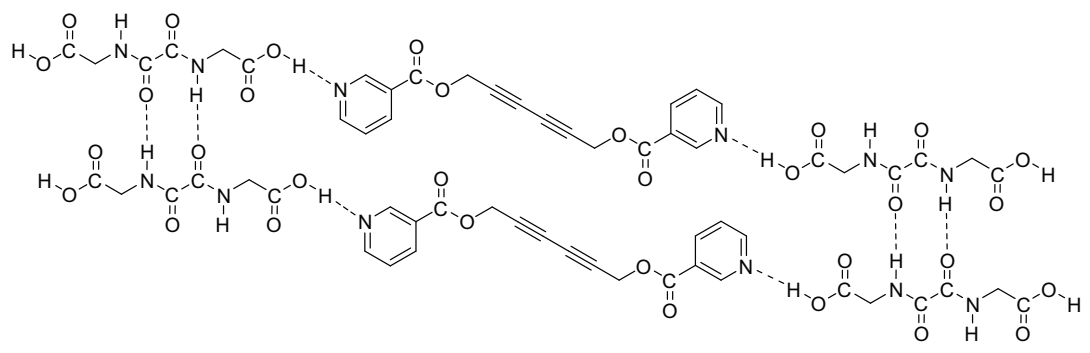

Figure 2.8: (a) Topochemical diacetylene polymerization. (b) Host-guest co-crystal structure of a glycine substituted oxalamide and a pyridine substituted diacetylene monomer. 


\subsection{Polyoxalamides}

Nylon-10,2 was the first polyoxalamide reported in the patent literature ${ }^{104}$. Since then, several patents and technical papers pointed out that oxalamide based polyamides possessed some interesting properties like unusual solubility characteristics, unusual high moduli of shaped materials, high melting temperatures and low water absorption ${ }^{105}$. Moreover, incorporation of oxalamide sequences in random or block polyamides, was shown to improve their physical properties and mechanical performance. However, (co)polyoxalamides have never reached commercial importance in spite of their potential as high temperature nylons, which is mainly due to difficulties encountered in their production and fabrication ${ }^{106}$.

\subsubsection{Polymerization}

Polyoxalamides cannot be easily prepared by regular polymerization techniques as used in the synthesis of polyamides since the melting temperatures are mostly close to their thermal decomposition temperatures ${ }^{105-107}$. Melt polycondensation of oxalic acid with diamines is accompanied by thermal degradation of oxalic acid as well as the polymer. Furthermore, the insolubility of most polyoxalamides in conventional solvents prevents the formation of high molecular weight polymers in solution polymerization, whereas interfacial polycondensation has not been useful because of the rapid hydrolysis of oxalyl chloride ${ }^{106,108}$.

The most frequent used polymerization method for the preparation of high molecular weight polyoxalamides is the reaction between an oxalate ester and a diamine ${ }^{105,109-111}$. Generally, these reactions are carried out in two steps (Scheme 2.3). The first step is a reaction in solution at low temperatures with low molecular weight prepolymers precipitating out. After purification of these prepolymers, post-polymerization is carried out in the solid state at temperatures between 250 and $300{ }^{\circ} \mathrm{C}$. In most cases, the polymers were found to be colored indicative of degradation reactions.

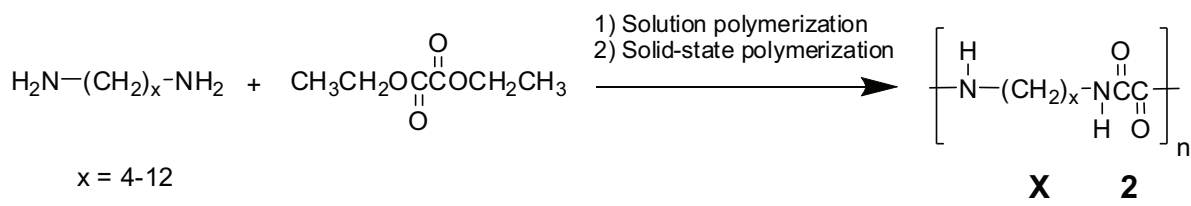

Scheme 2.3: Two step solution/solid-state polymerization of polyoxalamides ${ }^{105,109-111}$. 
Sokolov and coworkers developed a gas-liquid interfacial polymerization technique, which made it possible to prepare high molecular weight polyamides from rapidly hydrolyzing acid chlorides ${ }^{112}$. In this method oxalyl chloride is diluted with nitrogen and bubbled into a warm aqueous alkaline solution of the diamine (Scheme 2.4). The polycondensation reaction takes place at the gas-liquid interface. An important drawback of this system is the rather low output.

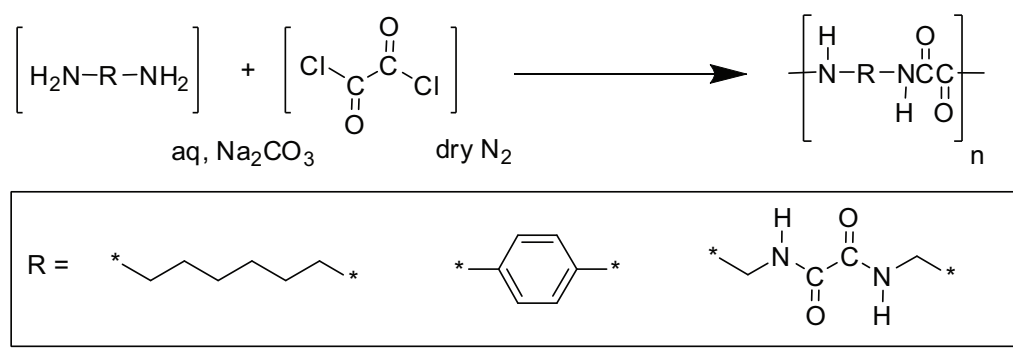

Scheme 2.4: Gas-liquid interfacial polymerization of polyoxalamides ${ }^{108,112,113}$.

In an attempt to overcome the problem of polymer decomposition in the preparation of nylon-6,2, Vogl et al ${ }^{114,115}$ investigated the ring-opening polymerization of cyclic oxalamides.

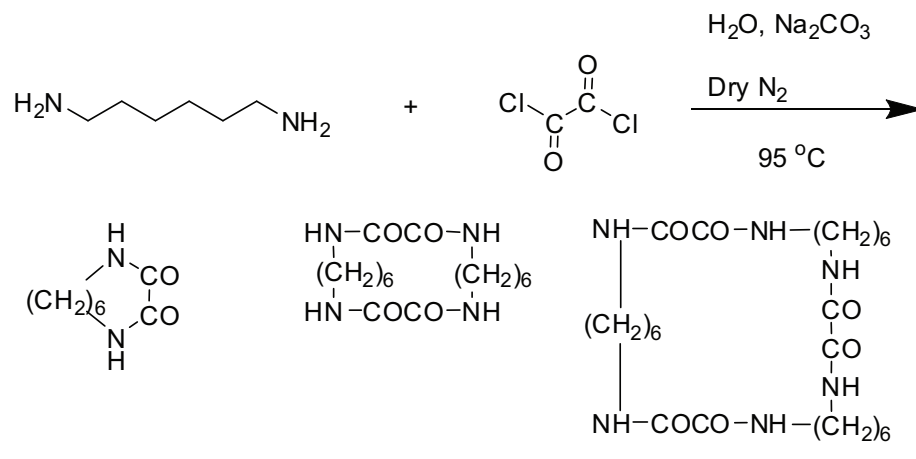

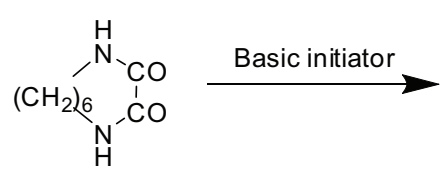<smiles>CCC(=O)C(=O)NCCCCCCN(C)CC</smiles>

Scheme 2.5: Ring-opening polymerization of cyclic oxalamides ${ }^{114,115}$. 
The cyclic monomer $(c-62)$ melts at $232{ }^{\circ} \mathrm{C}$, which is much lower than nylon-6,2 $\left(325{ }^{\circ} \mathrm{C}\right)$, and thus the region of thermal instability is avoided. Synthesis of the cyclic monomer was carried out in solution by reacting oxalyl chloride with 1,6diaminohexane (Scheme 2.5). The reaction yielded besides the cyclic monomer $c-62$, also the cyclic dimer $c$-6262 and trimer $c$-626262 having melting temperatures of 303 and $343{ }^{\circ} \mathrm{C}$, respectively. Anionic ring-opening polymerizations of $c-62$ were successfully carried out in the melt and were completed within minutes. However, still slow thermal decomposition was observed with evolution of $\mathrm{CO}$ and $\mathrm{CO}_{2}$. Ringopening polymerization of cyclic monomers such as, $c-22, c-42, c-82, c-6266$ could also be performed in a similar way (Scheme 2.5). Moreover, $c-62$ readily copolymerizes with other cyclic oxalamides or lactams affording copolyoxalamides.

A facile method to prepare copolyoxalamides of the type $\mathrm{X}-2-\mathrm{X}-\mathrm{P}$ is the condensation of aliphatic diamine-oxalamides $(\mathrm{X}-2-\mathrm{X})$ and diacid chlorides $(\mathrm{P})^{106,108,116-119}$. The diamine-oxalamide intermediates were prepared by reacting diethyl oxalate with an excess of different aliphatic diamines and subsequent polycondensation with an aliphatic or aromatic diacid chloride via liquid-liquid interfacial or solution polymerization depending on the solubility of the diamine in water (Scheme 2.6). The polymer molecular weights were high enough to obtain polymer films. Interfacial polymerization afforded higher molecular weights than solution polycondensation, but the yield of the solution polycondensation was higher.

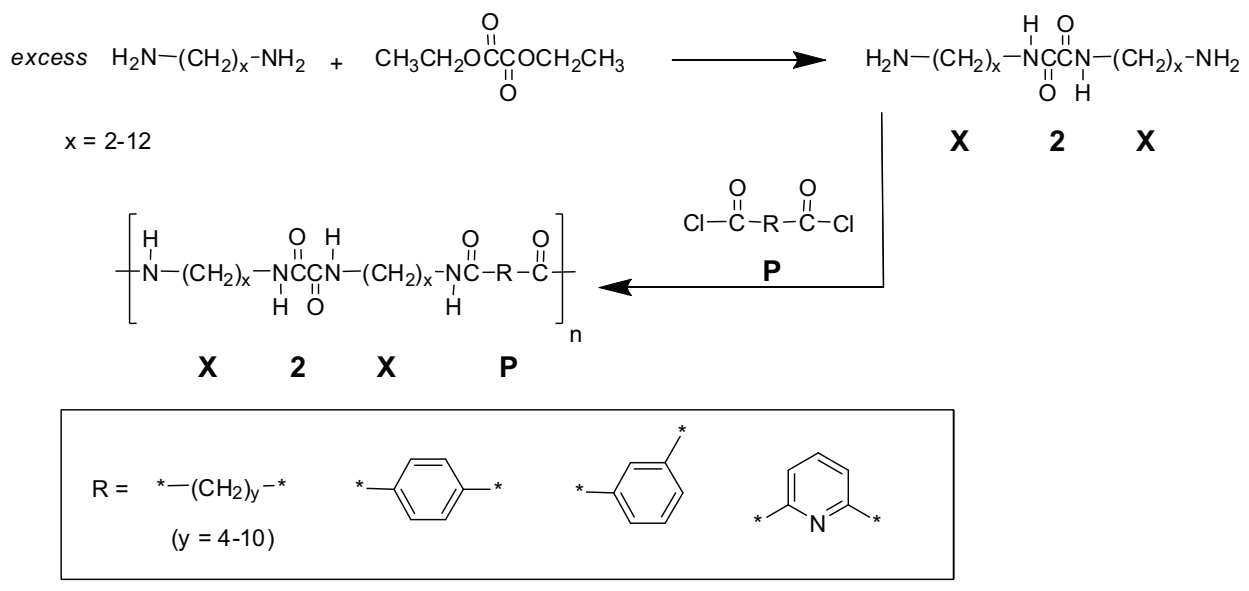

Scheme 2.6: Synthesis of regular copolyoxalamides ${ }^{106,108,116-119}$. 


\subsubsection{Thermal properties}

Although all polyoxalamides and oxalamide containing polymers are high melting materials, many papers and patents report the thermal instability during the preparation or processing of these materials especially at temperatures above $250{ }^{\circ} \mathrm{C}$. The melting temperatures of aliphatic polyoxalamides (nylon-X,2) ${ }^{105,109-111,119}$ and copolyoxalamides (nylon-X,2,X,P) ${ }^{106,117}$ are in between 200 and $400{ }^{\circ} \mathrm{C}$ (Figure 2.9a). By increasing the chain length of the diamine $(\mathrm{X})$ or the diacid $(\mathrm{P})$, the melting temperature decreases. Moreover, a regular odd-even effect was observed. Thermal degradation studies using thermal gravimetric analysis (TGA) revealed that degradation of polyoxalamides starts at temperatures lower then $300{ }^{\circ} \mathrm{C}$ (Figure 2.9b) ${ }^{105,107,117}$. Decomposition occurs between 400 and $475{ }^{\circ} \mathrm{C}$ by homolytic thermal cleavage of the oxalamide group. It was concluded that the thermal stability of polyoxamides is comparable to that of conventional nylons such as nylon-6,6, nylon-6 and nylon-12, but the difference in melting temperature and decomposition temperature in nylons is considerable larger allowing easier processing of the nylons.

\subsubsection{Crystalline structure}

Structural information on nylon-x,2 is scarce. Crystalline structures based on Xray and electron diffraction measurements are reported for nylon-6,2, nylon- 9,2 and nylon-12,2 109,110,113. Powder X-ray diffraction patterns have been published for nylon4,2 , nylon-6,2, nylon-8,2, and nylon-10,2 ${ }^{105,111}$. For all even nylon-X,2 polymers, an extended planar zig-zag conformation was proposed with intermolecular hydrogen bonding between neighboring chains in a single direction. Hydrogen bonded sheets are stacked upon each other with a progressive shift as a result of van der Waals forces similarly as observed in the $\alpha$-form of nylon-6,6. In Figure 2.10a the crystal structure of nylon-6,2, an $\alpha$-type crystal structure with progressive stacking of the hydrogen bonded sheets is depicted ${ }^{113}$. The interchain distance within a hydrogen bonded sheet and the intersheet distances are 4.94 and $4.04 \AA$, respectively. Remarkably, the chain axis shift between consecutive sheets is $6.4 \AA$ (Figure 2.10a) which deviates from the value observed in the $\alpha$-form of nylons such as nylons-6,6, 4,6 and 6 . The chain axis shift between consecutive sheets for those nylons is in between 3.0 and $4.0 \AA$. This difference is attributed to the distinct electron charge distribution of oxalamide groups compared to amide groups. Energy calculations confirmed the non-conventional sheet stacking ${ }^{120}$. For nylon-12,2 two crystalline structures have been observed, both based 
(a)

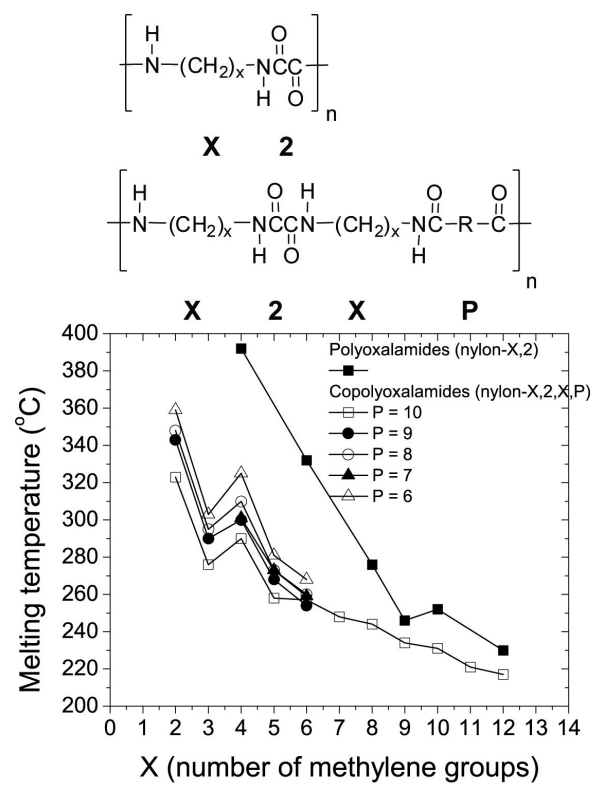

(b)

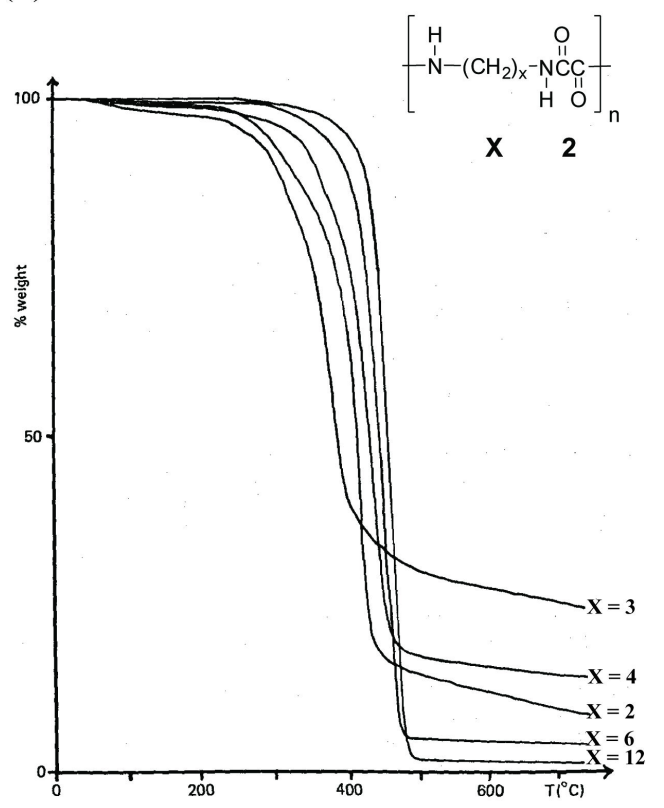

Figure 2.9: (a) Melting temperature as a function of number of methylene groups of the diamine $(\mathrm{X})$ for polyoxalamides (nylon-X,2) and copolyoxalamides (nylon$\mathrm{X}, 2, \mathrm{X}, \mathrm{P}), \mathrm{P}$ is the number of methylene groups of the diacid ${ }^{105,106,109-111,113,119}$.

(b) Thermal gravimetric analysis of polyoxalamides at a heating rate of 10 ${ }^{\circ} \mathrm{C} . \mathrm{min}^{-1}$ in nitrogen atmosphere ${ }^{119}$.

on progressive stacking of the hydrogen bonded sheets but with different chain axis shifts between the consecutive sheets ${ }^{109}$. One of these forms is similar to the $\alpha$-form of nylons whereas the second form displays an $\alpha$-type crystal form with a chain axis shift between consecutive sheets of $1 \AA$. This latter crystal form, based on energy calculations, was found to be the most stable.

Up to now only one crystalline structure of a polyoxalamide having an odd number of methylene groups between oxalamide groups, nylon-9,2, has been determined with Xray and electron diffraction ${ }^{110}$. Interestingly, this polymer does not adopt a structure with hydrogen bonds along a single direction, like the $\alpha, \beta$ and $\gamma$ forms in conventional nylons. The crystal structure of nylon-9,2, was postulated to have two different hydrogen bonding orientations i.e. each molecule is hydrogen bonded to its four neighbours (Figure 2.10b). The molecular chains are slightly contracted with respect to the all-trans conformation. Thus, the $\mathrm{NH}-\mathrm{CH}_{2}$ torsional angles deviate $25^{\circ}$ from 
the trans conformation in order to optimize the hydrogen bonds with neighboring chains. Energy calculations confirmed that odd polyoxalamides prefer a structure with hydrogen bonding in two directions whereas even polyoxalamides favor a structure with a single hydrogen bond direction ${ }^{120}$.
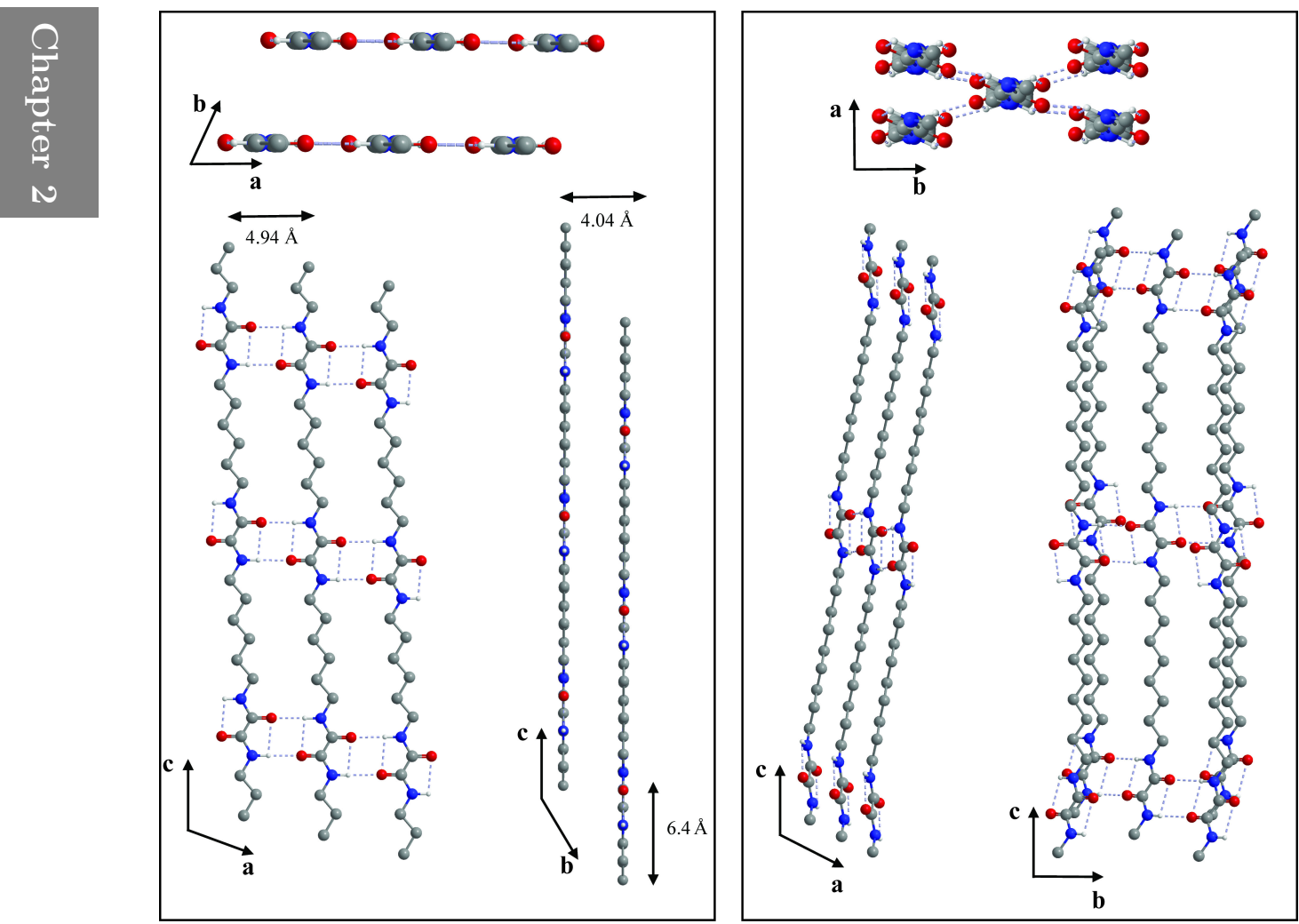

Figure 2.10: (a) Crystal structure of nylon-6,2 $(\mathrm{a}=5.15 \AA$, $\mathrm{b}=7.54 \AA$, $\mathrm{c}=12.39 \AA$, $\alpha=$ $\left.32.4^{\circ}, \beta=73.5^{\circ}, \gamma=61.9^{\circ}\right)^{113}$. (b) Crystal structure of nylon-9,2 $(\mathrm{a}=5.45$ $\left.\AA, \mathrm{b}=8.7 \AA, \mathrm{c}=31.8 \AA, \beta=47.9^{\circ}\right)^{110}$.

\subsection{References}

[1] Fakirov, S. Handbook of condensation thermoplastic elastomers; Wiley-VCH: Weinheim, 2005.

[2] Holden, G.; Legge, N. R.; Quirk, R. P.; Schroeder, H. E. Thermoplastic elastomers, 2nd ed.; Hanser Publishers: Munich, 1996. 
[3] Mark, H. F. Encyclopedia of polymer science and technology, 3rd ed.; WileyInterscience: New York, 2001.

[4] Cella, R. J. J Polym Sci: Symp No 47 1973, 42, 727-740.

[5] Boulares, A.; Tessier, M.; Marechal, E. Polymer 2000, 41, 3561-3580.

[6] Deleens, G.; Foy, P.; Marechal, E. Eur Polym J 1977, 13, 337-342.

[7] Deleens, G.; Foy, P.; Marechal, E. Eur Polym J 1977, 13, 343-351.

[8] Deleens, G.; Foy, P.; Marechal, E. Eur Polym J 1977, 13, 353-360.

[9] Gaymans, R. J.; Schwering, P.; Dehaan, J. L. Polymer 1989, 30, 974-977.

[10] Vanhutten, P. F.; Walch, E.; Veeken, A. H. M.; Gaymans, R. J. Polymer 1990, 31, 524-529.

[11] Yu, Y. C.; Jo, W. H. J Appl Polym Sci 1994, 54, 585-591.

[12] Sheth, J. P.; Xu, J. N.; Wilkes, G. L. Polymer 2003, 44, 743-756.

[13] Alberola, N. J Appl Polym Sci 1988, 36, 787-804.

[14] Bornschlegl, E.; Goldbach, G.; Meyer, K. Prog Colloid Polym Sci 1985, 71, $119-124$.

[15] Di Lorenzo, M. L.; Pyda, M.; Wunderlich, B. J Polym Sci Part B Polym Phys 2001, 39, 1594-1606.

[16] Di Lorenzo, M. L.; Pyda, M.; Wunderlich, B. J Polym Sci Part B Polym Phys 2001, 39, 2969-2981.

[17] Faruque, H. S.; Lacabanne, C. Polymer 1986, 27, 527-531.

[18] Ghosh, S.; Khastagir, D.; Bhowmick, A. K.; Bandyopadhyay, S.; Kao, G. J. P.; Kok, L. J Mater Sci Lett 2000, 19, 2161-2165.

[19] Ghosh, S.; Khastgir, D.; Bhowmick, A. K. Polymer 1998, 39, 3967-3975.

[20] Godovsky, Y. K.; Yanul, N. A.; Bessonova, N. P. Colloid Polym Sci 1991, 269, 901-915.

[21] Hatfield, G. R.; Guo, Y. H.; Killinger, W. E.; Andrejak, R. A.; Roubicek, P. M. Macromolecules 1993, 26, 6350-6353.

[22] Hatfield, G. R.; Bush, R. W.; Killinger, W. E.; Roubicek, P. M. Polymer 1994, 35, 3943-3947.

[23] Hucher, C.; Eustache, R. P.; Beaume, F.; Tekely, P. Macromolecules 2005, 38, 9200-9209.

[24] McLean, R. S.; Sauer, B. B. Macromolecules 1997, 30, 8314-8317.

[25] McLean, R. S.; Sauer, B. B. J Polym Sci Part B Polym Phys 1999, 37, 859-866.

[26] Sakurai, K.; Amador, G.; Takahashi, T. Polymer 1998, 39, 4089-4094.

[27] Sauer, B. B.; McLean, R. S.; Thomas, R. R. Polym Int 2000, 49, 449-452.

[28] Song, Y.; Yamamoto, H.; Nemoto, N. Macromolecules 2004, 37, 6219-6226. 
[29] Yang, I. K.; Tsai, P. H. J Polym Sci Part B Polym Phys 2005, 43, 2557-2567.

[30] Yu, Y. C.; Jo, W. H. J Appl Polym Sci 1995, 56, 895-904.

[31] Yu, Y. C.; Jo, W. H.; Lee, M. S. J Appl Polym Sci 1997, 64, 2155-2163.

[32] Xie, M.; Camberlin, Y. Makromol Chem 1986, 187, 383-400.

[33] Biemond, G. J. E.; Feijen, J.; Gaymans, R. J. Polym Eng Sci 2008, 48, 13891400.

[34] Krijgsman, J.; Gaymans, R. J. Polymer 2004, 45, 437-446.

[35] Das, S.; Cox, D. F.; Wilkes, G. L.; Klinedinst, D. B.; Yilgor, I.; Yilgor, E.; Beyer, F. L. J Macromol Sci Phys 2007, 46, 853-875.

[36] Das, S.; Yilgor, I.; Yilgor, E.; Inci, B.; Tezgel, O.; Beyer, F. L.; Wilkes, G. L. Polymer 2007, 48, 290-301.

[37] Das, S.; Yilgor, I.; Yilgor, E.; Wilkes, G. L. Polymer 2008, 49, 174-179.

[38] Yilgor, I.; Yilgor, E. Polym Rev 2007, 47, 487-510.

[39] Eisenbach, C. D.; Stadler, E. Macromol Chem Phys 1995, 196, 1981-1997.

[40] Fu, B.; Feger, C.; Macknight, W. J.; Schneider, N. S. Polymer 1985, 26, 889-894.

[41] Fu, B.; Macknight, W. J.; Schneider, N. S. Rubber Chem Technol 1986, 59, 896-911.

[42] Lai, Y. C.; Quinn, E. T.; Valint, P. L. J Polym Sci Part A Polym Chem 1995, 33, $1767-1772$.

[43] Harrell, L. L. Macromolecules 1969, 2, 607-612.

[44] Ng, H. N.; Allegrez, A. E.; Seymour, R. W.; Cooper, S. L. Polymer 1973, 14, $255-261$.

[45] Miller, J. A.; Lin, S. B.; Hwang, K. K. S.; Wu, K. S.; Gibson, P. E.; Cooper, S. L. Macromolecules 1985, 18, 32-44.

[46] Niesten, M. C. E. J.; Feijen, J.; Gaymans, R. J. Polymer 2000, 41, 8487-8500.

[47] van der Schuur, M.; Feijen, J.; Gaymans, R. J. Polymer 2005, 46, 4584-4595.

[48] Versteegen, R. M.; Sijbesma, R. P.; Meijer, E. W. Macromolecules 2005, 38, 3176-3184.

[49] Versteegen, R. M.; Kleppinger, R.; Sijbesma, R. P.; Meijer, E. W. Macromolecules 2006, 39, 772-783.

[50] Shirasaka, H.; Inoue, S.; Asai, K.; Okamoto, H. Macromolecules 2000, 33, 2776-2778.

[51] Biemond, G. J. E.; Feijen, J.; Gaymans, R. J. J Appl Polym Sci 2007, 105, 951-963.

[52] Krijgsman, J.; Husken, D.; Gaymans, R. J. Polymer 2003, 44, 7043-7053.

[53] Krijgsman, J.; Husken, D.; Gaymans, R. J. Polymer 2003, 44, 7573-7588. 
[54] Niesten, M. C. E. J.; Bouma, K.; Gaymans, R. J. Polymer 1998, 39, 93-98.

[55] Niesten, M. C. E. J.; Gaymans, R. J. J Appl Polym Sci 2001, 81, 1372-1381.

[56] Niesten, M. C. E. J.; Gaymans, R. J. Polymer 2001, 42, 6199-6207.

[57] Niesten, M. C. E. J.; Harkema, S.; van der Heide, E.; Gaymans, R. J. Polymer 2001, 42, 1131-1142.

[58] Niesten, M. C. E. J.; Tol, R.; Gaymans, R. J. Polymer 2001, 42, 931-939.

[59] Arun, A.; Dullaert, K.; Gaymans, R. J. Macromol Chem Phys 2009, 210, 48-59.

[60] Arun, A.; Gaymans, R. J. Macromol Chem Phys 2008, 209, 854-863.

[61] Arun, A.; Gaymans, R. J. Polymer 2008, 49, 2461-2470.

[62] Arun, A.; Gaymans, R. J. Eur Polym J 2009, 45, 2858-2866.

[63] Bouma, K.; Wester, G. A.; Gaymans, R. J. J Appl Polym Sci 2001, 80, 11731180.

[64] Gaymans, R. J.; Dehaan, J. L. Polymer 1993, 34, 4360-4364.

[65] van der Schuur, M.; Feijen, J.; Gaymans, R. J. Polymer 2005, 46, 4584-4595.

[66] van der Schuur, M.; Gaymans, R. J. J Polym Sci Part A Polym Chem 2006, 44, 4769-4781.

[67] van der Schuur, M. J.; Gaymans, R. J. Polymer 2007, 48, 1998-2006.

[68] van der Schuur, M.; van der Heide, E.; Feijen, J.; Gaymans, R. J. Polymer 2005, 46, 3616-3627.

[69] Husken, D.; Feijen, J.; Gaymans, R. J. J Polym Sci Part A Polym Chem 2007, $45,4522-4535$.

[70] Husken, D.; Krijgsman, J.; Gaymans, R. J. Polymer 2004, 45, 4837-4843.

[71] Brunsveld, L.; Folmer, B. J. B.; Meijer, E. W.; Sijbesma, R. P. Chem Rev 2001, 101, 4071-4097.

[72] Beijer, F. H.; Kooijman, H.; Spek, A. L.; Sijbesma, R. P.; Meijer, E. W. Angew Chem Int Ed 1998, 37, 75-78.

[73] Beijer, F. H.; Sijbesma, R. P.; Kooijman, H.; Spek, A. L.; Meijer, E. W. J Am Chem Soc 1998, 120, 6761-6769.

[74] Sontjens, S. H. M.; Sijbesma, R. P.; van Genderen, M. H. P.; Meijer, E. W. J Am Chem Soc 2000, 122, 7487-7493.

[75] Sijbesma, R. P.; Beijer, F. H.; Brunsveld, L.; Folmer, B. J. B.; Hirschberg, J.; Lange, R. F. M.; Lowe, J. K. L.; Meijer, E. W. Science 1997, 278, 1601-1604.

[76] Folmer, B. J. B.; Sijbesma, R. P.; Versteegen, R. M.; van der Rijt, J. A. J.; Meijer, E. W. Adv Mater 2000, 12, 874-878.

[77] Botterhuis, N. E.; van Beek, D. J. M.; van Gemert, G. M. L.; Bosman, A. W.; Sijbesma, R. P. J Polym Sci Part A Polym Chem 2008, 46, 3877-3885. 
[78] Kautz, H.; van Beek, D. J. M.; Sijbesma, R. P.; Meijer, E. W. Macromolecules 2006, 39, 4265-4267.

[79] Schulze, H. Thermoplastic adhesive polyoxamide from polyoxypropylene polyamine; US4,119,615, 1978.

[80] Coe, S.; Kane, J. J.; Nguyen, T. L.; Toledo, L. M.; Wininger, E.; Fowler, F. W.; Lauher, J. W. J Am Chem Soc 1997, 119, 86-93.

[81] Curtis, S. M.; Le, N.; Fowler, F. W.; Lauher, J. W. Cryst Growth Des 2005, 5, 2313-2321.

[82] Lauher, J. W.; Fowler, F. W.; Goroff, N. S. Acc Chem Res 2008, 41, 1215-1229.

[83] Nguyen, T. L.; Scott, A.; Dinkelmeyer, B.; Fowler, F. W.; Lauher, J. W. New J Chem 1998, 22, 129-135.

[84] Nguyen, T. L.; Fowler, F. W.; Lauher, J. W. J Am Chem Soc 2001, 123, 11057-11064.

[85] Karle, I. L.; Ranganathan, D.; Shah, K.; Vaish, N. K. Int J Pept Protein Res 1994, 43, 160-165.

[86] Karle, I. L.; Ranganathan, D. Biopolymers 1995, 36, 323-331.

[87] Karle, I. L.; Ranganathan, D. Int J Pept Protein Res 1995, 46, 18-23.

[88] Nowick, J. S. Acc Chem Res 2008, 41, 1319-1330.

[89] Frkanec, L.; Zinic, M. Chem Commun 2010, 46, 522-537.

[90] Jokic, M.; Makarevic, J.; Zinic, M. J Chem Soc, Chem Commun 1995, 17231724.

[91] Makarevic, J.; Jokic, M.; Peric, B.; Tomisic, V.; Kojic-Prodic, B.; Zinic, M. Chem-EurJ 2001, 7, 3328-3341.

[92] Makarevic, J.; Jokic, M.; Frkanec, L.; Katalenic, D.; Zinic, M. Chem Commun 2002, 2238-2239.

[93] Asin, L.; Armelin, E.; Montane, J.; Rodriguez-Galan, A.; Puiggali, J. J Polym Sci Part A Polym Chem 2001, 39, 4283-4293.

[94] Klaska, K. H.; Jarchow, O.; Scham, W.; Widjaja, H.; Voss, J.; Schmalle, H. W. J Chem Res 1980, 104-105.

[95] Aleman, C.; Casanovas, J. J Mol Struct Theochem 2004, 675, 9-17.

[96] Aleman, C.; Puiggali, J. J Org Chem 1999, 64, 351-358.

[97] Clou, K.; Janssens, J. F.; Blaton, N.; Lenstra, A. T. H.; Desseyn, H. O. Thermochim Acta 2003, 398, 47-58.

[98] Desseyn, H. O.; Perlepes, S. P.; Clou, K.; Blaton, N.; Van der Veken, B. J.; Dommisse, R.; Hansen, P. E. J Phys Chem A 2004, 108, 5175-5182.

[99] Hoffmann, M.; Rychlewska, U.; Warzajtis, B. Crystengcomm 2005, 7, 260-265. 
[100] Martinez-Martinez, F. J.; Arizacastolo, A.; Tlahuextl, H.; Tlahuextl, M.; Contreras, R. J Chem Soc Perk Trans 2 1993, 1481-1485.

[101] Martinez-Martinez, F. J.; Padilla-Martinez, I.; Brito, M. A.; Geniz, E. D.; Rojas, R. C.; Saavedra, J. B. R.; Hopfl, H.; Tlahuextl, M.; Contreras, R. J Chem Soc Perk Trans 2 1998, 401-406.

[102] Sun, A. W.; Lauher, J. W.; Goroff, N. S. Science 2006, 312, 1030-1034.

[103] Xi, O. Y.; Fowler, F. W.; Lauher, J. W. J Am Chem Soc 2003, 125, 12400-12401.

[104] Flory, P. J. Polymerization process; US2.172.374, 1939.

[105] Shalaby, S. W.; Pearce, E. M.; Frederic, R. J.; Turi, E. A. J Polym Sci Part B Polym Phys 1973, 11, 1-14.

[106] Pletcher, T. C.; Morgan, P. W. J Polym Sci Part A Polym Chem 1980, 18, $643-660$.

[107] Ballistreri, A.; Garozzo, D.; Montaudo, G.; Pollicino, A.; Giuffrida, M. Polymer 1987, 28, 139-146.

[108] Deits, W.; Grossman, S.; Vogl, O. J Macromol Sci Chem 1981, A15, 1027-1044.

[109] Casas, M. T.; Armelin, E.; Aleman, C.; Puiggali, J. Macromolecules 2002, 35, 8781-8787.

[110] Franco, L.; Subirana, J. A.; Puiggali, J. Macromolecules 1998, 31, 3912-3924.

[111] Gaymans, R. J.; Venkatraman, V. S.; Schuijer, J. J Polym Sci Part A Polym Chem 1984, 22, 1373-1382.

[112] Sokolov, L. B. J Polym Sci 1962, 58, 1253.

[113] Chatani, Y.; Ueda, Y.; Tadokoro, H.; Deits, W.; Vogl, O. Macromolecules 1978, 11, 636-638.

[114] Vogl, O.; Knight, A. C. Macromolecules 1968, 1, 311-315.

[115] Vogl, O.; Knight, A. C. Macromolecules 1968, 1, 315-318.

[116] Chang, H. J.; Vogl, O. J Polym Sci Part A Polym Chem 1977, 15, 311-322.

[117] Chang, H. J.; Vogl, O. J Polym Sci Part A Polym Chem 1977, 15, 1043-1060.

[118] Stevenson, D.; Beeber, A.; Gaudiana, R.; Vogl, O. J Macromol Sci Chem 1977, A 11, 779-809.

[119] Deabajo, J.; Kricheldorf, H. R. J Macromol Sci Chem 1984, A21, 411-426.

[120] Armelin, E.; Aleman, C.; Puiggali, J. J Org Chem 2001, 66, 8076-8085. 


\title{
Chapter 3
}

\section{Design and properties of segmented poly(ether amide)s with uniform oxalamide based hard segments}

\author{
N.J. Sijbrandi ${ }^{a}$, A.J. Kimenai ${ }^{b}$, E.P.C. Mes ${ }^{b}$, R. Broos ${ }^{b}$, P.J. Dijkstra ${ }^{a}$, J. Feijen ${ }^{a}$ \\ ${ }^{a}$ Department of Polymer Chemistry and Biomaterials, MIRA Institute for Biomedical Tech- \\ nology and Technical Medicine, Faculty of Science and Technology, University of Twente, \\ P.O. Box 217, 7500 AE Enschede, The Netherlands \\ ${ }^{\mathrm{b}}$ Core R\&D, DOW Benelux BV, P.O. Box 48, 4530 AA, Terneuzen, The Netherlands
}

\begin{abstract}
Segmented poly(ether amide)s based on flexible PTHF segments $\left(M_{n}=1.1 \times 10^{3}\right.$ g. $\mathrm{mol}^{-1}$ ) and uniform rigid oxalamide segments appear highly phase separated and have a high crystallinity of the hard phase. The amount of oxalamide groups in the hard segment and the spacer length of a bisoxalamide based hydrogen bonding array were varied systematically. Hydrogen bonding between the oxalamide groups and the thermal properties of the polymers were evaluated by FT-IR and DSC, respectively. Whereas a segmented poly(ether amide) comprising single oxalamide groups between polyether chains was a sticky solid, incorporation of uniform hard segments with two oxalamide groups provided polymers with elastic properties. By decreasing the aliphatic spacer length between oxalamide groups from 10 to 2 methylene groups, the melting transitions increased from 140 to $200{ }^{\circ} \mathrm{C}$. The thermal transitions were broad and the crystallization transitions were almost independent on the cooling rate. Increasing the number of oxalamide groups in the hard segment to three afforded an elastic material with a broad melting transition above $200{ }^{\circ} \mathrm{C}$. The results demonstrate that uniform hard segments containing oxalamide groups can be used to prepare segmented poly(ether amides). These thermoplastic elastomers show a fast crystallization and a strong hydrogen bonding resulting in highly ordered physical crosslinks.
\end{abstract}




\subsection{Introduction}

Segmented poly(ether amide)s (PEAs) consisting of rigid amide group containing hard segments and amorphous flexible polyether soft segments are thermoplastic elastomers (TPEs $)^{1,2}$. These polymers combine the physical properties of an elastomer and the ease of processing of thermoplastics due to their phase separated morphology ${ }^{3}$. The amide-rich hard phase usually contains crystalline lamellae and acts as a physical crosslinker for the amorphous soft phase. The soft phase has a sub-ambient glass transition temperature, which contributes to the flexibility and extensibility of the polymer. Above the melting temperature of the hard domains, the polymer will flow and can be easily processed.

In general, the amide segments in PEAs are mainly based on nylon-6, nylon-11 or nylon12 , although segmented copolymers based on nylon-6,6, nylon- 6,10 , nylon- 6,12 , nylon10,10 , nylon-11,6 or nylon-4,6 have also been prepared ${ }^{1,2,4-10}$. Poly(tetramethylene oxide), poly(ethylene oxide) and poly(propylene oxide) are often used as soft segments. Early approaches to prepare PEAs focused on covalently linking the amide blocks with polyether blocks via amide, urethane or urea linkages. To accomplish this, different polymerization methods, such as thermal polymerization, solution polymerization, interfacial polymerization and anionic polymerization, were applied ${ }^{1,2}$. Since the discovery of catalysts such as tetrabutyltitanate, Atochem pioneered in the synthesis of high molecular weight segmented poly(ether amide)s, which resulted in the commercialization of PEAs under the trade name PEBAX ${ }^{\circledR 5-7}$. These segmented poly(ether amide)s are prepared by polycondensation of preformed carboxylic acid end functionalized polyamide segments with hydroxyl end functionalized polyether prepolymers and thus contain ester linkages. By varying the polyamide/polyether weight ratio, polymer properties can be tuned from typical elastomeric to typical thermoplastic $^{11}$.

A disadvantage of the polyamide hard segments used in the PEAs described above is their broad molecular weight distribution. Polydispersity of the hard segment leads to an incomplete phase separation, and as a result, an increase in the glass transition temperature of the soft segment, and consequently a reduction in elastomeric properties. Also the rubber plateau becomes temperature dependent and generally the melt transition is broad. The use of uniform hard segments in segmented block copolymers revealed an effective way to improve the phase separation and mechanical properties of PEAs ${ }^{12-20}$. Gaymans and coworkers extensively studied segmented poly(ether 
amide)s with uniform amide segments ${ }^{17,21-25}$. Commonly used segments are aromatic di-amides (T $\Phi \mathrm{T})$ or the partially aromatic tetra-amides based on nylon-6,T (T6T6T). These segmented copolymers are generally prepared from synthetic mixtures of amide blocks, and subsequent reaction of these blocks with flexible polyether prepolymers in a two step solution/melt polymerization, affording high molecular weight transparent elastic materials. The polymers crystallize fast, have a relatively high modulus, an almost temperature independent rubber plateau and a sharp melting temperature. Besides, these copolymers are highly elastic and have high fracture strains.

Oxalamides, di-amides of oxalic acid, are good hydrogen bonding molecules ${ }^{26-28}$. Symmetric oxalamides strongly associate by donating and receiving two hydrogen bonds. The oxalamide group as a hydrogen bonding motif has been utilized in various research areas, like crystal engineering ${ }^{26-28}$, protein engineering ${ }^{29-31}$, organic gelators $^{32}$ and materials science ${ }^{33}$. Due to the conformational rigidity of oxalamide groups, nylon-x,2 type materials have high melting temperatures, high moduli and low solubility, properties of interest for TPEs ${ }^{34}$. To our knowledge, only Schulze has described PEAs that contain oxalamide based hard segments ${ }^{35}$. These polymers were prepared by end functionalizing Jeffamines ${ }^{\circledR}$ (amine terminated polyethers) with diethyl oxalate followed by melt polycondensation using a variety of diamines. The oxalamide hard segments in these copolymers were not uniform, and afforded polymers with properties varying from tough elastic to hard and brittle depending on the polymer composition.

In this paper, we describe the synthesis and structure of novel segmented poly(ether amide)s composed of polytetrahydrofuran flexible polyether segments $\left(\mathrm{M}_{\mathrm{n}}=1.1 \times 10^{3}\right.$ g.mol ${ }^{-1}$ ) and uniform oxalamide based hard segments. The number of oxalamide groups and aliphatic spacer length between oxalamide groups in the hard segment were systematically varied to determine the effects of an oxalamide based hydrogen bonding array on the thermal properties of the PEAs 


\subsection{Experimental}

\subsubsection{Materials}

Diethyl oxalate, bis(3-aminopropyl) polytetrahydrofuran $\left(1.1 \times 10^{3}\right.$ g.mol $\left.{ }^{-1}\right)$, 1,2-diaminoethane, 1,4-diaminobutane, 1,6-diaminohexane, 1,8-diaminooctane, 1,10-diaminodecane, 1,1,1,3,3,3-hexafluoro-2-propanol (HFIP), deuterated chloroform $\left(\mathrm{CDCl}_{3}-\mathrm{d}_{1}\right)$ and deuterated trifluoroacetic acid $\left(\mathrm{TFA}-\mathrm{d}_{1}\right)$ were purchased from Aldrich (Zwijndrecht, The Netherlands). Irganox1330 was kindly provided by Ciba (Geigi, Switzerland). HPLC-quality chloroform was purchased from Lab-Scan (Gliwice, Poland). Diethyl ether, tetrahydrofuran, dichloromethane and toluene were obtained from Biosolve (Valkenswaard, The Netherlands) and chloroform and tetrabutylorthotitanoate $\left(\mathrm{Ti}(\mathrm{OBu})_{4}\right)$ were purchased from Merck (Darmstadt, Germany). All materials were used as received.

\subsubsection{Synthesis}

\section{PTHF-OXA (2)}

Diethyl oxalate $(5.21 \mathrm{~g}, 0.036 \mathrm{~mol})$ and bis(3-aminopropyl) polytetrahydrofuran (1) $(39.25 \mathrm{~g}, 0.036 \mathrm{~mol})$ were placed in a polymerization tube. Irganox1330 (1 wt\% of the total mass) was added and the mixture was heated to $190{ }^{\circ} \mathrm{C}$ under a nitrogen flow. After $1 \mathrm{~h}$, the pressure was slowly reduced to $\sim 20$ mbar. The ethanol distilling off during this period was collected in a trap cooled with liquid nitrogen. Subsequently, the pressure was further reduced to $\sim 0.08$ mbar over the following $3 \mathrm{~h}$. The reaction mixture was cooled to room temperature under vacuum and the polymer was collected and dissolved in $200 \mathrm{ml}$ of chloroform. The solution was casted in a petridish and after evaporation of the solvent the polymer was dried at room temperature in vacuo. The product was obtained as a yellow transparent sticky solid in a yield of $95 \%$. ${ }^{1} \mathrm{H}$ NMR $\left(300 \mathrm{MHz} \mathrm{CDCl}_{3}-\mathrm{d}_{1}\right) \delta=7.73$ (bt, $\left.2 \mathrm{H}, \mathrm{NHCO}\right), 3.49$ (t, 4H, $\left.\mathrm{NHCH}_{2} \mathrm{CH}_{2} \mathrm{CH}_{2} \mathrm{O}\right)$, 3.30-3.50 (m, 54H, $\left.\mathrm{OCH}_{2} \mathrm{CH}_{2}\right), 3.30-3.50\left(\mathrm{~m}, 4 \mathrm{H}, \mathrm{NHCH}_{2} \mathrm{CH}_{2} \mathrm{CH}_{2} \mathrm{O}\right), 1.81(\mathrm{~m}, 4 \mathrm{H}$, $\left.\mathrm{NHCH}_{2} \mathrm{CH}_{2} \mathrm{CH}_{2} \mathrm{O}\right), 1.55-1.70\left(\mathrm{~m}, 54 \mathrm{H}, \mathrm{OCH}_{2} \mathrm{CH}_{2}\right)$.

\section{Bis(ethyl 2-(aminopropyl)-oxo acetate) polytetrahydrofuran (3)}

Diethyl oxalate $(53.10 \mathrm{~g}, 0.36 \mathrm{~mol})$ was added to a solution of bis(3-aminopropyl) polytetrahydrofuran (1) (100.00 g, $0.09 \mathrm{~mol})$ in $500 \mathrm{ml}$ of THF at room temperature. Subsequently, the mixture was stirred at room temperature for $16 \mathrm{~h}$. The solvent was 
removed at reduced pressure. The excess of diethyl oxalate was removed by vacuum distillation $(\sim 0.1 \mathrm{mbar})$ at $70{ }^{\circ} \mathrm{C}$ for $16 \mathrm{~h}$. The product was obtained as a viscous yellow/orange liquid in a yield of $98 \%$. ${ }^{1} \mathrm{H} \mathrm{NMR}\left(300 \mathrm{MHz}, \mathrm{CDCl}_{3}-\mathrm{d}_{1}\right) \delta=7.73$ (bt, $2 \mathrm{H}$, OCOCONH), 4.32 (q, 4H, $\mathrm{CH}_{3} \mathrm{CH}_{2} \mathrm{O}$ ), 3.54 (t, $4 \mathrm{H}, \mathrm{NHCH}_{2} \mathrm{CH}_{2} \mathrm{CH}_{2} \mathrm{O}$ ), 3.30-3.40 (m, 54H, OCH $\left.{ }_{2} \mathrm{CH}_{2}\right), 3.30-3.40\left(\mathrm{~m}, 4 \mathrm{H}, \mathrm{NHCH}_{2} \mathrm{CH}_{2} \mathrm{CH}_{2} \mathrm{O}\right), 1.81(\mathrm{~m}$, $4 \mathrm{H}, \mathrm{NHCH}_{2} \mathrm{CH}_{2} \mathrm{CH}_{2} \mathrm{O}$ ), 1.50-1.70 (m, $\left.54 \mathrm{H}, \mathrm{OCH}_{2} \mathrm{CH}_{2}\right), 1.31$ (t, $\left.6 \mathrm{H}, \mathrm{CH}_{3} \mathrm{CH}_{2} \mathrm{O}\right)$; $\underline{{ }^{13} \mathrm{C} \mathrm{NMR}}\left(75.26 \mathrm{MHz}, \mathrm{CDCl}_{3}-\mathrm{d}_{1}\right) \delta=160.9(\mathrm{OCOCONH}), 156.7(\mathrm{OCO} C \mathrm{ONH}), 70.8$ $\left(\mathrm{OCH}_{2} \mathrm{CH}_{2}\right), 70.0\left(\mathrm{NHCH}_{2} \mathrm{CH}_{2} \mathrm{CH}_{2} \mathrm{O}\right), 63.1\left(\mathrm{CH}_{3} C \mathrm{H}_{2} \mathrm{O}\right), 39.0\left(\mathrm{NHCH}_{2} \mathrm{CH}_{2} \mathrm{CH}_{2} \mathrm{O}\right)$, $28.8\left(\mathrm{NHCH}_{2} \mathrm{CH}_{2} \mathrm{CH}_{2} \mathrm{O}\right), 26.7\left(\mathrm{OCH}_{2} \mathrm{CH}_{2}\right), 14.1\left(\mathrm{CH}_{3} \mathrm{CH}_{2} \mathrm{O}\right)$.

\section{PTHF-OXA 2 X (4a-e)}

Bis(ethyl 2-(aminopropyl)-oxo acetate) polytetrahydrofuran (3) was polymerized with different $\alpha, \omega$-diamines. In a typical example, bis(ethyl 2-(aminopropyl)-oxo acetate) polytetrahydrofuran (3) (30.00 g, $0.023 \mathrm{~mol})$ and 1,6-diaminohexane (2.68 g, 0.023 $\mathrm{mol})$ were placed in a polymerization tube. To this mixture were added $\mathrm{Ti}(\mathrm{OBu})_{4}(0.2$ wt\% relative to the total mass and dissolved in $1 \mathrm{ml}$ of toluene) and Irganox1330 (1 wt\% of the total mass). The mixture was heated to $190{ }^{\circ} \mathrm{C}$ under a nitrogen flow. After $1 \mathrm{~h}$, the pressure was slowly reduced to $\sim 20$ mbar to distill off the ethanol. Subsequently, the pressure was reduced to $\sim 0.08$ mbar in the following $4 \mathrm{~h}$. The reaction mixture was then cooled to room temperature under vacuum. The polymer was collected and dissolved in $200 \mathrm{ml}$ of chloroform at $50{ }^{\circ} \mathrm{C}$ and subsequently precipitated in $2 \mathrm{~L}$ of diethyl ether. The polymer was filtered and dried at $60{ }^{\circ} \mathrm{C}$ at reduced pressure. The product was obtained as a yellow transparent elastic solid in a yield of $95 \%$.

PTHF-OXA 2 (4a): ${ }^{1} \mathrm{H}$ NMR $\left(300 \mathrm{MHz}, \mathrm{TFA}-\mathrm{d}_{1}\right) \delta=3.78\left(\mathrm{t}, 4 \mathrm{H}, \mathrm{OCH}_{2} \mathrm{CH}_{2} \mathrm{CH}_{2} \mathrm{NH}\right)$, 3.60-3.75 (m, 54H, $\left.\mathrm{OCH}_{2} \mathrm{CH}_{2}\right), 3.60-3.75\left(\mathrm{~m}, 4 \mathrm{H}, \mathrm{OCH}_{2} \mathrm{CH}_{2} \mathrm{CH}_{2} \mathrm{NH}\right), 3.51$ (t, $4 \mathrm{H}$, $\mathrm{CONHCH}_{2}$ ), 2.01 (m, 4H, $\left.\mathrm{OCH}_{2} \mathrm{CH}_{2} \mathrm{CH}_{2} \mathrm{NH}\right), 1.70-1.80\left(\mathrm{~m}, 54 \mathrm{H}, \mathrm{OCH}_{2} \mathrm{CH}_{2}\right)$;

PTHF-OXA 24 (4b): ${ }^{1} \mathrm{H}$ NMR $\left(300 \mathrm{MHz}, \mathrm{CDCl}_{3}-\mathrm{d}_{1}\right) \delta=7.83$ (bt, $2 \mathrm{H}, \mathrm{OCH}_{2} \mathrm{CH}_{2} \mathrm{CH}_{2^{-}}$ $\mathrm{NHCO}$ ), 7.54 (bt, $2 \mathrm{H}, \mathrm{CONHCH}_{2} \mathrm{CH}_{2}$ ), 3.48 (t, $\left.4 \mathrm{H}, \mathrm{OCH}_{2} \mathrm{CH}_{2} \mathrm{CH}_{2} \mathrm{NH}\right), 3.30-3.50$ (m, $54 \mathrm{H}, \mathrm{OCH}_{2} \mathrm{CH}_{2}$ ), 3.30-3.50 (m, 4H, $\left.\mathrm{OCH}_{2} \mathrm{CH}_{2} \mathrm{CH}_{2} \mathrm{NH}\right), 3.30$ (q, 4H, $\mathrm{CONHCH}_{2} \mathrm{CH}_{2}$ ), $1.80\left(\mathrm{~m}, 4 \mathrm{H}, \mathrm{OCH}_{2} \mathrm{CH}_{2} \mathrm{CH}_{2} \mathrm{NH}\right), 1.60-1.70\left(\mathrm{~m}, 54 \mathrm{H}, \mathrm{OCH}_{2} \mathrm{CH}_{2}\right), 1.50-1.60(\mathrm{~m}, 4 \mathrm{H}$, $\left.\mathrm{CONHCH}_{2} \mathrm{CH}_{2}\right)$;

PTHF-OXA 26 (4c): ${ }^{1} \mathrm{H} \mathrm{NMR}\left(300 \mathrm{MHz}, \mathrm{CDCl}_{3}-\mathrm{d}_{1}\right) \delta=7.83$ (bt, $2 \mathrm{H}, \mathrm{OCH}_{2} \mathrm{CH}_{2} \mathrm{CH}_{2}{ }^{-}$ $\mathrm{NHCO}$ ), 7.48 (bt, $2 \mathrm{H}, \mathrm{CONH} \mathrm{CH}_{2} \mathrm{CH}_{2} \mathrm{CH}_{2}$ ), 3.49 (t, $4 \mathrm{H}, \mathrm{OCH}_{2} \mathrm{CH}_{2} \mathrm{CH}_{2} \mathrm{NH}$ ), 3.30$3.50\left(\mathrm{~m}, 54 \mathrm{H}, \mathrm{OCH}_{2} \mathrm{CH}_{2}\right), 3.30-3.50\left(\mathrm{~m}, 4 \mathrm{H}, \mathrm{OCH}_{2} \mathrm{CH}_{2} \mathrm{CH}_{2} \mathrm{NH}\right), 3.30(\mathrm{t}, 4 \mathrm{H}$, $\left.\mathrm{CONHCH}_{2} \mathrm{CH}_{2} \mathrm{CH}_{2}\right), 1.79\left(\mathrm{~m}, 4 \mathrm{H}, \mathrm{OCH}_{2} \mathrm{CH}_{2} \mathrm{CH}_{2} \mathrm{NH}\right), 1.60-1.70\left(\mathrm{~m}, 54 \mathrm{H}, \mathrm{OCH}_{2} \mathrm{CH}_{2}\right)$, 1.50-1.60 (m, 4H, $\mathrm{CONHCH}_{2} \mathrm{CH}_{2} \mathrm{CH}_{2}$ ), 1.35 (m, $4 \mathrm{H}, \mathrm{CONHCH}_{2} \mathrm{CH}_{2} \mathrm{CH}_{2}$ ); 
PTHF-OXA 28 (4d): ${ }^{1} \mathrm{H}$ NMR $\left(300 \mathrm{MHz}, \mathrm{CDCl}_{3}-\mathrm{d}_{1}\right) \delta=7.83$ (bt, $2 \mathrm{H}, \mathrm{OCH}_{2} \mathrm{CH}_{2} \mathrm{CH}_{2}-$ $\mathrm{NHCO}$ ), 7.47 (bt, $2 \mathrm{H}, \mathrm{CONHCH}_{2} \mathrm{CH}_{2} \mathrm{CH}_{2} \mathrm{CH}_{2}$ ), 3.49 (t, $4 \mathrm{H}, \mathrm{OCH}_{2} \mathrm{CH}_{2} \mathrm{CH}_{2} \mathrm{NH}$ ), 3.30-3.50 (m, 54H, OCH $\left.{ }_{2} \mathrm{CH}_{2}\right), 3.30-3.50$ (m, 4H, $\left.\mathrm{OCH}_{2} \mathrm{CH}_{2} \mathrm{CH}_{2} \mathrm{NH}\right), 3.30$ (q, 4H, $\mathrm{CONHCH}_{2} \mathrm{CH}_{2} \mathrm{CH}_{2} \mathrm{CH}_{2}$ ), 1.81 (m, 4H, $\left.\mathrm{OCH}_{2} \mathrm{CH}_{2} \mathrm{CH}_{2} \mathrm{NH}\right), 1.60-1.70$ (m, $54 \mathrm{H}$, $\mathrm{OCH}_{2} \mathrm{CH}_{2}$ ), 1.50-1.60 (m, 4H, $\mathrm{CONHCH}_{2} \mathrm{CH}_{2} \mathrm{CH}_{2} \mathrm{CH}_{2}$ ), 1.36-1.27 (m, 4H, $\mathrm{CONHCH}_{2-}$ $\mathrm{CH}_{2} \mathrm{CH}_{2} \mathrm{CH}_{2}$ ), 1.36-1.27 (m, $4 \mathrm{H}, \mathrm{CONHCH}_{2} \mathrm{CH}_{2} \mathrm{CH}_{2} \mathrm{CH}_{2}$ );

PTHF-OXA 10 (4e): ${ }^{1} \mathrm{H}$ NMR $\left(300 \mathrm{MHz}, \mathrm{CDCl}_{3}-\mathrm{d}_{1}\right) \delta=7.83$ (bt, $2 \mathrm{H}, \mathrm{OCH}_{2} \mathrm{CH}_{2} \mathrm{CH}_{2}-$ $\mathrm{NHCO}$ ), 7.47 (bt, $2 \mathrm{H}, \mathrm{CONHCH}_{2} \mathrm{CH}_{2} \mathrm{CH}_{2} \mathrm{CH}_{2} \mathrm{CH}_{2}$ ), 3.48 (t, $4 \mathrm{H}, \mathrm{OCH}_{2} \mathrm{CH}_{2} \mathrm{CH}_{2} \mathrm{NH}$ ), 3.30-3.50 (m, 54H, OCH $\left.{ }_{2} \mathrm{CH}_{2}\right), 3.30-3.50$ (m, $\left.4 \mathrm{H}, \mathrm{OCH}_{2} \mathrm{CH}_{2} \mathrm{CH}_{2} \mathrm{NH}\right), 3.29$ (q, 4H, $\left.\mathrm{CONHCH}_{2} \mathrm{CH}_{2} \mathrm{CH}_{2} \mathrm{CH}_{2} \mathrm{CH}_{2}\right), 1.80\left(\mathrm{~m}, 4 \mathrm{H}, \mathrm{OCH}_{2} \mathrm{CH}_{2} \mathrm{CH}_{2} \mathrm{NH}\right), 1.60-1.70$ (m, 54 $\left.\mathrm{H}, \mathrm{OCH}_{2} \mathrm{CH}_{2}\right), 1.50-1.60\left(\mathrm{~m}, 4 \mathrm{H}, \mathrm{CONHCH}_{2} \mathrm{CH}_{2} \mathrm{CH}_{2} \mathrm{CH}_{2} \mathrm{CH}_{2}\right), 1.21-1.36(\mathrm{~m}, 4 \mathrm{H}$, $\mathrm{CONHCH}_{2} \mathrm{CH}_{2} \mathrm{CH}_{2} \mathrm{CH}_{2} \mathrm{CH}_{2}$ ), 1.21-1.36 (m, $4 \mathrm{H}, \mathrm{CONHCH}_{2} \mathrm{CH}_{2} \mathrm{CH}_{2} \mathrm{CH}_{2} \mathrm{CH}_{2}$ ), 1.21$1.36\left(\mathrm{~m}, 4 \mathrm{H}, \mathrm{CONHCH}_{2} \mathrm{CH}_{2} \mathrm{CH}_{2} \mathrm{CH}_{2} \mathrm{CH}_{2}\right)$;

Diethyl 2,2'-(hexane-1,6-diylbis(azanediyl))bis(2-oxoacetate) (OXA 6 6) (5) A solution of 1,6-diaminohexane $(20.00 \mathrm{~g}, 0.17 \mathrm{~mol})$ in $200 \mathrm{ml}$ of tetrahydrofuran was slowly added to diethyl oxalate $(252.00 \mathrm{~g}, 1.72 \mathrm{~mol})$. Subsequently the mixture was stirred at room temperature for $16 \mathrm{~h}$. The solvent and excess of diethyl oxalate were removed by filtration. The solids were dissolved in chloroform and filtered. The chloroform was removed under reduced pressure and the product was washed two times with diethyl ether and dried under vacuum. The product was obtained as a white powder in a yield of $85 \%\left(\mathrm{mp} 90{ }^{\circ} \mathrm{C}\right) \cdot \underline{{ }^{1} \mathrm{H} \mathrm{NMR}}\left(300 \mathrm{MHz}, \mathrm{CDCl}_{3}-\mathrm{d}_{1}\right) \delta=7.35$ (bt, $2 \mathrm{H}, \mathrm{OCOCONH}$ ), 4.25 (q, 4H, $\mathrm{CH}_{3} \mathrm{CH}_{2} \mathrm{O}$ ), 3.29 (m, $4 \mathrm{H}, \mathrm{NHCH}_{2} \mathrm{CH}_{2} \mathrm{CH}_{2}$ ), 1.59 (m, $4 \mathrm{H}, \mathrm{NHCH}_{2} \mathrm{CH}_{2} \mathrm{CH}_{2}$ ), $1.25\left(\mathrm{~m}, 4 \mathrm{H}, \mathrm{NHCH}_{2} \mathrm{CH}_{2} \mathrm{CH}\right.$ ), 1.25 (t, $\left.6 \mathrm{H}, \mathrm{CH}_{3} \mathrm{CH}_{2} \mathrm{O}\right)$; ${ }^{13} \mathrm{C} \mathrm{NMR}\left(75.26 \mathrm{MHz}, \mathrm{CDCl}_{3}-\mathrm{d}_{1}\right) \delta=160.9(\mathrm{OCOCONH}), 156.9(\mathrm{OCO} C \mathrm{ONH}), 63.4$ $\left(\mathrm{CH}_{3} \mathrm{CH}_{2} \mathrm{O}\right), 40.0\left(\mathrm{NHCH}_{2} \mathrm{CH}_{2} \mathrm{CH}_{2}\right), 29.1\left(\mathrm{NHCH}_{2} \mathrm{CH}_{2} \mathrm{CH}_{2}\right), 26.3\left(\mathrm{NHCH}_{2} \mathrm{CH}_{2} \mathrm{CH}_{2}\right)$, $14.2\left(\mathrm{CH}_{3} \mathrm{CH}_{2} \mathrm{O}\right)$.

\section{PTHF-OXA 6 - Method 2 (4c)}

Bis(3-aminopropyl) polytetrahydrofuran (1) (30.00 g, $0.023 \mathrm{mmol}$ ) and 2,2'-hexane1,6-diylbis(azanediyl))bis(2-oxo acetate) (5) (7.27 g, $0.023 \mathrm{~mol})$ were placed in a polymerization tube. To this mixture were added $\mathrm{Ti}(\mathrm{BuO})_{4}(0.2 \mathrm{wt} \%$ relative to the total mass dissolved in $1 \mathrm{ml}$ of toluene) and Irganox1330 (1 wt\% of the total mass). The mixture was heated to $190{ }^{\circ} \mathrm{C}$ under a nitrogen flow. After $1 \mathrm{~h}$, the pressure was slowly reduced to $\sim 20$ mbar. The ethanol distilling off during this period was collected in a trap cooled with liquid nitrogen. Subsequently, the pressure was further reduced to $\sim 0.08$ mbar in the following $4 \mathrm{~h}$. The reaction mixture was then cooled to 
room temperature under vacuum. The polymer was collected and dissolved in $200 \mathrm{ml}$ of chloroform at $50{ }^{\circ} \mathrm{C}$ for $4 \mathrm{~h}$ and subsequently precipitated in $2 \mathrm{~L}$ of diethyl ether. The polymer was filtered and dried at $60{ }^{\circ} \mathrm{C}$ at reduced pressure. The product was obtained as a yellow transparent elastic solid.

\section{N,N'-bis(6-aminohexyl)oxalamide (6)}

Diethyl oxalate $(19.30 \mathrm{~g}, 0.13 \mathrm{~mol})$ was slowly added to a solution of 1,6-diaminohexane (53.70 g, $1.32 \mathrm{~mol})$ in $300 \mathrm{ml}$ of chloroform at room temperature. Subsequently, the mixture was stirred at room temperature for $16 \mathrm{~h}$. After filtration, the product was washed twice with diethyl ether and dried under vacuum. The product was obtained as a white powder in a yield of $85 \%\left(\mathrm{mp} 120{ }^{\circ} \mathrm{C}\right) .{ }^{1} \mathrm{H} \mathrm{NMR}\left(300 \mathrm{MHz}, \mathrm{TFA}-\mathrm{d}_{1}\right) \delta=$ 6.83 (bt, $4 \mathrm{H}, \mathrm{NH}_{2}$ ), 3.56 (t, $4 \mathrm{H}, \mathrm{CH}_{2} \mathrm{CH}_{2} \mathrm{CH}{ }_{2} \mathrm{NH}$ ), 3.37 (m, 4H, $\mathrm{CH}_{2} \mathrm{CH}_{2} \mathrm{CH}_{2} \mathrm{NH}_{2}$ ), $1.95\left(\mathrm{~m}, 4 \mathrm{H}, \mathrm{CH}_{2} \mathrm{CH}_{2} \mathrm{CH}_{2} \mathrm{NH}\right), 1.82\left(\mathrm{~m}, 4 \mathrm{H}, \mathrm{CH}_{2} \mathrm{CH}_{2} \mathrm{CH}_{2} \mathrm{NH}_{2}\right), 1.60-1-70(\mathrm{~m}, 4 \mathrm{H}$, $\left.\mathrm{CH}_{2} \mathrm{CH}_{2} \mathrm{CH}_{2} \mathrm{NH}\right), 1.60-1.70\left(\mathrm{~m}, 4 \mathrm{H}, \mathrm{CH}_{2} \mathrm{CH}_{2} \mathrm{CH}_{2} \mathrm{NH}_{2}\right) ;{ }^{13} \mathrm{C} \mathrm{NMR}(75.26 \mathrm{MHz}$, TFA-d $\left.{ }_{1}\right) \delta=159.7(\mathrm{NHCO}), 40.7\left(\mathrm{CH}_{2} \mathrm{CH}_{2} C_{2} \mathrm{NH}_{2}\right), 39.7\left(\mathrm{CH}_{2} \mathrm{CH}_{2} C \mathrm{H}_{2} \mathrm{NH}\right)$, $27.3\left(\mathrm{CH}_{2} \mathrm{CH}_{2} \mathrm{CH}_{2} \mathrm{NH}_{2}\right), 26.2\left(\mathrm{CH}_{2} \mathrm{CH}_{2} \mathrm{CH}_{2} \mathrm{NH}\right), 25.0\left(\mathrm{CH}_{2} \mathrm{CH}_{2} \mathrm{CH}_{2} \mathrm{NH}_{2}\right), 24.6$ $\left(\mathrm{CH}_{2} \mathrm{CH}_{2} \mathrm{CH}_{2} \mathrm{NH}\right)$.

\section{PTHF-OXA 66 (7)}

N,N'-bis(6-aminohexyl)oxalamide (6) (7.69 g, $0.027 \mathrm{~mol}$ ) and bis(ethyl 2-(aminopropyl)oxo acetate) polytetrahydrofuran (3) $(34.94 \mathrm{~g}, 0.027 \mathrm{~mol})$ were placed in a polymerization tube. To this mixture was added Irganox1330 (1 wt\% of the total mass). The mixture was heated to $270{ }^{\circ} \mathrm{C}$ under a nitrogen flow. After $1 \mathrm{~h}$, the pressure was slowly reduced to $\sim 20$ mbar to distill off the ethanol. Subsequently, the pressure was reduced to $\sim 0.08$ mbar in the following $4 \mathrm{~h}$. The reaction mixture was then cooled to room temperature under vacuum. The polymer was dried at $60{ }^{\circ} \mathrm{C}$ at reduced pressure. The product was obtained as a yellow transparent elastic solid in a yield of $95 \%$. ${ }^{1} \mathrm{H} \mathrm{NMR}\left(300 \mathrm{MHz}, \mathrm{TFA}_{-} \mathrm{d}_{1}\right) \delta=3.80\left(\mathrm{t}, 4 \mathrm{H}, \mathrm{OCH}_{2} \mathrm{CH}_{2} \mathrm{CH}_{2} \mathrm{NH}\right), 3.60-3.75(\mathrm{~m}$, $\left.54 \mathrm{H}, \mathrm{OCH}_{2} \mathrm{CH}_{2}\right), 3.54\left(\mathrm{t}, 4 \mathrm{H}, \mathrm{OCH}_{2} \mathrm{CH}_{2} \mathrm{CH}_{2} \mathrm{NH}\right), 3.41$ (t, $4 \mathrm{H}, \mathrm{CONHCH}_{2} \mathrm{CH}_{2} \mathrm{CH}_{2}$ ), $2.03\left(\mathrm{~m}, 4 \mathrm{H}, \mathrm{OCH}_{2} \mathrm{CH}_{2} \mathrm{CH}_{2} \mathrm{NH}\right), 1.70-1.80\left(\mathrm{~m}, 54 \mathrm{H}, \mathrm{OCH}_{2} \mathrm{CH}_{2}\right), 1.69(\mathrm{~m}, 4 \mathrm{H}$, $\left.\mathrm{CONHCH}_{2} \mathrm{CH}_{2} \mathrm{CH}_{2}\right), 1.42\left(\mathrm{~m}, 4 \mathrm{H}, \mathrm{CONHCH}_{2} \mathrm{CH}_{2} \mathrm{CH} \mathrm{H}_{2}\right)$. 


\subsubsection{Methods}

\section{NMR}

${ }^{1} \mathrm{H}(300 \mathrm{MHz})$ and ${ }^{13} \mathrm{C} \mathrm{NMR}(75.26 \mathrm{MHz})$ spectra were recorded on a Varian Inova Nuclear Magnetic Resonance Spectrometer using $\mathrm{CDCl}_{3}-\mathrm{d}_{1}$ and TFA- $\mathrm{d}_{1}$ as solvents.

\section{GPC}

The GPC setup consisted of a Perkin Elmer series 200 binary pump, a Perkin Elmer series 200 autosampler, a Shimadzu CTO-AVP column oven, and a Shimadzu RID-10A refractive index detector. The eluent was $\mathrm{CHCl}_{3} / \mathrm{HFIP}(95 / 5 \mathrm{v} / \mathrm{v})$. The flow was set at $1 \mathrm{ml} . \mathrm{min}^{-1}$. The injection volume was $200 \mu \mathrm{L}$. The separation was performed on two PL Mixed-D columns $(300 \times 7.5 \mathrm{~mm})$ from Polymer Laboratories Ltd., packed with $5 \mu \mathrm{m}$ particles. The temperature of the columns was set at $30{ }^{\circ} \mathrm{C}$. Approximately $120 \mathrm{mg}$ of sample is weighed in a $50 \mathrm{ml}$ vial. To this vial $2 \mathrm{ml}$ of HFIP is added and the solution is allowed to stand for $2 \mathrm{~h}$. Next, $38 \mathrm{ml}$ of warm $\left(\sim 35^{\circ} \mathrm{C}\right)$ HPLC-quality chloroform is added and mixed thoroughly. Prior to injection the sample solution is filtered through a Millex-LCR $0.45 \mu \mathrm{m}$ filter (Millipore). The system was calibrated with 14 narrow polystyrene standards (Polymer Laboratories) with MW ranging from $5.8 \times 10^{2}$ to $1.0 \times 10^{6}$ g. $\mathrm{mol}^{-1}$. The standards were dissolved in $\mathrm{CHCl}_{3} / \mathrm{HFIP}(95 / 5 \mathrm{v} / \mathrm{v})$. Because the $\mathrm{K}$ and $\alpha$ values of the samples are not known and a viscometer was not available, no universal calibration could be performed. The reported molecular weights should, therefore, be regarded as PS-equivalent molecular weights. A calibration curve that is virtually linear over a broad molecular weight range was obtained. However, the three highest molecular weights tested $\left(6.75 \times 10^{5} \mathrm{~g} \cdot \mathrm{mol}^{-1}, 8.41 \times 10^{5} \mathrm{~g} \cdot \mathrm{mol}^{-1}\right.$ and $1.0 \times 10^{6}$ g.mol ${ }^{-1}$ ) elute near or in the exclusion limit of the column, causing an upward curvature at the high MW end.

\section{FT-IR}

To minimize the potential oxidation of the material, samples preparation comprised the following steps. The surface of a $32 \times 3 \mathrm{~mm} \mathrm{NaCl}$ disc (Thermo, International Crystal Labs) was roughened to prevent interfering fringes. Subsequently, a polymer solution (0.3-0.5 g. $\left.\mathrm{ml}^{-1}\right)$ in dichloromethane was drop casted on the disk and the solvent was allowed to evaporate. This step was repeated until the amount of polymer was enough for obtaining a maximum peak height of $0.5-0.7$. The IR sample was placed in the holder and a second (prepared) disc was put on top. The holder was placed in the cell in an inert atmosphere $\left(\mathrm{N}_{2}\right.$ purge glove bag or $\mathrm{N}_{2}$ purged IR sample compartment). The cell was heated to a temperature $20-50{ }^{\circ} \mathrm{C}$ above the $\mathrm{T}_{\mathrm{m}}$ of the 
polymer and subsequently cooled to room temperature. Fourier transform infra-red spectra were recorded on a Thermo 5700 spectrometer utilizing a DTGS detector at $4 \mathrm{~cm}^{-1}$ resolution. The temperature of the prepared polymer film between sodium chloride windows was controlled by an infra-red cell from Spectra Tech (model 0019019). The data were collected between 4000 and $500 \mathrm{~cm}^{-1}$ (16 scans were acquired). The graphs were prepared using OPUS 6.1 software. All spectra were normalized to the $2860 \mathrm{~cm}^{-1}$ signal. The carbonyl region was analyzed quantitatively in terms of free, bonded and ordered amide structures by curve fitting (Omnic version 7.2) and following the guidelines of Meier $e t a l^{36}$. The results are plotted as the relative intensity of the bonded amide versus the total amides.

\section{TGA}

Thermal gravimetric analysis was carried out with 5-10 mg samples under a nitrogen atmosphere in the $50-700{ }^{\circ} \mathrm{C}$ range at a heating rate of $10{ }^{\circ} \mathrm{C} \cdot \mathrm{min}^{-1}$, using a Perkin-Elmer Thermal Gravimetric Analyser TGA 7.

\section{DSC}

Thermal analysis was carried out using a Perkin-Elmer Pyris 1. Calibration was carried out with pure indium. Samples (5-10 mg) were heated from -50 to $250{ }^{\circ} \mathrm{C}$ at a rate of $20{ }^{\circ} \mathrm{C} \cdot \mathrm{min}^{-1}$, annealed for $5 \mathrm{~min}$, cooled to $-50{ }^{\circ} \mathrm{C}$ at a rate of $20{ }^{\circ} \mathrm{C} \cdot \mathrm{min}^{-1}$, and subsequently heated from -50 to $250{ }^{\circ} \mathrm{C}$ at a rate of $20{ }^{\circ} \mathrm{C} \cdot \mathrm{min}^{-1}$. Melting $\left(\mathrm{T}_{\mathrm{m}}\right)$ and crystallization $\left(\mathrm{T}_{\mathrm{c}}\right)$ temperatures were obtained from the peak maxima, melt $\left(\Delta \mathrm{H}_{\mathrm{m}}\right)$ and crystallization $\left(\Delta \mathrm{H}_{\mathrm{c}}\right)$ enthalpies were determined from the area under the curve. The data presented are taken from the first cooling scan and the second heating scan. 


\subsection{Results and Discussion}

\subsubsection{Synthesis and characterization}

In the preparation of segmented poly(ether amide)s comprising uniform oxalamide hard segments and polytetrahydrofuran soft segments, three pathways were explored. In the most straightforward approach, diethyl oxalate was polycondensated with an amino end functionalized polytetrahydrofuran prepolymer (1) with a molecular weight $\left(M_{n}\right)$ of $1.1 \times 10^{3}$ g.mol ${ }^{-1}$ (Scheme 3.1). In this way, a segmented poly(ether amide) (2) was obtained comprising single oxalamide units in the polymer chain. The polycondensation performed at $190{ }^{\circ} \mathrm{C}$ and low pressure resulted in a yellow transparent material in a high yield. In the ${ }^{1} \mathrm{H}$ NMR spectrum of the polymer no signals for the ethyl ester and amino methylene end groups could be observed indicating that the polymer had a relatively high molecular weight. GPC analysis revealed this material to have a molecular weight of $30 \times 10^{3}$ g. $\mathrm{mol}^{-1}$ with a PDI of 9, relative to polystyrene standards.

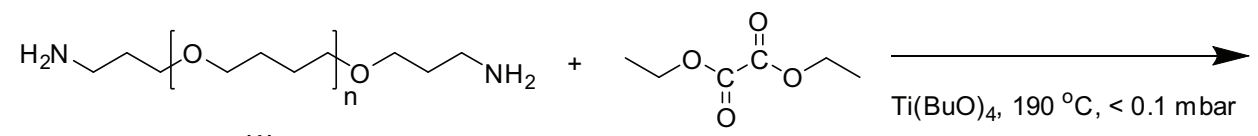

(1)<smiles>CC(C)(C)CCNC(=O)C(=O)NCCCOC(C)(O)CCCOC1CCCC1</smiles>

(2)

Scheme 3.1: Synthesis of PTHF-OXA (2).

Despite the relatively high molecular weight polymer that can be obtained, the material was sticky and difficult to handle. To improve the material properties the incorporation of a uniform hard segment with two oxalamide groups in the polymer was investigated. These segmented poly(ether amide)s were prepared in two steps. In the first step, an amine end functionalized polytetrahydrofuran (1) was reacted with an excess of diethyl oxalate to convert the amine end groups to the corresponding amide-ester groups (Scheme 3.2). The use of a fourfold excess of diethyl oxalate appeared sufficient to avoid polymerization. After removal of the excess of diethyl oxalate by distillation, the material was obtained as a slowly solidifying liquid. The ${ }^{1} \mathrm{H}$ NMR spectrum of the 
product confirmed full conversion of the amine end groups into the amide-ester end groups by the disappearance of the signal $(2.80 \mathrm{ppm})$ of the methylene protons adjacent to the amino groups. The integral ratio of the amide and ester methylene protons was $1: 2$, showing that no unwanted polymerization had taken place. ${ }^{13} \mathrm{C}$ NMR spectral data confirmed the structure of the prepolymer. In the carbonyl region, the amide and ester carbonyl carbon atoms are found at $\delta 157.5$ and $\delta 160.9$, respectively. The typical signal of the oxalamide carbonyl carbon atoms as found in $\mathbf{2}(\delta 160.1)$ appeared absent, also demonstrating that polymerization did not take place. Polycondensation of the newly end functionalized polytetrahydrofuran (3) with aliphatic $\alpha, \omega$-diamines, having 2, 4, 6, 8 and 10 methylene groups, afforded a series of poly(ether amide)s with uniform hard segments comprising two oxalamide groups (4a-e) (Scheme 3.2).

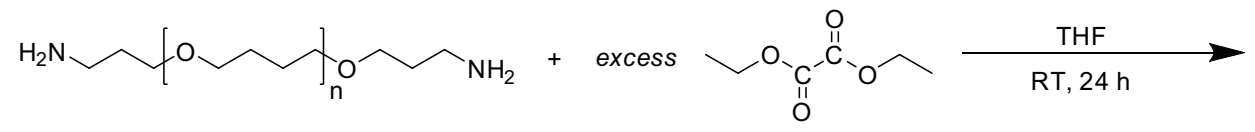

(1)<smiles>CCOC(=O)C(=O)NCCCNC(C)(C)OCCCCC(C)(C)OCCCNC(=O)C(=O)OCC</smiles>

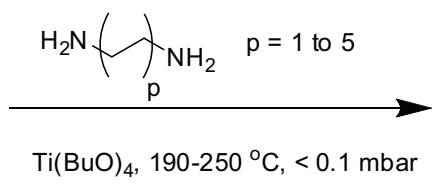

(3)

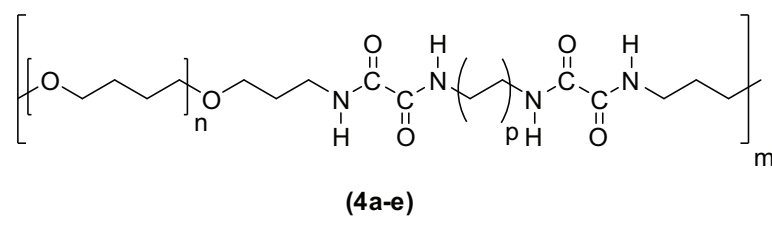

Scheme 3.2: Synthesis of PTHF-OXA 2 X with $\mathrm{p}=1$ to 5 (4a-e).

The polycondensation reactions were performed at $190{ }^{\circ} \mathrm{C}$ and low pressure for $4 \mathrm{~h}$ for those polymers prepared from diamines with spacer lengths of 6,8 and 10 methylene groups. To keep the polymerization mixture in the melt, reaction temperatures were increased to $250{ }^{\circ} \mathrm{C}$ and $210{ }^{\circ} \mathrm{C}$ for the polymers $4 \mathbf{a}$ and $\mathbf{4 b}$, respectively. All polymers were obtained as yellow elastic transparent solid materials in high yields. Also in these cases the absence of peaks for the ethyl ester or amino methylene groups in the ${ }^{1} \mathrm{H}$ NMR spectra of the polymers isolated indicated that the molecular weight of the polymers was relatively high. GPC analysis of the polymers revealed molecular weights in between $23 \times 10^{3}$ and $41 \times 10^{3}$ g. $\mathrm{mol}^{-1}$ with PDI's of 9-10 relative to polystyrene standards. 
An alternative pathway to prepare the segmented poly(ether amide)s $\mathbf{4}$ was investigated by the preparation of $\mathbf{4 c}$ as outlined in Scheme 3.3. In the first step a diester-diamide segment was prepared by reacting 1,6-diaminohexane with a tenfold excess of diethyl oxalate (Scheme 3.3). The product was obtained as a white powder with a high purity in a yield of $85 \%$. Polycondensation of the preformed $\mathrm{OXA}_{2} 6$ segment (5) with the amino functionalized polytetrahydrofuran (1) created the segmented poly(ether amide) 4c. Similarly to the bisoxalamide based segmented poly(ether amide)s as described above, the molecular weight of the polymer is relatively high (Table 3.1).

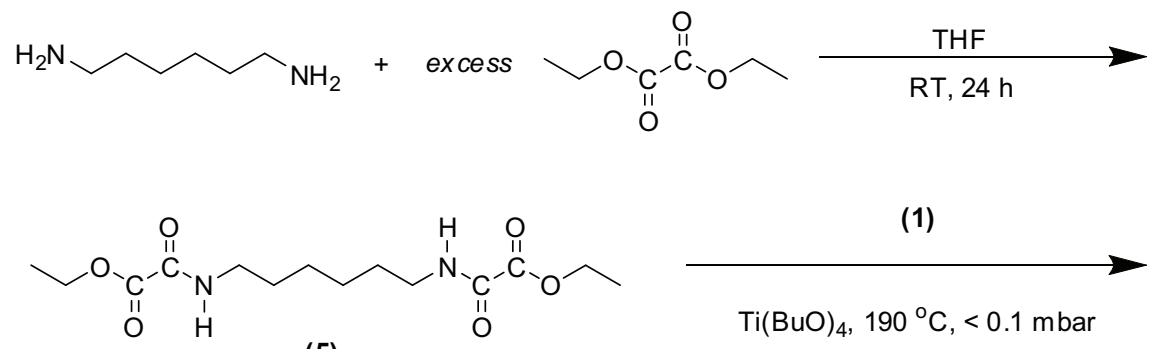

(5)<smiles>CC(C)(C)CCNC(=O)C(=O)NCCCCCCNC(=O)C(=O)NCCCOC(C)(C)CCCOC1CCCC1</smiles>

(4c)

Scheme 3.3: Synthesis of PTHF-OXA 6 via method 2 (4c).

In a slightly different way, and based on the easy access to oxalamide end functionalized PTHF, segmented poly(ether amide)s comprising three oxalamide groups in the hard segment were prepared (Scheme 3.4). First a preformed diamine-diamide segment, N,N'-bis(6-aminohexyl)oxalamide (6), was prepared by reacting diethyl oxalate with a tenfold excess of 1,6-diaminohexane. After purification, the product was obtained as a white powder in a yield of $85 \%$. The polymerization route was similar as described for the preparation of segmented poly(ether amide)s comprising two oxalamide groups in the hard segments. The amide-ester functionalized polytetrahydrofuran $\mathbf{3}$ was subsequently polycondensated with the diamine-diamide $\mathbf{6}$, creating the segmented poly(ether amide) 7 with three oxalamide groups in the hard segment. The polycondensation, when carried out at $270{ }^{\circ} \mathrm{C}$ and low pressure for $4 \mathrm{~h}$, provided an elastic transparent solid material in a high yield. The ${ }^{1} \mathrm{H}$ NMR spectra and GPC revealed a molecular weight of $19 \times 10^{3}$ g.mol ${ }^{-1}$ with a PDI of 10 . 


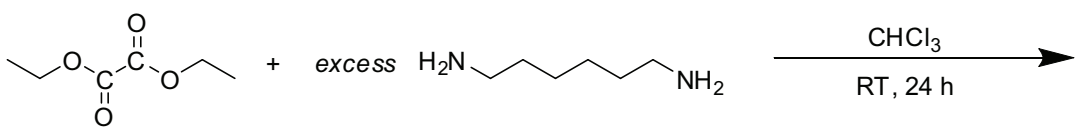<smiles>NCCCCCCNC(=O)C(=O)NCCCCCCN</smiles>

(6)
(3)<smiles>CC(C)(C)CCNC(=O)C(=O)NCCCCCCNC(=O)C(=O)NCCCCCCNC(=O)C(=O)NCCCOC(C)(C)CCCOC(C)(C)C</smiles>

(7)

Scheme 3.4: Synthesis of PTHF-OXA 66 (7).

Table 3.1: Molecular weights of segmented poly(ether amide)s (2, 4a-e and 7).

\begin{tabular}{lcccc}
\hline & $\begin{array}{c}\text { Spacer length } \\
(-)\end{array}$ & $\begin{array}{c}\text { Hard segment content } \\
(\mathrm{wt} \%)\end{array}$ & $\begin{array}{c}\mathrm{M}_{\mathrm{n}} \\
\left(\mathrm{g} . \mathrm{mol}^{-1} \times 10^{3}\right)\end{array}$ & $\begin{array}{c}\text { PDI } \\
(-)\end{array}$ \\
\hline PTHF-OXA (2) & - & 7.3 & 30 & 9 \\
PTHF-OXA $_{2}$ (4c) & 6 & 18.9 & 41 & 9 \\
PTHF-OXA 66 (7) & 66 & 27.8 & 19 & 10 \\
\hline & & & & \\
\hline PTHF-OXA $_{2}$ (4a) & 2 & 15.4 & 23 & 9 \\
PTHF-OXA $_{2}$ 4 (4b) & 4 & 17.2 & 30 & 10 \\
PTHF-OXA $_{2}$ 6 (4c) & 6 & 18.9 & 51 & 9 \\
PTHF-OXA $_{2}$ - method 2 (4c) & 6 & 18.9 & 32 & 7 \\
PTHF-OXA $_{2}$ (4d) & 8 & 20.5 & 32 & 9 \\
PTHF-OXA $_{2}$ 10 (4e) & 10 & 22.1 & & \\
\hline
\end{tabular}




\subsubsection{FT-IR}

In the FT-IR spectra of poly(ether amide)s, the N-H stretching vibration bands at $\sim 3300$ and $\sim 3400 \mathrm{~cm}^{-1}$ can be assigned to a hydrogen-bonded and free N-H stretching vibration, respectively (Figure 3.1). These vibrations are not conformationally sensitive and the broadness of these bands reflects a distribution of hydrogen bonded groups of varying strength dictated by distance and geometry ${ }^{37-39}$. The poly(ether amide) with single oxalamide units 2 shows a broad hydrogen bonded N-H band at $3330 \mathrm{~cm}^{-1}$ and a shoulder at $3390 \mathrm{~cm}^{-1}$ corresponding to free $\mathrm{N}-\mathrm{H}$ groups. Contrary, the segmented polymers 4c and $\mathbf{7}$ only show a sharp band at $3294 \mathrm{~cm}^{-1}$ indicative of the presence of only hydrogen-bonded oxalamide groups (Figure 3.2).

Non hydrogen-bonded

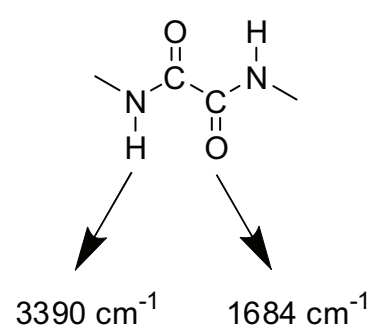

Hydrogen-bonded

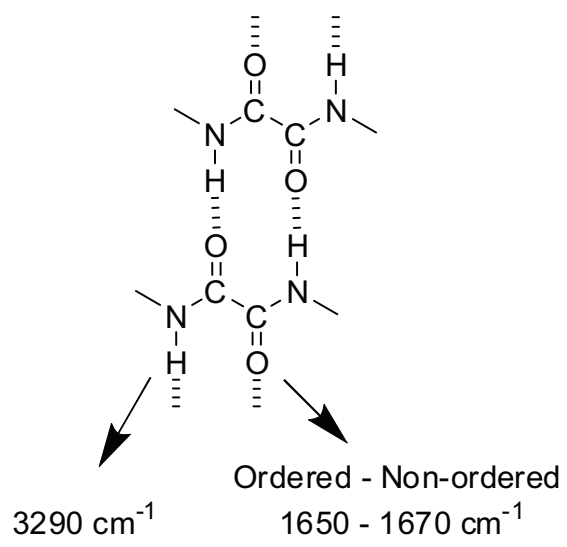

Figure 3.1: FT-IR wave numbers of non hydrogen-bonded and hydrogen bonded N-H and $\mathrm{C}=\mathrm{O}$ groups in oxalamides.

The amide I band, resulting from $\mathrm{C}=\mathrm{O}$ stretching vibrations is also sensitive to the arrangement of H-bonds. Hydrogen bonded carbonyl groups in the ordered state can be found at $1650 \mathrm{~cm}^{-1}$, whereas disordered hydrogen bonded and free carbonyl groups shift to higher wave numbers of 1670 and $1684 \mathrm{~cm}^{-1}$, respectively (Figure 3.1). This is illustrated in Figure 3.2 revealing a broad signal around $1680-1650 \mathrm{~cm}^{-1}$ of the poly(ether amide) (2) indicative of the presence of ordered and disordered hydrogen bonds. The H-bond ordering in polymers $\mathbf{4 c}$ and $\mathbf{7}$ is very high and a major sharp signal is found at $1648 \mathrm{~cm}^{-1}$. In summary, FT-IR spectra revealed extensive hydrogen bonding and ordering of hard segments present in polymers comprising two or three oxalamide groups compared to polymers comprising single oxalamide units. 

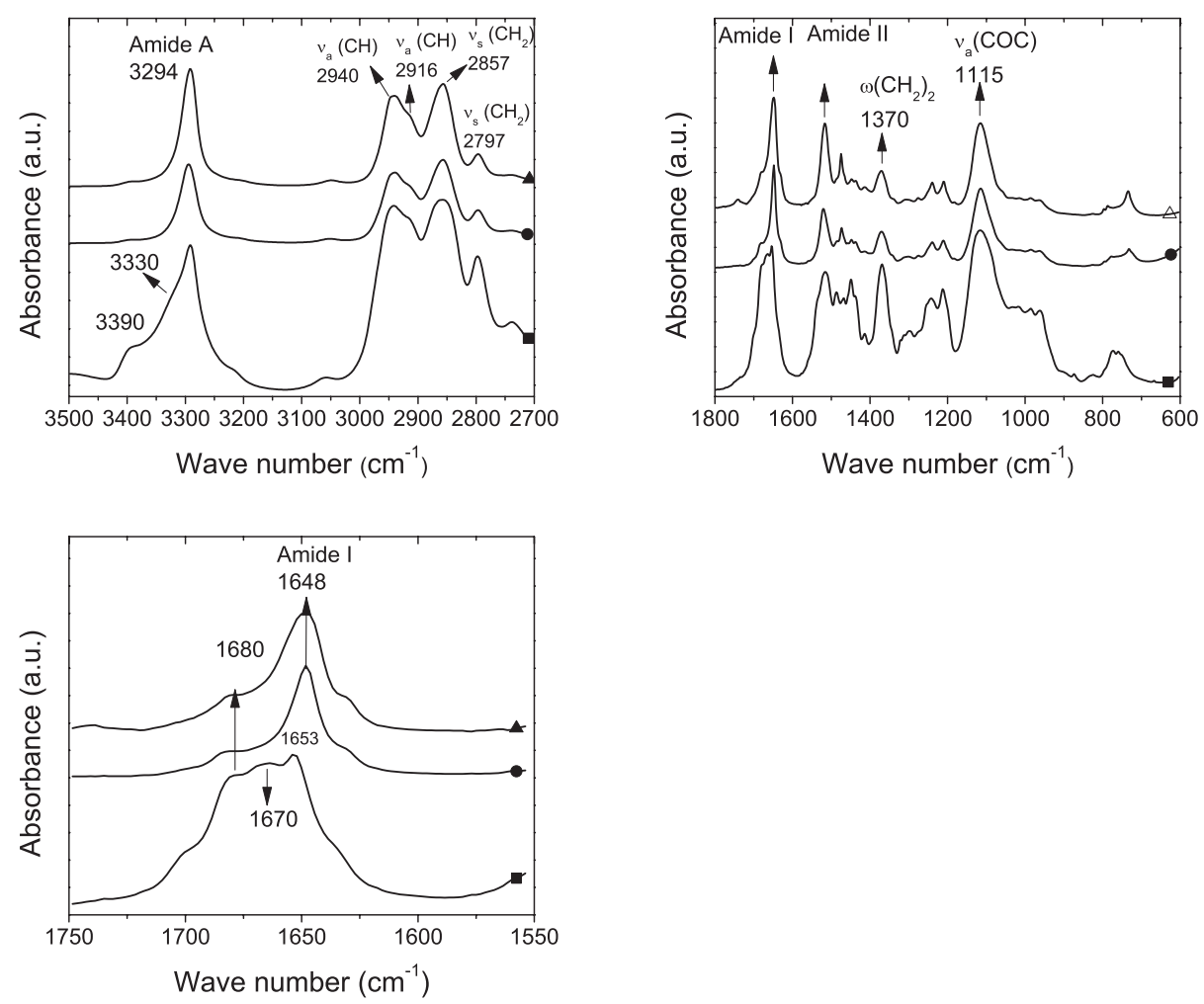

Figure 3.2: FT-IR spectra of segmented poly(ether amide)s with uniform oxalamide hard segments ( $)$ PTHF-OXA (2) at $25^{\circ} \mathrm{C},(\bullet)$ PTHF-OXA $26(4 \mathbf{c})$ at $50{ }^{\circ} \mathrm{C}$ and $(\triangle) \mathrm{PTHF}^{-\mathrm{OXA}} 366\left(\mathbf{7 )}\right.$ at $50{ }^{\circ} \mathrm{C}$.

In Figure 3.3, the FT-IR spectra of the segmented poly(ether amide)s with varying spacer lengths between the two oxalamide groups 4a-e are presented. All five polymers show a sharp $\mathrm{N}-\mathrm{H}$ stretching band and $\mathrm{C}=\mathrm{O}$ stretching band at 3296 and $1650 \mathrm{~cm}^{-1}$, respectively. The hard segment crystallinity can be determined from the ratio of the area of the hydrogen bonded ordered phase at $1650 \mathrm{~cm}^{-1}$ to the total area by deconvolution of the $\mathrm{C}=\mathrm{O}$ stretching band. For the polymers PTHF-OXA 2 (4a), PTHF-OXA $_{2} 4$ (4b) and PTHF-OXA 10 (4e) the hard segment crystallinity was calculated between 80 and $90 \%$, while this value was 66 and $67 \%$ for PTHF-OXA 6 (4c) and PTHF-OXA 28 (4d), respectively. 

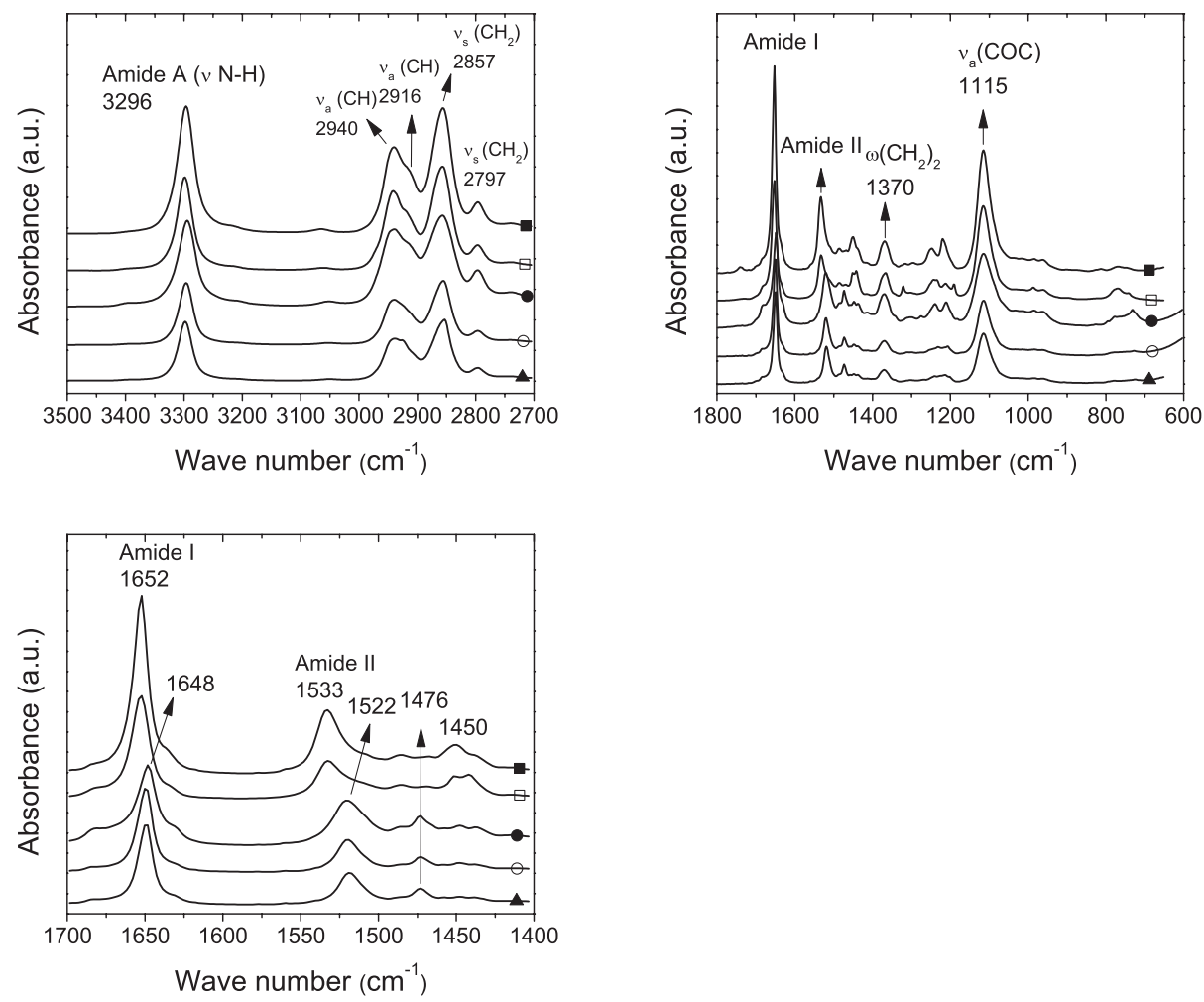

Figure 3.3: FT-IR spectra at $50{ }^{\circ} \mathrm{C}$ of segmented poly(ether amide)s with two oxalamide groups in the hard segment and with different spacer lengths ( $\mathbf{a}) \mathrm{PTHF}^{-\mathrm{OXA}_{2} 2}$ (4a), ( $\square$ ) PTHF-OXA 4 (4b), (•) PTHF-OXA 6 (4c), (O) PTHF-OXA 28 (4d) and ( $\Delta$ ) PTHF-OXA $210(\mathbf{4 e})$.

Another characteristic IR band in polyamides is the amide II band, which is a mixed mode with a major contribution of bending $\mathrm{N}-\mathrm{H}$ in plane deformation and C-N stretching. This band is especially sensitive to polymorphism resulting from a significant difference in chain conformation ${ }^{37-40}$. The polymers PTHF-OXA 22 (4a) and PTHF-OXA 4 (4b) show an amide II band at $1533 \mathrm{~cm}^{-1}$ which shifts to 1520 $\mathrm{cm}^{-1}$ for PTHF-OXA 26 , PTHF-OXA 28 and PTHF-OXA 210 (4c-e). This suggests that the hard segments with short spacer lengths crystallize in a different type of crystal structure than hard segments with 6,8 and 10 methylene units between the oxalamide groups. Nylon-x,2 polymers are known to crystallize in a fully extended planar zig-zag conformation. However it was shown that chain distortion and hence deviations from the extended conformation increased as the number of methylene groups decreased ${ }^{41,42}$. 


\subsubsection{Thermal properties}

The thermal stability of the segmented poly(ether amide)s under non-oxidative conditions was determined by thermal gravimetric analysis (TGA). All polymers are stable up to $\sim 410{ }^{\circ} \mathrm{C}$ and the TGA traces are characterized by a single step (Figure 3.4). For all polymers the decomposition temperatures are considerably higher than the melting temperatures, which is important for the processing of the materials.
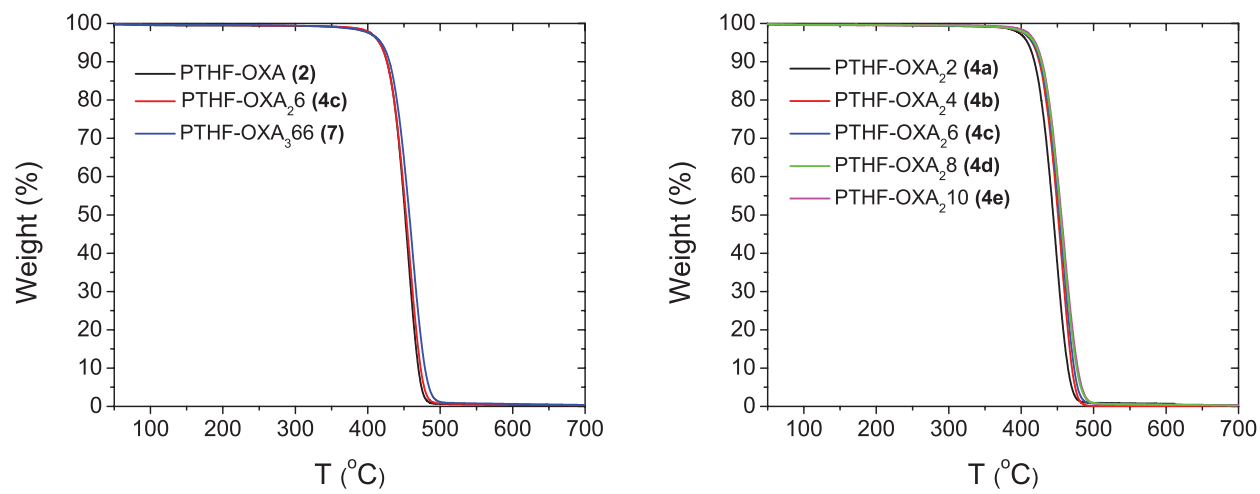

Figure 3.4: TGA thermograms of segmented poly(ether amide)s (2, 4a-e and 7).

The thermal properties of the segmented poly(ether amide)s were determined by differential scanning calorimetry (DSC). The crystallization and melting temperatures and corresponding enthalpies of the polymers were obtained from the first cooling scan and second heating scan and are reported in Table 3.2.

The DSC curves depicted in Figure 3.5, show the influence of the number of oxalamide groups in the uniform hard segment on the thermal properties. The thermal transitions reflect the observation that materials built from PTHF macromonomers separated by single oxalamide units $\mathbf{2}$ are sticky materials. This poly(ether amide) has a melting temperature of $18{ }^{\circ} \mathrm{C}$, and a crystallization transition at $-45^{\circ} \mathrm{C}$. A recrystallization exotherm preceding the melting transition indicates slow crystallization. Incorporating uniform hard segments with two oxalamide groups $\mathbf{4 c}$ increases the melting temperature with more than $100{ }^{\circ} \mathrm{C}$, although the transitions are very broad (also see Figure 3.6). Increasing the number of oxalamide groups in the uniform hard segments to three shifted the melting temperature to even higher values, although the transition also is broad. The relatively broad molecular weight distribution of all segmented copolymers may contribute to the broad thermal transitions observed. 
(a)

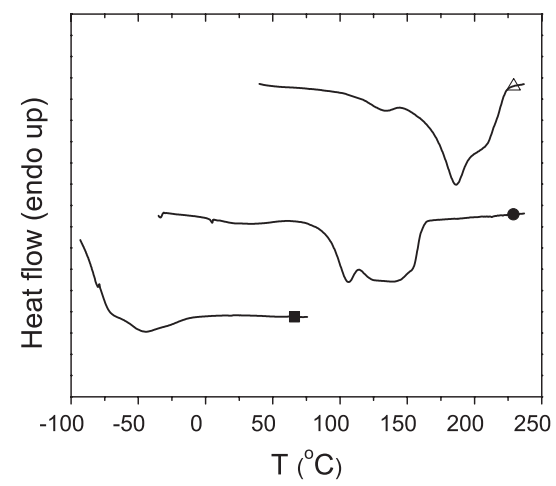

(b)

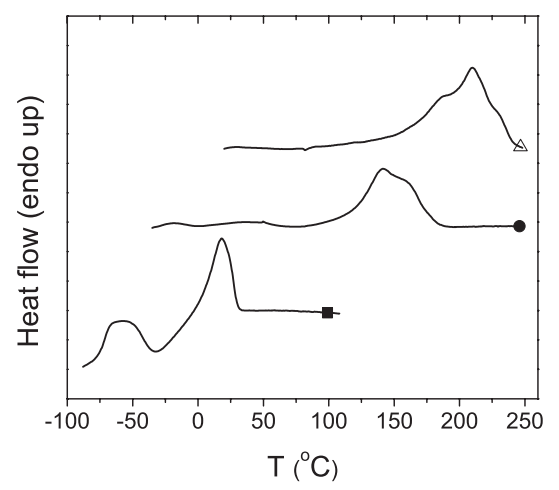

Figure 3.5: DSC cooling (a) and second heating (b) curves of segmented poly(ether amide)s with uniform oxalamide hard segments ( $)$ PTHF-OXA (2), (•) PTHF$\mathrm{OXA}_{2} 6(\mathbf{4 c})$ and $(\triangle)$ PTHF-OXA 66 (7).

The effect of the spacer length between two oxalamide groups (4a-e) on the thermal properties of the PEAs is depicted in Figure 3.6. All polymers have broad melting and crystallization transitions. The presence of multiple transitions suggests that different crystal structures and/or crystal thicknesses are present. Increasing the length between the oxalamide groups from 2 to 10 methylene groups decreases the melting and crystallization temperatures. Upon cooling from the melt, two distinct crystallization transitions were observed (peaks 1 and 2 in Figure 3.6a). With increasing spacer length, both the high and low temperature transitions shift to lower temperatures. Moreover, the lower temperature transition is predominant at shorter spacer lengths suggesting a difference in the crystal structure.

Increasing the cooling rate had little effect on the onset of crystallization of the hard segment (Figure 3.7). In addition, no changes in melting transition and no recrystallization were observed during reheating. This indicates that the crystallization of the bisoxalamide hard segment is fast and complete even at high cooling rates, which is favorable for processing in the melt. 
(a)

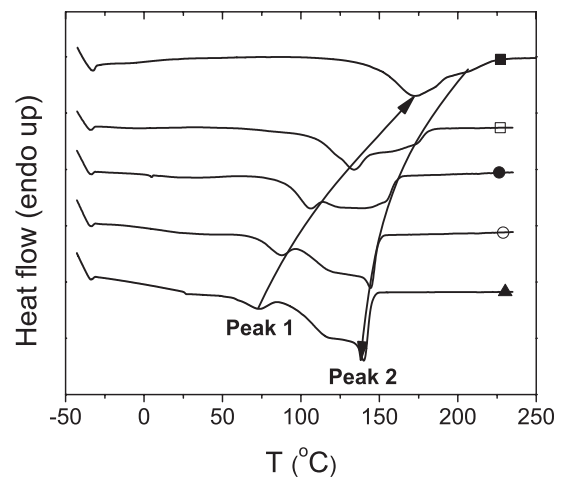

(b)

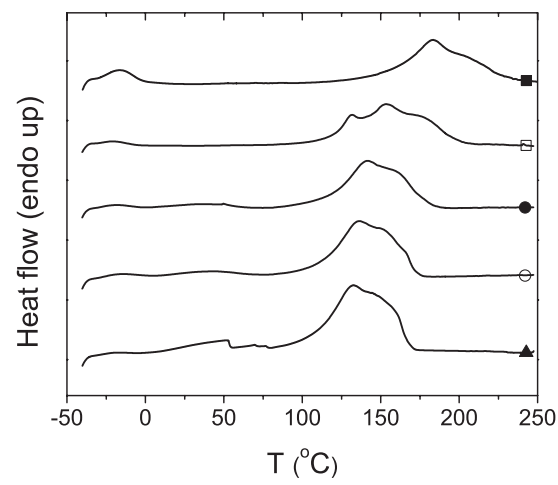

Figure 3.6: DSC cooling (a) and second heating (b) curves of segmented poly(ether amide)s with two oxalamide groups in the hard segment and with different spacer lengths

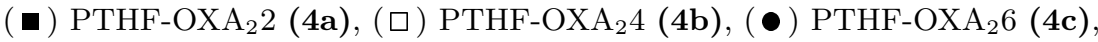

(O) PTHF-OXA 8 (4d) and ( $\Delta$ ) PTHF-OXA 10 (4e).

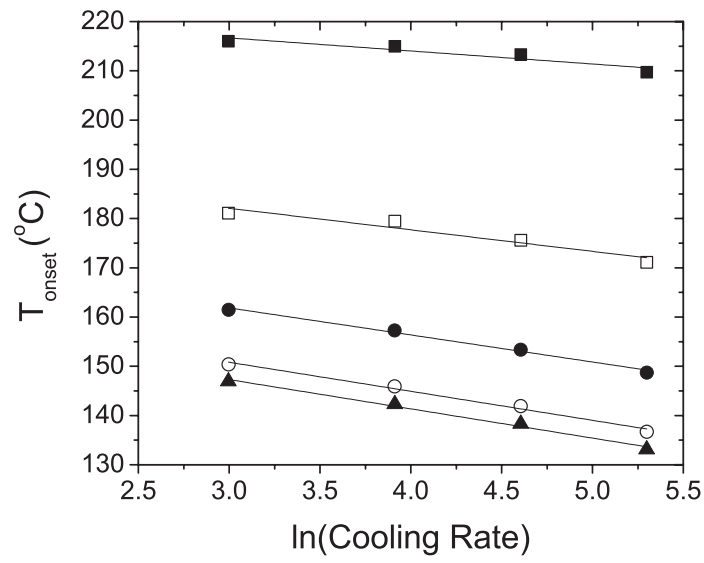

Figure 3.7: Crystallization onset temperature as a function of cooling rate for segmented

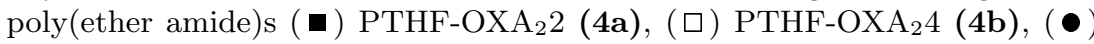
PTHF-OXA 6 (4c), ( O) PTHF-OXA 8 (4d) and ( $\mathbf{\Delta}$ ) PTHF-OXA 210 (4e). 
Table 3.2: Thermal properties of segmented poly(ether amide)s (2, 4a-e and $\mathbf{7})$.

\begin{tabular}{|c|c|c|c|c|c|}
\hline & $\begin{array}{l}\mathrm{T}_{\mathrm{m}} \\
\left({ }^{\circ} \mathrm{C}\right)\end{array}$ & $\begin{array}{c}\Delta \mathrm{H}_{\mathrm{m}} \\
\left(\mathrm{J} \cdot \mathrm{g}^{-1}\right)\end{array}$ & $\begin{array}{c}\mathrm{T}_{\mathrm{c}} \\
\left({ }^{\circ} \mathrm{C}\right)\end{array}$ & $\begin{array}{c}\Delta \mathrm{H}_{\mathrm{m}} \\
\left(\mathrm{J}^{\left.-\mathrm{g}^{-1}\right)}\right.\end{array}$ & $\begin{array}{c}\mathrm{T}_{\text {onset }} \\
\left({ }^{\circ} \mathrm{C}\right)\end{array}$ \\
\hline PTHF-OXA (2) & 18 & - & -45 & - & - \\
\hline $\mathrm{PTHF} \mathrm{OXA}{ }_{2} 6(4 \mathrm{c})$ & $141 / 158$ & 34 & $106 / 139$ & 34 & 162 \\
\hline $\mathrm{PTHF}-\mathrm{OXA}_{3} 66$ (7) & $189 / 210$ & 54 & $134 / 186$ & 47 & 225 \\
\hline $\mathrm{PTHF}-\mathrm{OXA}_{2} 2$ (4a) & $183 / 202$ & 36 & $173 /-$ & 30 & 216 \\
\hline $\mathrm{PTHF} \mathrm{OXA} \mathrm{A}_{2} 4(4 \mathrm{~b})$ & $131 / 174$ & 37 & $134 /-$ & 35 & 181 \\
\hline $\mathrm{PTHF}-\mathrm{OXA}_{2} 6$ (4c) & $141 / 158$ & 34 & $106 / 139$ & 34 & 162 \\
\hline $\mathrm{PTHF}-\mathrm{OXA}_{2} 8$ (4d) & $136 / 164$ & 35 & $87 / 144$ & 34 & 150 \\
\hline $\mathrm{PTHF}-\mathrm{OXA}_{2} 10(\mathbf{4 e})$ & $133 /-$ & 39 & $73 / 140$ & 38 & 147 \\
\hline
\end{tabular}

\subsection{Conclusions}

Novel segmented poly(ether amide)s based on flexible PTHF segments and uniform rigid oxalamide hydrogen bonding arrays were prepared. By changing the number of oxalamide groups in the hard segment and in one series the spacer length between two oxalamide groups the hard segment composition was varied. The polymer having a single oxalamide unit between PTHF blocks is a sticky transparent solid material with a melting temperature around room temperature. FT-IR showed weak hydrogen bonding between the oxalamide units. Uniform hard segments with two oxalamide groups provided PEAs with elastomeric properties and melting temperatures ranging from $140{ }^{\circ} \mathrm{C}$ to $200{ }^{\circ} \mathrm{C}$ depending on the number of methylene groups between the oxalamide groups. FT-IR revealed that the bisoxalamide based hard segments are strongly hydrogen bonded and highly ordered. The crystallization onset is almost cooling rate independent indicating that crystallization of the hard segment is fast. A segmented poly(ether amide) with three oxalamide groups in the hard segment is a transparent elastic material with a relatively high melting temperature above 200 ${ }^{\circ} \mathrm{C}$.

\subsection{References}

[1] Fakirov, S. Handbook of condensation thermoplastic elastomers; Wiley-VCH: Weinheim, 2005. 
1. Segmented poly(ether amide)s with uniform oxalamide based hard segments

[2] Holden, G.; Legge, N. R.; Quirk, R. P.; Schroeder, H. E. Thermoplastic elastomers, 2nd ed.; Hanser Publishers: Munich, 1996.

[3] Cella, R. J. J Polym Sci: Symp No 47 1973, 42, 727-740.

[4] Boulares, A.; Tessier, M.; Marechal, E. Polymer 2000, 41, 3561-3580.

[5] Deleens, G.; Foy, P.; Marechal, E. Eur Polym J 1977, 13, 337-342.

[6] Deleens, G.; Foy, P.; Marechal, E. Eur Polym J 1977, 13, 343-351.

[7] Deleens, G.; Foy, P.; Marechal, E. Eur Polym J 1977, 13, 353-360.

[8] Gaymans, R. J.; Schwering, P.; Dehaan, J. L. Polymer 1989, 30, 974-977.

[9] Vanhutten, P. F.; Walch, E.; Veeken, A. H. M.; Gaymans, R. J. Polymer 1990, 31, 524-529.

[10] Yu, Y. C.; Jo, W. H. J Appl Polym Sci 1994, 54, 585-591.

[11] Sheth, J. P.; Xu, J. N.; Wilkes, G. L. Polymer 2003, 44, 743-756.

[12] Biemond, G. J. E.; Feijen, J.; Gaymans, R. J. Polym Eng Sci 2008, 48, 1389-1400.

[13] Gaymans, R. J.; Dehaan, J. L. Polymer 1993, 34, 4360-4364.

[14] Harrell, L. L. Macromolecules 1969, 2, 607-612.

[15] Miller, J. A.; Lin, S. B.; Hwang, K. K. S.; Wu, K. S.; Gibson, P. E.; Cooper, S. L. Macromolecules 1985, 18, 32-44.

[16] Ng, H. N.; Allegrez, A. E.; Seymour, R. W.; Cooper, S. L. Polymer 1973, 14 , 255-261.

[17] Niesten, M. C. E. J.; Feijen, J.; Gaymans, R. J. Polymer 2000, 41, 8487-8500.

[18] van der Schuur, M.; Feijen, J.; Gaymans, R. J. Polymer 2005, 46, 4584-4595.

[19] Versteegen, R. M.; Sijbesma, R. P.; Meijer, E. W. Macromolecules 2005, 38, 3176-3184.

[20] Versteegen, R. M.; Kleppinger, R.; Sijbesma, R. P.; Meijer, E. W. Macromolecules 2006, 39, 772-783.

[21] Biemond, G. J. E.; Feijen, J.; Gaymans, R. J. J Appl Polym Sci 2007, 105, 951-963.

[22] Bouma, K.; Wester, G. A.; Gaymans, R. J. J Appl Polym Sci 2001, 80, 1173-1180.

[23] Husken, D.; Krijgsman, J.; Gaymans, R. J. Polymer 2004, 45, 4837-4843.

[24] Krijgsman, J.; Husken, D.; Gaymans, R. J. Polymer 2003, 44, 7573-7588.

[25] Krijgsman, J.; Husken, D.; Gaymans, R. J. Polymer 2003, 44, 7043-7053.

[26] Coe, S.; Kane, J. J.; Nguyen, T. L.; Toledo, L. M.; Wininger, E.; Fowler, F. W.; Lauher, J. W. J Am Chem Soc 1997, 119, 86-93.

[27] Nguyen, T. L.; Fowler, F. W.; Lauher, J. W. J Am Chem Soc 2001, 123, $11057-$ 11064.

[28] Lauher, J. W.; Fowler, F. W.; Goroff, N. S. Acc Chem Res 2008, 41, 1215-1229. 
[29] Karle, I. L.; Ranganathan, D.; Shah, K.; Vaish, N. K. Int J Pept Protein Res 1994, 43, 160-165.

[30] Karle, I. L.; Ranganathan, D. Int J Pept Protein Res 1995, 46, 18-23.

[31] Karle, I. L.; Ranganathan, D. Biopolymers 1995, 36, 323-331.

[32] Frkanec, L.; Zinic, M. Chem Commun 2010, 46, 522-537.

[33] Asin, L.; Armelin, E.; Montane, J.; Rodriguez-Galan, A.; Puiggali, J. J Polym Sci Part A Polym Chem 2001, 39, 4283-4293.

[34] Black, W. D.; Preston, J. Man-made fibers. science and technology, 2nd ed.; Interscience: New York, 1968.

[35] Schulze, H. Thermoplastic adhesive polyoxamide from polyoxypropylene polyamine; US4,119,615, 1978.

[36] Meier, R. J. Vib Spectrosc 2005, 39, 266-269.

[37] Aharoni, S. M. n-Nylons: their synthesis, structure, and properties; John Wiley \& Sons Ltd: Chichester, 1997.

[38] Skrovanek, D. J.; Howe, S. E.; Painter, P. C.; Coleman, M. M. Macromolecules 1985, 18, 1676-1683.

[39] Skrovanek, D. J.; Painter, P. C.; Coleman, M. M. Macromolecules 1986, 19, 699-705.

[40] Kohan, M. I. Nylon plastic handbook; Hansers Publisher: Munich, 1995.

[41] Armelin, E.; Aleman, C.; Puiggali, J. J Org Chem 2001, 66, 8076-8085.

[42] Shalaby, S. W.; Pearce, E. M.; Frederic, R. J.; Turi, E. A. J Polym Sci Part B Polym Phys 1973, 11, 1-14. 


\title{
Chapter 4
}

\section{Morphology and mechanical properties of segmented poly(ether amide)s with uniform oxalamide based hard segments}

\author{
N.J. Sijbrandi ${ }^{a}$, A.J. Kimenai ${ }^{b}$, E.P.C. Mes ${ }^{b}$, R. Broos ${ }^{b}$, G. Bar ${ }^{c}$, M. Rosenthal ${ }^{d}, Y$. \\ Odarchenko $^{d}$, D.A. Ivanov ${ }^{d}$, P.J. Dijkstra ${ }^{a}$, J. Feijen ${ }^{a}$

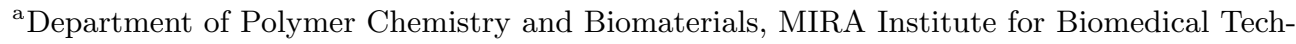 \\ nology and Technical Medicine, Faculty of Science and Technology, University of Twente, \\ P.O. Box 217, 7500 AE Enschede, The Netherlands \\ ${ }^{\mathrm{b}}$ Core R\&D, DOW Benelux BV, P.O. Box 48, 4530 AA, Terneuzen, The Netherlands \\ ${ }^{\mathrm{c}}$ Dow olefin verbund GmbH, P.O. Box 1163, D-06258, Schkopau, Germany \\ ${ }^{\mathrm{d}}$ Institut de Sciences des Matriaux de Mulhouse-IS2M, CNRS LRC 7228, Jean Starcky, 15, \\ F-68057 Mulhouse, France
}

\begin{abstract}
The morphology, temperature dependent behavior and mechanical properties of thermoplastic polyamide elastomers consisting of alternating flexible PTHF segments and uniform rigid segments comprising two or three oxalamide units were investigated. AFM imaging revealed the presence of fiber-like nano-crystals with lengths up to several hundreds of nanometers randomly dispersed in the soft PTHF matrix. The long dimension of the crystals is parallel to the direction of the hydrogen bonds. One of the other small dimensions of the crystal approximately equals the length of the oxalamide segment whereas the other one corresponds to the height of the stack containing ca. 10 to 20 hydrogen bonded sheets. Upon heating, the crystalline phase melts over a broad temperature range to give a homogeneous melt according to temperature dependent FT-IR, SAXS and rheology. All polymers have a low glass transition temperature and hence the rubber plateau starts at low temperatures and remains constant up to the flow temperature. By increasing the spacer length from 2 to 10 methylene groups in the bisoxalamide segment, the flow temperature decreased from 200 to $150{ }^{\circ} \mathrm{C}$. The segmented copolymers showed a distinct yield point and have an elastic modulus between 121 and $210 \mathrm{MPa}$, a stress at break ranging from 15 to $27 \mathrm{MPa}$ and a strain at break of 150 up to $900 \%$. The polymer with three oxalamide groups in the hard segment showed a rubber modulus of $75 \mathrm{MPa}$ and a flow temperature of 220 ${ }^{\circ} \mathrm{C}$. The results demonstrate that alternating copolymers with soft PTHF segments and uniform hard segments containing two or three oxalamide groups are TPEs with good thermal and mechanical properties.
\end{abstract}




\subsection{Introduction}

Segmented thermoplastic elastomers consisting of alternating hard and soft segments are melt processable materials with elastomeric properties at service temperature ${ }^{1,2}$. This typical behavior is due to the phase separated morphology, which is induced by the thermodynamic incompatibility of the hard and the soft segments ${ }^{3}$. Polyether or polyester chains are often used as the soft segments yielding domains with a low $T_{g}$, which provide the material with its elastomeric character. The hard segments used can be either polymers or short chains mostly containing urethane, ester or amide groups. These segments form rigid domains in the soft matrix and act as physical crosslinks providing the material with dimensional stability. When the material is heated above the melting point of the hard domains, the polymer becomes a viscous liquid and can be melt processed.

Poly(ether amide)s comprising nylon-6, nylon-11 or nylon-12 hard segments and polytetrahydrofuran, poly(propylene oxide) or poly(ethylene oxide) soft segments are typical examples of segmented thermoplastic elastomers ${ }^{1,2}$. Such polymers have a phase separated morphology depending on the molecular weight of the polyether and polyamide structural units ${ }^{4-23}$. In general, the polyamide segments crystallize in a lamellar type structure independent of the polyether/polyamide weight ratio. The segmented copolymers show typical elastomeric properties if the polyether matrix is the continuous phase in which the crystalline polyamide domains are dispersed. The moduli of these materials range from 10 to $30 \mathrm{MPa}$, the yield strain is in between 100 and $200 \%$ and strains at break are above $1000 \%$. Furthermore, the materials exhibit good recoverability, low permanent set and low mechanical hysteresis. On the other hand, at high polyamide ratios, the hard phase becomes more and more interconnected and polymer properties change to those of typical thermoplastics ${ }^{19}$.

The molecular weight distribution of the hard segments largely determines the polymer properties. Incomplete phase separation takes place when the polydispersity of the hard segments is high. The shorter segments mainly dissolve in the soft polymer matrix thereby increasing the glass transition temperature of the material and hence reducing the elastomeric properties. Moreover, the rubber plateau of the polymers becomes temperature dependent and melt transitions are broad. Contrary, segmented block copolymers with uniform hard segments show an almost complete phase separated morphology and therefore these materials possess a much broader thermal service window. Furthermore, the ultimate mechanical properties of these materials are considerably 
improved compared to materials with non-uniform hard segments ${ }^{24-30}$.

Poly(ether amide)s based on PTHF soft segments and uniform amide hard segments like the aramid di-amide segment (T $\Phi \mathrm{T})$ and the tetra-amide segment nylon-6, $\mathrm{T}$ (T6T6T) were extensively studied ${ }^{30-35}$. These polymers show a highly phase separated morphology with fiber-like nano-crystals randomly dispersed in the soft polymer matrix. Even at a low concentration of $3 \mathrm{wt} \%$ of hard segment, the polymers show a distinct micro-phase separated morphology and good elastomeric properties indicating that these hard segments are effective physical crosslinkers. Similar micro-phase separated morphologies have been reported for segmented poly(ether urea)s with uniform hard segments $^{28,36}$.

Because of their conformational rigidity, oxalamides are interesting hydrogen bonding groups to be applied in segmented thermoplastic elastomers. They are selfcomplementary capable of donating and receiving hydrogen bonds in one direction ${ }^{37-39}$. In addition, oxalamide groups provide nylon type materials with high melting points, low solubility and high moduli ${ }^{40,41}$. Such segmented block copolymers did not receive much attention and only Schulze described in a patent the preparation of copolymers based on Jeffamines ${ }^{\circledR}$ and oxalamides ${ }^{42}$. The properties of these polymers ranged from waxy materials to brittle solids.

Previously, we prepared segmented poly(ether amide)s (PEAs) consisting of polytetrahydrofuran (PTHF) soft segments and uniform oxalamide based hard segments ${ }^{43}$. These copolymers had uniform hard segments with either single oxalamide units or with two (or three) oxalamide groups separated by an even number of methylene groups (Figure 4.1). The length of the PTHF soft segments was kept $\operatorname{constant}\left(\mathrm{M}_{\mathrm{n}}=\right.$ $1.1 \times 10^{3}$ g. $\left.\mathrm{mol}^{-1}\right)$. A polymer in which PTHF blocks are separated by single oxalamide groups was a sticky solid with a melting transition of $\sim 25^{\circ} \mathrm{C}$. PEAs with hard segments containing two or three oxalamide groups were elastic materials. FT-IR revealed strong hydrogen bonding and a high hard segment crystallinity indicating high phase separation and highly ordered hard segments. These materials have melting temperatures ranging from 140 to $200{ }^{\circ} \mathrm{C}$ with decreasing spacer length.

In this paper, temperature dependent FT-IR and X-ray measurements performed on PEAs containing uniform bis- or trisoxalamide segments are described. The results are used to give a description of the organization of the oxalamide nano-fiber crystals present in a PTHF soft matrix as observed with AFM. 


\subsection{Experimental}

\subsubsection{Materials}

Segmented poly(ether amide)s (1, 2a-e and $\mathbf{3}$ ) were prepared as reported previously ${ }^{43}$. Dichloromethane and 3-methoxypropylamine were purchased from Aldrich (Zwijndrecht, The Netherlands) and chloroform was purchased from Merck (Darmstadt, Germany). All materials were used as received.

\subsubsection{Synthesis}

$\mathrm{N}^{1}, \mathrm{~N}^{1}$-(hexane-1,6-diyl)bis(N2-(3-methoxypropyl)oxalamide) (MeOProp-OXA 6 6-PropOMe) (4)

3-Methoxypropylamine $(5.64 \mathrm{~g}, 63.3 \mathrm{mmol})$ and $\mathrm{OXA}_{2} 6(10.0 \mathrm{~g}, 31.6 \mathrm{~mol})$ were dissolved in $100 \mathrm{ml}$ of chloroform. Subsequently, the solution was stirred at $70{ }^{\circ} \mathrm{C}$ for 16 h. The product was isolated by filtration and subsequently washed two times with chloroform and two times with diethyl ether and dried under vacuum. The product was obtained as a white powder in a yield of $95 \%\left(\operatorname{mp~} 210{ }^{\circ} \mathrm{C}\right) .{ }^{1} \mathrm{H}$ NMR $(300 \mathrm{MHz}, \mathrm{TFA}-$ $\left.\mathrm{d}_{1}\right): \delta=8.43\left(\mathrm{bt}, 2 \mathrm{H}, \mathrm{NHCH} \mathrm{CH}_{2} \mathrm{CH}_{2}\right), 8.29$ (bt, $2 \mathrm{H}, \mathrm{CH}_{3} \mathrm{OCH}_{2} \mathrm{CH}_{2} \mathrm{CH}_{2} \mathrm{NH}$ ), 3.58 (dt, $4 \mathrm{H}, \mathrm{NHCH}_{2} \mathrm{CH}_{2} \mathrm{CH}_{2}$ ), 3.39 (t, $4 \mathrm{H}, \mathrm{CH}_{3} \mathrm{OCH}_{2} \mathrm{CH}_{2} \mathrm{CH}_{2} \mathrm{NH}$ ), 3.36 (s, $\left.6 \mathrm{H}, \mathrm{CH}_{3} \mathrm{OCH}_{2} \mathrm{CH}_{2} \mathrm{CH}_{2} \mathrm{NH}\right), 1.85\left(\mathrm{~m}, 4 \mathrm{H}, \mathrm{CH}_{3} \mathrm{OCH}_{2} \mathrm{CH}_{2} \mathrm{CH}_{2} \mathrm{NH}\right), 1.48(\mathrm{~m}, 4 \mathrm{H}$, $\left.\mathrm{NHCH}_{2} \mathrm{CH}_{2} \mathrm{CH}_{2}\right), 1.24\left(\mathrm{~m}, 4 \mathrm{H}, \mathrm{NHCH}_{2} \mathrm{CH}_{2} \mathrm{CH}_{2}\right) ; \stackrel{13}{{ }^{13} \mathrm{NMR}}(75.26 \mathrm{MHz}$, TFA$\left.\mathrm{d}_{1}\right): \delta=160.1\left(\mathrm{CONHCH}_{2} \mathrm{CH}_{2} \mathrm{CH}_{2}\right), \quad 159.8\left(\mathrm{CH}_{3} \mathrm{OCH}_{2} \mathrm{CH}_{2} \mathrm{CH}_{2} \mathrm{NHCO}\right), 70.0$ $\left(\mathrm{CH}_{3} \mathrm{OCH} \mathrm{CH}_{2} \mathrm{CH}_{2} \mathrm{NH}\right), 57.0\left(\mathrm{CH}_{3} \mathrm{OCH}_{2} \mathrm{CH}_{2} \mathrm{CH}_{2} \mathrm{NH}\right), 40.2\left(\mathrm{NHCH}_{2} \mathrm{CH}_{2} \mathrm{CH}_{2}\right), 37.2$ $\left(\mathrm{CH}_{3} \mathrm{OCH}_{2} \mathrm{CH}_{2} \mathrm{CH}_{2} \mathrm{NH}\right), 27.8\left(\mathrm{NHCH}_{2} \mathrm{CH}_{2} \mathrm{CH}_{2}\right), 26.8\left(\mathrm{CH}_{3} \mathrm{OCH}_{2} \mathrm{CH}_{2} \mathrm{CH}_{2} \mathrm{NH}\right), 25.7$ $\left(\mathrm{NHCH}_{2} \mathrm{CH}_{2} \mathrm{CH}_{2}\right)$.

\subsubsection{Methods}

\section{Processing}

Compression molded bars $(75 \times 10 \times 2 \mathrm{~mm})$ were prepared using a hot press $(\mathrm{THB}$ 008, Fontijne Holland BV, the Netherlands). Polymers were heated for 4 min at approximately $20{ }^{\circ} \mathrm{C}$ above their $\mathrm{T}_{\text {flow }}$, pressed for $3 \mathrm{~min}$ at $300 \mathrm{kN}$, and cooled in approximately 5 min under pressure to room temperature. 


\section{FT-IR}

To minimize the potential oxidation of the materials, sample preparation comprised the following steps. The surface of a $32 \times 3 \mathrm{~mm} \mathrm{NaCl}$ disc (Thermo, International Crystal Labs) was roughened to prevent interfering fringes. Subsequently, a polymer solution of 0.3-0.5 g.ml-1 in dichloromethane was drop casted on the $\mathrm{NaCl}$ disk and the solvent was allowed to evaporate. This step was repeated until the polymer film thickness gave a maximum peak height of $0.5-0.7$. The holder was placed in the cell in an inert atmosphere $\left(\mathrm{N}_{2}\right.$ purge glove bag or $\mathrm{N}_{2}$ purged IR sample compartment). The cell was heated to $20-50{ }^{\circ} \mathrm{C}$ above the $\mathrm{T}_{\mathrm{m}}$ of the polymer and subsequently cooled to room temperature. Fourier transform infra-red spectra were recorded on a Thermo 5700 spectrometer utilizing a DTGS detector at $4 \mathrm{~cm}^{-1}$ resolution. The temperature of the prepared polymer film was controlled by an infra-red cell from Spectra Tech (model 0019-019). The data were collected between 4000 and $500 \mathrm{~cm}^{-1}$ (16 scans were acquired). The graphs were prepared using OPUS 6.1 software. All spectra were normalized to the $2860 \mathrm{~cm}^{-1}$ signal. The carbonyl region was analyzed quantitatively in terms of free, bonded and ordered amide structures by curve fitting (Omnic version 7.2) and following the guidelines of Meier et $a l^{44}$.

\section{AFM}

Atomic force microscopy images were obtained using a MultiMode scanning probe microscope (SPM) (Veeco Metrology Group, Santa Barbara, CA) with a Nano-Scope IV controller running software version 5.12. The TESP probe used was $125 \mu \mathrm{m}$ in length, had a tip radius of $8 \mathrm{~nm}$ and a force constant of $40 \mathrm{~N} . \mathrm{m}^{-1}$. A moderate tapping ratio of about 0.5 was applied in all measurements. Height and phase images were recorded at various magnifications. Samples were prepared by drop casting a $1 \mathrm{mg} \cdot \mathrm{ml}^{-1}$ chloroform solution on a silicon waver. After evaporation, the sample was heated to $20{ }^{\circ} \mathrm{C}$ above the $\mathrm{T}_{\text {flow }}$ for $15 \mathrm{~min}$ and slowly cooled to room temperature.

\section{X-ray diffraction}

Wide-angle X-ray diffraction (WAXD) and small-angle X-ray scattering (SAXS) experiments were conducted on the BM26B beamline of the European Synchrotron Radiation Facility in Grenoble, France, using X-ray photons of $10 \mathrm{keV}$. The 2D X-ray patterns were collected in transmission geometry using a $2 \mathrm{D}$ multi-wire gas-filled detector for the SAXS experiments and a 2D CCD from Photonica ${ }^{\circledR}$ for WAXD experiments. For the measurements on the model compound the powder like material was extruded through a die of $300 \mu \mathrm{m}$ diameter and quickly cooled down to room temperature to prevent reorientation of crystals. The uniaxial oriented material was 
placed with its fiber axis perpendicular to the incident X-ray beam. The modulus of the scattering vector $s=2 \sin (\Theta / \lambda)$, where $\Theta$ is the Bragg angle and $\lambda$ the wavelength, was calibrated using several diffraction orders of silver behenate and corundum for the SAXS and WAXD measurement, respectively. The data reduction and analysis including geometrical and background correction, visualization and resampling into polar coordinates of the 2D diffractograms were performed using home-built routines written in Igor Pro ${ }^{\circledR}$ software package from WaveMetrics $^{\mathrm{TM}}$.

\section{DMA}

Dynamic mechanical analysis was performed using a Myrenne ATM3 torsion pendulum at a frequency of approximately $1 \mathrm{~Hz}$. The storage modulus $\left(\mathrm{G}^{\prime}\right)$ and the loss modulus $\left(\mathrm{G}^{\prime \prime}\right)$ were measured as a function of temperature. Samples $(50 \times 10 \times 2 \mathrm{~mm})$ were cooled to $-100{ }^{\circ} \mathrm{C}$ and then heated at a rate of $1{ }^{\circ} \mathrm{C} \cdot \mathrm{min}^{-1}$. The temperature at which the loss modulus reached a maximum was taken as the glass transition temperature $\left(\mathrm{T}_{\mathrm{g}}\right)$. The flow temperature $\left(\mathrm{T}_{\text {flow }}\right)$ was taken at a storage modulus value of $1 \mathrm{MPa}$.

\section{Tensile testing}

Tensile tests were conducted with compression molded bars cut to dumbbells (ISO37 type 2). A Zwick Z020 universal tensile machine equipped with a $500 \mathrm{~N}$ load cell and extensometers was used to measure the stress at a strain rate of $0.4 \mathrm{~s}^{-1}$ (test speed: 60 mm. $\mathrm{min}^{-1}$ ) and a preload of 0.1 MPa. Measurements were performed on at least 5 different polymer bars.

\section{Rheology}

Rheological experiments were performed using an Advanced Rheometric Expansion System (ARES) equipped with parallel plate configuration. Measurements were performed on $25 \mathrm{~mm}$ diameter discs punched from $2 \mathrm{~mm}$ thick compression molded plaques. All samples were vacuum dried for at least $24 \mathrm{~h}$ at $60{ }^{\circ} \mathrm{C}$ prior to testing. The oven of the ARES was heated to a temperature of approximately $20{ }^{\circ} \mathrm{C}$ above the melting point of the material. A test specimen was placed between the parallel plates and the top plate was brought into contact with the sample immediately. When the viscosity was very low (normal force dissipates quickly) the sample was trimmed after $1 \mathrm{~min}$. When the normal force was decreasing slowly, a melting time of $3 \mathrm{~min}$ was taken before trimming. The total melting time was always 3 min. During melting, the gap between the two plates was adjusted to approximately $1.8 \mathrm{~mm}$. All measurements were performed under nitrogen atmosphere. After an additional $5 \mathrm{~min}$, a frequency sweep was started from 100 to 0.1 rad. $\mathrm{s}^{-1}$ (logarithmic mode 10 points per decade) with $20 \%$ imposed strain. A temperature sweep (cooling trace) was immediately started 
after the frequency sweep, with a cooling rate of $2{ }^{\circ} \mathrm{C} \cdot \mathrm{min}^{-1}$ to $100{ }^{\circ} \mathrm{C}$, a frequency of 10 rad.s $\mathrm{s}^{-1}$ and a strain of $20 \%$. The auto tension option and auto strain option were both activated to correct the gap and applied strain during solidification of the sample.

\subsection{Results and Discussion}

\subsubsection{Temperature dependent FT-IR}

An advantage of segmented thermoplastic elastomers compared to conventional rubbers is that they can be processed like thermoplastic materials. Upon heating above the melting temperature of the hard segments, the polymer chains can flow freely allowing melt processing. In previous research, it was shown that segmented poly(ether amide)s comprising uniform bisoxalamide and trisoxalamide hard segments (2a-e and 3, Figure 4.1) had melting temperatures higher than $100{ }^{\circ} \mathrm{C}$.<smiles>CC(C)(C)CCNC(=O)C(=O)NCCCOC(C)(C)CCCOC1CC2CCCC1C2</smiles>

(1)

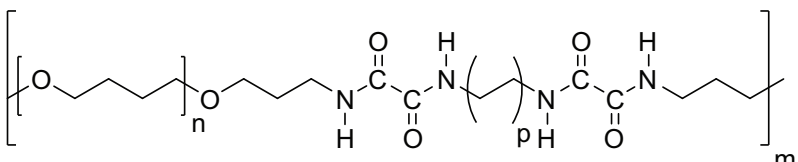

(2a-e) $p=1,2,3,4,5$<smiles>CC(C)(C)CCCNC(=O)C(=O)NCCCCCCNC(=O)C(=O)NCCCCCCNC(=O)C(=O)NCCCOC(C)(O)CCCOC(C)(C)C</smiles>

(3)

Figure 4.1: Segmented poly(ether amide)s with uniform oxalamide based hard segments 1, $\mathbf{2 a - e}(\mathrm{p}=1$ to 5$)$ and $\mathbf{3}$. 
With temperature dependent FT-IR the extent of hydrogen bonding and crystallinity of the hard segment was studied. The $\mathrm{N}-\mathrm{H}$ stretching vibration band of the polymer PTHF-OXA 26 (2c) at different temperatures is depicted in Figure 4.2a. This polymer had a broad melting transition between 100 and $188^{\circ} \mathrm{C}$. At temperatures higher than $100{ }^{\circ} \mathrm{C}$, the $\mathrm{N}-\mathrm{H}$ stretching band at $3296 \mathrm{~cm}^{-1}$ associated with amide-amide hydrogen bonding shifts to $3334 \mathrm{~cm}^{-1}$ and broadens, indicating that the strength of the hydrogen bonds decreases. In addition, a band at $3396 \mathrm{~cm}^{-1}$, attributed to free $\mathrm{N}-\mathrm{H}$ groups, arises. At $200{ }^{\circ} \mathrm{C}$, well above the melting transition, still hydrogen bonding appears to be present. The $\mathrm{C}=\mathrm{O}$ stretching region (Figure $4.2 \mathrm{~b}$ ) shows similar changes with temperature. Upon increasing the temperature from 100 to $200{ }^{\circ} \mathrm{C}$, the band at 1648 $\mathrm{cm}^{-1}$ characteristic for hydrogen-bonded carbonyl groups in the ordered state decreases, whereas the bands associated with hydrogen-bonded disordered carbonyl groups and free carbonyl groups at 1670 and $1684 \mathrm{~cm}^{-1}$, respectively, increase.

By deconvolution of the $\mathrm{C}=\mathrm{O}$ stretching band, the hard segment crystallinity, defined as the relative band area of the $\mathrm{H}$-bonded carbonyl ordered groups, was determined for the segmented poly(ether amide)s $\mathbf{2 a - e}$ and $\mathbf{3}$ as a function of temperature (Figure 4.3a). The change in crystallinity with temperature as determined from the FT-IR spectra corresponds well with the DSC melting transition as shown for polymer $\mathbf{2 c}$ in Figure $4.3 \mathrm{~b}$.

(a)

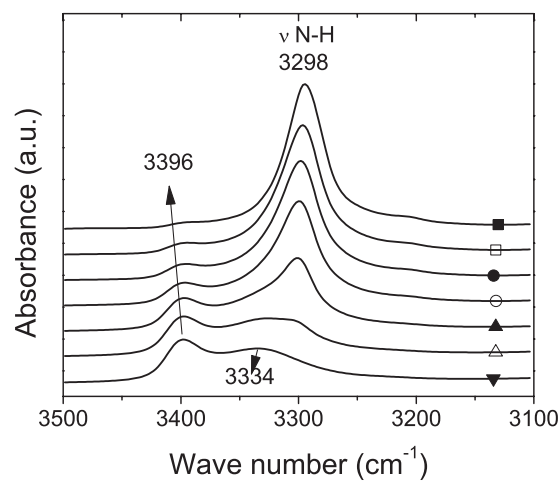

(b)

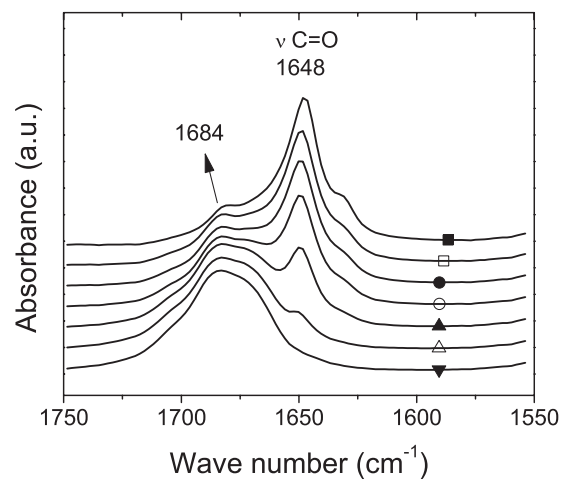

Figure 4.2: FT-IR spectra of PTHF-OXA 6 (2c) at $25(\boldsymbol{\square}), 100(\square), 120(\bullet), 140(\mathrm{O})$, $160(\boldsymbol{\Delta}), 180(\Delta)$ and $200{ }^{\circ} \mathrm{C}(\boldsymbol{\nabla})$ for (a) the N-H stretching vibration band and (b) the $\mathrm{C}=\mathrm{O}$ stretching vibration band. 
(a)

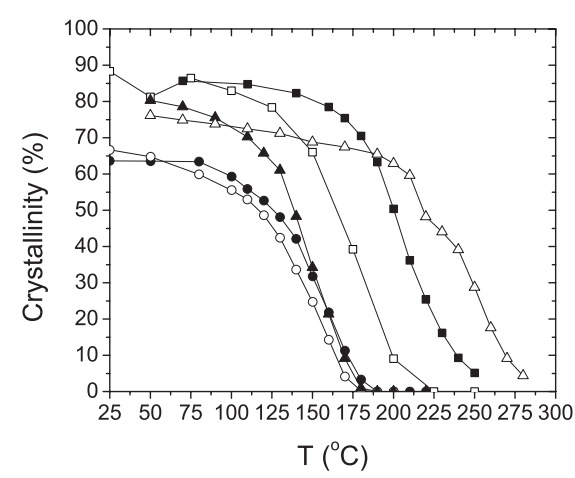

(b)

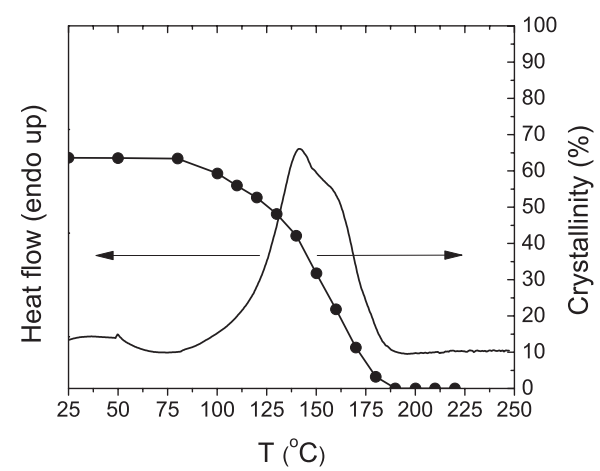

Figure 4.3: (a) Hard segment crystallinity as a function of temperature. ( $\mathbf{a})$ PTHF-OXA 22

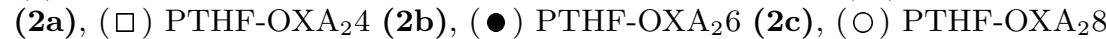
(2d), (ム) PTHF-OXA $10(\mathbf{2 e})$ and $(\triangle)$ PTHF-OXA $_{3} 66$ (3). (b) DSC second heating curve and the hard segments crystallinity as a function of temperature for PTHF-OXA 6 (2c).

\subsubsection{Atomic force microscopy}

The phase image of PTHF-OXA 6 (2c) as visualized with atomic force microscopy (AFM) in tapping mode revealed long fiber-like nano-crystals in the soft polymer matrix (Figure 4.4). This morphology suggests that crystallization is taken place by stacking of the uniform hard segments perpendicular to the fiber axis. Such a morphology is similar to that observed in aramid and nylon-6,T type segmented poly(ether amide)s and segmented poly(ether urea)s with uniform hard segments ${ }^{28,34-36}$.

Because the AFM tip has a radius of $8 \mathrm{~nm}$, an accurate determination of the fiber diameter $(\leq 2 \mathrm{~nm})$ was not possible. The length of the crystals is up to several hundreds of nanometers. However, the full length of the crystals cannot be determined since only the surface morphology of a sample is scanned. 
(a)

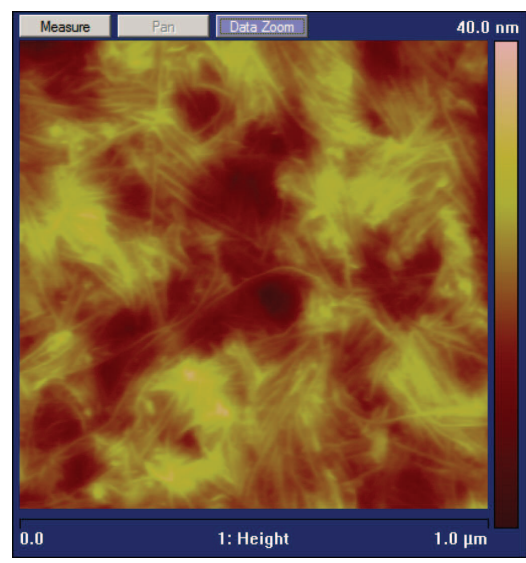

(b)

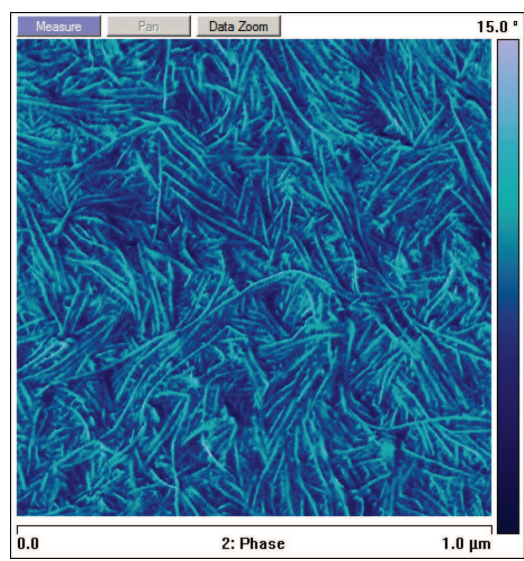

Figure 4.4: AFM height (a) and phase image (b) of PTHF-OXA 6 (2c).

\subsubsection{X-ray diffraction}

We have shown that segmented poly(ether amide)s comprising bisoxalamide or trisoxalamide hard segments are highly phase separated into relatively pure amide and polyether domains. FT-IR measurements revealed that the oxalamide based hard segments are strongly hydrogen bonded and that the hard segments are highly ordered. Moreover, a fibrillar morphology consisting of ribbon-like nano-crystals randomly dispersed in the polyether matrix was observed using AFM. These data suggest that the direction along fiber axis, is formed by stacking of the hard segments in the direction of the hydrogen bonding.

The phase separated morphology of the bisoxalamide based poly(ether amide)s (2a-e) was further investigated by performing wide angle X-ray diffraction (WAXD) and small angle x-ray scattering (SAXS) measurement.

To gain more insight into the morphology of the bisoxalamide crystals in the segmented poly(ether amide), a model compound was included in this study comprising a bisoxalamide group having a spacer length of 6 methylene groups substituted with 3-methoxypropyl moieties (MeOProp-OXA 26 -PropOMe) 4. The synthesis of the model compound is depicted in Scheme 4.1. In the first step, a diester-diamide segment was prepared by reacting 1,6-diaminohexane with a tenfold excess of diethyl oxalate as described previously ${ }^{43}$. Subsequent reaction of the bisoxalamide precursor with 3-methoxypropylamide afforded the model compound. 


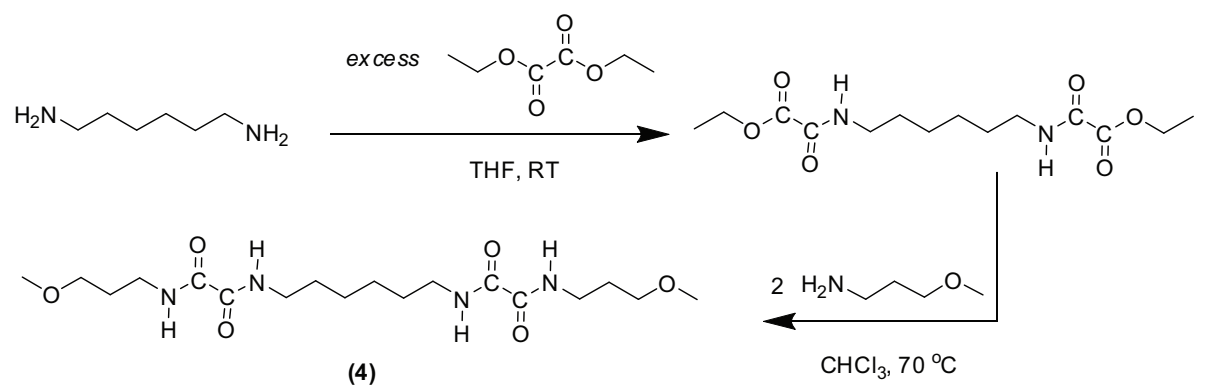

Scheme 4.1: Synthesis of a bisoxalamide compound substituted with 3-methoxypropyl moieties.

\section{WAXD}

A 2D diffractogram of the uniaxially-oriented compound 4 is given in Figure 4.5. The fiber pattern was indexed to an orthorhombic unit cell with $\boldsymbol{a}=5.05 \AA, \boldsymbol{b}=10.00 \AA$ and $\boldsymbol{c}=21.98 \AA$. With two monomers per unit cell the calculated density of the crystal amounts to $1.06 \mathrm{~g} \cdot \mathrm{cm}^{-3}$. The reflection indices and their calculated and experimental spacings are given in Figure 4.5.

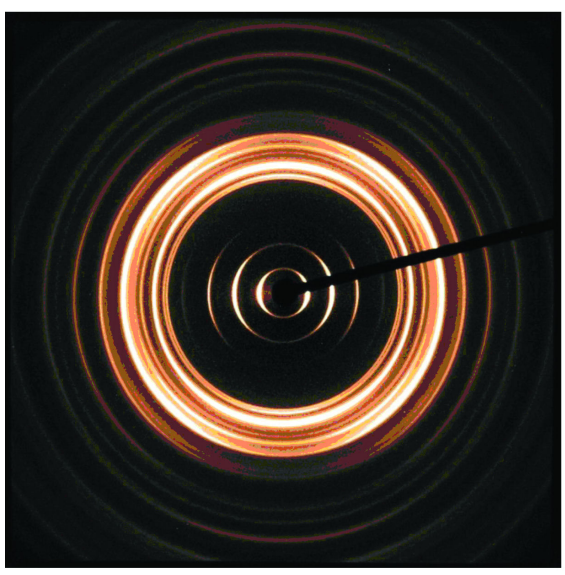

\begin{tabular}{|c|c|c|c|c|c|}
\hline & $\mathrm{h}$ & $\mathrm{k}$ & 1 & $\begin{array}{l}d_{\exp } \\
(\AA)\end{array}$ & $\begin{array}{r}\mathrm{d}_{\text {calc }} \\
(\AA)\end{array}$ \\
\hline \multirow[t]{11}{*}{ equator } & 0 & 0 & 1 & 22.03 & 21.98 \\
\hline & 0 & 0 & 2 & 10.95 & 10.99 \\
\hline & 0 & 0 & 3 & 7.29 & 7.33 \\
\hline & 0 & 0 & 4 & 5.48 & 5.49 \\
\hline & 0 & 1 & 5 & 4.00 & 4.02 \\
\hline & 0 & 2 & 4 & 3.68 & 3.70 \\
\hline & 0 & 0 & 6 & 3.61 & 3.66 \\
\hline & 0 & 3 & 0 & 3.32 & 3.33 \\
\hline & 0 & 3 & 2 & 3.24 & 3.19 \\
\hline & 0 & 2 & 6 & 2.90 & 2.96 \\
\hline & 0 & 1 & 8 & 2.62 & 2.65 \\
\hline first & 1 & 0 & 1 & 4.79 & 4.92 \\
\hline layer & 1 & 0 & 2 & 4.68 & 4.59 \\
\hline \multirow[t]{4}{*}{ line } & 1 & 1 & 0 & 4.36 & 4.42 \\
\hline & 1 & 1 & 3 & 3.83 & 3.84 \\
\hline & 1 & 1 & 6 & 2.85 & 2.84 \\
\hline & 1 & 3 & 2 & 2.73 & 2.70 \\
\hline second & 2 & 0 & 0 & 2.58 & 2.52 \\
\hline layer & 2 & 0 & 2 & 2.49 & 2.46 \\
\hline \multirow[t]{4}{*}{ line } & 2 & 1 & 2 & 2.38 & 2.39 \\
\hline & 2 & 1 & 3 & 2.34 & 2.32 \\
\hline & 2 & 0 & 4 & 2.30 & 2.29 \\
\hline & 2 & 2 & 2 & 2.21 & 2.21 \\
\hline
\end{tabular}

Figure 4.5: 2D X-ray pattern and its indexation of oriented model compound MeOProp$\mathrm{OXA}_{2} 6$-PropOMe (4). The fiber axis is vertical. 
The 2D WAXD pattern exhibits a series of strong equatorial peaks that can be assigned to a smectic like structure, the period of which is close to the long molecular dimension (c-direction). The two other directions likely correspond to the molecular width within the hydrogen-bonded planes ( $\boldsymbol{a}$-direction) and an integer number of the hydrogen bonded sheet thickness (b-direction). The $\boldsymbol{a}$-parameter corresponding to inter-chain distance is ca. $5 \AA$, which is in agreement with values reported in literature $^{37}$. The value of the $\boldsymbol{b}$-parameter corresponds to twice the thickness of a hydrogen-bonded sheet. The sheet thickness is higher than found for example in nylon-6,2 (4.04 $\AA)^{45}$. This increase probably reflects a slight non-planarity of the molecular conformation. However, the exact deviation of the molecular conformation from the all-trans conformation is difficult to quantify at this stage.

A sketch of the crystalline structure of compound 4 is depicted in Figure 4.6. The length of the fully extended molecule is $28.75 \AA$, whereas the $\boldsymbol{c}$-parameter of the lattice equals $21.89 \AA$. In additional experiments (data not shown here) the X-ray diffraction of an oriented copolymer PTHF-OXA 26 (2c) revealed a molecular tilt of the bisoxalamide blocks of $25^{\circ}$ with respect to the normal to smectic layers. The 3 -methoxypropyl tails have to be inclined at a bigger angle in order to match the experimental $\boldsymbol{c}$-parameter (Figure 4.6). However, the exact conformation of the end groups with respect to the central bisoxalamide block has not been determined.

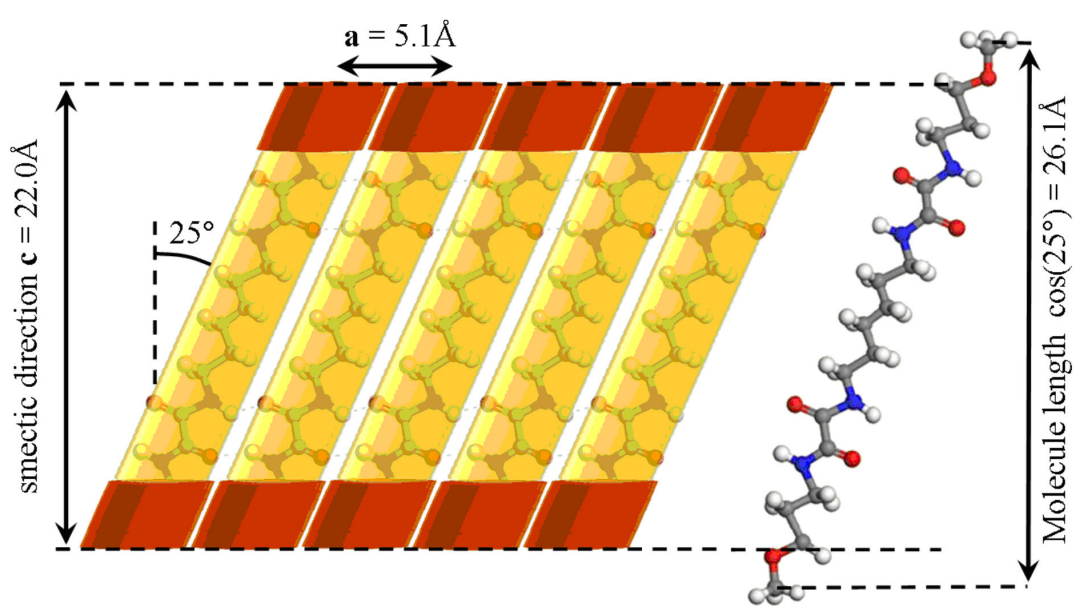

Figure 4.6: Sketch of the crystalline structure of model compound MeOProp-OXA 2 6PropOMe (4). The fully extended molecular structure is given for the sake of comparison. 
The WAXD curves of the model compound and the corresponding segmented poly(ether amide) 2c are depicted in Figure 4.7. The diffraction peaks of the bisoxalamide model compounds are almost absent in the curve of the corresponding copolymer and only a broad amorphous halo originating from the PTHF phase is visible. This can be explained by the small crystal size along the $\boldsymbol{c}$-direction. The peak on top of the amorphous halo at $4.36 \AA$ corresponds to the 110 peak whereas the small peak at 2.57 $\AA$ is the 200 peak. The reciprocal vectors corresponding to these diffraction peaks are oriented perpendicular to the $\boldsymbol{c}$-direction.

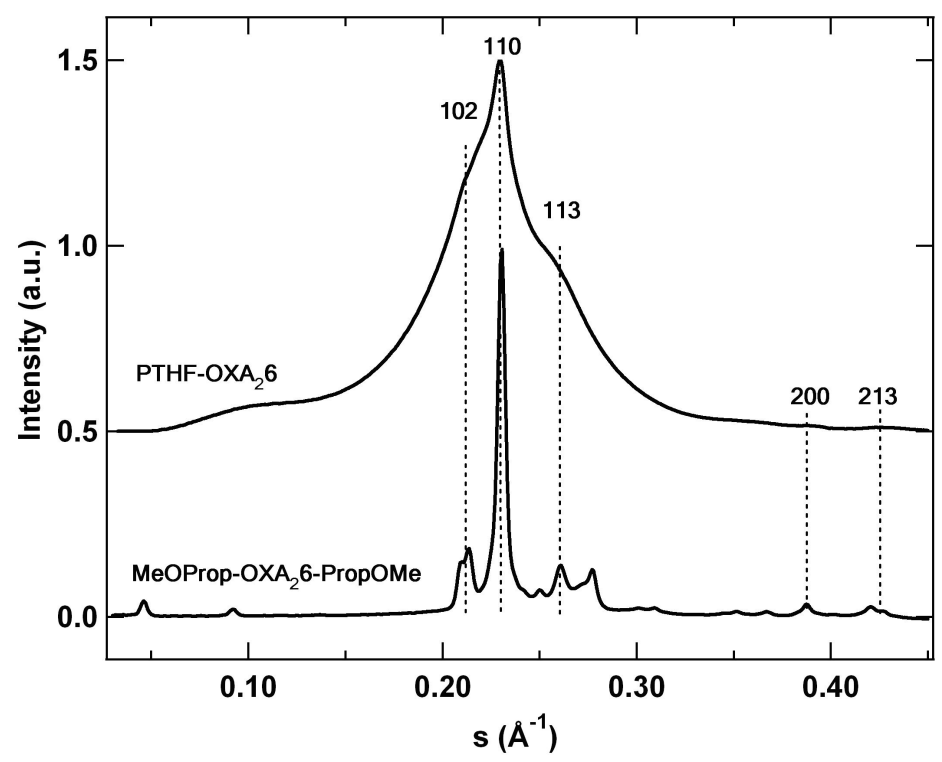

Figure 4.7: WAXD curves of MeOProp-OXA 2 6-PropOMe (4) and corresponding segmented poly(ether amide) PTHF-OXA 6 (2c).

It can be suggested that the long direction of the fibrillar crystals is in the $\boldsymbol{a}$-direction, i.e. the direction of the hydrogen bonded sheets, which is parallel to the fiber axis. This conclusion is in agreement with the results obtained for an oriented fiber of model compound MeOProp-OXA 2 6-PropOMe using polarized Raman spectroscopy as shown in Figure 4.8 . 
In Figure 4.8 the $\mathrm{N}-\mathrm{H}$ and $\mathrm{C}=\mathrm{O}$ stretching bands at 3291 and $1675 \mathrm{~cm}^{-1}$, respectively, show parallel polarization since the intensity of these bands is stronger in the spectra where the fiber axis is parallel to the direction of the polarizer and analyzer. On the other hand, the amide II band at $1547 \mathrm{~cm}^{-1}$, which is attributed to C-N stretching and $\mathrm{N}-\mathrm{H}$ in-plane bending, shows perpendicular polarization. These results clearly indicate that the beta-sheets are oriented parallel to the stretching direction, i.e. parallel to the $\boldsymbol{a}$-direction.
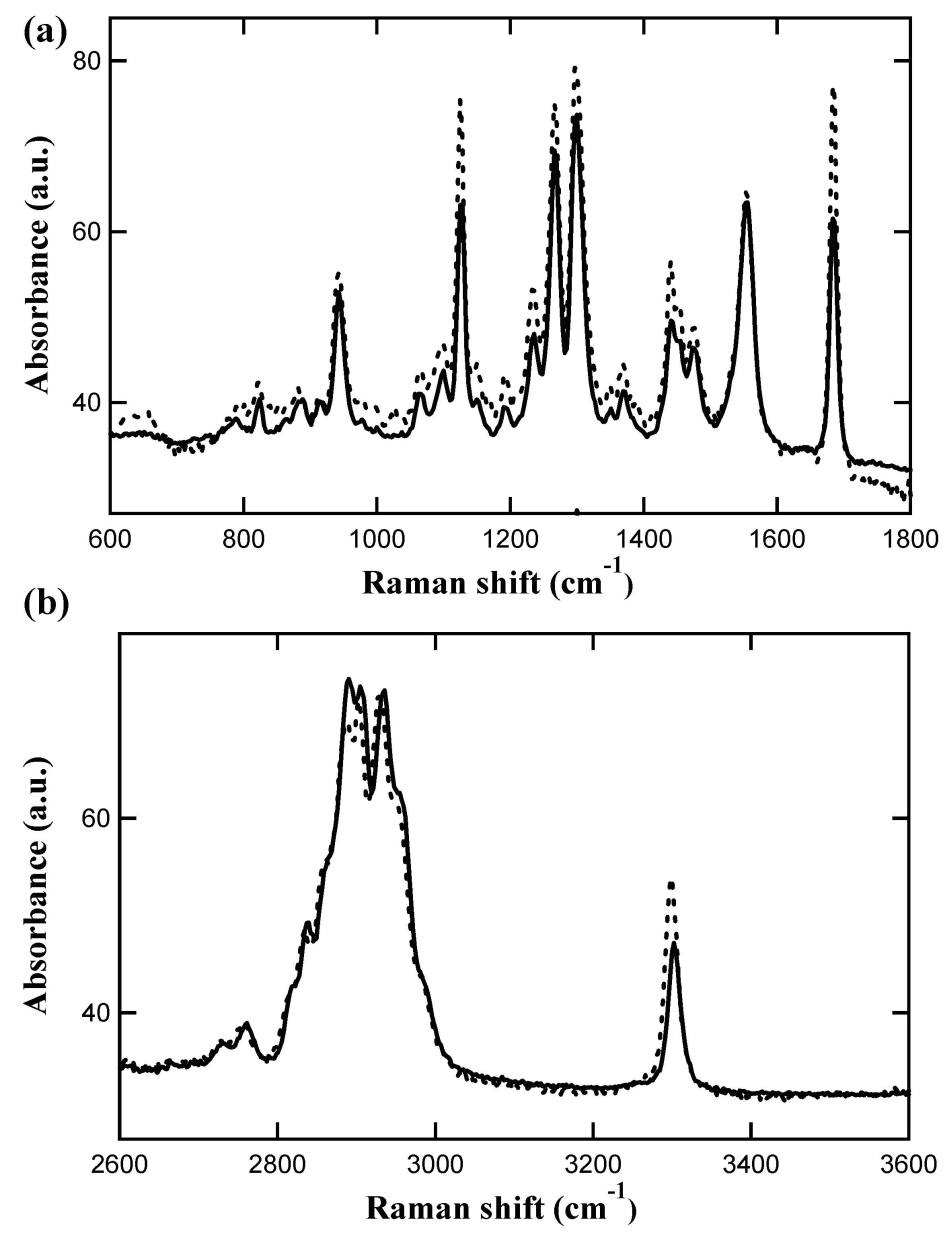

Figure 4.8: Polarized Raman spectra of an oriented MeOProp-OXA 2 6-PropOMe (4) fiber showing the regions from 600 to $1800 \mathrm{~cm}^{-1}$ (a) and from 2600 to $3600 \mathrm{~cm}^{-1}$ (b). The spectra corresponding to situations where the fiber axis is parallel and perpendicular to the polarizer/analyzer plane are given in dotted and solid lines, respectively. 


\section{SAXS}

Room-temperature SAXS curves are given in Figure 4.9a. The scattering intensity is plotted as a function of the norm of the scattering vector $s$. The SAXS curves show an interference maximum indicative of the phase separated domains. Based on the fibrillar structure observed by AFM, the SAXS curves can be interpreted in terms of a 2D model (and not a conventional 1D lamellar model) as schematically illustrated in Figure 4.9c.

(a)

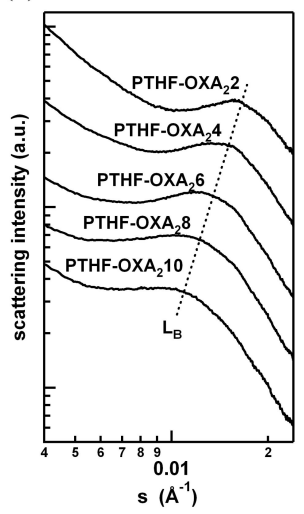

(b)

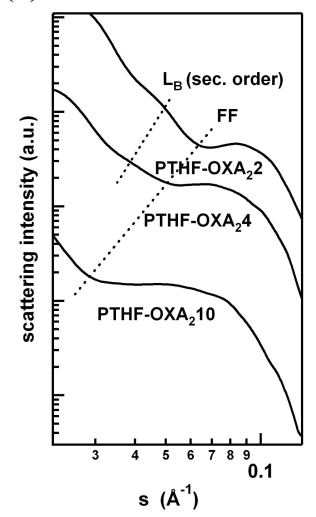

(c)

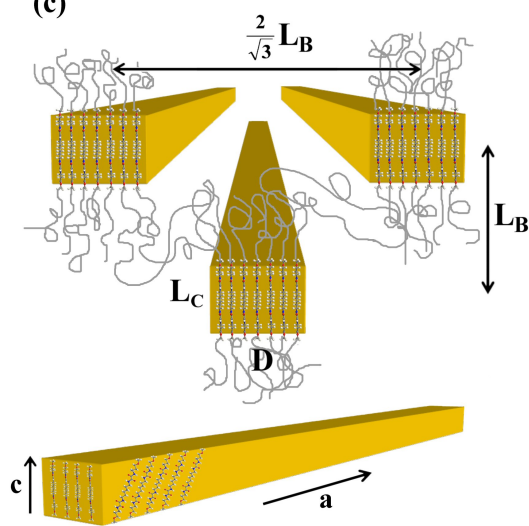

Figure 4.9: (a) SAXS intensities corresponding to bisoxalamide based segmented poly(ether amide)s (2a-e). (b) Medium-angle scattering intensities for bisoxalamide based segmented poly(ether amide)s (2a, 2c and $\mathbf{2 e}$ ) extracted from WAXS curves. (c) The model of hexagonally-packed fibrillar crystals used to interpret the SAXS data.

Here it is assumed that the crystalline domains are much longer in one direction than in the two others and can therefore be considered as virtually infinite fibrils. The micro-structural parameters of the samples (Figure 4.9c) such as the long spacing $\left(\mathrm{L}_{\mathrm{B}}\right)$, crystal thickness $\left(\mathrm{L}_{\mathrm{c}}\right)$ and amorphous domain thickness $\left(\mathrm{L}_{\mathrm{a}}\right)$ can be derived from the SAXS curves in the approximation of a hexagonal packing of the fibrillar crystals. The $\mathrm{L}_{\mathrm{B}}$ corresponds to the position of the Bragg peak (Figure 4.9a) whereas the crystalline domain thickness $\left(\mathrm{L}_{\mathrm{c}}\right)$ was calculated from the position of the form factor (Figure 4.9b) visible in the medium-angle range assuming the following form of the scattering intensity:

$$
I(s) \propto \frac{1}{s^{2}}\left(\frac{\sin \left(\pi \times s \times \mathrm{E}_{\mathrm{c}}\right)}{\pi \times s \times \mathrm{E}_{\mathrm{c}}}\right)^{2}
$$


The crystal width $\mathrm{D}$ was calculated using the crystalline volume fraction $\Theta_{\mathrm{vol}}$ of the bisoxalamide vs. PTHF.

$$
\begin{aligned}
& \Theta_{\text {vol }}=\frac{S_{\text {crystalline core }}}{S_{\text {lamellar surface }}} \\
& \frac{\frac{M_{\text {bisoxalamide }}}{\rho_{\text {bisoxalamide }}}}{\frac{M_{\text {bisoxalamide }}}{\rho_{\text {bisoxalamide }}}+\frac{M_{\mathrm{PTHF}}}{\rho_{\mathrm{PTHF}}}}=\frac{L_{\mathrm{c}} \times D}{\frac{2}{\sqrt{3}} \times L_{\mathrm{B}}{ }^{2}} \\
& D=\frac{\Theta_{\text {vol }} \times \frac{2}{\sqrt{3}} \times L_{\mathrm{B}}{ }^{2}}{L_{\mathrm{c}}}
\end{aligned}
$$

Here $\rho$ is the density (0.982 and $1.21{\mathrm{~g} . \mathrm{cm}^{-3}}$ for amorphous PTHF and bisoxalamide

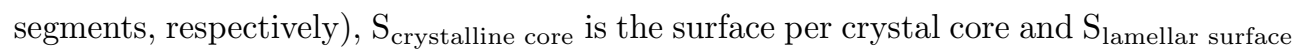
is the total surface of the 2D lattice formed by the fibrils assuming hexagonal packing of the crystals.

The long spacing $\mathrm{L}_{\mathrm{B}}$, the lateral crystal dimensions $\left(\mathrm{L}_{\mathrm{c}}\right.$ and $\left.\mathrm{D}\right)$ as well as the amorphous thickness $\left(\mathrm{L}_{\mathrm{a}}\right)$ of the segmented poly(ether amide)s are given in Table 4.1. As expected, $\mathrm{L}_{\mathrm{c}}$ and $\mathrm{L}_{\mathrm{B}}$ increase with the number of methylene groups in the hard segment. The $\mathrm{L}_{\mathrm{c}}$ is in good agreement with the theoretically calculated hard block length assuming a fully extended planar zig-zag conformation. Moreover, the crystal width D ranges between 60 and $87 \AA$ corresponding to a stack of 12 to 18 hydrogen bonded sheets. The amorphous layer thickness $\mathrm{L}_{\mathrm{a}}$ also increases with increasing spacer length, which is somehow unexpected since the soft segment length in all polymers is identical and equal to $1.1 \times 10^{3}$ g. $\mathrm{mol}^{-1}$. A possible explanation can be that the segment tilt influences the local density of the PTHF at the crystal-amorphous interface, which results in a change of the total amorphous layer thickness.

As discussed above, the long dimension of the crystals is parallel to the direction of the hydrogen bonds ( $\boldsymbol{a}$-direction). One of the two other small dimensions of the crystal approximately equals the length of one bisoxalamide segment $\left(\mathrm{L}_{\mathrm{c}}\right)$ whereas the other one (D) corresponds to the height of the stack containing ca. 10 to 20 hydrogen bonded sheets. 
Table 4.1: Long spacing $\left(\mathrm{L}_{\mathrm{B}}\right)$, crystalline lamellar thickness $\left(\mathrm{L}_{\mathrm{c}}\right.$ and $\left.\mathrm{D}\right)$ and amorphous lamellar thickness $\left(\mathrm{L}_{\mathrm{a}}\right)$ for bisoxalamide based segmented poly(ether amide)s (2a-e).

\begin{tabular}{lcccccc}
\hline & $\begin{array}{c}\mathrm{L}_{\mathrm{B}} \\
(\AA)\end{array}$ & $\begin{array}{c}\mathrm{L}_{\mathrm{c}} \\
(\AA)\end{array}$ & $\begin{array}{c}\mathrm{D} \\
(\AA)\end{array}$ & $\begin{array}{c}\mathrm{L}_{\mathrm{a}} \\
(\AA)\end{array}$ & $\begin{array}{c}\text { Tilt } \\
\text { angle }^{\mathrm{a}} \\
(\AA)\end{array}$ & $\begin{array}{c}\text { Hard block } \\
\text { length }^{\mathrm{b}} \\
(\AA)\end{array}$ \\
\hline PTHF-OXA $_{2}$ (2a) & 65.1 & $15.2^{\mathrm{c}}$ & - & 50.0 & 16 & 12.5 \\
PTHF-OXA $_{2} 4 \mathbf{( 2 b )}$ & 69.6 & 15.3 & 54 & 54.3 & 21 & 15.0 \\
PTHF-OXA $_{2} 6 \mathbf{( 2 c )}$ & 75.7 & 16.5 & 64 & 59.2 & 25 & 17.5 \\
PTHF-OXA $_{2} 8(\mathbf{2 d})$ & 86.9 & 19.2 & 79 & 67.7 & 30 & 20.0 \\
PTHF-OXA $_{2} 10 \mathbf{( 2 e )}$ & 95.3 & 22.6 & 87 & 72.7 & 32 & 22.5 \\
\hline
\end{tabular}

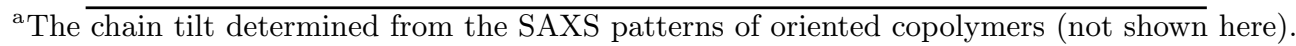
${ }^{\mathrm{b}}$ The hard block is defined here as the part of the molecule delimited by the hydrogen bonds; it is assumed that it is in the extended-chain conformation.

${ }^{\mathrm{c}}$ The distance determined from the SAXS patterns of the oriented copolymer.

In order to correlate the thermal behavior of the segmented poly(ether amide) hard segments, observed with variable temperature FT-IR and DSC, with the evolution of the fibrillar crystalline structure, temperature-resolved SAXS measurements were performed.

In Figure 4.10a, the scattering intensity is given as a function of temperature for polymer 2c. It is clearly visible that during heating the interference maximum indicative of the phase separated morphology disappears at $165{ }^{\circ} \mathrm{C}$ thereby marking the melting point of the bisoxalamide segments. In Figure $4.10 \mathrm{~b}$ the reverse of the first derivative of the SAXS invariant (Q) is given as a function of temperature for samples 2a-e.

The maximum of the curves observed in the range from $163{ }^{\circ} \mathrm{C}$ up to $220{ }^{\circ} \mathrm{C}$ corresponds to a rapid decrease of $\mathrm{Q}$. The peak temperatures are in agreement with the maximum decreasing rate of the hard segment crystallinity as measured by FT-IR and melting endotherm as measured by DSC (Figure 4.10b). Although FT-IR revealed the presence of hydrogen bonds well above the melting temperature (Figure $4.2 \mathrm{~b}$ ), no structural features are observed in SAXS suggesting the homogeneous state of the melt (Figure 4.10a). 

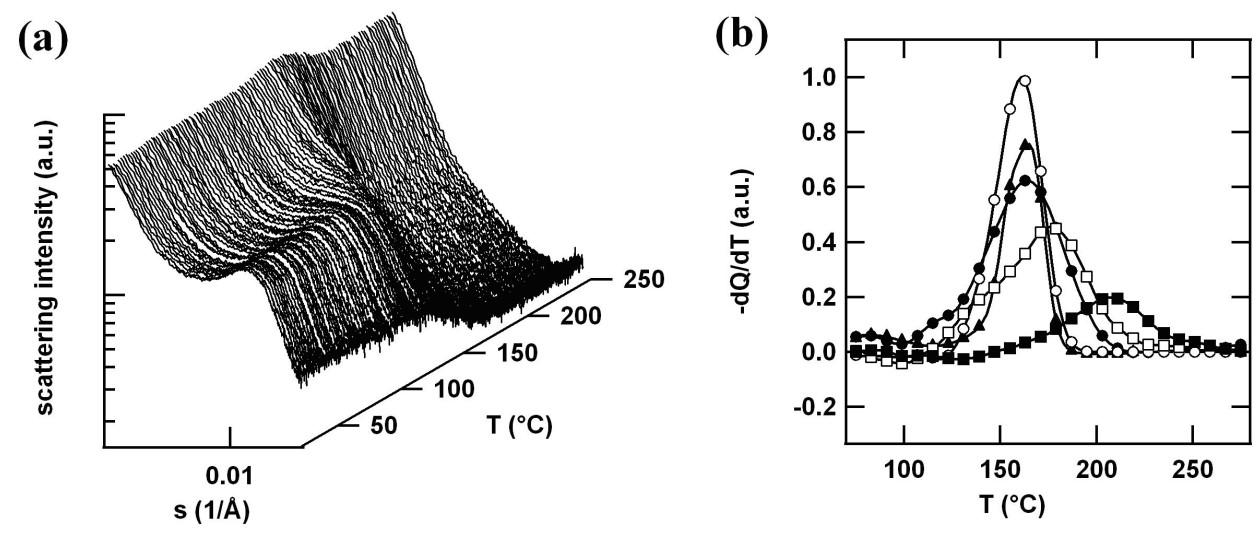

Figure 4.10: (a) Scattering intensity plots as a function of temperature for PTHF-OXA 6 (2c). (b) The negative of the first derivative of the scattering invariant $\mathrm{dQ} / \mathrm{dT}$ as a function of temperature for segmented poly(ether amide)s; ( $\boldsymbol{\square})$

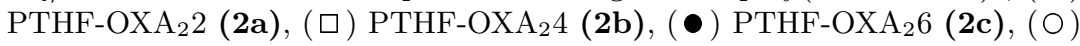

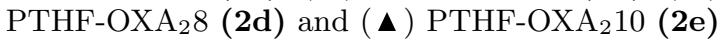

\subsubsection{Dynamic mechanical analysis}

The effect of temperature on polymer properties was studied by dynamic mechanical analysis (DMA). The storage modulus and loss modulus of the segmented poly(ether amide)s (1, 2a-e and $\mathbf{3}$ ) as a function of the temperature are depicted in Figure 4.11 and Figure 4.12, respectively.

The glass transition temperature $\left(\mathrm{T}_{\mathrm{g}}\right)$ of all segmented poly(ether amide)s are in between -70 and $-65{ }^{\circ} \mathrm{C}$ (Table 4.2 ). Interestingly, the $\mathrm{T}_{\mathrm{g}}$ of PTHF is $-86{ }^{\circ} \mathrm{C}^{46}$, which indicates that the segmented copolymers are highly phase separated.

The rubber plateau starts at temperatures below $0{ }^{\circ} \mathrm{C}$. Except for the segmented poly(ether amide) comprising single oxalamide groups (2), all polymers show a broad and fairly constant rubber plateau which is typical for segmented block copolymers with uniform hard segments. The storage modulus at $25{ }^{\circ} \mathrm{C}$, which is a measure of the stiffness, increases with increasing number of oxalamide groups in the hard segment and can be ascribed to an increasing hard segment content. No correlation was found between spacer length and the rubber modulus which ranges from 48 to $65 \mathrm{MPa}$ for polymers 2a-e. 
The rubber plateau is followed by a drastic drop in modulus indicating softening of the polymer and thus melting of the hard segments. The flow temperatures of the copolymers 2a-e increase from 150 to $200{ }^{\circ} \mathrm{C}$ as the number of methylene groups between two oxalamide groups decreases. The segmented poly(ether amide) with three oxalamide groups in the hard segment (3) flows at a temperature of $220^{\circ} \mathrm{C}$.

(a)

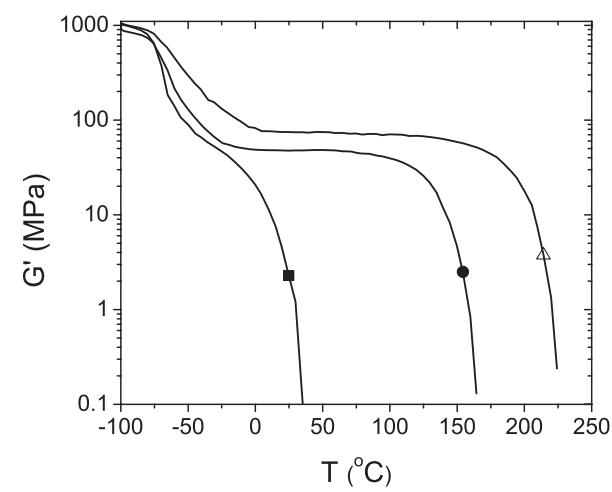

(b)

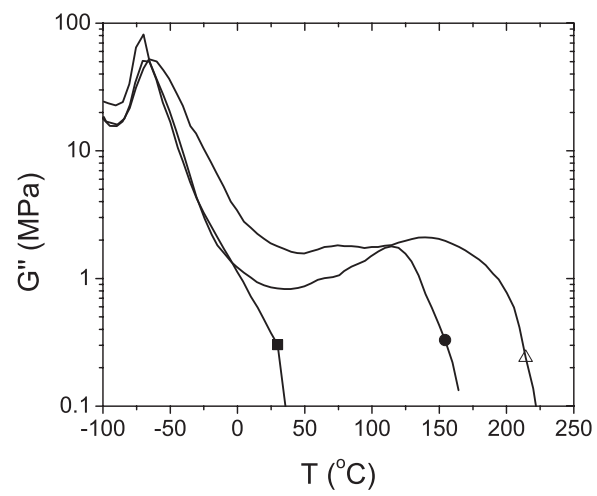

Figure 4.11: Storage modulus $\left(G^{\prime}\right)$ and loss modulus $\left(G^{\prime \prime}\right)$ as a function of temperature. (匹) PTHF-OXA (1), (•) PTHF-OXA 6 (2c) and $(\triangle)$ PTHF-OXA $_{3} 66$ (3).

(a)

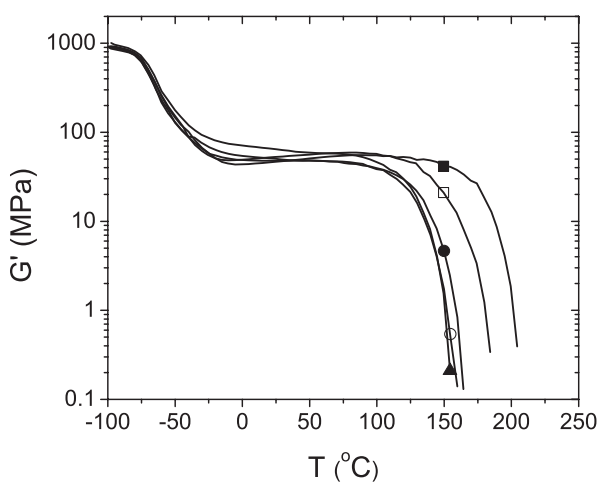

(b)

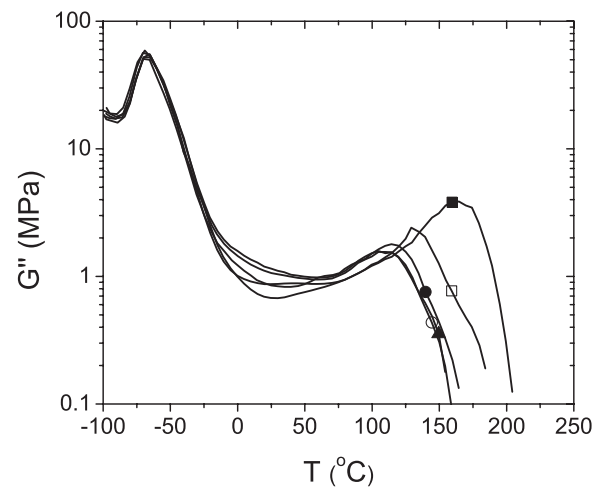

Figure 4.12: Storage modulus (G') and loss modulus (G") as a function of temperature.

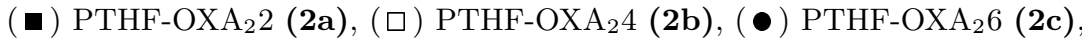

(O) PTHF-OXA 8 (2d) and ( $\mathbf{\Delta}) \mathrm{PTHF}_{2} \mathrm{OXA}_{2} 10$ (2e). 
Table 4.2: Dynamic mechanical properties of segmented poly(ether amide)s (1, 2a-e and 3).

\begin{tabular}{|c|c|c|c|c|c|}
\hline & \multicolumn{2}{|c|}{ Hard segment } & \multirow[b]{2}{*}{$\begin{array}{c}\mathrm{T}_{\mathrm{g}} \\
\left({ }^{\circ} \mathrm{C}\right)\end{array}$} & \multirow[b]{2}{*}{$\begin{array}{l}\mathrm{G}^{\prime} 25^{\circ} \mathrm{C} \\
(\mathrm{MPa})\end{array}$} & \multirow[b]{2}{*}{$\begin{array}{l}\mathrm{T}_{\text {flow }} \\
\left({ }^{\circ} \mathrm{C}\right)\end{array}$} \\
\hline & $\begin{array}{l}\text { Content } \\
(\mathrm{wt} \%)\end{array}$ & $\begin{array}{c}\text { Crystallinity }^{\mathrm{a}} \\
(\%)\end{array}$ & & & \\
\hline PTHF-OXA (1) & 7.3 & - & -70 & 2 & 25 \\
\hline $\mathrm{PTHF}_{-} \mathrm{OXA}{ }_{2} 6(\mathbf{2 c})$ & 18.9 & 66 & -70 & 48 & 160 \\
\hline $\mathrm{PTHF}_{-} \mathrm{OXA}_{3} 66$ (3) & 27.8 & 75 & -65 & 75 & 220 \\
\hline $\mathrm{PTHF} \mathrm{OX} \mathrm{A}_{2} 2$ (2a) & 15.4 & 90 & -70 & 46 & 200 \\
\hline $\mathrm{PTHF}_{-O X A_{2}} 4(2 \mathrm{~b})$ & 17.2 & 85 & -70 & 53 & 180 \\
\hline $\mathrm{PTHF}_{-\mathrm{OXA}} 6$ (2c) & 18.9 & 66 & -70 & 48 & 160 \\
\hline $\mathrm{PTHF} \mathrm{OX} \mathrm{A}_{2} 8$ (2d) & 20.5 & 67 & -65 & 49 & 150 \\
\hline $\mathrm{PTHF} \mathrm{OX} \mathrm{A}_{2} 10(\mathbf{2 e})$ & 22.1 & 85 & -65 & 65 & 150 \\
\hline
\end{tabular}

a Crystallinity according to amide I band in FT-IR spectra

\subsubsection{Mechanical properties}

The tensile properties were studied using compression molded bars cut to dumbbells (ISO37 s2). No tensile experiments were performed on the poly(ether amide) $\mathbf{1}$ as the stickiness of the material hindered sample preparation. Typical stress-strain curves are presented in Figure 4.13.

The E-modulus was determined at small deformations where stress linearly increases with strain. The E-modulus (E) and rubber modulus (G') are related according to

$$
E=2 G^{\prime}(1+\nu)
$$

with $\nu$ as the Poisson ratio ${ }^{47}$.

For incompressible materials, like elastomers, no volume change on deformation occurs and the Poisson ratio is 0.5 . The relation between $\mathrm{E} / \mathrm{G}^{\prime}$ for such polymers is approximately 3. It should be noted that the E-modulus is determined at 0.1-0.25\% strain and the rubber modulus is determined at $0.1 \%$ torsion. Not surprisingly, the values of the E-modulus follow the same trends as observed for the rubber modulus (Table 4.3). 
As the stress increases, the stress-strain curves deviate from Hookean behavior and the materials starts to deform permanently. In all cases, the segmented poly(ether amide)s show pronounced yield points followed by necking. This behavior indicates the presence of long-range hard segment connectivity and a well percolated hard phase throughout the soft matrix ${ }^{36,48-50}$. Just above the yield point, the well percolated hard phase disrupts and the fiber-like nano-crystals break up in their lateral direction.

At strains higher than $400 \%$, the segmented poly(ether amide)s with spacer length $\mathrm{x}=6,8$ and 10 (2c-e) showed strain hardening, while strain hardening was absent or started above $700 \%$ strain for the polymers with a spacer length of $\mathrm{x}=2$ and 4 (2a-b). The segmented poly(ether amide)s $\mathbf{2 a - e}$ have strains at break between $\sim 700$ and $900 \%$ and stresses at break ranging from 11.7 to $27.5 \mathrm{MPa}$, depending on the presence of a strain hardening effect. The stress and strain at break of the segmented poly(ether amide) comprising three oxalamide groups (3) is $16.6 \mathrm{MPa}$ and $130 \%$, respectively.

(a)

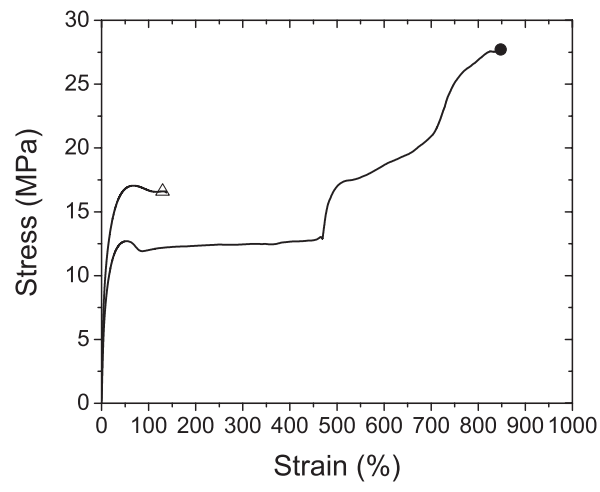

(b)

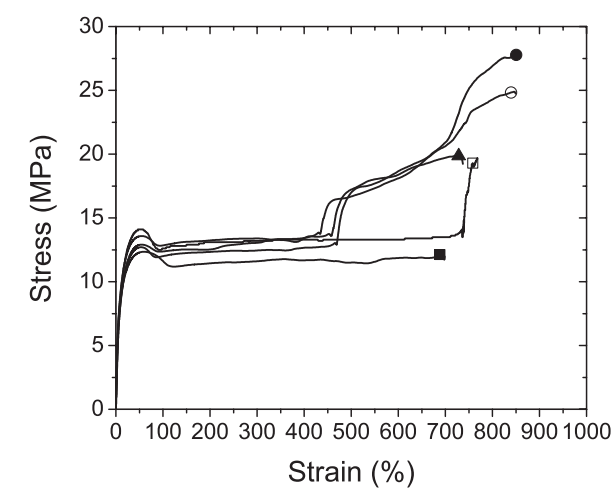

Figure 4.13: Stress-strain curves for segmented poly(ether amide)s ( $)$ PTHF-OXA 22 (2a), ( $\square)$ PTHF-OXA 4 (2b), (•) PTHF-OXA 6 (2c), (O) PTHF-OXA 28

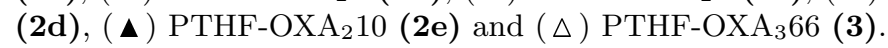




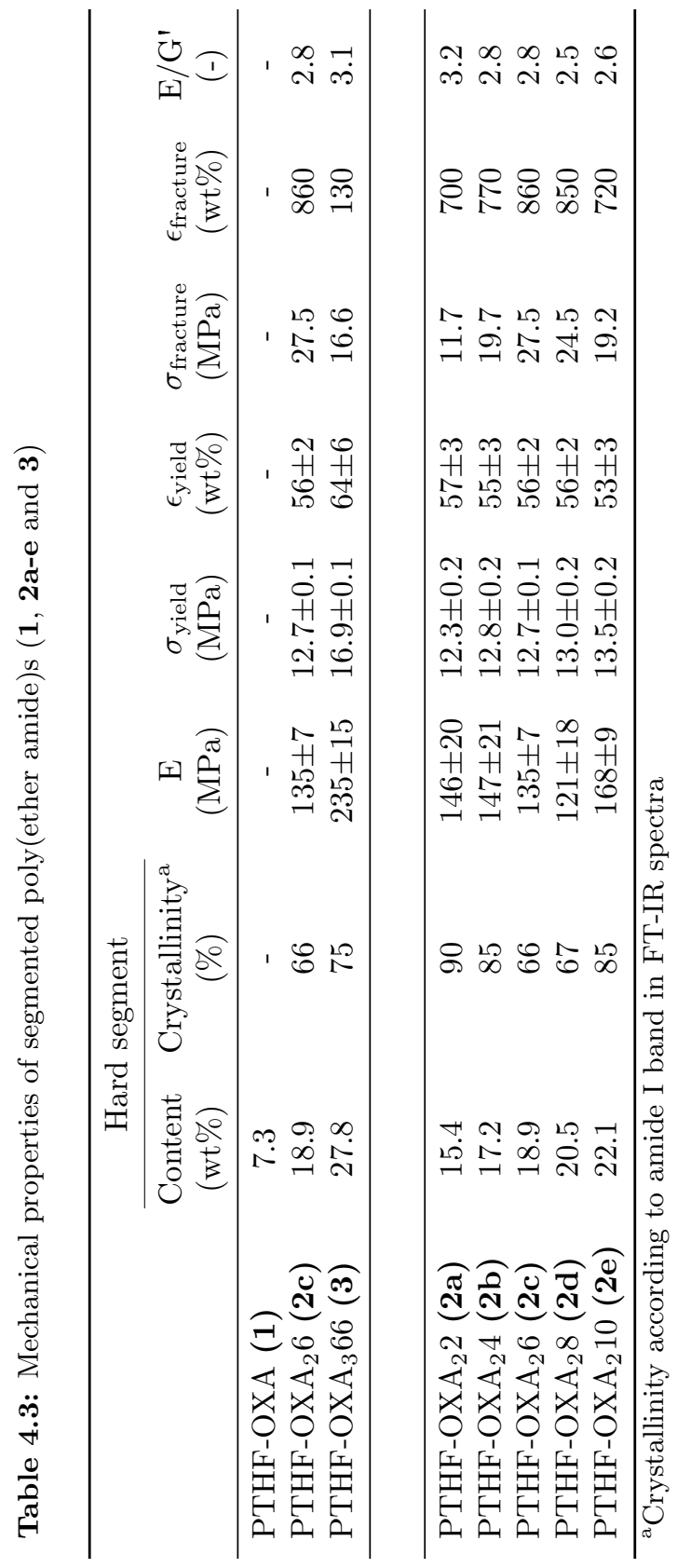




\subsubsection{Rheology}

The morphology of a segmented block copolymer changes above the melting temperature of the hard segments from a micro-phase separated material to a homogeneous melt ${ }^{51}$. The temperature at which this phenomenon occurs is called the micro-phase separation transition (MST). A method to determine this transition is to measure the storage modulus $\left(\mathrm{G}^{\prime}\right)$ as a function of temperature. The MST can be identified by a sharp rise in the storage modulus upon cooling as illustrated in Figure 4.14. The MSTs correspond well with the onset of crystallization transition temperatures found with DSC (Table 4.4).

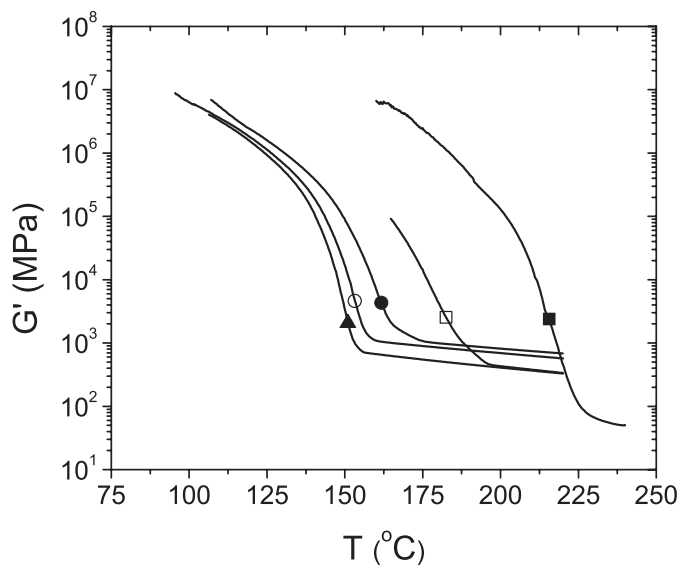

Figure 4.14: Temperature sweep with a frequency of $10 \mathrm{rad}_{\mathrm{s}} \mathrm{s}^{-1}$ and a strain of $20 \%$ for bisoxalamide based segmented poly(ether amide)s ( $\boldsymbol{\square}) \mathrm{PTHF}^{-\mathrm{OXA}_{2} 2}$ (2a), () PTHF-OXA 4 (2b), (•) PTHF-OXA 6 (2c), ( O) PTHF-OXA 8 (2d) and (ム) $\mathrm{PTHF}^{-O X A_{2}} 10(\mathbf{2 e})$.

Table 4.4: Crystallization onset temperatures $\left(\mathrm{T}_{\text {onset }}\right)$ and microphase transition temperatures $\left(\mathrm{T}_{\mathrm{MST}}\right)$ of segmented poly(ether amide)s (2a-e).

\begin{tabular}{lcc}
\hline & $\begin{array}{r}\mathrm{DSC}-\mathrm{T}_{\text {onset }} \\
\left({ }^{\circ} \mathrm{C}\right)\end{array}$ & $\begin{array}{c}\text { Rheology - } \\
\left({ }^{\circ} \mathrm{C}\right)\end{array}$ \\
\hline PTHF-OXA $_{2} 2 \mathbf{( 2 a )}$ & 216 & $\sim 225$ \\
PTHF-OXA $_{2} 4(\mathbf{2 b})$ & 181 & 191 \\
PTHF-OXA $_{2} 6(\mathbf{2 c})$ & 162 & 170 \\
PTHF-OXA $_{2} 8(\mathbf{2 d})$ & 150 & 160 \\
PTHF-OXA $_{2} 10(\mathbf{2 e})$ & 147 & 155 \\
\hline
\end{tabular}




\subsection{Conclusions}

Segmented poly(ether amide)s consisting of polytetrahydrofuran soft segments and uniform hard segments comprising at least two oxalamide groups are highly phase separated TPEs. These materials have temperature independent rubber plateaus starting at low temperatures. By increasing the number of oxalamide groups in the hard segment from 1 to 3 the rubber modulus increased from 2 to $75 \mathrm{MPa}$ and the flow temperature increased from 25 to $220{ }^{\circ} \mathrm{C}$. Changing the spacer length between two oxalamide groups from 2 to 10 methylene groups resulted in rubber moduli in between 46 and $64 \mathrm{MPa}$ and a decreasing flow temperature. Temperature dependent FT-IR, SAXS and rheology revealed broad hard segment melting transitions and homogeneous melts. Segmented copolymers with two and three oxalamide groups in the hard segments have an elastic modulus between 121 and $210 \mathrm{MPa}$, a stress at break ranging from 15 to $27 \mathrm{MPa}$ and strain at break of 150 up to $900 \%$. In all cases the polymers showed a distinct yield point indicative for long-range hard segment connectivity and a well percolated hard phase throughout the soft polymer matrix. It can be concluded that hard segments comprising two or three oxalamide groups provide segmented poly(ether amide)s with attractive thermal and mechanical properties. Furthermore, the thermal behavior of the polymers can be tuned by changing the spacer length between two oxalamide groups.

\subsection{References}

[1] Fakirov, S. Handbook of condensation thermoplastic elastomers; Wiley-VCH: Weinheim, 2005.

[2] Holden, G.; Legge, N. R.; Quirk, R. P.; Schroeder, H. E. Thermoplastic elastomers, 2nd ed.; Hanser Publishers: Munich, 1996.

[3] Cella, R. J. J Polym Sci: Symp No 47 1973, 42, 727-740.

[4] Alberola, N. J Appl Polym Sci 1988, 36, 787-804.

[5] Bornschlegl, E.; Goldbach, G.; Meyer, K. Prog Colloid Polym Sci 1985, 71, 119-124.

[6] Di Lorenzo, M. L.; Pyda, M.; Wunderlich, B. J Polym Sci Part B Polym Phys 2001, 39, 1594-1606. 
2. Segmented poly(ether amide)s with uniform oxalamide based hard segments

[7] Di Lorenzo, M. L.; Pyda, M.; Wunderlich, B. J Polym Sci Part B Polym Phys 2001, 39, 2969-2981.

[8] Faruque, H. S.; Lacabanne, C. Polymer 1986, 27, 527-531.

[9] Ghosh, S.; Khastagir, D.; Bhowmick, A. K.; Bandyopadhyay, S.; Kao, G. J. P.; Kok, L. J Mater Sci Lett 2000, 19, 2161-2165.

[10] Ghosh, S.; Khastgir, D.; Bhowmick, A. K. Polymer 1998, 39, 3967-3975.

[11] Godovsky, Y. K.; Yanul, N. A.; Bessonova, N. P. Colloid Polym Sci 1991, 269, 901-915.

[12] Hatfield, G. R.; Guo, Y. H.; Killinger, W. E.; Andrejak, R. A.; Roubicek, P. M. Macromolecules 1993, 26, 6350-6353.

[13] Hatfield, G. R.; Bush, R. W.; Killinger, W. E.; Roubicek, P. M. Polymer 1994, 35, 3943-3947.

[14] Hucher, C.; Eustache, R. P.; Beaume, F.; Tekely, P. Macromolecules 2005, 38, 9200-9209.

[15] McLean, R. S.; Sauer, B. B. Macromolecules 1997, 30, 8314-8317.

[16] McLean, R. S.; Sauer, B. B. J Polym Sci Part B Polym Phys 1999, 37, 859-866.

[17] Sakurai, K.; Amador, G.; Takahashi, T. Polymer 1998, 39, 4089-4094.

[18] Sauer, B. B.; McLean, R. S.; Thomas, R. R. Polym Int 2000, 49, 449-452.

[19] Sheth, J. P.; Xu, J. N.; Wilkes, G. L. Polymer 2003, 44, 743-756.

[20] Song, Y.; Yamamoto, H.; Nemoto, N. Macromolecules 2004, 37, 6219-6226.

[21] Yang, I. K.; Tsai, P. H. J Polym Sci Part B Polym Phys 2005, 43, 2557-2567.

[22] Yu, Y. C.; Jo, W. H. J Appl Polym Sci 1995, 56, 895-904.

[23] Yu, Y. C.; Jo, W. H.; Lee, M. S. J Appl Polym Sci 1997, 64, 2155-2163.

[24] Harrell, L. L. Macromolecules 1969, 2, 607-612.

[25] Ng, H. N.; Allegrez, A. E.; Seymour, R. W.; Cooper, S. L. Polymer 1973, 14 , 255-261.

[26] Miller, J. A.; Lin, S. B.; Hwang, K. K. S.; Wu, K. S.; Gibson, P. E.; Cooper, S. L. Macromolecules 1985, 18, 32-44.

[27] Biemond, G. J. E.; Feijen, J.; Gaymans, R. J. Polym Eng Sci 2008, 48, 1389-1400.

[28] Versteegen, R. M.; Kleppinger, R.; Sijbesma, R. P.; Meijer, E. W. Macromolecules 2006, 39, 772-783.

[29] van der Schuur, M.; Feijen, J.; Gaymans, R. J. Polymer 2005, 46, 4584-4595.

[30] Niesten, M. C. E. J.; Feijen, J.; Gaymans, R. J. Polymer 2000, 41, 8487-8500.

[31] Bouma, K.; Wester, G. A.; Gaymans, R. J. J Appl Polym Sci 2001, 80, 1173-1180.

[32] Gaymans, R. J.; Dehaan, J. L. Polymer 1993, 34, 4360-4364.

[33] Husken, D.; Krijgsman, J.; Gaymans, R. J. Polymer 2004, 45, 4837-4843. 
[34] Krijgsman, J.; Husken, D.; Gaymans, R. J. Polymer 2003, 44, 7573-7588.

[35] Biemond, G. J. E.; Feijen, J.; Gaymans, R. J. J Appl Polym Sci 2007, 105, 951-963.

[36] Yilgor, I.; Yilgor, E. Polym Rev 2007, 47, 487-510.

[37] Coe, S.; Kane, J. J.; Nguyen, T. L.; Toledo, L. M.; Wininger, E.; Fowler, F. W.; Lauher, J. W. J Am Chem Soc 1997, 119, 86-93.

[38] Desseyn, H. O.; Perlepes, S. P.; Clou, K.; Blaton, N.; Van der Veken, B. J.; Dommisse, R.; Hansen, P. E. J Phys Chem A 2004, 108, 5175-5182.

[39] Aleman, C.; Casanovas, J. J Mol Struct Theochem 2004, 675, 9-17.

[40] Shalaby, S. W.; Pearce, E. M.; Frederic, R. J.; Turi, E. A. J Polym Sci Part B Polym Phys 1973, 11, 1-14.

[41] Black, W. D.; Preston, J. Man-made fibers. science and technology, 2nd ed.; Interscience: New York, 1968.

[42] Schulze, H. Thermoplastic adhesive polyoxamide from polyoxypropylene polyamine; US4,119,615, 1978.

[43] Sijbrandi, N. J.; Kimenai, A. J.; Mes, E. P. C.; Broos, R.; Dijkstra, P. J.; Feijen, J. Chapter 3, this thesis; University of Twente, 2011.

[44] Meier, R. J. Vib Spectrosc 2005, 39, 266-269.

[45] Chatani, Y.; Ueda, Y.; Tadokoro, H.; Deits, W.; Vogl, O. Macromolecules 1978, 11, 636-638.

[46] van Krevelen, D. W.; te Nijenhuis, K. Properties of polymers, 4th ed.; Elsevier: Amsterdam, 2009.

[47] Cowie, J. M. G. Polymer: chemistry $\&$ physics of modern materials, 2nd ed.; Blackie Academic \& Professional: London, 1991.

[48] Das, S.; Cox, D. F.; Wilkes, G. L.; Klinedinst, D. B.; Yilgor, I.; Yilgor, E.; Beyer, F. L. J Macromol Sci Phys 2007, 46, 853-875.

[49] Das, S.; Yilgor, I.; Yilgor, E.; Inci, B.; Tezgel, O.; Beyer, F. L.; Wilkes, G. L. Polymer 2007, 48, 290-301.

[50] Das, S.; Yilgor, I.; Yilgor, E.; Wilkes, G. L. Polymer 2008, 49, 174-179.

[51] Veenstra, H.; Hoogvliet, R. M.; Norder, B.; de Boer, A. P. J Polym Sci Part B Polym Phys 1998, 36, 1795-1804. 


\title{
Chapter 5
}

\section{Effect of polytetrahydrofuran or oxamic acid ethyl ester end groups on the properties of low molecular weight bisoxalamide based segmented poly(ether amide)s}

\author{
N.J. Sijbrandi ${ }^{a}$, E.P.C. Mes ${ }^{b}$, R. Broos ${ }^{b}$, P.J. Dijkstra ${ }^{a}$, J. Feijen ${ }^{a}$ \\ ${ }^{a}$ Department of Polymer Chemistry and Biomaterials, MIRA Institute for Biomedical Tech- \\ nology and Technical Medicine, Faculty of Science and Technology, University of Twente, \\ P.O. Box 217, 7500 AE Enschede, The Netherlands \\ ${ }^{\mathrm{b}}$ Core R\&D, DOW Benelux BV, P.O. Box 48, 4530 AA, Terneuzen, The Netherlands
}

\begin{abstract}
Low molecular weight bisoxalamide based segmented poly(ether amide)s either with PTHF or oxamic acid ethyl ester end groups have been prepared by melt polycondensation of an $\alpha, \omega$-amine end functionalized PTHF and a bisoxalamide precursor applying different molar feed ratios. Polymers with PTHF end groups show melting transitions at -18 to $15{ }^{\circ} \mathrm{C}$ and between 85 and $192{ }^{\circ} \mathrm{C}$. The melting transitions in the range of -18 to $15{ }^{\circ} \mathrm{C}$ increase for polymers with decreasing molecular weights. The two transitions are ascribed to melting of crystals comprising PTHF end groups and bisoxalamide segments, respectively. The polymers with oxamic acid ethyl ester end groups show one melting transition between 80 and $186{ }^{\circ} \mathrm{C}$. All polymers have low glass transition temperatures and display extended temperature independent rubber plateaus up to the flow temperatures ranging from 140 to $160{ }^{\circ} \mathrm{C}$. Polymers have relatively high rubber moduli, ranging from 57 to $85 \mathrm{MPa}$. By decreasing the molecular weight and consequently the melt viscosity, the mechanical properties of the polymers decrease. The polymers demonstrate ductile behavior at molecular weights above $15 \times 10^{3} \mathrm{~g} \cdot \mathrm{mol}^{-1}$.
\end{abstract}




\subsection{Introduction}

Segmented poly(ether amide)s consisting of alternating low $\mathrm{T}_{\mathrm{g}}$ polyether soft segments and rigid amide containing hard segments are a class of thermoplastic elastomers ${ }^{1,2}$. At ambient temperatures, the hard and soft segments are thermodynamically immiscible and the amide rich phase separates by crystallization ${ }^{3}$. The crystallized hard phase acts as a physical crosslinker providing the material with dimensional stability, whereas the soft polyether matrix contributes to the elastomeric character of the polymer at service temperature. When the hard segments are uniform in length, the phase separation and mechanical properties of segmented poly(ether amide)s improve considerably $^{4-11}$.

Well known segmented poly(ether amide)s comprise polytetrahydrofuran (PTHF) and nylon-12 segments ${ }^{1,2}$. Generally, these polymers are prepared by melt polycondensation of preformed carboxylic acid end functionalized nylon-12 segments and an $\alpha, \omega$-hydroxyl end functionalized PTHF. The polymers exhibit a micro-phase separated morphology over a broad temperature range. At low polyamide content, the polymers exhibit typical elastomeric behavior such as good recoverability, low permanent set, low mechanical hysteresis and high extensibility. By increasing the hard segment content, the interconnectivity of the hard phase increases and the polymer becomes typical thermoplastic $^{12}$. Other widely investigated segmented poly(ether amide)s with PTHF soft segments are based on uniform aromatic di-amides $(\mathrm{T} \Phi \mathrm{T})^{8}$ or the partially aromatic tetra-amides nylon-6,T $(\mathrm{T} 6 \mathrm{~T} 6 \mathrm{~T})^{13}$. Such polymers were prepared via a two step solution/melt polycondensation of $\alpha, \omega$-hydroxyl end functionalized PTHF and pre-synthesized ester end functionalized amide blocks. These polymers show a highly phase separated morphology with fiber-like nano-crystals randomly dispersed in the soft polymer matrix. Typical material properties are fast crystallization, a relatively high modulus, a temperature independent rubber plateau and a sharp melting transition. Besides, these copolymers are highly elastic and have high fracture strains.

In general, the processability of polymers improves when their melt viscosity decreases. Important parameters determining the melt viscosity are the molecular weight, molecular weight distribution and temperature ${ }^{14}$. Decreasing the molecular weight results in a lower melt viscosity, however the mechanical properties also decline and the material may become brittle due to the loss of chain entanglements. Low molecular weight segmented poly(ether amide)s based on PTHF soft segments (A) and uniform aromatic 
di-amide (aramide) hard segments $(\mathbf{B})$ were investigated by Arun et al ${ }^{15-20}$. The copolymers were prepared using pre-synthesized mono- or di-ester end functionalized aramide segments and $\alpha, \omega$-hydroxyl end functionalized PTHF. To obtain longer soft segments, the PTHF block was extended with dimethyl terephthalate. In this way, relatively low molecular weight copolymers of type $\mathbf{B}(\mathbf{A B})_{\mathbf{n}}, \mathbf{B A B}{ }^{17,18}, \mathbf{A B A}$ and $\mathbf{A B}^{16,18}$ with molecular weights up to $20 \times 10^{3} \mathrm{~g} \cdot \mathrm{mol}^{-1}$ were prepared.

Similar to high molecular weight analogues $(\mathbf{A B})_{\mathbf{n}}$, these copolymers display highly phase separated morphologies with fiber-like nano-crystals randomly dispersed in the soft polymer matrix. For polymers with aramide end groups, $\mathbf{B}(\mathbf{A B})_{\mathbf{n}}$ and $\mathbf{B A B}$, the hard segment crystallinity, flow temperature and modulus at room temperature appeared higher than for their high molecular weight counterparts ${ }^{15,17,18}$. These polymers showed ductile behavior at molecular weights higher than $6 \times 10^{3}$ g.mol ${ }^{-117,20}$. On the other hand, copolymers comprising one aramide segment, $\mathbf{A B A}$ and $\mathbf{A B}$, with comparable molecular weights displayed a brittle behavior, indicating the lack of network formation by crystallization of the aramide segments ${ }^{15}$. Moreover, unusual melt rheological behavior was found for copolymers with aramide end groups, $\mathbf{B}(\mathbf{A B})_{\mathbf{n}}$, $\mathbf{B A B}$ and $\mathbf{A B}{ }^{15-19}$. A strong gelling behavior was observed indicating association of aramide groups in the melt, whereas $(\mathbf{A B})_{\mathbf{n}}$ and $\mathbf{A B A}$ copolymers displayed the rheological behavior of a homogeneous melt.

In previous research, we prepared novel segmented poly(ether amide)s consisting of polytetrahydrofuran soft segments $\left(1.1 \times 10^{3}\right.$ g.mol $\left.{ }^{-1}\right)$ and uniform bisoxalamide based hard segments with relative high molecular weights $\left(M_{n}=30-60 \times 10^{3} \text { g.mol }{ }^{-1}\right)^{21,22}$. The polymers were highly phase separated and had a broad temperature independent rubber plateau. The bisoxalamide hard segments crystallized in fiber-like nano-crystals with high aspect ratio, randomly dispersed in the soft polymer matrix. Above the melting temperature of the bisoxalamide hard segments, the polymers changed in homogeneous melts with high melt viscosities. The high crystallinity of the oxalamide hard phase results in a highly phase separated polymer with attractive mechanical properties. These properties predominantly depend on physical crosslinking of the material by the bisoxalamide hard segments. This prompted us to study the relationship between molecular weight and mechanical properties of oxalamide based poly(ether amide)s. Because for low molecular weight polymers the type of end groups becomes important in the final polymer properties, poly(ether amide)s with either PTHF or oxamic acid ethyl ester end groups were prepared. The effect of these end groups on the thermal and mechanical properties of the polymers was evaluated. 


\subsection{Experimental}

\subsubsection{Materials}

Diethyl oxalate, bis(3-aminopropyl) polytetrahydrofuran $\left(\mathrm{M}_{\mathrm{n}}=1.1 \times 10^{3} \mathrm{~g} \cdot \mathrm{mol}^{-1}\right), 1,6$ diaminohexane, 1,1,1,3,3,3-hexafluoro-2-propanol (HFIP) and deuterated chloroform $\left(\mathrm{CDCl}_{3}-\mathrm{d}_{1}\right)$ were purchased from Aldrich (Zwijndrecht, The Netherlands). Irganox1330 was kindly provided by Ciba (Geigi, Switzerland). HPLC-quality chloroform was purchased from Lab-Scan (Gliwice, Poland). Diethyl ether and tetrahydrofuran were obtained from Biosolve (Valkenswaard, The Netherlands) and chloroform and tetrabutylorthotitanoate $\left(\mathrm{Ti}(\mathrm{OBu})_{4}\right)$ were purchased from Merck (Darmstadt, Germany). All materials were used as received.

\subsubsection{Synthesis}

Diethyl 2,2'-(hexane-1,6-diylbis(azanediyl))bis(2-oxoacetate) (OXA 2 6) (2) A solution of 1,6-diaminohexane $(20.00 \mathrm{~g}, 0.17 \mathrm{~mol})$ in $200 \mathrm{ml}$ of tetrahydrofuran was slowly added to diethyl oxalate $(252.00 \mathrm{~g}, 1.72 \mathrm{~mol})$. Subsequently the mixture was stirred at room temperature for $16 \mathrm{~h}$. The solvent and excess of diethyl oxalate were removed by filtration. The solids were dissolved in chloroform and filtered. The chloroform was removed under reduced pressure and the product was washed two times with diethyl ether and dried under vacuum. The product was obtained as a white powder in a yield of $85 \%\left(\mathrm{mp} 90{ }^{\circ} \mathrm{C}\right) \cdot{ }^{1} \mathrm{H} \mathrm{NMR}\left(300 \mathrm{MHz}, \mathrm{CDCl}_{3}-\mathrm{d}_{1}\right) \delta=7.35$ (bt, $2 \mathrm{H}, \mathrm{OCOCONH}$ ), 4.25 (q, $\left.4 \mathrm{H}, \mathrm{CH}_{3} \mathrm{CH}_{2} \mathrm{O}\right), 3.29$ (m, $4 \mathrm{H}, \mathrm{NHCH}_{2} \mathrm{CH}_{2} \mathrm{CH}_{2}$ ), 1.59 $\left(\mathrm{m}, 4 \mathrm{H}, \mathrm{NHCH}_{2} \mathrm{CH}_{2} \mathrm{CH}_{2}\right), 1.25\left(\mathrm{~m}, 4 \mathrm{H}, \mathrm{NHCH}_{2} \mathrm{CH}_{2} \mathrm{CH}_{2}\right), 1.25$ (t, $\left.6 \mathrm{H}, \mathrm{CH}_{3} \mathrm{CH}_{2} \mathrm{O}\right)$; ${ }^{13} \mathrm{C} \mathrm{NMR}\left(75.26 \mathrm{MHz}, \mathrm{CDCl}_{3}-\mathrm{d}_{1}\right) \delta=160.9(\mathrm{OCOCONH}), 156.9(\mathrm{OCOCONH}), 63.4$ $\left(\mathrm{CH}_{3} \mathrm{CH}_{2} \mathrm{O}\right), 40.0\left(\mathrm{NHCH}_{2} \mathrm{CH}_{2} \mathrm{CH}_{2}\right), 29.1\left(\mathrm{NHCH}_{2} \mathrm{CH}_{2} \mathrm{CH}_{2}\right), 26.3\left(\mathrm{NHCH}_{2} \mathrm{CH}_{2} \mathrm{CH}_{2}\right)$, $14.2\left(\mathrm{CH}_{3} \mathrm{CH}_{2} \mathrm{O}\right)$.

\section{Low molecular weight PTHF-OXA 6 (3a-e) and (4a-e)}

Bis(3-aminopropyl) polytetrahydrofuran (1) was polymerized with $\mathrm{OXA}_{2} 6$ (2) at different molar feed ratios. In a typical example, bis(3-aminopropyl) polytetrahydrofuran (1) (62.66 g, $0.057 \mathrm{~mol})$ and $\mathrm{OXA}_{2} 6$ (2) (15.00 g, $0.047 \mathrm{~mol}$ ) were placed in a polymerization tube. To this mixture Irganox1330 ( $1 \mathrm{wt} \%$ of the total mass) was added. The mixture was heated to $190{ }^{\circ} \mathrm{C}$ under a nitrogen flow. After $1 \mathrm{~h}$, the pressure was slowly reduced to $\sim 20$ mbar to distill off the ethanol in approximately 30 
min. Subsequently, the pressure was reduced to $\sim 0.08$ mbar during the following 1.5 h. The reaction mixture was then cooled to room temperature under vacuum. The polymer was dissolved in $200 \mathrm{ml}$ of chloroform at $50{ }^{\circ} \mathrm{C}$ and subsequently precipitated in $2 \mathrm{~L}$ of diethyl ether. The polymer was filtered and dried at $60{ }^{\circ} \mathrm{C}$ at reduced pressure. The product was obtained as a yellow transparent elastic solid.

\section{High molecular weight PTHF-OXA 6 (5)}

The polymerization was performed as described above using bis(3-aminopropyl) polytetrahydrofuran (1) (30.00 g, $0.023 \mathrm{mmol}), \mathrm{OXA}_{2} 6$ (2) $(7.27 \mathrm{~g}, 0.023 \mathrm{~mol}), \mathrm{Ti}(\mathrm{OBu})_{4}$ (0.2 wt\% relative to the total mass dissolved in $1 \mathrm{ml}$ of toluene) and Irganox1330 ( $1 \mathrm{wt} \%$ of the total mass). The reaction time at a pressure of $\sim 0.08$ mbar of this polymerization was $4 \mathrm{~h}$. The product was obtained as a yellow transparent elastic solid.

\subsubsection{Methods}

\section{NMR}

${ }^{1} \mathrm{H}(300 \mathrm{MHz})$ and ${ }^{13} \mathrm{C} \mathrm{NMR}(75.26 \mathrm{MHz})$ spectra were recorded on a Varian Inova Nuclear Magnetic Resonance Spectrometer using $\mathrm{CDCl}_{3}-\mathrm{d}_{1}$ as solvent.

\section{GPC}

The GPC setup consisted of a Perkin Elmer series 200 binary pump, a Perkin Elmer series 200 autosampler, a Shimadzu CTO-AVP column oven, and a Shimadzu RID-10A refractive index detector. The eluent was $\mathrm{CHCl}_{3} / \mathrm{HFIP}(95 / 5 \mathrm{v} / \mathrm{v})$. The flow was set at $1 \mathrm{ml} . \mathrm{min}^{-1}$. The injection volume was $200 \mu \mathrm{L}$. The separation was performed on two PL Mixed-D columns $(300 \times 7.5 \mathrm{~mm})$ from Polymer Laboratories Ltd., packed with $5 \mu \mathrm{m}$ particles. The temperature of the columns was set at $30{ }^{\circ} \mathrm{C}$. Approximately $120 \mathrm{mg}$ of sample is weighed in a $50 \mathrm{ml}$ vial. To this vial $2 \mathrm{ml}$ of HFIP is added and the solution is allowed to stand for $2 \mathrm{~h}$. Next, $38 \mathrm{ml}$ of warm $\left(\sim 35{ }^{\circ} \mathrm{C}\right)$ HPLC-quality chloroform is added and mixed thoroughly. Prior to injection the sample solution is filtered through a Millex-LCR $0.45 \mu \mathrm{m}$ filter (Millipore). The system was calibrated with 14 narrow polystyrene standards (Polymer Laboratories) with MW ranging from $5.8 \times 10^{2}$ to $1.0 \times 10^{6}$ g. $\mathrm{mol}^{-1}$. The standards were dissolved in $\mathrm{CHCl}_{3} / \mathrm{HFIP}(95 / 5 \mathrm{v} / \mathrm{v})$. Because the $\mathrm{K}$ and $\alpha$ values of the samples are not known and a viscometer was not available, no universal calibration could be performed. The reported molecular weights should, therefore, be regarded as PS-equivalent molecular weights. Moreover, it is important to note that the reported molecular weights are highly dependent on 
the type of standard used. A calibration curve that is virtually linear over a broad molecular weight range was obtained. However, the highest molecular weights tested $\left(6.75 \times 10^{5}\right.$ g.mol ${ }^{-1}, 8.41 \times 10^{5}$ g.mol ${ }^{-1}$, and $1.0 \times 10^{6}$ g.mol $\left.{ }^{-1}\right)$ elute near or in the exclusion limit of the column, causing an upward curvature at the high MW end.

\section{DSC}

Thermal analysis was carried out using a Perkin-Elmer Pyris 1. Calibration was carried out with pure indium. Samples (5-10 mg) were heated from -100 to $200{ }^{\circ} \mathrm{C}$ at a rate of $20{ }^{\circ} \mathrm{C} \cdot \mathrm{min}^{-1}$, annealed for $5 \mathrm{~min}$, cooled to $-100{ }^{\circ} \mathrm{C}$ at a rate of $20{ }^{\circ} \mathrm{C} \cdot \mathrm{min}^{-1}$, and subsequently heated from -100 to $200{ }^{\circ} \mathrm{C}$ at a rate of $20{ }^{\circ} \mathrm{C} \cdot \mathrm{min}^{-1}$. Melting $\left(\mathrm{T}_{\mathrm{m}}\right)$ and crystallization $\left(\mathrm{T}_{\mathrm{c}}\right)$ temperatures were obtained from the peak maxima, melting $\left(\Delta \mathrm{H}_{\mathrm{m}}\right)$ and crystallization $\left(\Delta \mathrm{H}_{\mathrm{c}}\right)$ enthalpies were determined from the area under the curve. The data presented are taken from the first cooling scan and the second heating scan.

\section{Processing}

Compression molded bars $(75 \times 10 \times 2 \mathrm{~mm})$ were prepared using a hot press $(\mathrm{THB}$ 008, Fontijne Holland BV, the Netherlands). Polymers were heated for $3 \mathrm{~min}$ at approximately $20{ }^{\circ} \mathrm{C}$ above their $\mathrm{T}_{\text {flow }}$, pressed at $300 \mathrm{kN}$, and cooled in approximately 5 min under pressure to room temperature.

\section{DMA}

Dynamic mechanical analysis was performed using a Myrenne ATM3 torsion pendulum at a frequency of approximately $1 \mathrm{~Hz}$. The storage modulus $\left(\mathrm{G}^{\prime}\right)$ and the loss modulus $\left(\mathrm{G}^{\prime \prime}\right)$ were measured as a function of temperature. Samples $(50 \times 10 \times 2 \mathrm{~mm})$ were cooled to $-100{ }^{\circ} \mathrm{C}$ and then heated at a rate of $1{ }^{\circ} \mathrm{C} \cdot \mathrm{min}^{-1}$. The temperature at which the loss modulus reached a maximum was taken as the glass transition temperature $\left(\mathrm{T}_{\mathrm{g}}\right)$. The flow temperature $\left(\mathrm{T}_{\text {flow }}\right)$ was taken at a storage modulus value of $1 \mathrm{MPa}$.

\section{Tensile testing}

Tensile tests were conducted with compression molded bars cut to dumbbells (ISO37 type 2). A Zwick Z020 universal tensile machine equipped with a $500 \mathrm{~N}$ load cell and extensometers was used to measure the stress at a strain rate of $0.4 \mathrm{~s}^{-1}$ (test speed: 60 $\mathrm{mm} \cdot \mathrm{min}^{-1}$ ) and a preload of $0.1 \mathrm{MPa}$. Measurements were performed on at least 5 different polymer bars. 


\subsection{Results and Discussion}

\subsubsection{Synthesis and characterization}

Segmented poly(ether amide)s with different molecular weights were prepared by polycondensation of the $\alpha, \omega$-amine end functionalized polytetrahydrofuran $\mathbf{1}\left(\mathrm{M}_{\mathrm{n}}=\right.$ $1.1 \times 10^{3}$ g.mol $\left.{ }^{-1}\right)$ and the bisoxalamide hard segment precursor $2\left(\mathrm{OXA}_{2} 6\right)$ in the melt (Scheme 5.1). Polymer molecular weights were varied by changing the macro-monomer molar feed ratio.<smiles>[X]CCCOC(C)(C)CCCCC(C)(C)OCCCN</smiles>

(1)

(2)

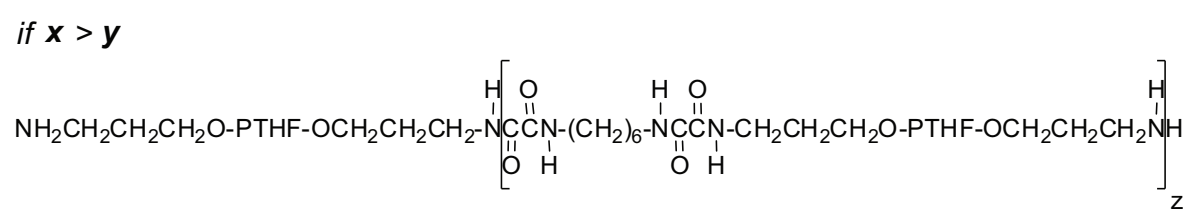

(3a-e) $(z=1,2,5,8$ or 12$)$

if $x<y$

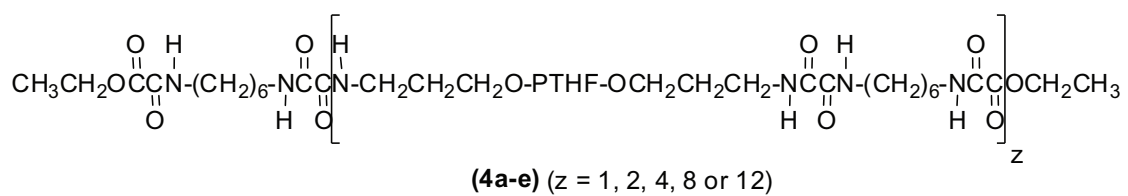<smiles>CC(C)OCCCC(C)(C)OCCCNC(=O)C(=O)NCCCCCCNC(=O)C(=O)NCCCC(C)(C)C</smiles>

High MW PTHF-OXA 6 (5)

Scheme 5.1: Synthesis and structure of segmented poly(ether amide)s with polytetrahydrofuran end groups 3a-e or $\mathrm{OXA}_{2} 6$ end groups $\mathbf{4 a - e}$ and a high molecular weight segmented poly(ether amide) 5 . 
Depending on the monomer in excess, segmented poly(ether amide)s with either polytetrahydrofuran end groups 3a-e or oxamic acid ethyl ester type end groups $\left(\mathrm{OXA}_{2} 6\right)$ 4a-e were obtained. The monomer feed ratio was chosen such that values of $\mathrm{z}$ ranged from 1 to 12 and hence molecular weights were between 1670 and 17348 g. $\mathrm{mol}^{-1}$. The polycondensation reactions were performed at $190{ }^{\circ} \mathrm{C}$ and low pressure and afforded yellow transparent solid materials. A high molecular weight segmented poly(ether amide) $5\left(59 \times 10^{3}\right.$ g. $\left.\mathrm{mol}^{-1}\right)$ was included in this study ${ }^{21}$.

${ }^{1} \mathrm{H}$ NMR spectra of low molecular weight copolymers with polytetrahydrofuran end groups (3a), $\mathrm{OXA}_{2} 6$ end groups (4a) and the high molecular weight analogue $\mathbf{5}$ are shown in Figure 5.1.

The presence of the characteristic signal of the methylene protons adjacent to the amine end group at $\delta=2.8\left(\mathrm{CH}_{2} \mathrm{NH}_{2}(b)\right)$ in polymers $\mathbf{3 a - e}$ and absence of the signal of ethyl ester end groups revealed high conversion in the polycondensation reactions. Similarly, polymers 4a-e showed the presence of the ester methylene protons at $\delta=$ $4.2\left(\mathrm{CH}_{3} \mathrm{CH}_{2} \mathrm{O}(p)\right)$ and the absence of the $\mathrm{CH}_{2}-\mathrm{NH}_{2}$ methylene protons in the ${ }^{1} \mathrm{H}$ NMR spectra. Molecular weights were calculated from the integral values of the end group signal and the central propyl methylene protons at $\delta=1.8\left(\mathrm{OCH}_{2} \mathrm{CH}_{2} \mathrm{CH}_{2} \mathrm{NH}\right.$ $(h))$. 


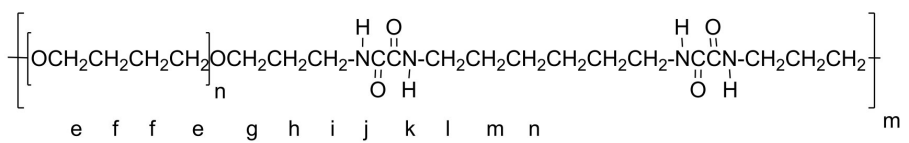

High MW PEA (5)

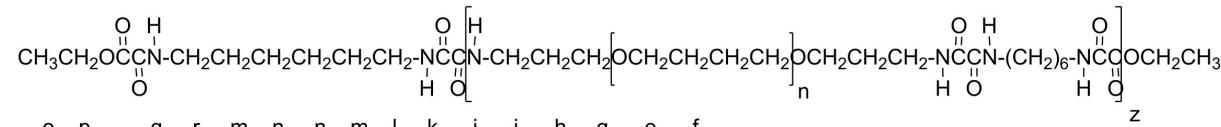

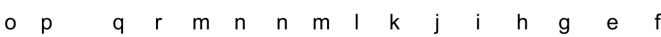

(4a-e)

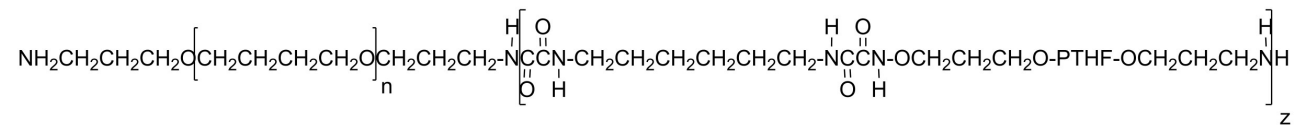

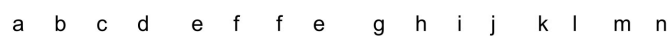

(3a-e)

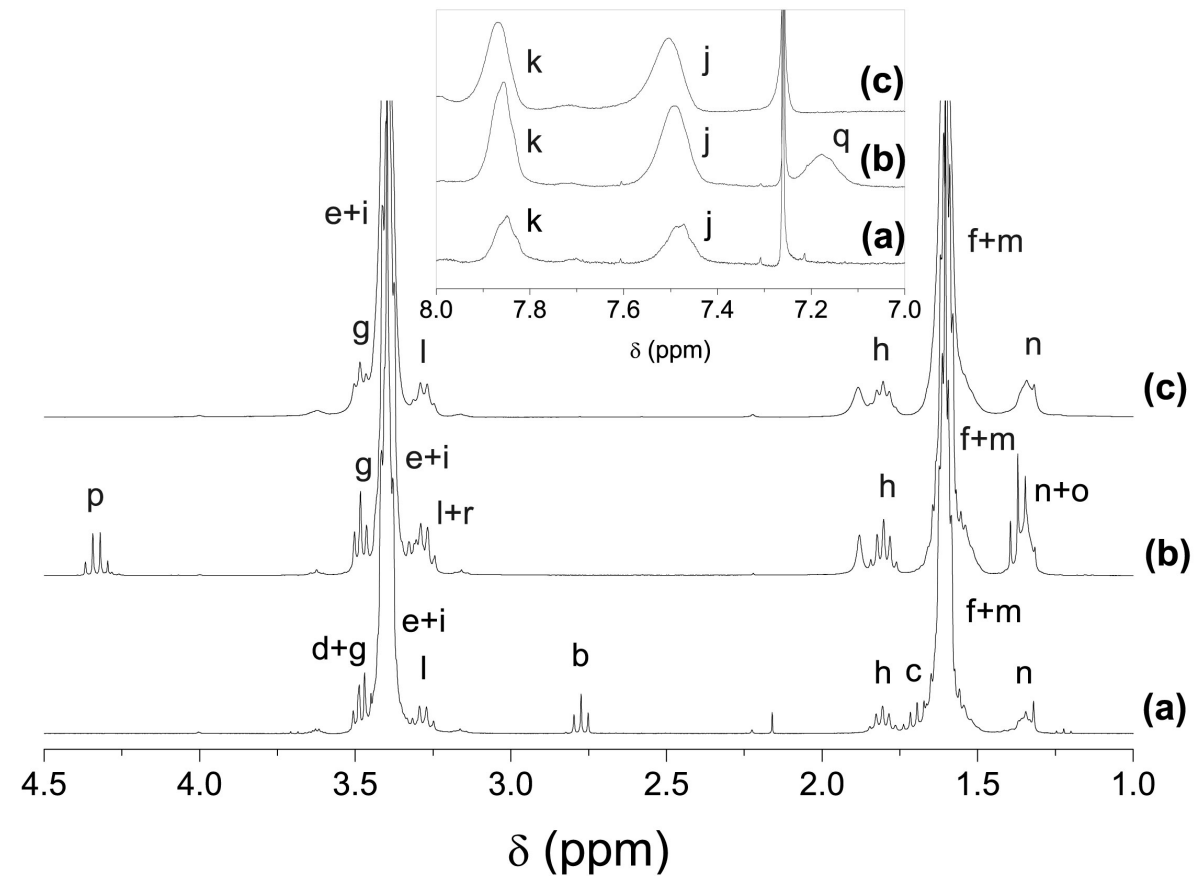

Figure 5.1: ${ }^{1} \mathrm{H}$ NMR spectra of (a) 3a (b) 4a and (c) High MW PEA 5. 
The molecular weights of the as-polymerized materials $\mathbf{3 a - e}$ as determined with ${ }^{1} \mathrm{H}$ NMR were close to the calculated molecular weights. The molecular weights of the purified materials as determined by ${ }^{1} \mathrm{H}$ NMR were higher likely due to loss of lower molecular weight polymers during precipitation (Table 5.1).

Also the molecular weights of the segmented poly(ether amide)s with oxalamide type end groups 4 a-e were higher than intended. The molecular weights of the aspolymerized and precipitated materials are comparable indicating that loss of lower molecular weight species during precipitation is not the reason for the deviations observed. A higher molecular weight than intended indicates that part of the monomer in excess did not react during polymerization. On the basis of ${ }^{1} \mathrm{H}$ NMR data, the amount of non-reacted $\mathrm{OXA}_{2} 6$ calculated was 10, 19, 8 and 6 wt\% for polymers $4 \mathbf{a}$, 4b, 4c and 4d, respectively. Most probably some of the $\mathrm{OXA}_{2} 6$ (2) monomer was distilled off during the polycondensation at reduced pressure.

Table 5.1: Molecular weights of segmented poly(ether amide)s 3a-e, 4a-e and $\mathbf{5}$.

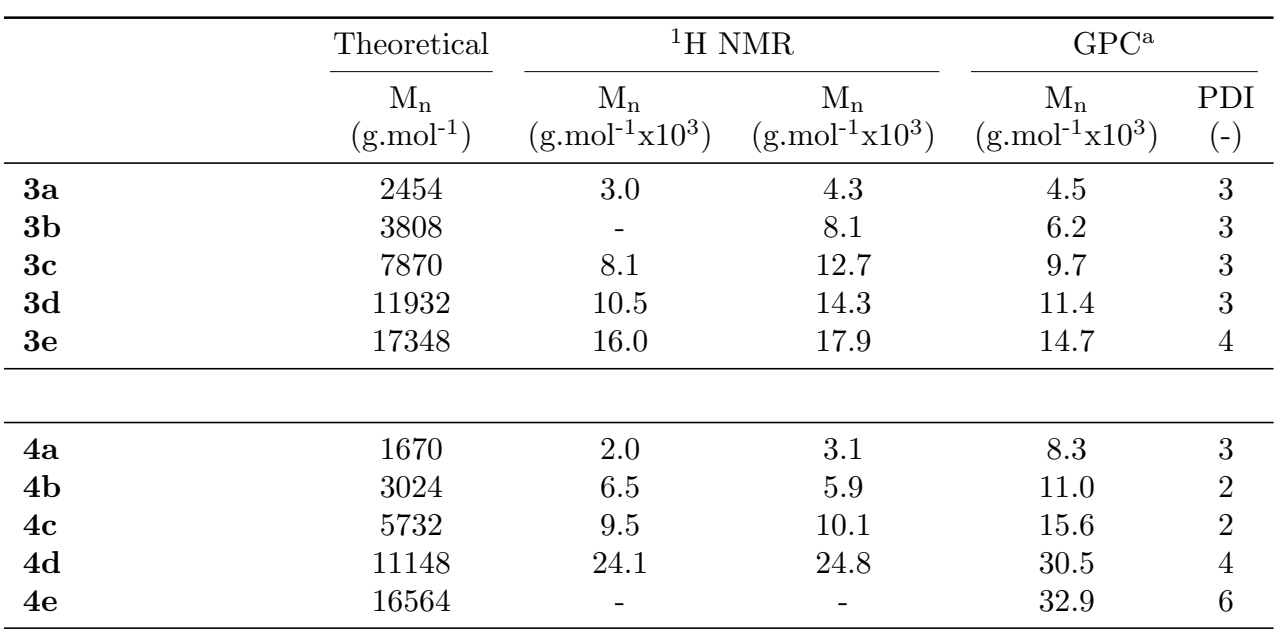

\begin{tabular}{llllll}
\hline High MW PEA (5) & - & - & - & 59.1 & 7 \\
\hline
\end{tabular}

${ }^{a}$ Values relative to polystyrene standards 


\subsubsection{Thermal analysis}

In previous research, it was shown that the high molecular weight segmented poly(ether amide) $\mathbf{5}$ has broad crystallization and melting transitions. These transitions, resulting from the crystallization of the bisoxalamide segments, consist of multiple peaks suggesting that different crystal structures and/or crystal thicknesses are present ${ }^{21}$.

The polymers 3a-e having polytetrahydrofuran end groups also show broad crystallization and melting transitions (Figure 5.2). The transitions at lower temperatures in the heating and cooling curves are close to the melting and crystallization temperatures of bis(3-aminopropyl) polytetrahydrofuran (1) $\left(\mathrm{M}_{\mathrm{n}}=1.1 \times 10^{3} \mathrm{~g} \cdot \mathrm{mol}^{-1}\right)\left(25\right.$ and $5{ }^{\circ} \mathrm{C}$, respectively). By increasing the molecular weight and thus decreasing the amount of polytetrahydrofuran end groups, these melting and crystallization temperatures decrease from 15 to $-18{ }^{\circ} \mathrm{C}$ and 1 to $-31^{\circ} \mathrm{C}$, respectively. Moreover, the corresponding melting and crystallization enthalpies also decrease (Figure 5.2). However, when the polytetrahydrofuran chain is part of a high MW PEA like $\mathbf{5}$ crystallization is fully suppressed. Likely, a high chain mobility of polytetrahydrofuran blocks appears necessary to allow their crystallization.

(a)

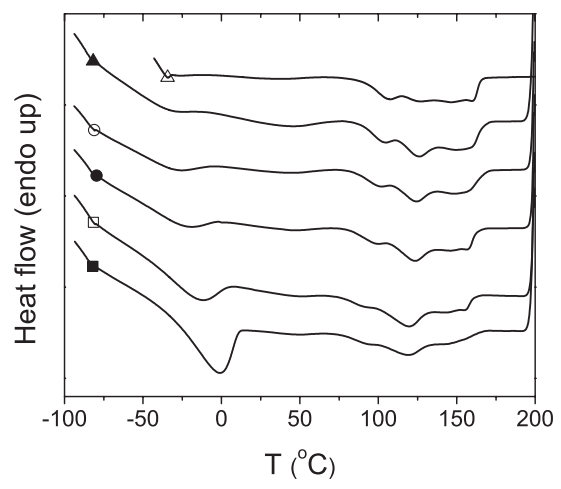

(b)

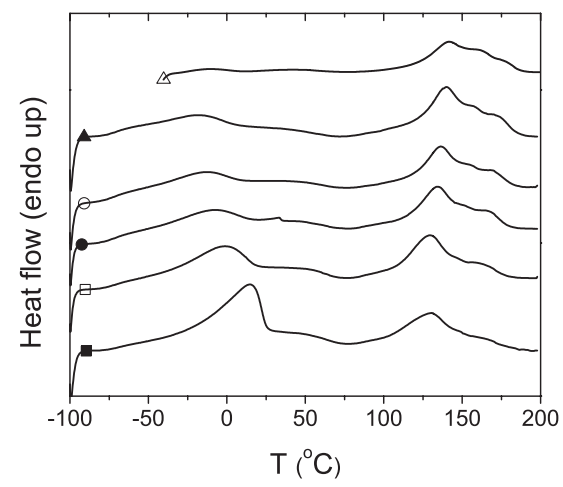

Figure 5.2: DSC cooling (a) and second heating (b) scans of segmented poly(ether amide)s with polytetrahydrofuran end groups ( $)$ (3a), ( $\square)(\mathbf{3 b}),(\bullet)(3 \mathbf{c}),(\bigcirc)$ (3d), ( $)$ (3e) and $(\triangle)$ High MW PEA (5). 
Similar to the high MW PEA 5, the melting and crystallization transitions of the hard segment crystalline phase in polymers 3a-e are broad and appear almost independent on the molecular weight and the bisoxalamide hard segment content (Table 5.2). The main crystallization and melting peak shift slightly from 119 to $126{ }^{\circ} \mathrm{C}$ and from 131 to $140{ }^{\circ} \mathrm{C}$, respectively, with increasing molecular weight (Figure 5.2). Moreover, the melting and crystallization enthalpies increase with increasing molecular weight due to the increasing bisoxalamide hard segment content.

Contrary to polymers 3a-e the segmented poly(ether amide)s with $\mathrm{OXA}_{2} 6$ end groups 4a-e only show melting and crystallization transitions of the hard segments (Figure 5.3). The copolymers contain two types of hard segments; the bisoxalamide segments in the chain and the end groups containing one oxalamide unit and one amide-ester unit. These end groups may co-crystallize because of their conformational resemblance to the bisoxalamide moieties and hydrogen bonding capabilities. The thermal transitions of the polymers resemble the transitions observed for the high MW PEA 5 which suggests that the different types of hard segments co-crystallize. Because the melting and crystallization enthalpies decrease with increasing number of $\mathrm{OXA}_{2} 6$ end groups in the copolymer, the $\mathrm{OXA}_{2} 6$ end groups may well disturb the organization of the hard crystalline phase.

(a)

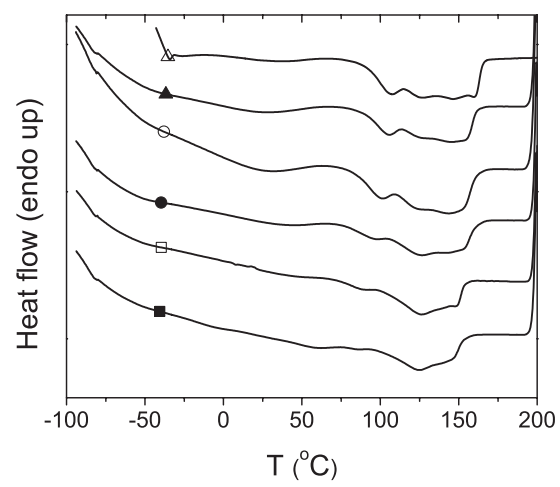

(b)

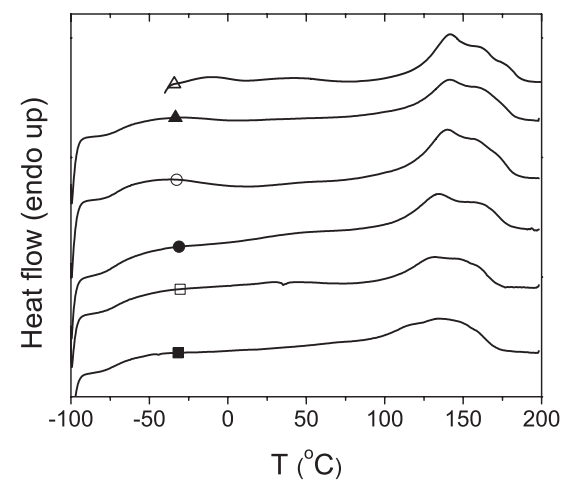

Figure 5.3: DSC cooling (a) and second heating (b) scans of segmented poly(ether amide)s with $\mathrm{OXA}_{2} 6$ end groups ( $)$ (4a), ( $\left.\square\right)(4 \mathrm{~b}),(\bullet)(4 \mathrm{c}),(\mathrm{O})(\mathbf{4 d}),(\mathbf{\Delta})$ (4e) and $(\triangle)$ High MW PEA (5). 
Table 5.2: Thermal properties of segmented poly(ether amide)s $\mathbf{3 a - e , ~ 4 a - e ~ a n d ~} \mathbf{5}$.

\begin{tabular}{|c|c|c|c|c|c|c|c|c|}
\hline & \multicolumn{4}{|c|}{ Soft segment } & \multicolumn{4}{|c|}{ Hard segment } \\
\hline & $\begin{array}{l}\mathrm{T}_{\mathrm{m}} \\
\left({ }^{\circ} \mathrm{C}\right)\end{array}$ & $\begin{array}{c}\Delta \mathrm{H}_{\mathrm{m}} \\
\left(\mathrm{J}_{\mathrm{g}} \mathrm{g}^{-1}\right)\end{array}$ & $\begin{array}{c}\mathrm{T}_{\mathrm{c}} \\
\left({ }^{\circ} \mathrm{C}\right)\end{array}$ & $\begin{array}{c}\Delta \mathrm{H}_{\mathrm{c}} \\
\left(\mathrm{J} \cdot \mathrm{g}^{-1}\right)\end{array}$ & $\begin{array}{l}\mathrm{T}_{\mathrm{m}}{ }^{\mathrm{a}} \\
\left({ }^{\circ} \mathrm{C}\right)\end{array}$ & $\begin{array}{c}\Delta \mathrm{H}_{\mathrm{m}} \\
\left(\mathrm{J} \cdot \mathrm{g}^{-1}\right)\end{array}$ & $\begin{array}{l}\mathrm{T}_{\mathrm{c}}^{\mathrm{a}} \\
\left({ }^{\circ} \mathrm{C}\right)\end{array}$ & $\begin{array}{c}\Delta \mathrm{H}_{\mathrm{c}} \\
\left(\mathrm{J}^{-\mathrm{g}^{-1}}\right)\end{array}$ \\
\hline $3 \mathbf{a}$ & 15 & 29 & -1 & 25 & $92-192$ & 20 & $71-166$ & 20 \\
\hline $3 b$ & -2 & 16 & -14 & 16 & $86-181$ & 30 & $72-168$ & 27 \\
\hline $3 c$ & -8 & 10 & -24 & 8 & $86-182$ & 34 & $79-169$ & 33 \\
\hline $3 d$ & -12 & 6 & -27 & 5 & $88-188$ & 36 & 79-169 & 35 \\
\hline $3 e$ & -18 & 7 & -31 & 3 & $92-192$ & 35 & $81-169$ & 35 \\
\hline $4 a$ & - & - & - & - & $80-172$ & 25 & $75-160$ & 18 \\
\hline $4 b$ & - & - & - & - & $83-175$ & 29 & $68-160$ & 29 \\
\hline $4 c$ & - & - & - & - & $85-180$ & 29 & $71-168$ & 26 \\
\hline $4 d$ & - & - & - & - & $82-185$ & 31 & $79-168$ & 29 \\
\hline $4 e$ & - & - & - & - & $91-186$ & 36 & $78-169$ & 32 \\
\hline High MW PEA (5) & - & - & - & - & 99-191 & 36 & $77-170$ & 35 \\
\hline
\end{tabular}

\subsubsection{Dynamic mechanical properties}

The storage and loss modulus of the copolymers were determined as a function of temperature by dynamical mechanical analysis (DMA) (Figures 5.4 and 5.5). The low molecular weight polymer $\mathbf{3 a}$ was too brittle to obtain a sample for measurement.

All the segmented poly(ether amide)s with polytetrahydrofuran end groups (3b-e) have a glass transition temperature of $-65^{\circ} \mathrm{C}$, close to the glass transition temperature of the polytetrahydrofuran macro-monomer of $-86{ }^{\circ} \mathrm{C}^{23}$. This indicates that these polymers have a highly phase separated morphology. Prior to the start of the rubber plateau, a small shoulder in the graph of the storage modulus of $\mathbf{3} \mathbf{b}$ is observed due to melting of a crystalline phase formed by polytetrahydrofuran end groups. With decreasing molar ratio of end groups with respect to the polymer main chain this effect becomes less pronounced. The rubber plateaus are broad and almost temperature independent which is typical for segmented polymers with uniform hard segments. By increasing the molecular weight, the rubber modulus increases from 51 to $71 \mathrm{MPa}$ due to the increasing bisoxalamide hard segment content. 
Interestingly, polymers 3c-e have a higher rubber modulus than the high MW PEA 5 despite their somewhat lower hard segment content (Table 5.3). This may result from a higher aspect ratio of the bisoxalamide crystals thereby increasing the reinforcing effect on the soft polymer matrix. The flow temperatures increase from 152 to $160{ }^{\circ} \mathrm{C}$ with increasing hard segment content, a trend also observed in the DSC measurements.

Similar to the polymer series described above, the segmented poly(ether amide)s with $\mathrm{OXA}_{2} 6$ end groups (4a-e) have low glass transition temperatures and broad rubber plateaus. These rubber plateaus appear temperature dependent and this effect is more prominent at lower molecular weights. The flow temperature of the polymers decreases with molecular weight and like polymers 3a-e are always between 140 and $160{ }^{\circ} \mathrm{C}$. The results suggest that partial phase mixing occurs for low molecular weight polymer and/or the amide-ester end groups hamper the crystallization of the hard segments.

Table 5.3: Dynamic mechanical properties of segmented poly(ether amide)s 3a-e, 4a-e and 5.

\begin{tabular}{|c|c|c|c|c|c|}
\hline & \multicolumn{2}{|c|}{ Hard segment } & \multirow[b]{2}{*}{$\begin{array}{l}\mathrm{T}_{\mathrm{g}} \\
\left({ }^{\circ} \mathrm{C}\right)\end{array}$} & \multirow[b]{2}{*}{$\begin{array}{l}\mathrm{G}^{\prime}{ }_{25^{\circ} \mathrm{C}} \\
(\mathrm{MPa})\end{array}$} & \multirow[b]{2}{*}{$\begin{array}{l}\mathrm{T}_{\text {flow }} \\
\left({ }^{\circ} \mathrm{C}\right)\end{array}$} \\
\hline & $\begin{array}{l}\text { In chain }{ }^{\mathrm{a}} \\
(\mathrm{wt} \%)\end{array}$ & $\begin{array}{l}\text { End group }{ }^{\mathrm{b}} \\
\quad(\mathrm{wt} \%)\end{array}$ & & & \\
\hline $3 \mathbf{a}$ & 13.8 & - & - & - & - \\
\hline $3 b$ & 16.0 & - & -65 & 51 & 152 \\
\hline $3 c$ & 17.1 & - & -65 & 64 & 158 \\
\hline $3 d$ & 17.4 & - & -65 & 65 & 160 \\
\hline $3 e$ & 17.7 & - & -65 & 71 & 160 \\
\hline $4 a$ & 8.7 & 18.5 & -65 & 85 & 142 \\
\hline $4 b$ & 13.6 & 9.7 & -65 & 78 & 147 \\
\hline $4 c$ & 15.8 & 5.7 & -70 & 80 & 152 \\
\hline $4 d$ & 17.6 & 2.3 & -65 & 63 & 157 \\
\hline $4 e$ & 18.1 & 1.5 & -65 & 57 & 160 \\
\hline High MW PEA (5) & 18.9 & - & -65 & 53 & 160 \\
\hline
\end{tabular}

${ }^{\mathrm{a}}$ Weight percentages of bisoxalamide segments in the polymer chain. Values are calculated using molecular weights determined by ${ }^{1} \mathrm{H}$ NMR.

${ }^{\mathrm{b}}$ Weight percentages of $\mathrm{OXA}_{2} 6$ end groups.

Values are calculated using molecular weights determined by ${ }^{1} \mathrm{H}$ NMR. 


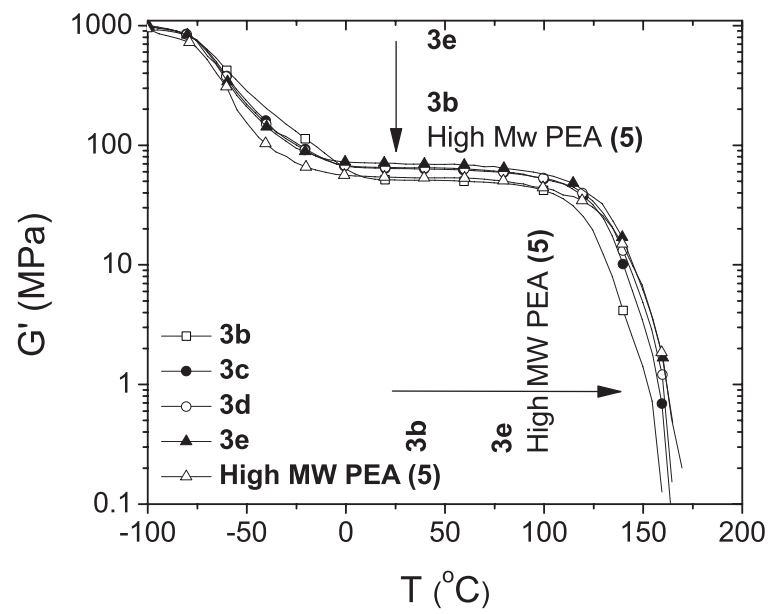

Figure 5.4: Storage modulus as a function of temperature for segmented poly(ether amide)s with polytetrahydrofuran end groups $\mathbf{3 b}$-e.

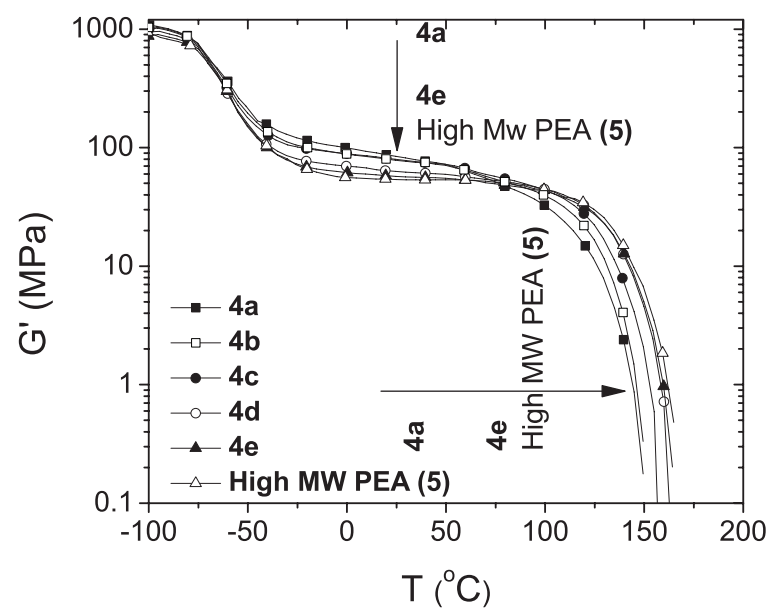

Figure 5.5: Storage modulus as a function of temperature for segmented poly(ether amide)s with $\mathrm{OXA}_{2} 6$ endgroups 4 a-e. 


\subsubsection{Mechanical properties}

Generally, when the molecular weight of polymers is lowered the mechanical properties decline and the polymers eventually become brittle due to a loss of chain entanglements. The change in mechanical properties by changing the molecular weight of the segmented poly(ether amide)s was determined by tensile testing (Figures 5.6 and 5.7). No tensile experiments were performed on polymer $\mathbf{3 a}$ since this material was too brittle to obtain suitable samples for tensile testing.

The E-moduli of $\mathbf{3 b - e}$ and $\mathbf{4 a - e}$ ranged from 153 to $226 \mathrm{MPa}$ and followed a similar trend as the rubber modulus $\left(G^{\prime}\right)$ measured by DMA. The $\mathrm{E} / \mathrm{G}^{\prime}$ ratio was approximately 3 suggesting an ideal rubber-like behavior at low strains. Polymers $\mathbf{3 b} \mathbf{b} \mathbf{d}$ and $\mathbf{4 a}-\mathbf{b}$ fracture before the yield point and thus have a brittle nature. The polymers $\mathbf{3 e}$ and 4c-e showed a pronounced yield point which is indicative for long-range hard segment connectivity and a well percolated hard phase throughout the soft polymer matrix. The polymers 4d-e and the high MW PEA $\mathbf{5}$ gave yield points followed by necking and subsequent strain hardening while polymers $\mathbf{3 e}$ and $\mathbf{4 c}$ fractured directly after yielding. These tensile measurements indicate that the transition from brittle to ductile of these segmented poly(ether amide)s is found at a $\mathrm{M}_{\mathrm{n}}\left({ }^{1} \mathrm{H} \mathrm{NMR}\right)$ of $\sim 15 \times 10^{3}$ g. $\mathrm{mol}^{-1}$.

(a)

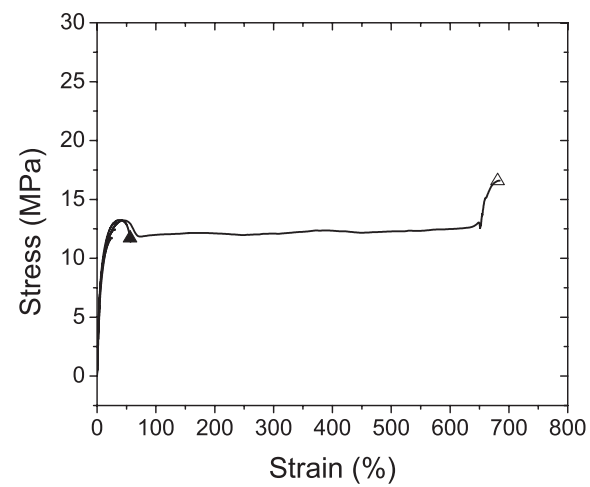

(b)

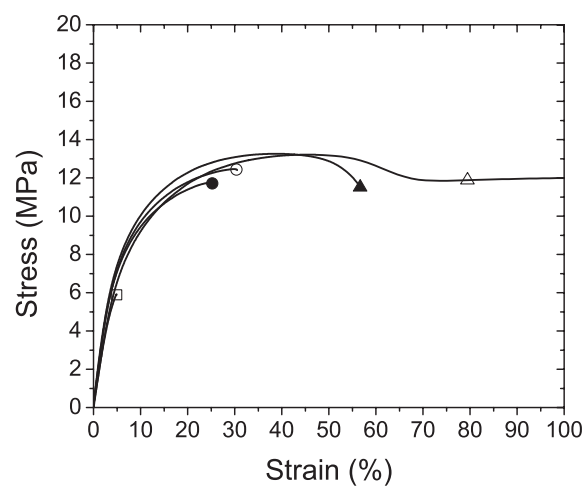

Figure 5.6: Stress-strain curves for segmented poly(ether amide)s with polytetrahydrofuran end groups $(\square)(\mathbf{3 b}),(\bullet)(\mathbf{3 c}),(\bigcirc)(\mathbf{3 d}),(\boldsymbol{\Delta})(\mathbf{3 e})$ and $(\triangle)$ High MW PEA (5). 
(a)

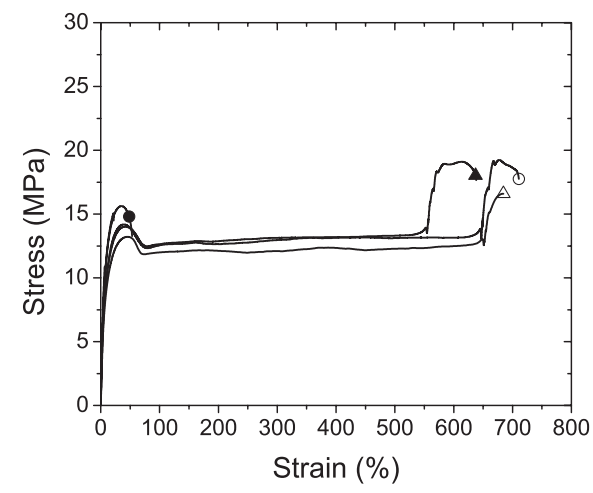

(b)

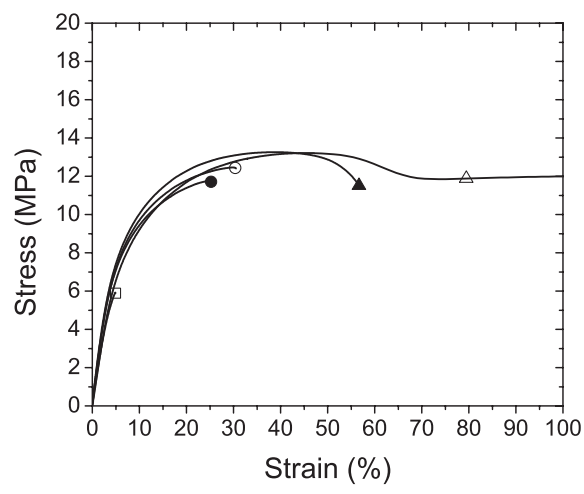

Figure 5.7: Stress-strain curves for segmented poly(ether amide)s with $\mathrm{OXA}_{2} 6$ end groups $(\square)$ (4a), ( $\square)$ (4b), (•) (4c), (O) (4d), ( $)$ ) (4e) and $(\triangle)$ High MW PEA (5).

Table 5.4: Mechanical properties of segmented poly(ether amide)s $\mathbf{3 a - e , ~} \mathbf{4 a - e}$ and $\mathbf{5}$.

\begin{tabular}{|c|c|c|c|c|c|c|c|c|c|}
\hline & \multirow[b]{2}{*}{$\begin{array}{c}\mathrm{M}_{\mathrm{n}}^{\mathrm{a}} \\
\text { (g.mol }{ }^{-1} \mathrm{x} 10^{3} \text { ) }\end{array}$} & \multicolumn{2}{|c|}{ Hard segment } & \multirow[b]{2}{*}{$\begin{array}{c}\mathrm{E} \\
(\mathrm{MPa})\end{array}$} & \multirow[b]{2}{*}{$\begin{array}{c}\sigma_{\text {yield }} \\
(\mathrm{MPa})\end{array}$} & \multirow[b]{2}{*}{$\begin{array}{c}\epsilon_{\text {yield }} \\
(\%)\end{array}$} & \multirow[b]{2}{*}{$\begin{array}{c}\sigma_{\text {fracture }} \\
(\mathrm{MPa})\end{array}$} & \multirow[b]{2}{*}{$\begin{array}{c}\epsilon_{\text {fracture }} \\
(\%)\end{array}$} & \multirow[b]{2}{*}{$\begin{array}{c}\mathrm{E} / \mathrm{G}^{\prime} \\
(-)\end{array}$} \\
\hline & & $\begin{array}{l}\text { In chain }{ }^{\mathrm{b}} \\
(\mathrm{wt} \%)\end{array}$ & $\begin{array}{c}\text { End group } \\
\quad(w t \%)\end{array}$ & & & & & & \\
\hline $3 \mathbf{a}$ & 4.3 & 13.8 & - & - & - & - & - & - & - \\
\hline $3 b$ & 8.1 & 16.0 & - & $153 \pm 4$ & - & - & 5.9 & 5 & 3.0 \\
\hline $3 c$ & 12.7 & 17.1 & - & $186 \pm 5$ & - & - & 11.7 & 25 & 2.9 \\
\hline $3 d$ & 14.3 & 17.4 & - & $191 \pm 5$ & - & - & 12.5 & 30 & 2.9 \\
\hline $3 e$ & 17.9 & 17.7 & - & $195 \pm 9$ & $13.5 \pm 0.5$ & $39 \pm 1$ & 12.1 & 59 & 2.7 \\
\hline $4 a$ & 3.1 & 8.7 & 18.5 & $226 \pm 8$ & - & - & 10.9 & 7 & 2.7 \\
\hline $4 b$ & 5.9 & 13.6 & 9.7 & $226 \pm 6$ & - & - & 14.5 & 22 & 2.9 \\
\hline $4 c$ & 10.1 & 15.8 & 5.7 & $215 \pm 7$ & $16.6 \pm 0.2$ & $35 \pm 2$ & 13.3 & 53 & 2.7 \\
\hline $4 d$ & 24.8 & 17.6 & 2.3 & $183 \pm 18$ & $14.3 \pm 0.2$ & $42 \pm 1$ & 19.2 & 667 & 2.9 \\
\hline $4 e$ & - & 18.1 & 1.5 & $179 \pm 12$ & $14.2 \pm 0.2$ & $44 \pm 2$ & 19.7 & 632 & 3.1 \\
\hline 5 & - & 18.9 & - & $157 \pm 13$ & $13.0 \pm 0.1$ & $44 \pm 2$ & 16.3 & 703 & 3.0 \\
\hline
\end{tabular}

${ }^{\mathrm{a}}$ Determined by ${ }^{1} \mathrm{H}$ NMR.

${ }^{\mathrm{b}}$ Weight percentages of bisoxalamide segments in the polymer chain.

Values are calculated using molecular weights determined by ${ }^{1} \mathrm{H}$ NMR.

${ }^{\mathrm{c}}$ Weight percentages of $\mathrm{OXA}_{2} 6$ end groups.

Values are calculated using molecular weights determined by ${ }^{1} \mathrm{H}$ NMR. 


\subsection{Conclusions}

Bisoxalamide based segmented poly(ether amide)s with different molecular weights and either polytetrahydrofuran or $\mathrm{OXA}_{2} 6$ end groups are all highly phase separated materials which display extended temperature independent rubber plateaus. The rubber moduli range from 57 to $85 \mathrm{MPa}$ and the flow temperatures from 140 to $160{ }^{\circ} \mathrm{C}$ depending on the bisoxalamide content and the type of end groups present. The polymers with polytetrahydrofuran end groups have two melting transitions, corresponding to melting of crystallized polytetrahydrofuran end groups as well as melting of the crystallized bisoxalamide phase. At higher molecular weights the melting temperature of the polytetrahydrofuran end group crystals decreases from 15 to -18 ${ }^{\circ} \mathrm{C}$ whereas the broad melting traject of the crystalline phase of the bisoxalamide hard segments between 90 and $190{ }^{\circ} \mathrm{C}$ does not change. Polymers having $\mathrm{OXA}_{2} 6$ end groups display only one broad melting transition ranging from $80-190{ }^{\circ} \mathrm{C}$. Increasing the molecular weight reveals a brittle to ductile transition at a molecular weight of $\sim 15 \times 10^{3}$ g. $\mathrm{mol}^{-1}$.

\subsection{References}

[1] Fakirov, S. Handbook of condensation thermoplastic elastomers; Wiley-VCH: Weinheim, 2005.

[2] Holden, G.; Legge, N. R.; Quirk, R. P.; Schroeder, H. E. Thermoplastic elastomers, 2nd ed.; Hanser Publishers: Munich, 1996.

[3] Cella, R. J. J Polym Sci: Symp No 47 1973, 42, 727-740.

[4] Biemond, G. J. E.; Feijen, J.; Gaymans, R. J. Polym Eng Sci 2008, 48, 1389-1400.

[5] Harrell, L. L. Macromolecules 1969, 2, 607-612.

[6] Miller, J. A.; Lin, S. B.; Hwang, K. K. S.; Wu, K. S.; Gibson, P. E.; Cooper, S. L. Macromolecules 1985, 18, 32-44.

[7] Ng, H. N.; Allegrez, A. E.; Seymour, R. W.; Cooper, S. L. Polymer 1973, 14, $255-261$.

[8] Niesten, M. C. E. J.; Feijen, J.; Gaymans, R. J. Polymer 2000, 41, 8487-8500.

[9] van der Schuur, M.; Feijen, J.; Gaymans, R. J. Polymer 2005, 46, 4584-4595.

[10] Versteegen, R. M.; Sijbesma, R. P.; Meijer, E. W. Macromolecules 2005, 38, 3176-3184. 
[11] Versteegen, R. M.; Kleppinger, R.; Sijbesma, R. P.; Meijer, E. W. Macromolecules 2006, 39, 772-783.

[12] Sheth, J. P.; Xu, J. N.; Wilkes, G. L. Polymer 2003, 44, 743-756.

[13] Krijgsman, J.; Husken, D.; Gaymans, R. J. Polymer 2003, 44, 7573-7588.

[14] van Krevelen, D. W.; te Nijenhuis, K. Properties of polymers, 4th ed.; Elsevier: Amsterdam, 2009.

[15] Arun, A.; Dullaert, K.; Gaymans, R. J. Macromol Chem Phys 2009, 210, 48-59.

[16] Arun, A.; Dullaert, K.; Gaymans, R. J. Polym Eng Sci 2010, 50, 756-761.

[17] Arun, A.; Gaymans, R. J. Macromol Chem Phys 2008, 209, 854-863.

[18] Arun, A.; Gaymans, R. J. Polymer 2008, 49, 2461-2470.

[19] Arun, A.; Gaymans, R. J. J Appl Polym Sci 2009, 112, 2663-2668.

[20] Arun, A.; Gaymans, R. J. J Appl Polym Sci 2009, 111, 1780-1785.

[21] Sijbrandi, N. J.; Kimenai, A. J.; Mes, E. P. C.; Broos, R.; Dijkstra, P. J.; Feijen, J. Chapter 3, this thesis; University of Twente, 2011.

[22] Sijbrandi, N. J.; Kimenai, A. J.; Mes, E. P. C.; Broos, R.; Bar, G.; Rosenthal, M.; Odarchenko, Y.; Ivanov, D. A.; Dijkstra, P. J.; Feijen, J. Chapter 4, this thesis; University of Twente, 2011.

[23] Flory, P. J. Trans Faraday Soc 1955, 51, 848-857. 


\title{
Chapter 6
}

\section{Conformation and crystal structure of bisester-bisoxalamides}

\author{
N.J. Sijbrandi ${ }^{a}$, A.J. Kimenai ${ }^{b}$, E.P.C. Mes ${ }^{b}$, R. Broos ${ }^{b}$, G. Bar ${ }^{c}$, M. Rosenthal ${ }^{d}, Y$. \\ Odarchenko $^{d}$, D.A. Ivanov ${ }^{d}$, P.J. Dijkstra ${ }^{a}$, J. Feijen $^{a}$

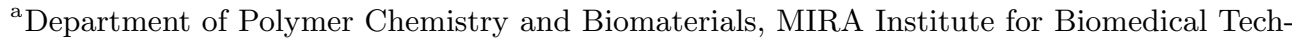 \\ nology and Technical Medicine, Faculty of Science and Technology, University of Twente, \\ P.O. Box 217, 7500 AE Enschede, The Netherlands \\ ${ }^{\mathrm{b}}$ Core R\&D, DOW Benelux BV, P.O. Box 48, 4530 AA, Terneuzen, The Netherlands \\ ${ }^{\mathrm{c}}$ Dow olefin verbund GmbH, P.O. Box 1163, D-06258, Schkopau, Germany \\ ${ }^{\mathrm{d}}$ Institut de Sciences des Matriaux de Mulhouse-IS2M, CNRS LRC 7228, Jean Starcky, 15, \\ F-68057 Mulhouse, France
}

\begin{abstract}
Bisoxalamides are structural units in hard segments that can act as physical crosslinks in segmented thermoplastic elastomers through hydrogen bonding. Depending on the groups present in the bisoxalamide based structural units, polymers based on these units show large differences in their thermal behavior. Bisoxalamide units end functionalized with glycine or $\beta$-alanine ester groups show distinct thermal transitions. To relate the changes in thermal transitions of hard segments in TPEs to the structure of the bisoxalamide units used, model compounds were prepared and studied by FT-IR and X-ray diffraction measurements. The model compounds form hydrogen bonded sheets in which the hydrogen bonds are solely formed between the oxalamide groups. Moreover, the ester side groups are spatially tilted away from the oxalamide plane. The hydrogen bonding distance and inter-sheet distance are both $\sim 5 \AA$ for all model compounds. The increased melting temperature of the $\beta$-alanine based model compound as compared to the glycine derivatives may be related to an enhanced packing of the $\beta$-alanine ester groups as compared to the glycine ester groups.
\end{abstract}




\subsection{Introduction}

Oxalamide groups are self-complementary, capable of unidirectional hydrogen bonding and units containing these groups can thereby assemble in robust one-dimensional hydrogen bonded structures. In this respect oxalamides are interesting structural units for e.g. supramolecular engineering ${ }^{1-3}$ and organogelators ${ }^{4}$. Recently, we demonstrated that uniform oxalamide units in segmented poly(ether amide)s provide thermoplastic elastomers due to strong hydrogen bonding and fast crystallization of the oxalamide rich phase ${ }^{5,6}$. Consequently, the oxalamide containing hard segments are able to efficiently crosslink soft polymer matrices.

The solid state structure of several oxalamide group containing compounds has been determined by X-ray diffraction. The amide groups in N,N'-disubstituted oxalamides assume a rigid planar trans conformation favored by the establishment of intermolecular hydrogen bonds and intramolecular hydrogen bonds of a pseudo- $\mathrm{C}_{5}$ type ${ }^{7-9}$. This conformation is illustrated by the crystal structure of N,N'-dimethyloxalamide (Figure 6.1).

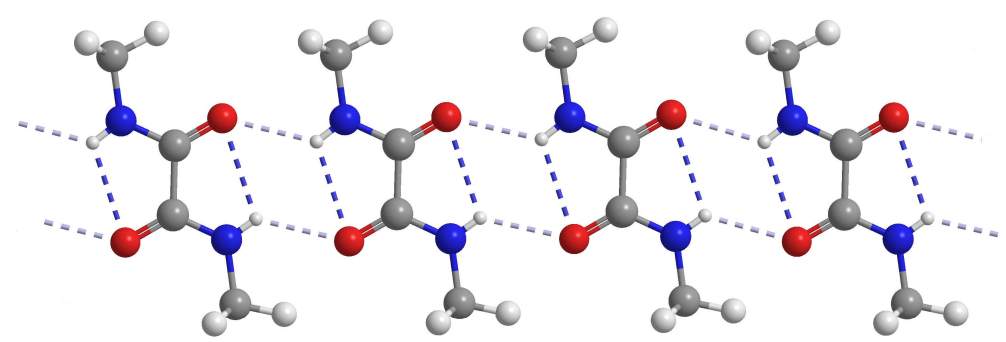

Figure 6.1: Crystal structure of N,N'-dimethyloxalamide ${ }^{9}$.

Replacing the methyl groups with glycine or $\beta$-alanine moieties results in two distinctive modes of crystallization, which are governed by (1) like-to-like amide-amide hydrogen bonds ${ }^{1,10-14}$ or (2) like-to-unlike amide-acid (amide-ester) hydrogen bonds ${ }^{1,15-17}$. This can be illustrated by compounds $\mathbf{C 1 - 5}$, which show distinctive hydrogen bonding patterns in their crystal structure ${ }^{1}$.

Compound $\mathbf{C 1}$ forms a two-dimensional hydrogen bonded structure via like-to-like hydrogen bonding of oxalamide groups in one direction and by dimerization of the carboxylic acid groups in a second direction (Figure 6.3a). Compound C1, however can also crystallize into a structure with like-to-unlike hydrogen bonds between the oxalamide and glycine carboxyl groups (Figure 6.3b). 
Coe et al [1], Shkolnikova et al [13]<smiles>CC(C)(NC(=O)C(=O)NCC(=O)O)C(=O)O</smiles>

C1: $\mathrm{n}=1$

C2: $\mathrm{n}=2$

C3: $\mathrm{n}=3$

C $4: n=4$
C5: $n=5$
Armelin et al [18]

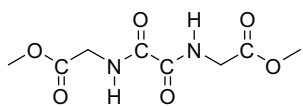

c6
Urpi et al [20]<smiles>CCOC(=O)CNC(=O)CCCCCCC(=O)NCC(=O)OCC</smiles>

C7

Figure 6.2: Oxalamide compounds with neighboring acid or ester groups.

Whereas compounds C2, C4 and C5 crystallize with like-to-like amide-amide hydrogen bonds, compound C3 only crystallizes in the like-to-unlike hydrogen bonded form. The crystal structure of $\mathbf{C 6}$, the methyl ester of $\mathbf{C 1}$, is characterized by the presence of like-to-unlike amide-ester hydrogen bonds Figure $6.4^{18}$. No crystal data are available for the ester derivatives of compounds C2-5.

The torsional angles of the glycine residue in compound $\mathbf{C 6}$ are $\varphi(\mathrm{C} 2-\mathrm{C} 3-\mathrm{N} 1-\mathrm{C} 4)$ and $\psi$ (O1-C2-C3-N1) $80.54^{\circ}$ and $-160.85^{\circ} 18$, respectively, close to those found in the structure of poly(glycine) II $\left(75^{\circ} \text { and }-145^{\circ} \text {, respectively }\right)^{19}$. The glycine residue is spatially tilted away from the oxalamide plain, which is illustrated in Figure 6.5. A similar tilting of the glycine residue is found in the crystal structure of C1. As a consequence of this molecular conformation, the compound forms pleated two-dimensional hydrogen bonded sheets (Figure 6.3a) ${ }^{1}$.

(a)

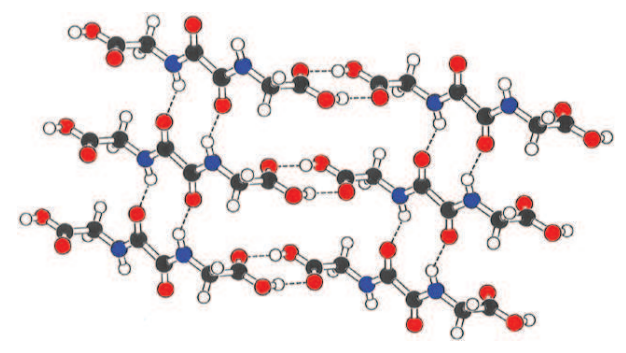

(b)

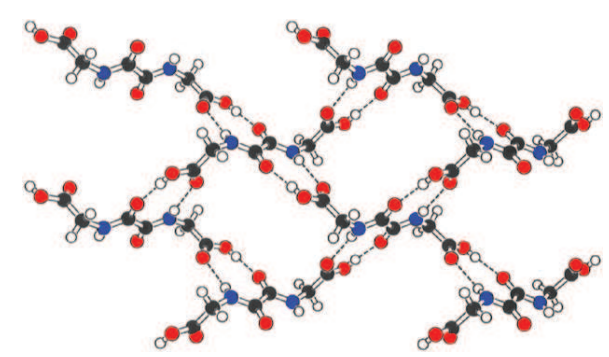

Figure 6.3: Crystal structures with hydrogen bonding patterns of a bisglycine substituted oxalamide $(\mathbf{C 1})^{1}$ (a) like-to-like amide-amide and acid-acid hydrogen bonds, (b) like-to-unlike amide-acid hydrogen bonds. 


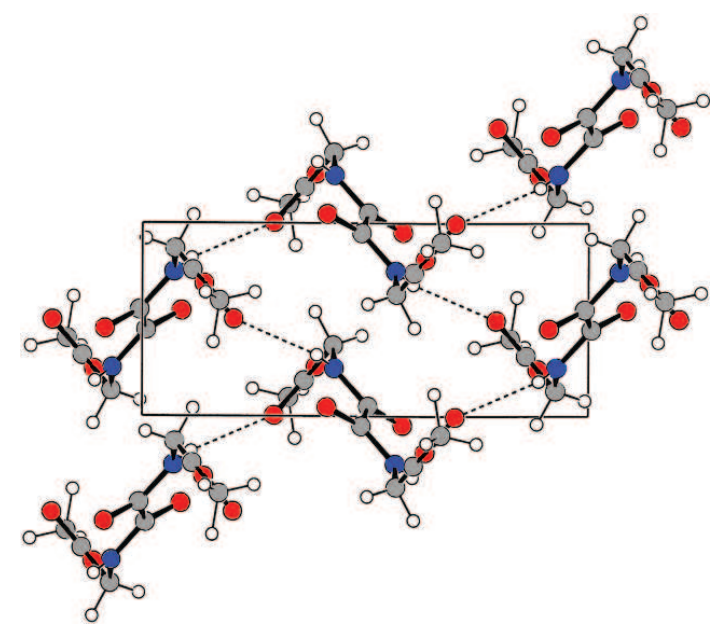

Figure 6.4: Crystal structure and hydrogen bonding pattern of a bisglycine methyl ester substituted oxalamide $(\mathbf{C 6})^{18}$.

Similar findings were reported by Urpi et $a l^{20}$ for the structure of the suberamide C7 having terminal glycine ethyl ester groups (Figure 6.2). The glycine residue in this compound adopts a similar conformation as found in C6. Additionally, the hexamethylene bisamide unit is in an all-trans conformation forming like-to-like amide-amide hydrogen bonds and the packing of this moiety shows the characteristic features of the $\alpha$-form of nylons. The $\beta$-alanine residues in compound C2 are also tilted out of the oxalamide plane but the torsional angles are different compared to glycine residues in $\mathbf{C 6}$ (Figure 6.5). The torsional angle between the methylene group and the oxalamide group (C4-N1-C3-C2) is $180^{\circ}$, whereas the torsional angels of $\varphi^{\prime}$ $(\mathrm{C} 1-\mathrm{C} 2-\mathrm{C} 3-\mathrm{N} 1)$ and $\psi^{\prime}(\mathrm{O} 2-\mathrm{C} 1-\mathrm{C} 2-\mathrm{C} 3)$ are $74.8^{\circ}$ and $-3.1^{\circ}$, respectively ${ }^{13}$.

In recent work we studied the properties of segmented poly(ether ester amides) comprising structural units like $\mathbf{C 1}$ and C2 as hard segments and polytetrahydrofuran soft segments. Preliminary results showed fast crystallization of the hard segments which efficiently crosslink the matrix and thereby provide thermoplastic elastomers with interesting mechanical properties. In order to obtain insight in the hard segment crystalline structure, a series of model compounds comprising bisoxalamides substituted with glycine, $\beta$-alanine or 3-methoxypropyl moieties were studied. Structural analysis is based on FT-IR and X-ray diffraction measurements. 
<smiles>COC(=O)CNC(=O)C(=O)NC(C)CC(=O)OC</smiles>

C6

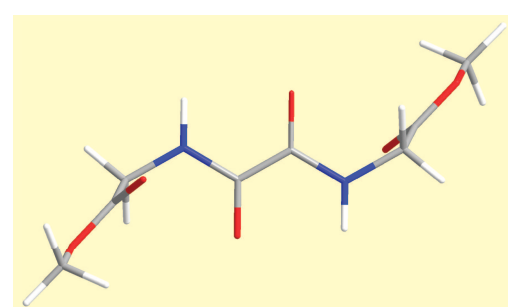

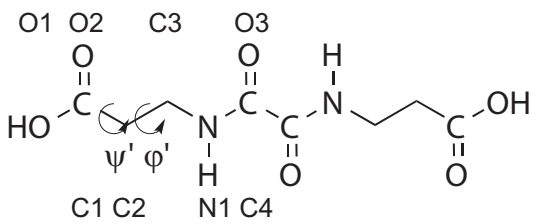

C2

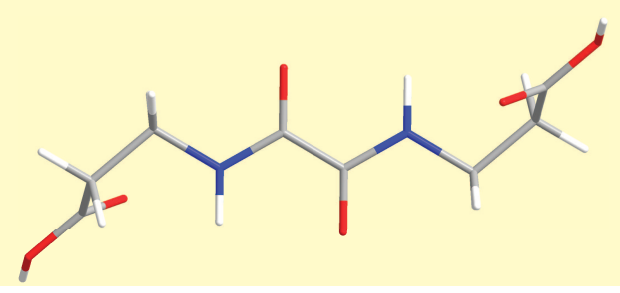

Figure 6.5: Conformation of an oxalamide with terminal glycine methyl ester groups $\mathbf{C 6}^{18}$ or $\beta$-alanine groups $\mathbf{C 2}{ }^{13}$. 


\subsection{Experimental}

\subsubsection{Materials}

MeOProp-OXA 2 6-PropOMe (4) was prepared as reported previously ${ }^{6}$. Diethyl oxalate, 1,2-diaminoethane, 1,4-diaminobutane, 1,6-diaminohexane, glycine ethyl ester hydrochloride, $\beta$-alanine ethyl ester hydrochloride, triethylamine, chloroform- $\mathrm{d}_{1}$ $\left(\mathrm{CDCl}_{3}-\mathrm{d}_{1}\right)$ and trifluoroacetic acid- $\mathrm{d}_{1}\left(\mathrm{TFA}-\mathrm{d}_{1}\right)$ were purchased from Aldrich (Zwijndrecht, The Netherlands). Diethyl ether and tetrahydrofuran were obtained from Biosolve (Valkenswaard, The Netherlands) and chloroform was purchased from Merck (Darmstadt, Germany). All materials were used as received.

\subsubsection{Synthesis}

\section{Bisoxalamide precursors \\ $\left(\mathrm{OXA}_{2} \mathrm{X}\right)(\mathbf{1 a - c})$}

Diethyl oxalate was reacted with $\alpha, \omega$-diamines having two, four or six methylene groups. In a typical example, a solution of 1,6-diaminohexane (20.0 g, $172.4 \mathrm{mmol})$ in $200 \mathrm{ml}$ of tetrahydrofuran was slowly added to diethyl oxalate (252 g, $1.72 \mathrm{~mol})$. Subsequently, the mixture was stirred at room temperature for $16 \mathrm{~h}$. The crude product was isolated by filtration, in which chloroform and excess diethyl oxalate were removed. The product was then dissolved in chloroform and the solution was filtered. Subsequently, the chloroform was removed under reduced pressure and the product was washed two times with diethyl ether and dried under vacuum. The product was obtained as a white powder in a yield of $85 \%$.

$\mathrm{OXA}_{2} 2$ (1a): ${ }^{1} \mathrm{H} \mathrm{NMR}\left(300 \mathrm{MHz}, \mathrm{CDCl}_{3}-\mathrm{d}_{1}\right) \delta=7.69$ (bt, 2H, $\left.\mathrm{NHCH}_{2}\right), 4.37$ (q,

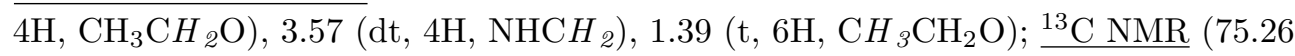
$\left.\mathrm{MHz} \mathrm{CDCl}_{3}-\mathrm{d}_{1}\right) \delta=160.6(\mathrm{OCOCONH}), 157.7(\mathrm{OCOCONH}), 63.4\left(\mathrm{CH}_{3} C_{\mathrm{H}} \mathrm{O}\right)$, $39.5\left(\mathrm{NHCH}_{2}\right), 14.1\left(\mathrm{CH}_{3} \mathrm{CH}_{2} \mathrm{O}\right)$.

$\mathrm{OXA}_{2} 4$ (1b): ${ }^{1} \mathrm{H} \mathrm{NMR}\left(300 \mathrm{MHz}, \mathrm{CDCl}_{3}-\mathrm{d}_{1}\right) \delta=7.36$ (bt, $\left.2 \mathrm{H}, \mathrm{NHCH}_{2} \mathrm{CH}_{2}\right), 4.30$ $\left(\mathrm{q}, 4 \mathrm{H}, \mathrm{CH}_{3} \mathrm{CH}{ }_{2} \mathrm{O}\right), 3.33\left(\mathrm{dt}, 4 \mathrm{H}, \mathrm{NHCH}_{2} \mathrm{CH}_{2}\right), 1.57\left(\mathrm{~m}, 4 \mathrm{H}, \mathrm{NHCH}_{2} \mathrm{CH}_{2}\right), 1.33$

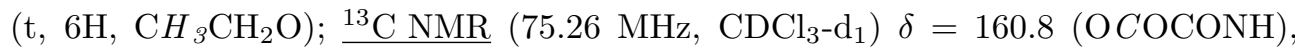
157.0 (OCOCONH), $63.3\left(\mathrm{CH}_{3} \mathrm{CH}_{2} \mathrm{O}\right), 39.5\left(\mathrm{NHCH}_{2} \mathrm{CH}_{2}\right), 26.6\left(\mathrm{NHCH}_{2} C \mathrm{H}_{2}\right), 14.1$ $\left(\mathrm{CH}_{3} \mathrm{CH}_{2} \mathrm{O}\right)$. 
$\mathrm{OXA}_{2} 6$ (1c): ${ }^{1} \mathrm{H}$ NMR $\left(300 \mathrm{MHz}, \mathrm{CDCl}_{3}-\mathrm{d}_{1}\right) \delta=7.25$ (bt, $\left.2 \mathrm{H}, \mathrm{NH} \mathrm{CH}_{2} \mathrm{CH}_{2} \mathrm{CH}_{2}\right)$, $4.33\left(\mathrm{q}, 4 \mathrm{H}, \mathrm{CH}_{3} \mathrm{CH}{ }_{2} \mathrm{O}\right), 3.32$ (dt, $\left.4 \mathrm{H}, \mathrm{NHCH}_{2} \mathrm{CH}_{2} \mathrm{CH}_{2}\right), 1.53\left(\mathrm{~m}, 4 \mathrm{H}, \mathrm{NHCH}_{2} \mathrm{CH}_{2} \mathrm{CH}_{2}\right.$ ), $1.36\left(\mathrm{~m}, 4 \mathrm{H}, \mathrm{NHCH}_{2} \mathrm{CH}_{2} \mathrm{CH}_{2}\right), 1.36\left(\mathrm{t}, 6 \mathrm{H}, \mathrm{CH}_{3} \mathrm{CH}_{2} \mathrm{O}\right) ;{ }^{13} \mathrm{C} \mathrm{NMR}(75.26 \mathrm{MHz}$, $\left.\mathrm{CDCl} 3-\mathrm{d}_{1}\right) \delta=160.9(\mathrm{OCOCONH}), 156.8(\mathrm{OCOCONH}), 62.3\left(\mathrm{CH}_{3} \mathrm{CH}_{2} \mathrm{O}\right), 39.8$ $\left(\mathrm{NHCH}_{2} \mathrm{CH}_{2} \mathrm{CH}_{2}\right), 29.1\left(\mathrm{NHCH}_{2} \mathrm{CH}_{2} \mathrm{CH}_{2}\right), 26.5\left(\mathrm{NHCH}_{2} \mathrm{CH}_{2} \mathrm{CH}_{2}\right), 14.1\left(\mathrm{CH}_{3} \mathrm{CH}_{2} \mathrm{O}\right)$.

\section{Diethyl 4,5,10,11-tetraoxo-3,6,9,12-tetraazatetradecane-1,14-dioate} (Gly-OXA 2 2-Gly) (2a)

Glycine ethyl ester hydrochloride $(21.5 \mathrm{~g}, 153.8 \mathrm{mmol})$, triethylamine $(23.4 \mathrm{~g}, 230.8$ mmol) and $\mathrm{OXA}_{2} 2$ (1a) $(20.0 \mathrm{~g}, 76.9 \mathrm{mmol})$ were dissolved in $200 \mathrm{ml}$ of chloroform. Subsequently, the solution was stirred at $70{ }^{\circ} \mathrm{C}$ for $48 \mathrm{~h}$. The product was isolated by filtration and subsequently washed one time with ethanol, two times with chloroform and two times with diethyl ether and dried under vacuum. The product was obtained as a white powder in a yield of $67 \%\left(\mathrm{mp} 235{ }^{\circ} \mathrm{C}\right)$.

${ }^{1} \mathrm{H}$ NMR $\left(300 \mathrm{MHz}\right.$, TFA-d $\left.\mathrm{d}_{1}\right): \delta=4.39\left(\mathrm{q}, 4 \mathrm{H}, \mathrm{CH}_{3} \mathrm{CH}_{2} \mathrm{O}\right), 4.29\left(\mathrm{~d}, 4 \mathrm{H}, \mathrm{OCOC}_{2} \mathrm{NH}\right)$, $3.73\left(\mathrm{dt}, 4 \mathrm{H}, \mathrm{NHCH}_{2}\right), 1.36\left(\mathrm{t}, 6 \mathrm{H}, \mathrm{CH}_{3} \mathrm{CH}_{2} \mathrm{O}\right) ;{ }^{13} \mathrm{C} \mathrm{NMR}\left(75.26 \mathrm{MHz}\right.$, TFA-d $\left.\mathrm{d}_{1}\right): \delta=$ $171.8\left(\mathrm{OCOCH}_{2} \mathrm{NH}\right), 160.6\left(\mathrm{OCOCH}_{2} \mathrm{NHCO}\right), 160.2\left(\mathrm{CONHCH}_{2}\right), 63.9\left(\mathrm{CH}_{3} \mathrm{CH}_{2} \mathrm{O}\right)$, $41.4\left(\mathrm{OCOCH}_{2} \mathrm{NH}\right), 39.0\left(\mathrm{NHCH}_{2}\right), 12.1\left(\mathrm{CH}_{3} \mathrm{CH}_{2} \mathrm{O}\right)$.

\section{Diethyl 4,5,12,13-tetraoxo-3,6,11,14-tetraazahexadecane-1,16-dioate (Gly-OXA 4 -Gly) (2b)}

Glycine ethyl ester hydrochloride (19.4 g, $138.9 \mathrm{mmol})$, triethylamine (19.4 g, 208.3 mmol) and $\mathrm{OXA}_{2} 4$ (1b) (20.0 g, $\left.69.4 \mathrm{mmol}\right)$ were dissolved in $200 \mathrm{ml}$ of chloroform. Subsequently, the solution was stirred at $70{ }^{\circ} \mathrm{C}$ for $72 \mathrm{~h}$. The product was isolated by filtration and subsequently washed one time with ethanol, two times with chloroform and two times with diethyl ether and dried under vacuum. The product was obtained as a white powder in a yield of $62 \%\left(\mathrm{mp} 215{ }^{\circ} \mathrm{C}\right) \cdot{ }^{1} \mathrm{H} \mathrm{NMR}\left(300 \mathrm{MHz}, \mathrm{TFA}-\mathrm{d}_{1}\right): \delta$ $=4.41\left(\mathrm{q}, 4 \mathrm{H}, \mathrm{CH}_{3} \mathrm{CH}_{2} \mathrm{O}\right), 4.33\left(\mathrm{~d}, 4 \mathrm{H}, \mathrm{OCOCH}_{2} \mathrm{NH}\right), 3.49\left(\mathrm{dt}, 4 \mathrm{H}, \mathrm{NHCH}_{2} \mathrm{CH}_{2}\right)$, $1.77\left(\mathrm{~m}, 4 \mathrm{H}, \mathrm{NHCH}_{2} \mathrm{CH}_{2}\right), 1.38\left(\mathrm{t}, 6 \mathrm{H}, \mathrm{CH}_{3} \mathrm{CH}_{2} \mathrm{O}\right) ;{ }^{13} \mathrm{C} \mathrm{NMR}(75.26 \mathrm{MHz}$, TFA$\left.\mathrm{d}_{1}\right): \delta=171.8\left(\mathrm{OCOCH}_{2} \mathrm{NH}\right), 160.6\left(\mathrm{OCOCH}_{2} \mathrm{NHCO}\right), 159.5\left(\mathrm{CONHCH}_{2} \mathrm{CH}_{2}\right)$, $64.0\left(\mathrm{CH}_{3} \mathrm{CH}_{2} \mathrm{O}\right), 41.4\left(\mathrm{OCOCH} \mathrm{H}_{2} \mathrm{NH}\right), 39.8\left(\mathrm{NHCH}_{2} \mathrm{CH}_{2}\right), 25.2\left(\mathrm{NHCH}_{2} \mathrm{CH}_{2}\right), 12.0$ $\left(\mathrm{CH}_{3} \mathrm{CH}_{2} \mathrm{O}\right)$.

\section{Diethyl 4,5,14,15-tetraoxo-3,6,13,16-tetraazaoctadecane-1,18-dioate (Gly-OXA 6 -Gly) (2c)}

Glycine ethyl ester hydrochloride (17.5 g, $126.6 \mathrm{mmol})$, triethylamine $(19.2 \mathrm{~g}, 189.9$ mmol) and $\mathrm{OXA}_{2} 6$ (1c) $(20.0 \mathrm{~g}, 63.3 \mathrm{mmol})$ were dissolved in $200 \mathrm{ml}$ of chloroform. 
Subsequently, the solution was stirred at $70{ }^{\circ} \mathrm{C}$ for $16 \mathrm{~h}$. The product was isolated by filtration and subsequently washed one time with ethanol, two times with chloroform and two times with diethyl ether and dried under vacuum. The product was obtained as a white powder in a yield of $73 \%\left(\mathrm{mp} 181^{\circ} \mathrm{C}\right) \cdot{ }^{1} \mathrm{H}$ NMR $\left(300 \mathrm{MHz}, \mathrm{TFA}-\mathrm{d}_{1}\right): \delta=4.50$ (q, $4 \mathrm{H}, \mathrm{CH}_{3} \mathrm{CH}{ }_{2} \mathrm{O}$ ), 4.40 (d, $\left.4 \mathrm{H}, \mathrm{OCOCH}_{2} \mathrm{NH}\right), 3.56$ (dt, $4 \mathrm{H}, \mathrm{NHCH}_{2} \mathrm{CH}_{2} \mathrm{CH}_{2}$ ), 1.79 $\left(\mathrm{m}, 4 \mathrm{H}, \mathrm{NHCH}_{2} \mathrm{CH}_{2} \mathrm{CH}_{2}\right), 1.55\left(\mathrm{~m}, 4 \mathrm{H}, \mathrm{NHCH}_{2} \mathrm{CH}_{2} \mathrm{CH}_{2}\right), 1.47$ (t, $\left.6 \mathrm{H}, \mathrm{CH}_{3} \mathrm{CH}_{2} \mathrm{O}\right)$; ${ }^{13} \mathrm{C} \mathrm{NMR}\left(75.26 \mathrm{MHz}, \mathrm{TFA}-\mathrm{d}_{1}\right): \delta=171.7\left(\mathrm{OCOCH}_{2} \mathrm{NH}\right), 161.0\left(\mathrm{OCOCH}_{2} \mathrm{NHCO}\right)$, $159.4\left(\mathrm{CONHCH}_{2} \mathrm{CH}_{2} \mathrm{CH}_{2}\right), 63.9\left(\mathrm{CH}_{3} \mathrm{CH}_{2} \mathrm{O}\right), 41.4\left(\mathrm{OCOCH}_{2} \mathrm{NH}\right), 40.4\left(\mathrm{NHCH}_{2} \mathrm{CH}_{2^{-}}\right.$ $\left.\mathrm{CH}_{2}\right), 27.8\left(\mathrm{NHCH}_{2} \mathrm{CH}_{2} \mathrm{CH}_{2}\right), 25.7\left(\mathrm{NHCH}_{2} \mathrm{CH}_{2} \mathrm{CH}_{2}\right), 12.1\left(\mathrm{CH}_{3} \mathrm{CH}_{2} \mathrm{O}\right)$.

\section{Diethyl 4,5,14,15-tetraoxo-3,6,13,16-tetraazaoctadecane-1,18-dioate ( $\beta$ Ala-OXA 2 6- $\beta$ Ala) (3)}

$\beta$-alanine ethyl ester hydrochloride $(19.4 \mathrm{~g}, 126.6 \mathrm{mmol})$, triethylamine $(19.2 \mathrm{~g}, 189.9$ mmol) and $\mathrm{OXA}_{2} 6$ (1c) $(20.0 \mathrm{~g}, 63.3 \mathrm{~mol})$ were dissolved in $200 \mathrm{ml}$ of chloroform. Subsequently, the solution was stirred at $70{ }^{\circ} \mathrm{C}$ for $16 \mathrm{~h}$. The product was isolated by filtration and subsequently washed one time with ethanol, two times with chloroform and two times with diethyl ether and dried under vacuum. The product was obtained as a white powder in a yield of $55 \%\left(\mathrm{mp} 196{ }^{\circ} \mathrm{C}\right) .{ }^{1} \mathrm{H}$ NMR $(300 \mathrm{MHz}$, TFA-d $\left.{ }_{1}\right): \delta=4.32\left(\mathrm{q}, 4 \mathrm{H}, \mathrm{CH}_{3} \mathrm{CH}_{2} \mathrm{O}\right), 3.77$ (dt, $\left.4 \mathrm{H}, \mathrm{OCOCH}_{2} \mathrm{CH}_{2} \mathrm{NH}\right), 3.42$ (dt, $4 \mathrm{H}$, $\mathrm{NHCH}_{2} \mathrm{CH}_{2} \mathrm{CH}_{2}$ ), 2.81 (t, $\left.4 \mathrm{H}, \mathrm{OCOCH}_{2} \mathrm{CH}_{2} \mathrm{NH}\right), 1.65$ (m, 4H, $\mathrm{NHCH}_{2} \mathrm{CH}_{2} \mathrm{CH}_{2}$ ), $1.41\left(\mathrm{~m}, 4 \mathrm{H}, \mathrm{NHCH}_{2} \mathrm{CH}_{2} \mathrm{CH}_{2}\right), 1.29$ (t, 6H, $\left.\mathrm{CH}_{3} \mathrm{CH}_{2} \mathrm{O}\right) ;{ }^{13} \mathrm{C} \mathrm{NMR}(75.26 \mathrm{MHz}$, TFA$\left.\mathrm{d}_{1}\right): \delta=175.3\left(\mathrm{OCOCH}_{2} \mathrm{CH}_{2} \mathrm{NH}\right), 160.3\left(\mathrm{OCOCH}_{2} \mathrm{CH}_{2} \mathrm{NHCO}\right), 159.8\left(\mathrm{CONHCH}_{2^{-}}\right.$ $\left.\mathrm{CH}_{2} \mathrm{CH}_{2}\right), 63.2\left(\mathrm{CH}_{3} \mathrm{CH}_{2} \mathrm{O}\right), 40.4\left(\mathrm{OCOCH}_{2} \mathrm{CH}_{2} \mathrm{NH}\right), 35.5\left(\mathrm{OCOCH}_{2} \mathrm{CH}_{2} \mathrm{NH}\right), 33.0$ $\left(\mathrm{NHCH}_{2} \mathrm{CH}_{2} \mathrm{CH}_{2}\right), 27.9\left(\mathrm{NHCH}_{2} \mathrm{CH}_{2} \mathrm{CH}_{2}\right), 25.8\left(\mathrm{NHCH}_{2} \mathrm{CH}_{2} C \mathrm{H}_{2}\right), 12.1\left(\mathrm{CH}_{3} \mathrm{CH}_{2} \mathrm{O}\right)$.

\subsubsection{Methods}

\section{NMR}

${ }^{1} \mathrm{H}(300 \mathrm{MHz})$ and ${ }^{13} \mathrm{C} \mathrm{NMR}(75.26 \mathrm{MHz})$ spectra were recorded on a Varian Inova Nuclear Magnetic Resonance Spectrometer using $\mathrm{CDCl}_{3}-\mathrm{d}_{1}$ and TFA- $\mathrm{d}_{1}$ as solvents.

\section{TGA}

Thermal gravimetric analysis of 5-10 $\mathrm{mg}$ samples was carried out under a nitrogen atmosphere in the $50-700{ }^{\circ} \mathrm{C}$ range at a heating rate of $10{ }^{\circ} \mathrm{C} . \mathrm{min}^{-1}$, using a PerkinElmer Thermal Gravimetric Analyser TGA 7. 


\section{DSC}

Thermal analysis was carried out using a Perkin-Elmer Pyris 1. Calibration was carried out with pure indium. Samples $(5-10 \mathrm{mg})$ were heated from 0 to $250{ }^{\circ} \mathrm{C}$ at a rate of 20 ${ }^{\circ} \mathrm{C} \cdot \mathrm{min}^{-1}$, annealed for $5 \mathrm{~min}$, cooled to $0{ }^{\circ} \mathrm{C}$ at a rate of $20{ }^{\circ} \mathrm{C} \cdot \mathrm{min}^{-1}$, and subsequently heated from 0 to $250{ }^{\circ} \mathrm{C}$ at a rate of $20{ }^{\circ} \mathrm{C} \cdot \mathrm{min}^{-1}$. Melting $\left(\mathrm{T}_{\mathrm{m}}\right)$ and crystallization $\left(\mathrm{T}_{\mathrm{c}}\right)$ temperatures were obtained from the peak maxima, melt $\left(\Delta \mathrm{H}_{\mathrm{m}}\right)$ and crystallization $\left(\Delta \mathrm{H}_{\mathrm{c}}\right)$ enthalpies were determined from the area under the curve. The data presented are taken from the first cooling scan and the second heating scan.

\section{FT-IR}

To minimize the potential oxidation of the material, sample preparation comprised the following steps. The surface of a $32 \times 3 \mathrm{~mm} \mathrm{NaCl}$ disc (Thermo, International Crystal Labs) was roughened to prevent interfering fringes. Subsequently, a suspension of the compound in dichloromethane was drop casted on the $\mathrm{NaCl}$ disk and the solvent was allowed to evaporate. The holder was placed in the cell in an inert atmosphere ( $\mathrm{N}_{2}$ purge glove bag or $\mathrm{N}_{2}$ purged IR sample compartment). Materials were analyzed as-received using an ATR accessory (Diamond crystal, $45^{\circ}$, single bounce) installed on a Nicolet 5700 spectrometer at a $4 \mathrm{~cm}^{-1}$ resolution. The data were collected between 4000-500 $\mathrm{cm}^{-1}$ (16 scans were acquired). The graphs were prepared using OPUS 6.1 software. All spectra were normalized to the $2860 \mathrm{~cm}^{-1}$ signal.

\section{X-ray diffraction}

Wide-angle X-ray diffraction (WAXD) and small-angle X-ray scattering (SAXS) experiments were conducted on the BM26B beamline of the European Synchrotron Radiation Facility in Grenoble, France, using X-ray photons of $12 \mathrm{keV}$. The 2D X-ray patterns were collected in transmission geometry using a 2D multi-wire gas-filled detector for the SAXS experiments and a 2D Frelon ${ }^{\circledR}$ CCD for WAXD experiments using a $2 \times 2$ binning ending up with a pixel resolution of $100 \mu \mathrm{m}$ in both lateral directions. For the measurements on the model compounds the uniaxial oriented material was placed with its fiber axis perpendicular to the incident X-ray beam. The modulus of the scattering vector $s=2 \sin (\Theta / \lambda)$, where $\Theta$ is the Bragg angle and $\lambda$ the wavelength, was calibrated using several diffraction orders of silver behenate and corundum for the SAXS and WAXD measurement, respectively. The data reduction and analysis including geometrical and background correction, visualization and resampling into polar coordinates of the 2D diffractograms were performed using home-built routines written in Igor Pro ${ }^{\circledR}$ software package from WaveMetrics $^{\mathrm{TM}}$. 


\subsection{Results and Discussion}

\subsubsection{Synthesis and characterization}

The synthesis of symmetrical bisoxalamides $\mathbf{2 a - c}$ and $\mathbf{3}$ with neighboring glycine ethyl ester or $\beta$-alanine ethyl ester groups is depicted in Scheme 6.1. First, bisoxalamide precursors 1a-c were prepared by reacting $\alpha, \omega$-diamines with an excess of diethyl oxalate. The compounds were obtained in good yields after purification as described previously $^{5}$.

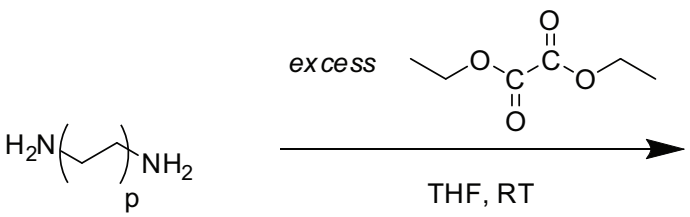<smiles>CCOC(=O)C(=O)NC(C)NC(=O)C(=O)N(C)CC</smiles>

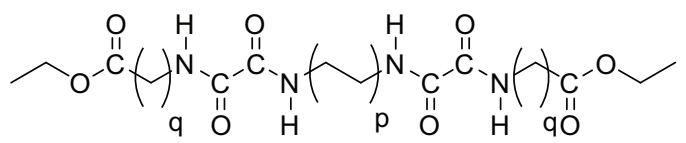

$p=1, q=1$ Gly-OXA 2 -Gly (2 a)

$p=2, q=1$ Gly-OXA $24-G l y(2$ b)

$p=3, q=1$ Gly-OXA 6 -Gly (2 c)

$p=3, q=2 \beta$ Ala-OXA $26-\beta$ Ala (3)<smiles></smiles>

$\mathrm{p}=3$ MeOProp-OXA $26-$ PropOMe (4) $p=1 O^{O X A} 2(1$ a)

$p=2 O_{2 X A} 4(1 b)$

$p=3 \operatorname{OXA}_{2} 6(1 \mathrm{c})$

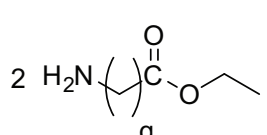

q

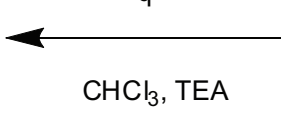

$70^{\circ} \mathrm{C}$

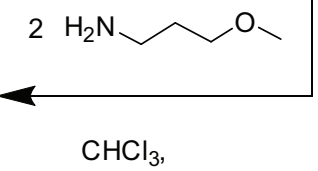

$70^{\circ} \mathrm{C}$

Scheme 6.1: Synthesis of bisoxalamide derivatives.

The ${ }^{1} \mathrm{H}$ and ${ }^{13} \mathrm{C}$ NMR analysis of the crude products revealed the formation of small amounts of oligomers, which were removed by selective extraction with chloroform. Reaction of 1a-c with glycine ethyl ester afforded the bisester-bisoxalamides 2a-c. 
Similarly, 3 was prepared from 1c upon reaction with $\beta$-alanine ethyl ester. The ${ }^{1} \mathrm{H}$ NMR spectra of the products revealed a high purity of $\mathbf{2 a - c}$ and $\mathbf{3}$ by comparing the integral values of the glycine or $\beta$-alanine methylene protons with the central methylene protons next to the amide groups. Side reactions, like the reaction of $\mathbf{2 a}$ with glycine ethyl ester, were not observed as ${ }^{13} \mathrm{C}$ NMR spectral data showed no carbonyl peaks found at $\delta=178$ characteristic of single amides ${ }^{21}$. The 3-methoxypropyl functionalized bisoxalamide 4 was included in this study to serve as a model compound for the bisoxalamide hard segment in the segmented poly(ether amide)s comprising uniform bisoxalamide moieties linked by PTHF macro-monomers ${ }^{6}$. The model compound 4 was prepared by reacting 1c with 3-methoxypropylamine (Scheme 6.1).

\subsubsection{Thermal properties}

The thermal stability of the bisester-bisoxalamides 2a-c and $\mathbf{3}$ under non-oxidative conditions was investigated by thermal gravimetrical analysis (TGA). The decomposition temperatures $\left(\mathrm{T}_{\mathrm{d}}\right)$ taken as the inflection point are listed in Table 6.1. The Gly-OXA 24 -Gly, Gly-OXA 2 -Gly (2b-c) and $\beta$ Ala-OXA 6 - $\beta$ Ala (3) are thermally stable up to $\sim 360{ }^{\circ} \mathrm{C}$, whereas the degradation of Gly-OXA 2 2-Gly (2a) starts at a lower temperature of $\sim 340{ }^{\circ} \mathrm{C}$.

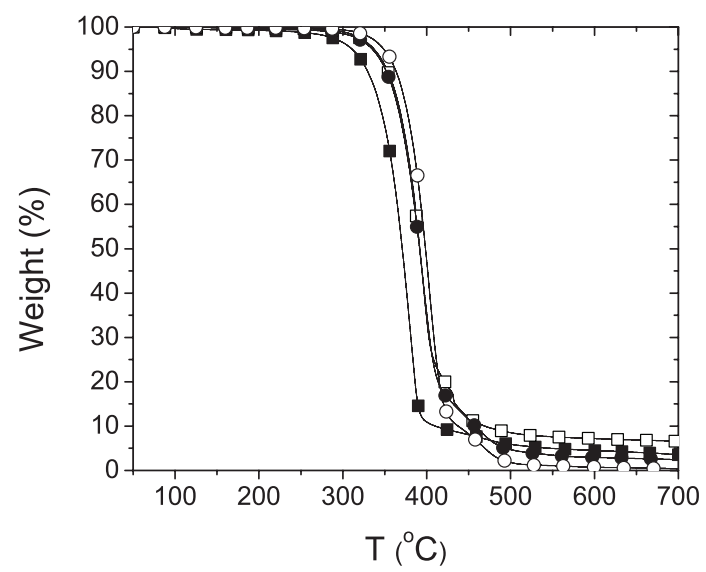

Figure 6.6: TGA thermograms of bisester-bisoxalamides ( $\boldsymbol{\square})$ Gly-OXA 2 2-Gly (2a), ( $\square$ ) Gly-OXA 24 -Gly (2b), (•) Gly-OXA 26 -Gly (2c) and ( O ) $\beta$ Ala-OXA $26-\beta$ Ala (3). 
The bisester-bisoxalamides $\mathbf{2 a - c}$ and $\mathbf{3}$ show single sharp melting and crystallization transitions (Figure 6.7). As expected, increasing the number of methylene groups between the two oxalamide groups decreases the melting and crystallization temperatures. Interestingly, the $\beta$-alanine based compound $\mathbf{3}$ has a higher melting temperature compared to its glycine analogue 2c. Apparently, the conformation of the glycine residue disturbs the crystal packing more than the $\beta$-alanine residue. In contrast to the bisester-bisoxalamides $\mathbf{2 c}$ and $\mathbf{3}$, compound $\mathbf{4}$ exhibits two melting and crystallization transitions. The transition at lower temperatures may be the result of a crystal rearrangement. Two thermal transitions are found at higher temperatures, which may indicate that MeOProp-OXA 26 -PropOMe (4) exists in two different thermodynamically stable crystalline structures. However, the two peaks may also be attributed to a melt and recrystallization process that renders more perfect and thicker crystals.

(a)

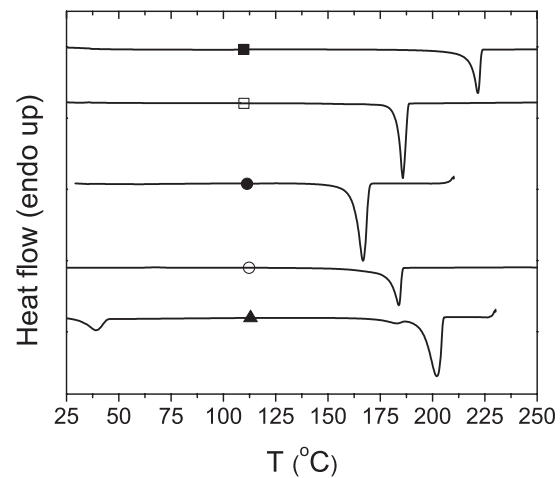

(b)

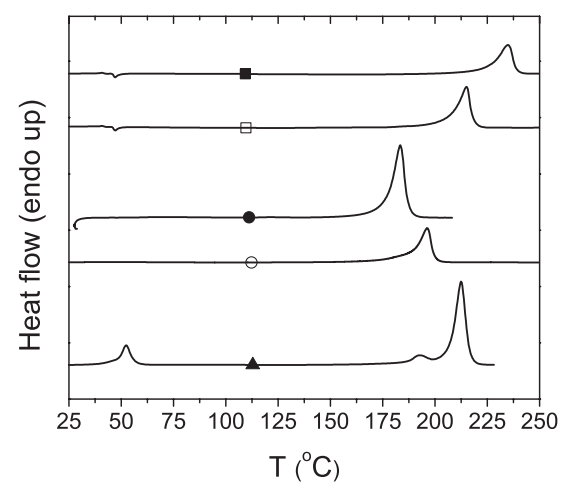

Figure 6.7: DSC cooling curves (a) and second heating curves (b) of bisoxalamide compounds ( $)$ Gly-OXA 2 2-Gly (2a), ( $\square$ ) Gly-OXA 2 4-Gly (2b), (•) Gly-OXA 26 -

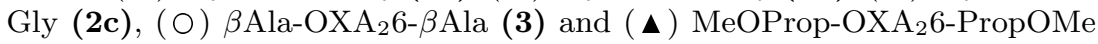
(4).

\subsubsection{FT-IR}

The ATR FT-IR spectra of the bisoxalamide compounds 2a-c, 3 and $\mathbf{4}$ show characteristic IR-bands at $\sim 3296$ (Amide A, $\nu$ N-H, H-bonded), $\sim 1650$ (Amide $\mathrm{I}, \nu \mathrm{C}=\mathrm{O}$, $\mathrm{H}$-bonded) and $\sim 1530$ (Amide II, $\nu \mathrm{C}-\mathrm{N}+\delta \mathrm{N}-\mathrm{H})$ and between $1732-1741 \mathrm{~cm}^{-1}(\nu \mathrm{C}=\mathrm{O}$ ester, free) (Table 6.2). The $\mathrm{N}-\mathrm{H}$ stretching vibration band and $\mathrm{C}=\mathrm{O}$ amide stretching vibration band appear at $\sim 3296$ and $\sim 1650 \mathrm{~cm}^{-1}$, respectively, which indicates that 
Table 6.1: Thermal properties of diamide-diester and bisoxalamide compounds.

\begin{tabular}{|c|c|c|c|c|c|c|c|c|}
\hline & & $\begin{array}{l}\mathrm{T}_{\mathrm{d}}^{\mathrm{a}} \\
\left({ }^{\circ} \mathrm{C}\right)\end{array}$ & $\begin{array}{l}\mathrm{T}_{\mathrm{m}} \\
\left({ }^{\circ} \mathrm{C}\right)\end{array}$ & $\begin{array}{c}\Delta \mathrm{H}_{\mathrm{m}} \\
\left(\mathrm{J} \cdot \mathrm{g}^{-1}\right)\end{array}$ & $\begin{array}{l}\mathrm{T}_{\mathrm{c}} \\
\left({ }^{\circ} \mathrm{C}\right)\end{array}$ & $\begin{array}{c}\Delta \mathrm{H}_{\mathrm{c}} \\
\left(\mathrm{J} \cdot \mathrm{g}^{-1}\right)\end{array}$ & $\begin{array}{c}\mathrm{T}_{\text {onset }} \\
\left({ }^{\circ} \mathrm{C}\right)\end{array}$ & $\begin{array}{c}\text { Supercooling }^{\mathrm{b}} \\
\left({ }^{\circ} \mathrm{C}\right)\end{array}$ \\
\hline $\mathrm{OXA}_{2} 2$ & $1 \mathrm{a}$ & 296 & 132 & 111 & 98 & 104 & 100 & 32 \\
\hline $\mathrm{OXA}_{2} 4$ & $1 b$ & 321 & 103 & 99 & 74 & 99 & 77 & 26 \\
\hline $\mathrm{OXA}_{2} 6$ & $1 \mathrm{c}$ & 320 & 93 & 126 & 62 & 124 & 67 & 26 \\
\hline Gly-OXA 2 2-Gly & $2 a$ & 343 & 236 & 126 & 224 & 124 & 226 & 10 \\
\hline Gly-OXA 24 -Gly & $2 b$ & 361 & 216 & 111 & 187 & 119 & 190 & 26 \\
\hline Gly-OXA 2 6-Gly & $2 \mathrm{c}$ & 361 & 181 & 116 & 161 & 111 & 167 & 14 \\
\hline$\beta$ Ala-OXA ${ }_{2} 6-\beta$ Ala & 3 & 361 & 199 & 118 & 184 & 113 & 186 & 10 \\
\hline MeOProp-OXA 2 6-PropOMe & 4 & - & $\begin{array}{c}48 \\
198 / 212\end{array}$ & $\begin{array}{c}33 \\
167\end{array}$ & $\begin{array}{c}39 \\
183 / 202\end{array}$ & $\begin{array}{c}32 \\
164\end{array}$ & 205 & 7 \\
\hline
\end{tabular}

${ }^{\mathrm{a}}$ Taken as the inflection point

${ }^{\mathrm{b}}$ Difference between $\mathrm{T}_{\mathrm{m}}$ and $\mathrm{T}_{\text {onset }}$

strong hydrogen bonds are solely formed between the oxalamide groups. According to Herrebout et $a l^{22}$, the influence of alkyl substituents on the oxalamide amide fundamentals is very small. Compounds 2c, $\mathbf{3}$ and $\mathbf{4}$, having a hexamethylene spacer between the oxalamide groups, exhibit almost similar amide wavenumbers for the N-H and $\mathrm{C}=\mathrm{O}$ stretching vibrations. Apparently, the adjacent carbonyl donor functionality introduced does not affect the amide frequencies and no hydrogen bonding between the amide and ester carbonyls is occurring. This suggest that there is no interaction between the contiguous carbonyl and the amide functionality i.e. that the carbonyl ester is spatially tilted away from the amide plane analogous as observed in compounds C1-2, 6 and 7 (Figure 6.2). Reducing the spacer length between the oxalamide groups does not seem to alter this picture.

Heating Gly-OXA 2 2-Gly (2a) up to $260{ }^{\circ} \mathrm{C}$ for a prolonged time resulted in a completely changed FT-IR spectrum. These changes are indicative of thermal degradation. Narrow $\mathrm{N}-\mathrm{H}$ stretching vibration bands and the $\mathrm{C}=\mathrm{O}$ amide stretching vibration bands of $\mathbf{2} \mathbf{b}-\mathbf{c}$, 3 and 4 at $\sim 3296$ and $\sim 1650 \mathrm{~cm}^{-1}$ indicated that also after heating and subsequent cooling strong and a single type of hydrogen bonds are established between the oxalamide groups. On the other hand, the spectra reveal different amide II and carbonyl ester stretching band positions compared to the spectra of the as crystallized compounds (Figure 6.8) and also the fine structure was not similar, which suggest a change in crystal structure. 
(a)

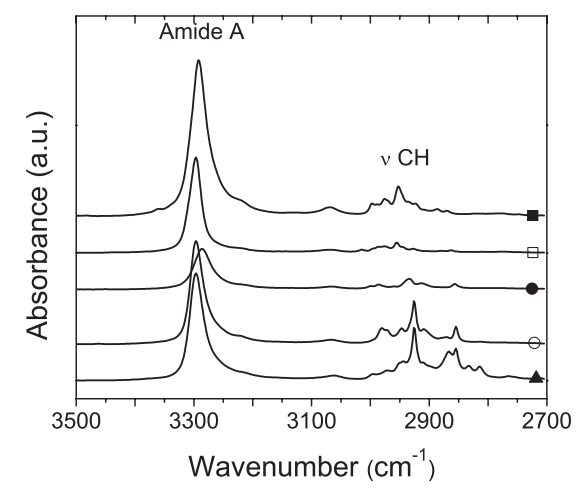

(b)

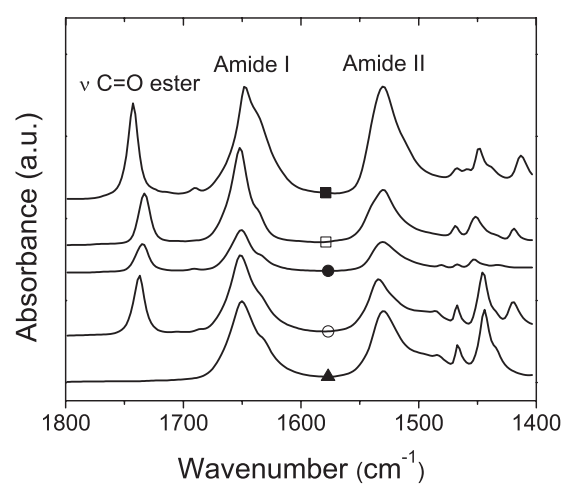

Figure 6.8: ATR FT-IR spectra of bisoxalamide compounds ( $\boldsymbol{\square})$ Gly-OXA 2 2-Gly (2a), ( $\square$ ) Gly-OXA 2 -Gly (2b), (•) Gly-OXA 26 -Gly (2c), (O) $\beta$ Ala-OXA $26-\beta$ Ala (3) and ( $)$ MeOProp-OXA 2 6-PropOMe (4) as received at room temperature.

After cooling from the melt, the ester carbonyl stretching band of the $\beta$-alanine ester substituted bisoxalamide 3 remains almost at the same position $\sim 1732 \mathrm{~cm}^{-1}$, whereas this band shifted to $1746 \mathrm{~cm}^{-1}$ for the glycine ester based compounds $\mathbf{2 b - c}$ (Figure 6.9). These data reveal that the glycine ester $\mathrm{C}=\mathrm{O}$ rotates into a more a-polar surrounding. Probably after annealing crystal perfection occurs and the glycine carbonyls align better at the edge of the crystal. More evidence of a change in crystal structure was found in the shift of the amide II band, which is especially sensitive to polymorphism resulting from a significant difference in chain conformation.

Because FT-IR spectroscopic data on polyoxalamides and oxalamide containing compounds is scarce, the statements in the following discussion are speculative. The amide II band of the glycine based compounds 2b-c shift from 1530 to $1540 \mathrm{~cm}^{-1}$. Possibly, the glycine group is tilted further away from the oxalamide plane after heat treatment. Moreover, this increased rotation may force the oxalamide group to tilt relative to the chain axis similar as observed in the $\gamma$-type structure of conventional nylons i.e the oxalamide group is not in the same plane as the spacer between the two oxalamide groups.

Contrary, the amide II band of $\beta$ Ala-OXA 6 - $\beta$ Ala (3) shifts from 1530 to $1520 \mathrm{~cm}^{-1}$ which may indicate a shift of the bisoxalamide groups into a more planar trans zig-zag conformation and the $\beta$-alanine methylene next to the amide group are in the same plane as the spacer between the two oxalamide groups. This is in agreement with 
compound C2 (Figure 6.5) which revealed a torsional angle of the methylene group of the $\beta$-alanine adjacent to the oxalamide and the oxalamide (C4-N1-C3-C2 in Figure 6.5) of $180^{\circ}$ and hence the oxalamide group and the $\beta$-alanine methylene groups are in the same plane. A similar shift of the amide II vibration band is observed for compound 4, which also indicates a planar trans zig-zag conformation (Figure 6.9).

(a)

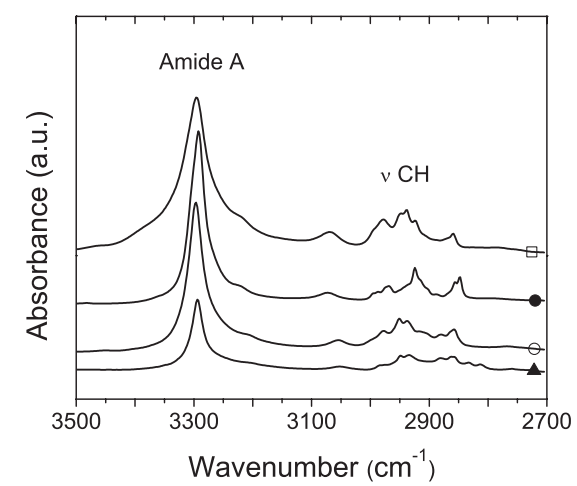

(b)

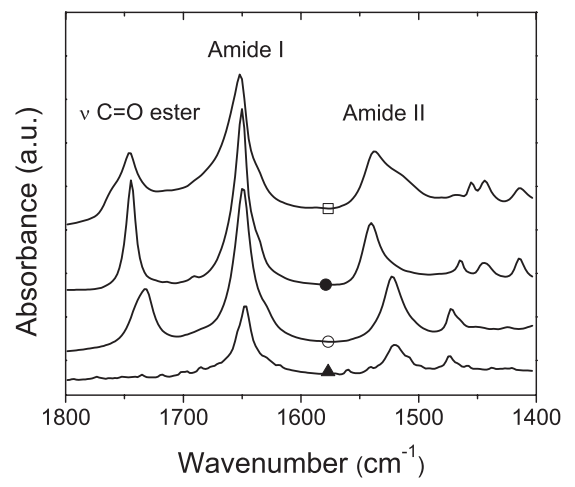

Figure 6.9: ATR FT-IR spectra of bisoxalamide compounds ( $\square)$ Gly-OXA 2 -Gly (2b), (•) Gly-OXA 26 -Gly (2c), (O) $\beta$ Ala-OXA $26-\beta$ Ala (3) and ( $\mathbf{\Delta}$ ) MeOProp$\mathrm{OXA}_{2} 6$-PropOMe (4) at room temperature after cooling from the melt.

Table 6.2: Characteristic infrared bands $\left(\mathrm{cm}^{-1}\right)$ of bisoxalamide compounds $\mathbf{2 a - c}, \mathbf{3}$ and $\mathbf{4}$.

\begin{tabular}{|c|c|c|c|c|c|}
\hline & \multicolumn{5}{|c|}{ As recieved - ATR } \\
\hline & & Amide A & $\nu \mathrm{C}=\mathrm{O}$ (ester) & Amide I & Amide II \\
\hline Gly-OXA 2 2-Gly & $\mathbf{2 a}$ & 3292 & 1741 & 1647 & 1530 \\
\hline Gly-OXA $24-G l y$ & $2 \mathrm{~b}$ & 3296 & 1732 & 1651 & 1530 \\
\hline Gly-OXA 2 6-Gly & $2 \mathrm{c}$ & 3286 & 1734 & 1649 & 1531 \\
\hline$\beta$ Ala-OXA $26-\beta$ Ala & 3 & 3296 & 1736 & 1651 & 1533 \\
\hline \multirow[t]{3}{*}{ MeOProp-OXA ${ }_{2} 6$-PropOMe } & 4 & 3296 & - & 1650 & 1530 \\
\hline & & \multicolumn{4}{|c|}{ After heat treatment - ATR } \\
\hline & & Amide A & $\nu \mathrm{C}=\mathrm{O}$ (ester) & Amide I & Amide II \\
\hline Gly-OXA $24-G l y$ & $2 \mathrm{~b}$ & 3296 & 1746 & 1652 & 1537 \\
\hline Gly-OXA 26 -Gly & $2 \mathrm{c}$ & 3292 & 1746 & 1650 & 1540 \\
\hline$\beta$ Ala-OXA $26-\beta$ Ala & 3 & 3298 & 1732 & 1650 & 1522 \\
\hline MeOProp-OXA 2 6-PropOMe & 4 & 3294 & - & 1647 & 1520 \\
\hline
\end{tabular}




\subsubsection{X-ray diffraction}

Since, FT-IR did not provide conclusive evidence to explain the difference in melting point between the glycine and $\beta$-alanine bisoxalamide model compounds. X-ray diffraction experiments were performed. To this end, powder-like compounds were heated above the melting temperature and subsequently extruded through a die of $300 \mu \mathrm{m}$ diameter followed by fast cooling down to room temperature to prevent reorientation of crystals. The $2 \mathrm{D}$ diffraction patterns of compounds are exemplified in Figure 6.10 for $\mathbf{2 c}$ and $\mathbf{3}$ compounds. The obtained crystallographic data is summarized in Table 6.3.

All five compounds exhibit a series of strong equatorial peaks that can be assigned to the layered structure ( $\boldsymbol{c}$-parameter), the period of which is close to the long molecular dimension. The other directions likely correspond to the molecular width within the hydrogen bonded planes ( $\boldsymbol{a}$-parameter) and the distance between the planes $(\boldsymbol{b}$ parameter). The value of the $\boldsymbol{a}$-parameter corresponding hydrogen bonding distance value is for all model compounds $\sim 5 \AA$, which is in agreement with oxalamides presented in the literature ${ }^{1}$. The $\boldsymbol{b}$-parameter of $\sim 10 \AA$ corresponds to the thickness of two successive hydrogen-bonded layers. The inter-sheet distance is approximately of $5 \AA$, which is higher than for Nylon-6,2 with fully planar chains $(4.04 \AA)^{23}$. This indicates that the glycine ester or $\beta$-alanine ester groups are tilted away from the hydrogenbonded sheet, which is in line with the previously discussed FT-IR data.
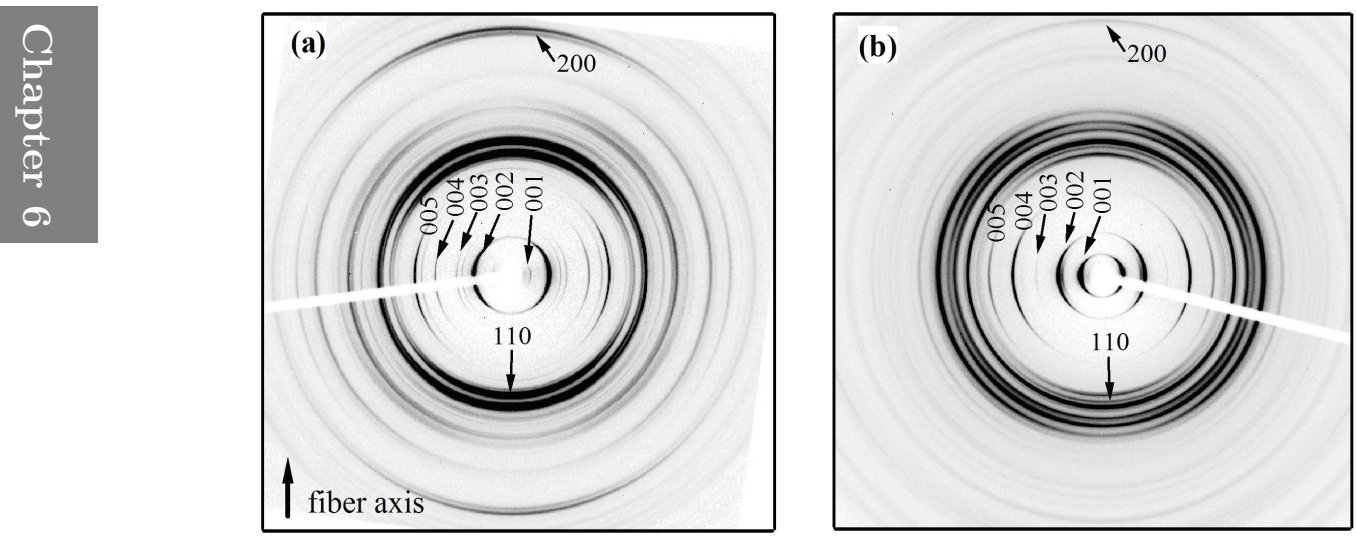

Figure 6.10: 2D WAXS patterns of oriented model compounds (a) Gly-OXA 2 6-Gly (2c) and (b) $\beta$ Ala-OXA $26-\beta$ Ala (3). 
A sketch of the crystal structure of Gly-OXA 2 6-Gly (2c) is shown in Figure 6.11. The calculated molecular length of $\mathbf{2 c}$ is $\sim 28.75 \AA$ whereas the $\boldsymbol{c}$-parameter is $27.27 \AA$. The tilt of the molecule with respect to the normal to the layers was addressed from $\mathrm{X}$-ray patterns of the oriented copolymer $\mathrm{PTHF}_{1000}-\mathrm{Gly}_{\mathrm{O}} \mathrm{OXA}_{2} 6-\mathrm{Gly}^{24}$. From the characteristic four-spot SAXS patterns it was found that the hard segment has a slight tilt of $\sim 5-10^{\circ}$ i.e. the central part of the molecule is oriented almost perpendicular to the smectic planes. Consequently, the ethyl ester tail groups are inclined much stronger with respect to the $\boldsymbol{c}$-direction and are probably rotated out of the $\boldsymbol{a c}$-plane. The exact conformation of the end groups was not determined at this stage. Similar structural models can be proposed for compounds $\mathbf{2 a - b}, \mathbf{3}$ and $\mathbf{4}$.

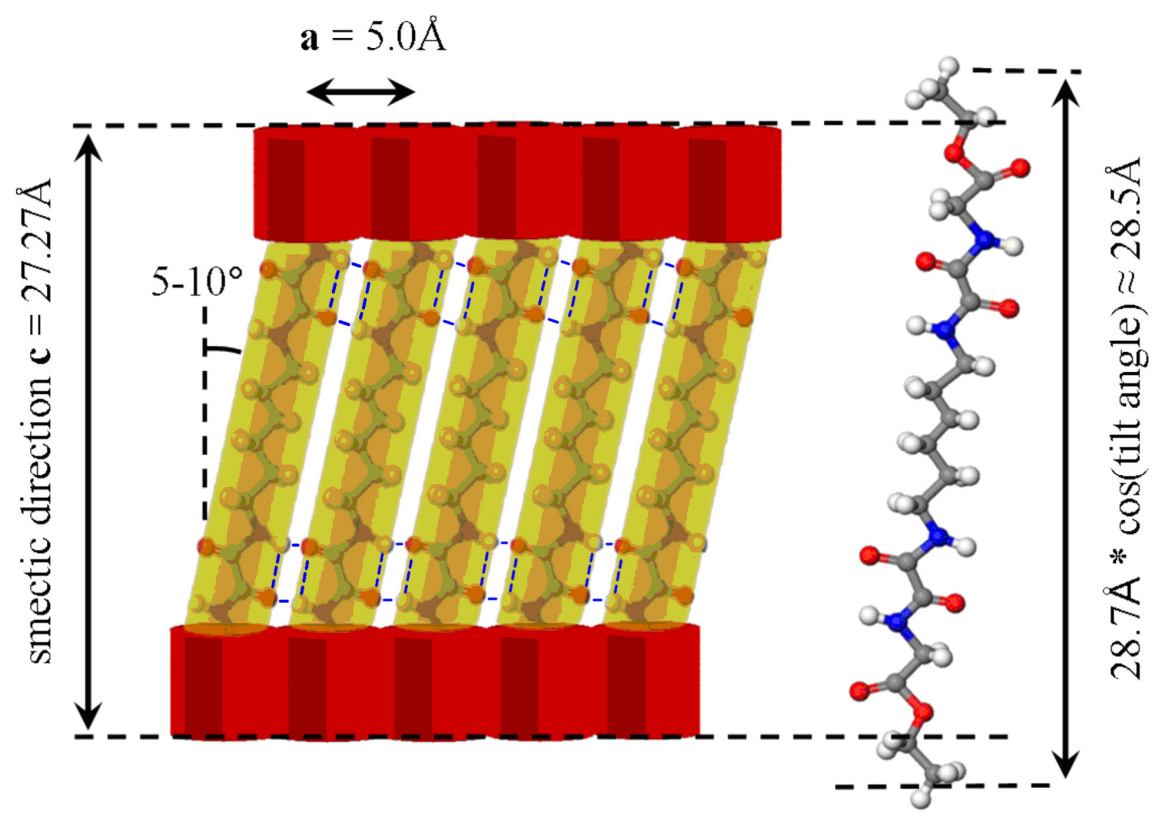

Figure 6.11: Sketch of the crystal structure of Gly-OXA 2 6-Gly (2c) in the $\boldsymbol{a c}$-plane.

Both X-ray diffraction and FT-IR do not provide conclusive evidence explaining the difference in melting point between Gly-OXA 26 -Gly (2c) and $\beta \mathrm{AlaOXA}_{2} 6$ - $\beta$ Ala (3). The H-bonding distances as measured with $\mathrm{X}$-ray and wavenumbers measured with FT-IR are similar for both model compounds. Apparently, the higher melting point of model compound $\mathbf{3}$ is due to a better packing of the $\beta$-alanine end group in the crystal. 
Table 6.3: Structural data of bisoxalamides compounds 2a-c, 3 and $\mathbf{4}$.

\begin{tabular}{|c|c|c|c|c|c|c|c|c|}
\hline & & \multicolumn{3}{|c|}{ Orthorhombic $^{\mathrm{a}}$} & \multirow[b]{2}{*}{$\begin{array}{c}\rho \\
\left(\text { g.cm } \mathrm{cm}^{-3}\right)\end{array}$} & \multirow[b]{2}{*}{$\begin{array}{c}\text { Length }^{\mathrm{b}} \\
\left({ }^{\circ}\right)\end{array}$} & \multirow[b]{2}{*}{$\begin{array}{c}\text { Chain } \\
\text { tilt }^{c} \\
\left({ }^{\circ}\right)\end{array}$} & \multirow[b]{2}{*}{$\begin{array}{c}\text { Ester } \\
\text { tail angle } \\
\left({ }^{\circ}\right)\end{array}$} \\
\hline & & $\begin{array}{c}a \\
(\AA)\end{array}$ & $\begin{array}{c}\boldsymbol{b} \\
(\AA)\end{array}$ & $\begin{array}{c}c \\
(\AA)\end{array}$ & & & & \\
\hline Gly-OXA 2 2-Gly & $2 \mathbf{a}$ & 4.94 & 9.97 & 21.75 & 1.09 & 23.75 & $\sim 5-10$ & $\sim 35$ \\
\hline Gly-OXA 24 -Gly & $2 \mathrm{~b}$ & 4.96 & 10.43 & 24.37 & 1.00 & 26.25 & $\sim 5-10$ & $\sim 36$ \\
\hline Gly-OXA 26 -Gly & $2 \mathrm{c}$ & 5.00 & 10.36 & 27.27 & 0.96 & 28.75 & $\sim 5-10$ & $\sim 32$ \\
\hline$\beta$ Ala-OXA $26-\beta$ Ala & 3 & 5.03 & 11.03 & 25.18 & 1.04 & 31.25 & $\sim 28$ & $\sim 47$ \\
\hline MeOProp-OXA ${ }_{2} 6$-PropOMe & 4 & 5.05 & 10.00 & 21.98 & 1.06 & 28.75 & $\sim 25$ & $\sim 57$ \\
\hline
\end{tabular}

${ }^{\mathrm{a}}$ Peak indexation to an orthorhombic unit cel

${ }^{\mathrm{b}}$ The length of the model compound assuming the extended chain conformation

${ }^{\mathrm{c}}$ The chain tilt is determined using the SAXS signal of an oriented copolymer consisting of PTHF segments $\left(\mathrm{M}_{\mathrm{n}}=1.0 \times 10^{3} \mathrm{~g} \cdot \mathrm{mol}^{-1}\right)$ and bisoxalamide model compounds

${ }^{\mathrm{d}}$ The angle of the ester and ether groups with respect to the $c$-direction

\subsection{Conclusions}

The conformation of and hydrogen bonding between bisoxalamides substituted with glycine, $\beta$-alanine or 3-methoxypropyl moieties was determined with FT-IR and X-ray measurements. Upon heating, the bisoxalamides with glycine and $\beta$-alanine end groups showed a single melting endotherm whereas the 3-methoxypropyl substituted bisoxalamide showed three melting endotherms. The melting temperature of the compounds increased as the number of methylene groups in the spacer connecting the two oxalamide units decreased. Moreover, the melting temperature increased as the end group was changed from glycine to $\beta$-alanine to 3 -methoxypropyl, respectively. A qualitative model of the crystalline structure of the bisoxalamides was proposed on the basis of X-ray diffraction and FT-IR measurements. All compounds form hydrogen bonded sheets by stacking of the bisoxalamide units forming like-to-like amide-amide hydrogen bonds with a hydrogen bonding distance of $\sim 5 \AA$. Moreover, it was concluded that the glycine and $\beta$-alanine carbonyl ester groups are spatially tilted away from the oxalamide plane. The distance between the hydrogen bonded sheets was for all compounds $\sim 5 \AA$. The increased melting temperature of the $\beta$-alanine based model compound may be related to a better packing of the $\beta$-alanine ester compared to the glycine ester groups. The preferential stacking by amide to amide hydrogen bond formation makes these bisoxalamides interesting to use as hard segments in thermoplastic elastomers. 


\subsection{References}

[1] Coe, S.; Kane, J. J.; Nguyen, T. L.; Toledo, L. M.; Wininger, E.; Fowler, F. W.; Lauher, J. W. J Am Chem Soc 1997, 119, 86-93.

[2] Lauher, J. W.; Fowler, F. W.; Goroff, N. S. Acc Chem Res 2008, 41, 1215-1229.

[3] Nguyen, T. L.; Scott, A.; Dinkelmeyer, B.; Fowler, F. W.; Lauher, J. W. New J Chem 1998, 22, 129-135.

[4] Frkanec, L.; Zinic, M. Chem Commun 2010, 46, 522-537.

[5] Sijbrandi, N. J.; Kimenai, A. J.; Mes, E. P. C.; Broos, R.; Dijkstra, P. J.; Feijen, J. Chapter 3, this thesis; University of Twente, 2011.

[6] Sijbrandi, N. J.; Kimenai, A. J.; Mes, E. P. C.; Broos, R.; Bar, G.; Rosenthal, M.; Odarchenko, Y.; Ivanov, D. A.; Dijkstra, P. J.; Feijen, J. Chapter 4, this thesis; University of Twente, 2011.

[7] Aleman, C.; Casanovas, J. J Mol Struct Theochem 2004, 675, 9-17.

[8] Desseyn, H. O.; Perlepes, S. P.; Clou, K.; Blaton, N.; Van der Veken, B. J.; Dommisse, R.; Hansen, P. E. J Phys Chem A 2004, 108, 5175-5182.

[9] Klaska, K. H.; Jarchow, O.; Scham, W.; Widjaja, H.; Voss, J.; Schmalle, H. W. J Chem Res 1980, 104-105.

[10] Jokic, M.; Makarevic, J.; Zinic, M. J Chem Soc, Chem Commun 1995, 1723-1724.

[11] Makarevic, J.; Jokic, M.; Peric, B.; Tomisic, V.; Kojic-Prodic, B.; Zinic, M. Chem-EurJ 2001, 7, 3328-3341.

[12] Peric, B.; Kojic-Prodic, B.; Makarevic, J.; Jokic, M.; Zinic, M. Acta Crystallogr Sect C: Cryst Struct Commun 2001, 57, 747-748.

[13] Shkolnikova, L. M.; Gasparyan, A. V.; Poznyak, A. L.; Belskii, V. K.; Dyatlova, N. M. Koordinats Khim 1990, 16, 50-62.

[14] Stefanic, Z.; Kojic-Prodic, B.; Dzolic, Z.; Katalenic, D.; Zinic, M.; Meden, A. Acta Crystallogr Sect C: Cryst Struct Commun 2003, 59, O286-O288.

[15] Karle, I. L.; Ranganathan, D.; Shah, K.; Vaish, N. K. Int J Pept Protein Res 1994, 43, 160-165.

[16] Karle, I. L.; Ranganathan, D. Biopolymers 1995, 36, 323-331.

[17] Karle, I. L.; Ranganathan, D. Int J Pept Protein Res 1995, 46, 18-23.

[18] Armelin, E.; Urpi, L.; Solans, X.; Puiggali, J. Acta Crystallogr Sect C: Cryst Struct Commun 2001, 57, 932-933.

[19] Crick, F. H. C.; Rich, A. Nature 1955, 176.

[20] Urpi, L.; Rodriguez-Galan, A.; Puiggali, J. Macromol Chem Phys 1998, 199, 
1167-1173.

[21] Asin, L.; Armelin, E.; Montane, J.; Rodriguez-Galan, A.; Puiggali, J. J Polym Sci Part A Polym Chem 2001, 39, 4283-4293.

[22] Herrebout, W.; Clou, K.; Desseyn, H. O.; Blaton, N. Spectrochim Acta Part A 2003, 59, 47-59.

[23] Chatani, Y.; Ueda, Y.; Tadokoro, H.; Deits, W.; Vogl, O. Macromolecules 1978, 11, 636-638.

[24] Sijbrandi, N. J.; Kimenai, A. J.; Mes, E. P. C.; Broos, R.; Bar, G.; Rosenthal, M.; Odarchenko, Y.; Ivanov, D. A.; Dijkstra, P. J.; Feijen, J. Chapter 7, this thesis; University of Twente, 2011. 


\title{
Synthesis, morphology and properties of segmented poly(ether ester amide)s comprising uniform glycine or $\beta$-alanine extended bisoxalamide hard segments
}

\author{
N.J. Sijbrandi ${ }^{a}$, A.J. Kimenai ${ }^{b}$, E.P.C. Mes ${ }^{b}$, R. Broos ${ }^{b}$, G. Bar ${ }^{c}$, M. Rosenthal ${ }^{d}, Y$. \\ Odarchenko $^{d}$, D.A. Ivanov ${ }^{d}$, P.J. Dijkstra ${ }^{a}$, J. Feijen ${ }^{a}$

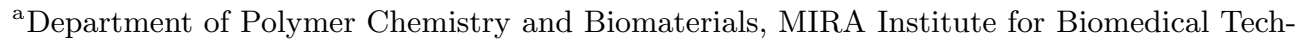 \\ nology and Technical Medicine, Faculty of Science and Technology, University of Twente, \\ P.O. Box 217, 7500 AE Enschede, The Netherlands \\ ${ }^{\mathrm{b}}$ Core R\&D, DOW Benelux BV, P.O. Box 48, 4530 AA, Terneuzen, The Netherlands \\ ${ }^{\mathrm{c}}$ Dow olefin verbund GmbH, P.O. Box 1163, D-06258, Schkopau, Germany \\ ${ }^{\mathrm{d}}$ Institut de Sciences des Matriaux de Mulhouse-IS2M, CNRS LRC 7228, Jean Starcky, 15, \\ F-68057 Mulhouse, France
}

\begin{abstract}
Poly(ether ester amide)s comprising glycine or $\beta$-alanine extended bisoxalamide hard segments are highly phase separated thermoplastic elastomers with a broad temperature independent rubber plateau. These materials with molecular weights, $M_{n}$, exceeding $30 \times 10^{3} \mathrm{~g} . \mathrm{mol}^{-1}$ are conveniently prepared by polycondensation of preformed bisesterbisoxalamides and commercially available PTHF diols. FT-IR revealed strongly hydrogen bonded and highly ordered bisoxalamide hard segments with degrees of crystallinity between 73 and $99 \%$. The morphology consists of fiber-like nano-crystals randomly dispersed in the soft polymer matrix. The long dimension of these crystals is in the direction of the hydrogen bonds. The melting transitions of the hard segments are narrow with temperatures up to $170{ }^{\circ} \mathrm{C}$. These polymers have an elastic modulus in the range of 139 to $170 \mathrm{MPa}$, a stress at break in the range of 19 to $31 \mathrm{MPa}$ combined with strains at break of higher than $800 \%$. The segmented copolymer comprising the $\beta$-alanine based bisoxalamide hard segment with a spacer length of 6 methylene groups has a melting transition of $141{ }^{\circ} \mathrm{C}$ which is higher than the melting transition of its glycine analogue of $119^{\circ} \mathrm{C}$. Likewise, the fracture stress increased from 22 to 31 $\mathrm{MPa}$ when the glycine ester group in the hard segment was replaced with $\beta$-alanine. The improved thermal and mechanical properties of the latter polymers is related to the crystal packing of the $\beta$-alanine based hard segments in the copolymer compared to the packing of the hard segments comprising glycine ester groups.
\end{abstract}




\subsection{Introduction}

Segmented block copolymers consisting of alternating elastomeric soft segments and rigid crystallizable hard segments are thermoplastic elastomers ${ }^{1,2}$. These materials show elastomeric behavior at ambient temperatures and are melt-processable as a result of their phase separated morphology. At ambient temperatures, the hard segments form rigid crystalline domains in a matrix of soft segments ${ }^{3}$. These domains act as physical crosslinks providing stiffness and strength to the material. The properties of these segmented block copolymers are significantly affected by the symmetry, nature of hydrogen bonding and size distribution of the hard segment ${ }^{4-16}$. Symmetrical and uniform hard segments in segmented copolymers can easily crystallize and high degrees of crystallinity can be obtained. Consequently, copolymers with such segments usually have broad and temperature independent rubber plateaus, relatively high moduli and good ultimate mechanical properties.

Segmented block copolymers with uniform amide based hard segments have been prepared by Gaymans and coworkers ${ }^{13,17-29}$. The main two hard segments which have been used are the di-amide segment (T $\Phi \mathrm{T})$ based on 1.5 repeating unit poly $(\mathrm{p}-$ phenylene terephthalamide) and the tetra-amide segment based on 2.5 repeating unit nylon-6,T (T6T6T). The corresponding segmented copolymers have been generally prepared by first purifying the amide group containing monomers and subsequently reacting these monomers with polyether prepolymers in a two step solution/melt polymerization. Although the hard segments are relatively short, they crystallize fast and almost completely in the segmented copolymer. TEM and AFM analysis of these copolymers show a morphology of fiber-like nano-crystals randomly dispersed in a soft polymer matrix. Even at a hard segment concentration of $\sim 3 \mathrm{wt} \%$, the polymers show a distinct phase separated morphology and hence good elastomeric and mechanical properties.

In previous work, we prepared segmented poly(ether amide)s based on uniform rigid oxalamide segments and flexible PTHF segments and studied their properties ${ }^{30,31}$. Copolymers comprising hard segments with two or three oxalamide units appear highly phase separated affording elastic materials. The oxalamide containing hard segments are strongly hydrogen bonded and highly ordered, forming fiber-like nano-crystals which are randomly dispersed in a soft polymer matrix. The flow temperatures of bisoxalamide based segmented poly(ether amide)s increased from 150 to $200{ }^{\circ} \mathrm{C}$ when the number of methylene groups between the two bisoxalamide groups was decreased 
from 10 to 2. Copolymers with three oxalamide groups in the hard segment had a flow temperature of $220{ }^{\circ} \mathrm{C}$. The use of hard segments with either two or three oxalamide groups provided materials with attractive mechanical properties. Due to the high flow temperatures of the copolymers with three oxalamide groups in the hard segment, melt processing of these materials becomes difficult. Therefore, incorporation of two oxalamide groups in the hard segment to prepare these polymers seems to be the optimum balance between the material properties and processability.

The bisoxalamide based segmented poly(ether amide)s were previously prepared by first reacting bis(3-aminopropyl) functionalized polytetrahydrofuran with an excess of diethyl oxalate ${ }^{30}$. Subsequently, the amide-ester functionalized polytetrahydrofuran was polycondensated in the melt with a linear aliphatic $\alpha, \omega$-diamine. Although the synthesis of these polymers is straightforward, $\alpha, \omega$-amine end functionalized prepolymers are needed. In general, the commercial availability of these prepolymers is limited and/or they are relatively expensive. In contrast, a wide range of $\alpha, \omega$ hydroxyl end functionalized prepolymers is commercially available or synthetically easily accessible.

Therefore, a better strategy to prepare bisoxalamide based segmented block copolymers is the polycondensation of $\alpha, \omega$-hydroxyl end functionalized prepolymers and preformed bisester-bisoxalamides ${ }^{32}$. Such monomers were conveniently synthesized in two steps. In the first step, bisoxalamide precursors were prepared by reacting $\alpha, \omega$-diamines with an excess of diethyl oxalate. Subsequently, the product was reacted with (pseudo) amino acid esters, glycine and $\beta$-alanine ethyl ester, affording the bisester-bisoxalamides.

In the current work we have prepared segmented copolymers based on hard segments containing two oxalamide groups, in which these groups are separated by spacers with different lengths. Moreover the hard segments were either terminated by a glycine or a $\beta$-alanine residue. The molecular weight $\left(\mathrm{M}_{\mathrm{n}}\right)$ of the soft PTHF segment was varied from $1.0 \times 10^{3}$ to $2.9 \times 10^{3}$ g. $\mathrm{mol}^{-1}$. The influence of the structure of the hard segment and the $\mathrm{M}_{\mathrm{n}}$ of the soft PTHF block on the properties of the resulting copolymers was evaluated. 


\subsection{Experimental}

\subsubsection{Materials}

Gly-OXA 2 2-Gly (2a), Gly-OXA 2 4-Gly (2b), Gly-OXA 2 6-Gly (2c), $\beta$ Ala-OXA 2 6$\beta$ Ala (3) and $\mathrm{PTHF}_{1100}-\mathrm{OXA}_{2} 6$ (8) were prepared as reported previously ${ }^{30,32}$. Hydroxyl end functionalized polytetrahydrofuran with molecular weights $\left(\mathrm{M}_{\mathrm{n}}\right)$ of $1.0 \times 10^{3}$, $2.0 \times 10^{3}$ and $2.9 \times 10^{3}$ g. mol $^{-1}\left(\mathrm{PTHF}_{1000}, \mathrm{PTHF}_{2000}\right.$ and $\left.\mathrm{PTHF}_{2900}\right)$, chloroform- $\mathrm{d}_{1}$ $\left(\mathrm{CDCl}_{3}-\mathrm{d}_{1}\right)$ and 1,1,1,3,3,3-hexafluoro-2-propanol (HFIP) were purchased from Aldrich (Zwijndrecht, The Netherlands). Irganox1330 was kindly provided by Ciba (Geigi, Switzerland). HPLC-quality chloroform was purchased from Lab-Scan (Gliwice, Poland). Diethyl ether, tetrahydrofuran, dichloromethane and toluene were obtained from Biosolve (Valkenswaard, The Netherlands). Chloroform and tetrabutylorthotitanoate $\left(\mathrm{Ti}(\mathrm{OBu})_{4}\right)$ were purchased from Merck (Darmstadt, Germany). All materials were used as received.

\subsubsection{Synthesis}

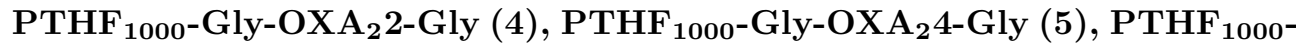
$\beta$ Ala-OXA 6 - $\beta$ Ala (7)

Hydroxyl end functionalized polytetrahydrofuran with a molecular weight of $1.0 \times 10^{3}$ g.mol ${ }^{-1}$ (1a) $\left(\mathrm{PTHF}_{1000}\right)$ was polymerized with Gly-OXA 2 2-Gly (2a), Gly-OXA 2 -Gly (2b) or $\beta$ Ala-OXA $26-\beta$ Ala (3). In a typical example, $\mathrm{PTHF}_{1000}$ (1a) (25.00 g, 0.025 $\mathrm{mol}$ ) and Gly-OXA 2 -Gly (2a) (9.35 g, $0.025 \mathrm{~mol}$ ) were placed in a polymerization tube. To this mixture were added $\mathrm{Ti}(\mathrm{OBu})_{4}(0.2 \mathrm{wt} \%$ relative to the total mass and dissolved in $1 \mathrm{ml}$ of toluene) and Irganox1330 (1 wt\% of the total mass). The mixture was heated to $230^{\circ} \mathrm{C}$ under a nitrogen flow until the reaction mixture was transparent. Subsequently, the temperature was lowered to $190{ }^{\circ} \mathrm{C}$. After $1 \mathrm{~h}$, the pressure was slowly reduced to $\sim 20$ mbar to distill off the ethanol in approximately 30 min. Subsequently, the pressure was reduced to $\sim 0.08$ mbar in the following $3 \mathrm{~h}$. The reaction mixture was then cooled to room temperature under vacuum. The polymer was dissolved in $100 \mathrm{ml}$ of chloroform at $50{ }^{\circ} \mathrm{C}$ and subsequently precipitated in $2 \mathrm{~L}$ of diethyl ether. The polymer was filtered off and dried at $60{ }^{\circ} \mathrm{C}$ at reduced pressure. The product was obtained as a transparent elastic solid in a yield of $\sim 95 \%$. 
PTHF $_{1000}$-Gly-OXA 2 2-Gly (4): ${ }^{1} \mathrm{H}$ NMR (300 MHz, $\left.\mathrm{CDCl}_{3}-\mathrm{d}_{1}\right): \delta=8.61$ (bt, $2 \mathrm{H}$, $\mathrm{COCH}_{2} \mathrm{NHCO}$ ), 7.99 (bt, $2 \mathrm{H}, \mathrm{CONHCH}_{2}$ ), 4.28 (t, 4H, $\mathrm{CH}_{2} \mathrm{CH}_{2} \mathrm{OCO}$ ), 4.07 (d, $4 \mathrm{H}$, $\mathrm{COCH}_{2} \mathrm{NHCO}$ ), 3.49 (q, $4 \mathrm{H}, \mathrm{CONHCH}_{2}$ ), 3.43-3.34 (m, $54 \mathrm{H}, \mathrm{OCH}_{2} \mathrm{CH}_{2}$ ), 1.71 (t, $\left.4 \mathrm{H}, \mathrm{CH}_{2} \mathrm{CH}_{2} \mathrm{OCO}\right), 1.66-1.52\left(\mathrm{~m}, 54 \mathrm{H}, \mathrm{OCH}_{2} \mathrm{CH}_{2}\right)$.

PTHF $_{1000}$-Gly-OXA 24 -Gly (5): ${ }^{1} \mathrm{H}$ NMR (300 MHz, $\left.\mathrm{CDCl}_{3}-\mathrm{d}_{1}\right): \delta=7.93$ (bt, $2 \mathrm{H}$, $\mathrm{COCH}_{2} \mathrm{NHCO}$ ), 7.54 (bt, $2 \mathrm{H}, \mathrm{CONHCH}_{2} \mathrm{CH}_{2}$ ), 4.17 (t, 4H, $\mathrm{CH}_{2} \mathrm{CH}_{2} \mathrm{OCO}$ ), 4.05 (d, $\left.4 \mathrm{H}, \mathrm{COCH}_{2} \mathrm{NHCO}\right), 3.43-3.35\left(\mathrm{~m}, 54 \mathrm{H}, \mathrm{OCH}_{2} \mathrm{CH}_{2}\right), 3.31$ (q, $4 \mathrm{H}, \mathrm{CONHCH}_{2} \mathrm{CH}_{2}$ ), $1.71\left(\mathrm{t}, 4 \mathrm{H}, \mathrm{CH}_{2} \mathrm{CH}_{2} \mathrm{OCO}\right), 1.67-1.50\left(\mathrm{~m}, 54 \mathrm{H}, \mathrm{OCH}_{2} \mathrm{CH}_{2}\right), 1.66-1.52(\mathrm{~m}, 4 \mathrm{H}$, $\left.\mathrm{CONHCH}_{2} \mathrm{CH}_{2}\right)$.

PTHF $_{1000}-\beta$ Ala-OXA $26-\beta$ Ala (7): ${ }^{1} \mathrm{H} \mathrm{NMR}\left(300 \mathrm{MHz}_{2} \mathrm{CDCl}_{3}-\mathrm{d}_{1}\right): \delta=7.87$ (bt, $2 \mathrm{H}$, $\mathrm{COCH}_{2} \mathrm{CH}_{2} \mathrm{NHCO}$ ), 7.48 (bt, $2 \mathrm{H}, \mathrm{CONHCH}_{2} \mathrm{CH}_{2} \mathrm{CH}_{2}$ ), 4.11 (t, $4 \mathrm{H}, \mathrm{CH}_{2} \mathrm{CH}_{2} \mathrm{OCO}$ ), 3.58 (q, 4H, $\mathrm{COCH}_{2} \mathrm{CH}_{2} \mathrm{NHCO}$ ), 3.49-3.39 (m, 54H, $\mathrm{OCH}_{2} \mathrm{CH}_{2}$ ), 3.29 (q, 4H, $\mathrm{CONHCH}_{2} \mathrm{CH}_{2} \mathrm{CH}_{2}$ ), 2.57 (t, $\left.4 \mathrm{H}, \mathrm{COCH}_{2} \mathrm{CH}_{2} \mathrm{NHCO}\right), 1.68$ (t, $4 \mathrm{H}, \mathrm{CH}_{2} \mathrm{CH}_{2} \mathrm{OCO}$ ), 1.66-1.47 (m, 54H, $\left.\mathrm{OCH}_{2} \mathrm{CH}_{2}\right), 1.66-1.47\left(\mathrm{~m}, 4 \mathrm{H}, \mathrm{CONHCH}_{2} \mathrm{CH}_{2} \mathrm{CH}_{2}\right), 1.34(\mathrm{~m}, 4 \mathrm{H}$, $\left.\mathrm{CONHCH}_{2} \mathrm{CH}_{2} \mathrm{CH}_{2}\right)$.

\section{PTHF-Gly-OXA 6 6-Gly (6a-c)}

Hydroxyl end functionalized polytetrahydrofuran with molecular weights of $1.0 \times 10^{3}$, $2.0 \times 10^{3}$ or $2.9 \times 10^{3}$ g. mol $^{-1}$ (1a-c) were polymerized with Gly-OXA 6 -Gly (2c). In a typical example, PTHF $_{1000}$ (1a) (25.00 g, $0.025 \mathrm{~mol}$ ) and Gly-OXA 6 -Gly (2c) (10.58 g, $0.025 \mathrm{~mol})$ were placed in a polymerization tube. To this mixture were added $\mathrm{Ti}(\mathrm{OBu})_{4}(0.2 \mathrm{wt} \%$ relative to the total mass and dissolved in $1 \mathrm{ml}$ of toluene) and Irganox1330 (1 wt\% of the total mass). The mixture was heated to $150{ }^{\circ} \mathrm{C}$ under a nitrogen flow and subsequently the temperature was raised every $0.5 \mathrm{~h}, 30{ }^{\circ} \mathrm{C}$ to 250 ${ }^{\circ} \mathrm{C}$. After $1 \mathrm{~h}$, the pressure was slowly reduced to $\sim 20$ mbar to distill off the ethanol in approximately $30 \mathrm{~min}$. Subsequently, the pressure was reduced to $\sim 0.08 \mathrm{mbar}$ in the following $2 \mathrm{~h}$. The reaction mixture was then cooled to room temperature under vacuum. The polymer was dissolved in $200 \mathrm{ml}$ of chloroform at $50{ }^{\circ} \mathrm{C}$ and subsequently precipitated in $2 \mathrm{~L}$ of diethyl ether. The polymer was filtered off and dried at $60{ }^{\circ} \mathrm{C}$ at reduced pressure. The product was obtained as a yellow transparent elastic solid in a yield of $\sim 95 \%$. 
PTHF $_{1000}$-Gly-OXA 6 -Gly (6a): $\left.{ }^{1} \mathrm{H} \mathrm{NMR} \mathrm{(300} \mathrm{MHz,} \mathrm{CDCl}_{3}-\mathrm{d}_{1}\right) \delta=7.91$ (bt, $2 \mathrm{H}$,

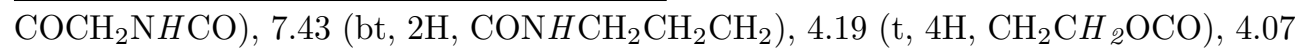
(d, $4 \mathrm{H}, \mathrm{COCH}_{2} \mathrm{NHCO}$ ), $3.47-3.35\left(\mathrm{~m}, 54 \mathrm{H}, \mathrm{OCH}_{2} \mathrm{CH}_{2}\right.$ ), 3.31 (q, $4 \mathrm{H}, \mathrm{CONHCH}_{2} \mathrm{CH}_{2}$ $\left.\mathrm{CH}_{2}\right), 1.72\left(\mathrm{t}, 4 \mathrm{H}, \mathrm{CH}_{2} \mathrm{CH}_{2} \mathrm{OCO}\right), 1.67-1.54\left(\mathrm{~m}, 54 \mathrm{H}, \mathrm{OCH}_{2} \mathrm{CH}_{2}\right), 1.67-1.54(\mathrm{~m}, 4 \mathrm{H}$, $\left.\mathrm{CONHCH}_{2} \mathrm{CH}_{2} \mathrm{CH}_{2}\right), 1.36\left(\mathrm{~m}, 4 \mathrm{H}, \mathrm{CONHCH}_{2} \mathrm{CH}_{2} \mathrm{CH}_{2}\right.$ ).

PTHF $_{2000}$-Gly-OXA 6 -Gly (6b): ${ }^{1} \mathrm{H}$ NMR $\left(300 \mathrm{MHz}, \mathrm{CDCl}_{3}\right.$-d $\left.\mathrm{d}_{1}\right) \delta=7.89$ (bt, $2 \mathrm{H}$, $\mathrm{COCH}_{2} \mathrm{NHCO}$ ), 7.40 (bt, $2 \mathrm{H}, \mathrm{CONHCH}_{2} \mathrm{CH}_{2} \mathrm{CH}_{2}$ ), 4.19 (t, $4 \mathrm{H}, \mathrm{CH}_{2} \mathrm{CH}{ }_{2} \mathrm{OCO}$ ), 4.07 (d, $4 \mathrm{H}, \mathrm{COCH}{ }_{2} \mathrm{NHCO}$ ), 3.53-3.34 (m, $108 \mathrm{H}, \mathrm{OCH}_{2} \mathrm{CH}_{2}$ ), 3.31 (q, $4 \mathrm{H}, \mathrm{CONHCH}_{2} \mathrm{CH}_{2}-$ $\mathrm{CH}_{2}$ ), 1.71 (t, $\left.4 \mathrm{H}, \mathrm{CH}_{2} \mathrm{CH}_{2} \mathrm{OCO}\right), 1.66-1.48\left(\mathrm{~m}, 108 \mathrm{H}, \mathrm{OCH}_{2} \mathrm{CH}_{2}\right), 1.66-1.48(\mathrm{~m}, 4 \mathrm{H}$, $\left.\mathrm{CONHCH}_{2} \mathrm{CH}_{2} \mathrm{CH}_{2}\right), 1.36\left(\mathrm{~m}, 4 \mathrm{H}, \mathrm{CONHCH}_{2} \mathrm{CH}_{2} \mathrm{CH}_{2}\right.$ ).

PTHF $_{1000}$-Gly-OXA 6 -Gly (6a): ${ }^{1} \mathrm{H} \mathrm{NMR}\left(300 \mathrm{MHz}, \mathrm{CDCl}_{3}-\mathrm{d}_{1}\right) \delta=7.89$ (bt, $2 \mathrm{H}$,

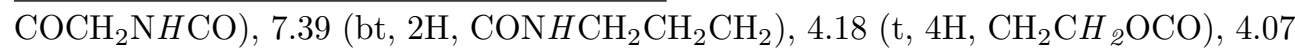
(d, $\left.4 \mathrm{H}, \mathrm{COCH}_{2} \mathrm{NHCO}\right), 3.50-3.33\left(\mathrm{~m}, 156 \mathrm{H}, \mathrm{OCH}_{2} \mathrm{CH}_{2}\right), 3.31$ (q, $4 \mathrm{H}, \mathrm{CONHCH}_{2} \mathrm{CH}_{2}$ $\left.\mathrm{CH}_{2}\right), 1.71\left(\mathrm{t}, 4 \mathrm{H}, \mathrm{CH}{ }_{2} \mathrm{CH}_{2} \mathrm{OCO}\right), 1.69-1.54\left(\mathrm{~m}, 156 \mathrm{H}, \mathrm{OCH}_{2} \mathrm{CH}_{2}\right), 1.69-1.54(\mathrm{~m}, 4 \mathrm{H}$, $\left.\mathrm{CONHCH}_{2} \mathrm{CH}_{2} \mathrm{CH}_{2}\right), 1.35$ (m, $4 \mathrm{H}, \mathrm{CONHCH}_{2} \mathrm{CH}_{2} \mathrm{CH}_{2}$ ).

\subsubsection{Methods}

\section{NMR}

${ }^{1} \mathrm{H}(300 \mathrm{MHz})$ and ${ }^{13} \mathrm{C}$ NMR $(75.26 \mathrm{MHz})$ spectra were recorded on a Varian Inova Nuclear Magnetic Resonance Spectrometer using $\mathrm{CDCl}_{3}-\mathrm{d}_{1}$ as solvent.

\section{GPC}

The GPC setup consisted of a Perkin Elmer series 200 binary pump, a Perkin Elmer series 200 autosampler, a Shimadzu CTO-AVP column oven, and a Shimadzu RID-10A refractive index detector. The eluent was $\mathrm{CHCl}_{3} / \mathrm{HFIP}(95 / 5 \mathrm{v} / \mathrm{v})$. The flow was set at $1 \mathrm{ml} \cdot \mathrm{min}^{-1}$. The injection volume was $200 \mu \mathrm{L}$. The separation was performed on two PL Mixed-D columns $(300 \times 7.5 \mathrm{~mm})$ from Polymer Laboratories Ltd., packed with $5 \mu \mathrm{m}$ particles. The temperature of the columns was set at $30{ }^{\circ} \mathrm{C}$. Approximately $120 \mathrm{mg}$ of sample is weighed in a $50 \mathrm{ml}$ vial. To this vial $2 \mathrm{ml}$ of HFIP is added and the solution is allowed to stand for $2 \mathrm{~h}$. Next, $38 \mathrm{ml}$ of warm $\left(\sim 35^{\circ} \mathrm{C}\right)$ HPLC-quality chloroform is added and mixed thoroughly. Prior to injection the sample solution is filtered through a Millex-LCR $0.45 \mu \mathrm{m}$ filter (Millipore). The system was calibrated with 14 narrow polystyrene standards (Polymer Laboratories) with MW ranging from $5.8 \times 10^{2}$ to $1.0 \times 10^{6}$ g.mol ${ }^{-1}$. The standards were dissolved in $\mathrm{CHCl}_{3} / \mathrm{HFIP}(95 / 5 \mathrm{v} / \mathrm{v})$. 
Because the $\mathrm{K}$ and $\alpha$ values of the samples are not known and a viscometer was not available, no universal calibration could be performed. The reported molecular weights should, therefore, be regarded as PS-equivalent molecular weights. A calibration curve that is virtually linear over a broad molecular weight range was obtained. However, the three highest molecular weights tested $\left(6.75 \times 10^{5}\right.$ g.mol ${ }^{-1}, 8.41 \times 10^{5}$ g.mol ${ }^{-1}$, and $1.0 \times 10^{6}$ g.mol ${ }^{-1}$ ) elute near or in the exclusion limit of the column, causing an upward curvature at the high MW end.

\section{FT-IR}

To minimize the potential oxidation of the material, sample preparation comprised the following steps. The surface of a $32 \times 3 \mathrm{~mm} \mathrm{NaCl}$ disc (Thermo, International Crystal Labs) was roughened to prevent interfering fringes. Subsequently, a polymer solution of 0.3-0.5 g.ml-1 in dichloromethane was drop casted on the $\mathrm{NaCl}$ disk and the solvent was allowed to evaporate. This step was repeated until the polymer film thickness gave a maximum peak height of $0.5-0.7$. The holder was placed in the cell in an inert atmosphere $\left(\mathrm{N}_{2}\right.$ purge glove bag or $\mathrm{N}_{2}$ purged IR sample compartment). The cell was heated to $20-50{ }^{\circ} \mathrm{C}$ above the $\mathrm{T}_{\mathrm{m}}$ of the polymer and subsequently cooled to room temperature. Fourier transform infra-red spectra were recorded on a Thermo 5700 spectrometer utilizing a DTGS detector at $4 \mathrm{~cm}^{-1}$ resolution. The temperature of the prepared polymer film was controlled by an infra-red cell from Spectra Tech (model 0019-019). The data were collected between 4000 and $500 \mathrm{~cm}^{-1}$ (16 scans were acquired). The graphs were prepared using OPUS 6.1 software. All spectra were normalized to the $2860 \mathrm{~cm}^{-1}$ signal. The carbonyl region was analyzed quantitatively in terms of free, bonded and ordered amide structures by curve fitting (Omnic version 7.2) and following the guidelines of Meier et $a l^{33}$.

\section{DSC}

Thermal analysis was carried out using a Perkin-Elmer Pyris 1. Calibration was carried out with pure indium. Samples (5-10 mg) were heated from -100 to $200{ }^{\circ} \mathrm{C}$ at a rate of $20{ }^{\circ} \mathrm{C} \cdot \mathrm{min}^{-1}$, annealed for $5 \mathrm{~min}$, cooled to $-100{ }^{\circ} \mathrm{C}$ at a rate of $20{ }^{\circ} \mathrm{C} \cdot \mathrm{min}^{-1}$, and subsequently heated from -100 to $200{ }^{\circ} \mathrm{C}$ at a rate of $20{ }^{\circ} \mathrm{C} \cdot \mathrm{min}^{-1}$. Melting $\left(\mathrm{T}_{\mathrm{m}}\right)$ and crystallization $\left(\mathrm{T}_{\mathrm{c}}\right)$ temperatures were obtained from the peak maxima, melting $\left(\Delta \mathrm{H}_{\mathrm{m}}\right)$ and crystallization $\left(\Delta \mathrm{H}_{\mathrm{c}}\right)$ enthalpies were determined from the area under the curve. The data presented are taken from the first cooling scan and the second heating scan. 


\section{TGA}

Thermal gravimetric analysis was carried out with 5-10 mg samples under a nitrogen atmosphere in the $50-700{ }^{\circ} \mathrm{C}$ range at a heating rate of $10{ }^{\circ} \mathrm{C} \cdot \mathrm{min}^{-1}$, using a Perkin-Elmer Thermal Gravimetric Analyser TGA 7.

\section{AFM}

Atomic force microscopy images were obtained using a MultiMode scanning probe microscope (SPM) (Veeco Metrology Group, Santa Barbara, CA) with a Nano-Scope IV controller running software version 5.12. The TESP probe used was $125 \mu \mathrm{m}$ in length, had a tip radius of $8 \mathrm{~nm}$ and a force constant of $40 \mathrm{~N} . \mathrm{m}^{-1}$. A moderate tapping ratio of about 0.5 was applied in all measurements. Height and phase images were recorded at various magnifications. Samples were prepared by drop casting a $1 \mathrm{mg} \cdot \mathrm{ml}^{-1}$ chloroform solution on a silicon waver. After evaporation, the sample was heated to $20{ }^{\circ} \mathrm{C}$ above the $\mathrm{T}_{\text {flow }}$ for $15 \mathrm{~min}$ and slowly cooled to room temperature.

\section{X-ray diffraction}

Wide- (WAXS) and small-angle X-ray scattering (SAXS) measurements were performed on the BM26 beamline of the ESRF (Grenoble, France) using the wavelength of 1.04 $\AA$. The experimental setup comprised a motorized stage with a Frelon detector, which ensured adjustable sample-to-detector distance and allowed to record the signal in the $s$-range $\left(s=2 \sin \Theta / \lambda\right.$, where $\Theta$ is the Bragg angle) from 0.01 to $0.5 \AA^{-1}$. The modulus of the scattering vector $s$ was calibrated using diffraction orders of silver behenate in both setups. The diffraction patterns were collected in transmission geometry. The sample temperature was controlled by a Linkam heating stage.

\section{Processing}

Compression molded bars $(75 \times 10 \times 2 \mathrm{~mm})$ were prepared using a hot press $(\mathrm{THB}$ 008, Fontijne Holland BV, the Netherlands). Polymers were heated for 4 min at approximately $20{ }^{\circ} \mathrm{C}$ above their $\mathrm{T}_{\text {flow }}$, pressed for $3 \mathrm{~min}$ at $300 \mathrm{kN}$, and cooled in approximately 5 min under pressure to room temperature.

\section{DMA}

Dynamic mechanical analysis was performed using a Myrenne ATM3 torsion pendulum at a frequency of approximately $1 \mathrm{~Hz}$. The storage modulus $\left(\mathrm{G}^{\prime}\right)$ and the loss modulus $\left(\mathrm{G}^{\prime \prime}\right)$ were measured as a function of temperature. Samples $(50 \times 10 \times 2 \mathrm{~mm})$ were cooled to $-100{ }^{\circ} \mathrm{C}$ and then heated at a rate of $1{ }^{\circ} \mathrm{C} \cdot \mathrm{min}^{-1}$. The temperature at which the loss modulus reached a maximum was taken as the glass transition temperature $\left(\mathrm{T}_{\mathrm{g}}\right)$. The flow temperature $\left(\mathrm{T}_{\text {flow }}\right)$ was taken at a storage modulus value of $1 \mathrm{MPa}$. 


\section{Tensile testing}

Tensile tests were conducted with compression molded bars cut to dumbbells (ISO37 type 2). A Zwick Z010 universal tensile machine equipped with a $2500 \mathrm{~N}$ load cell was used to measure the stress at a strain rate of $0.4 \mathrm{~s}^{-1}$ (test speed: $60 \mathrm{~mm} . \mathrm{min}^{-1}$ ) and a preload of $0.1 \mathrm{MPa}$. Measurements were performed on at least 5 different polymer bars.

\section{Compression set}

Polymer samples $(10 \times 10 \times 2 \mathrm{~mm})$, cut from compression molded bars, were placed between two metal plates at $25{ }^{\circ} \mathrm{C}$ (ASTM 395 B standard) and compressed to 75 $\%$ of their original thickness for $24 \mathrm{~h}$. The sample thickness was determined $30 \mathrm{~min}$ after the load was released. The measurements were performed in triplicate. The compression set (CS) is calculated according to:

$$
C S=\frac{d_{0}-d_{2}}{d_{0}-d_{1}} \times 100 \%
$$

where $d_{0}, d_{1}$ and $d_{2}$ are the sample thicknesses before, during and after compression, respectively. 


\subsection{Results and Discussion}

\subsubsection{Synthesis and characterization}

The synthesis of bisester-bisoxalamides $\mathbf{2 a - c}$ and $\mathbf{3}$ was described in Chapter $6^{32}$. Segmented poly(ether ester amide)s were prepared by melt polycondensation of $\alpha, \omega-$ hydroxyl end functionalized polytetrahydrofuran 1a-c $\left(\mathrm{M}_{\mathrm{n}}=1.0 \times 10^{3}, 2.0 \times 10^{3}\right.$ and $2.9 \times 10^{3}$ g. mol $^{-1}$ ) and bisester-bisoxalamides $\mathbf{2 a - c}$ and $\mathbf{3}$ (Scheme 7.1).<smiles>CC(O)CCCO</smiles>

$1.0 \times 10^{3} \mathrm{~g}^{\mathrm{mol}}{ }^{-1}(1 \mathrm{a})$
$2.0 \times 10^{3} \mathrm{~g} \cdot \mathrm{mol}^{-1}(1 \mathrm{~b})$
$2.9 \times 10^{3} \mathrm{~g} \cdot \mathrm{mol}^{-1}(1 \mathrm{c})$<smiles></smiles>

$p=1, q=1$ Gly-OXA 2 -Gly $(2$ a)

$p=2, q=1$ Gly-OXA $24-G l y(2$ b)

$p=3, q=1$ Gly-OXA $26-$ Gly $(2 \mathrm{c})$

$p=3, q=2 \beta$ Ala-OXA $26-\beta$ Ala (3)

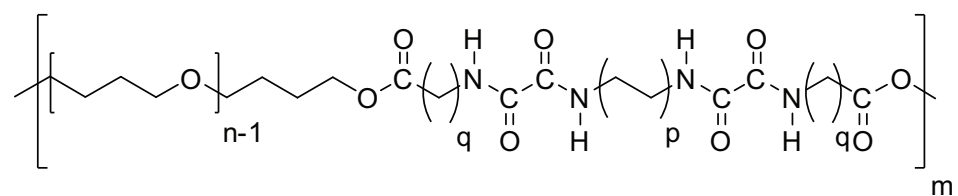

Gly-OXA $26-$ Gly

$$
\mathrm{PTHF}=1.0 \times 10^{3} \mathrm{~g} \cdot \mathrm{mol}^{-1}
$$

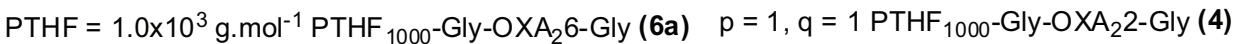

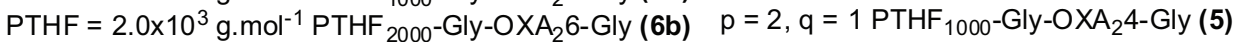

$\mathrm{PTHF}=2.9 \times 10^{3} \mathrm{~g} \cdot \mathrm{mol}^{-1} \mathrm{PTHF}_{2900}-\mathrm{Gly}_{\mathrm{O}} \mathrm{OXA}_{2} 6-\mathrm{Gly}(6 \mathrm{c}) \quad \mathrm{p}=3, \mathrm{q}=2 \mathrm{PTHF}_{1000}-\beta$ Ala-OXA $26-\beta$ Ala (7)<smiles>CC(C)CCCNC(=O)C(=O)NCCCCCCNC(=O)C(=O)NCCCOC(C)(C)CCCOC1CCCC1</smiles>

$\mathrm{PTHF}_{1100}-\mathrm{OXA}_{2} 6$ (8)

Scheme 7.1: Synthesis of segmented poly(ether ester amide)s 4-7. Polymer 8 was used for comparison $^{30}$. 
The condensation reactions of PTHF-Gly-OXA 2 6-Gly (6a-c) were performed at 250 ${ }^{\circ} \mathrm{C}$ and low pressure for $3 \mathrm{~h}$. The polymers were obtained as yellow elastic transparent solids in high yields. To prevent thermal degradation, which was observed during polycondensation of $\mathrm{PTHF}_{1000}$-Gly-OXA 2 -Gly (4) at $250{ }^{\circ} \mathrm{C}$, the synthesis of polymers 4, 5 and $\mathbf{7}$ was performed in a slightly different way. First, the reaction mixture was heated to a temperature of approximately $230{ }^{\circ} \mathrm{C}$. When the melt was transparent, the temperature was decreased to $190{ }^{\circ} \mathrm{C}$ and the reaction was continued for $3 \mathrm{~h}$ at low pressure. Also these materials were obtained as transparent elastic solids and their color changed from yellow (4) to colorless for polymers 5 and $\mathbf{7}$. ${ }^{1} \mathrm{H}$ NMR analysis revealed the absence of ethyl ester or hydroxyl end groups indicating relatively high molecular weights. GPC analysis revealed molecular weight values between $34.10^{3}$ and $83.10^{3}$ g. $\mathrm{mol}^{-1}$ and PDI's of 2-3 relative to polystyrene standards (Table 7.1 ). The segmented poly(ether amide) $\mathrm{PTHF}_{1100}-\mathrm{OXA}_{2} 6$ (8) reported previously is included in this study ${ }^{30}$.

Table 7.1: Molecular weights of segmented poly(ether ester amide)s 4-7.

\begin{tabular}{|c|c|c|c|c|}
\hline & \multicolumn{2}{|c|}{ Content $^{\mathrm{a}}$} & \multirow[b]{2}{*}{$\frac{\mathrm{M}_{\mathrm{n}}}{\left(\text { g. } \mathrm{mol}^{-1} \times 10^{3} \text { ) }\right.}$} & \multirow[b]{2}{*}{$\begin{array}{c}\text { PDI } \\
(-)\end{array}$} \\
\hline & $\begin{array}{l}\text { Hard segment } \\
\quad(\text { wt } \%)\end{array}$ & $\begin{array}{l}\text { Soft segment } \\
\quad(\text { wt } \%)\end{array}$ & & \\
\hline $\mathrm{PTHF}_{1000}$-Gly-OXA 26 -Gly (6a) & 74.6 & 25.4 & 42 & 3 \\
\hline $\mathrm{PTHF}_{2000}$-Gly-OXA 26 -Gly (6b) & 85.5 & 14.5 & 62 & 3 \\
\hline $\mathrm{PTHF}_{2900}$-Gly-OXA 26 -Gly (6c) & 89.5 & 10.5 & 83 & 3 \\
\hline PTHF $_{1000}$-Gly-OXA 2 2-Gly (4) & 77.8 & 22.2 & 34 & 2 \\
\hline PTHF $_{1000}$-Gly-OXA 24 -Gly (5) & 76.2 & 23.8 & 52 & 2 \\
\hline $\mathrm{PTHF}_{1000}-\beta$ Ala-OXA $26-\beta$ Ala (7) & 73.1 & 26.9 & 59 & 2 \\
\hline $\mathrm{PTHF}_{1100}-\mathrm{OXA}_{2} 6$ (8) & 81.1 & 18.9 & 41 & 9 \\
\hline
\end{tabular}

${ }^{\text {a }}$ The ester groups are included in the calculation of the hard segment content.

\subsubsection{FT-IR}

The FT-IR spectra of the segmented poly(ether ester amide)s with varying hard segments (4-7) are presented for the selected wave number regions 3500-2700, 18001400 and $180-600 \mathrm{~cm}^{-1}$ in Figure 7.1. Characteristic IR bands are found at $\sim 3295$ (Amide A, $\nu$ N-H, H-bonded), 1736-1751 ( $\nu \mathrm{C}=\mathrm{O}$ ester, non H-bonded), 1650 

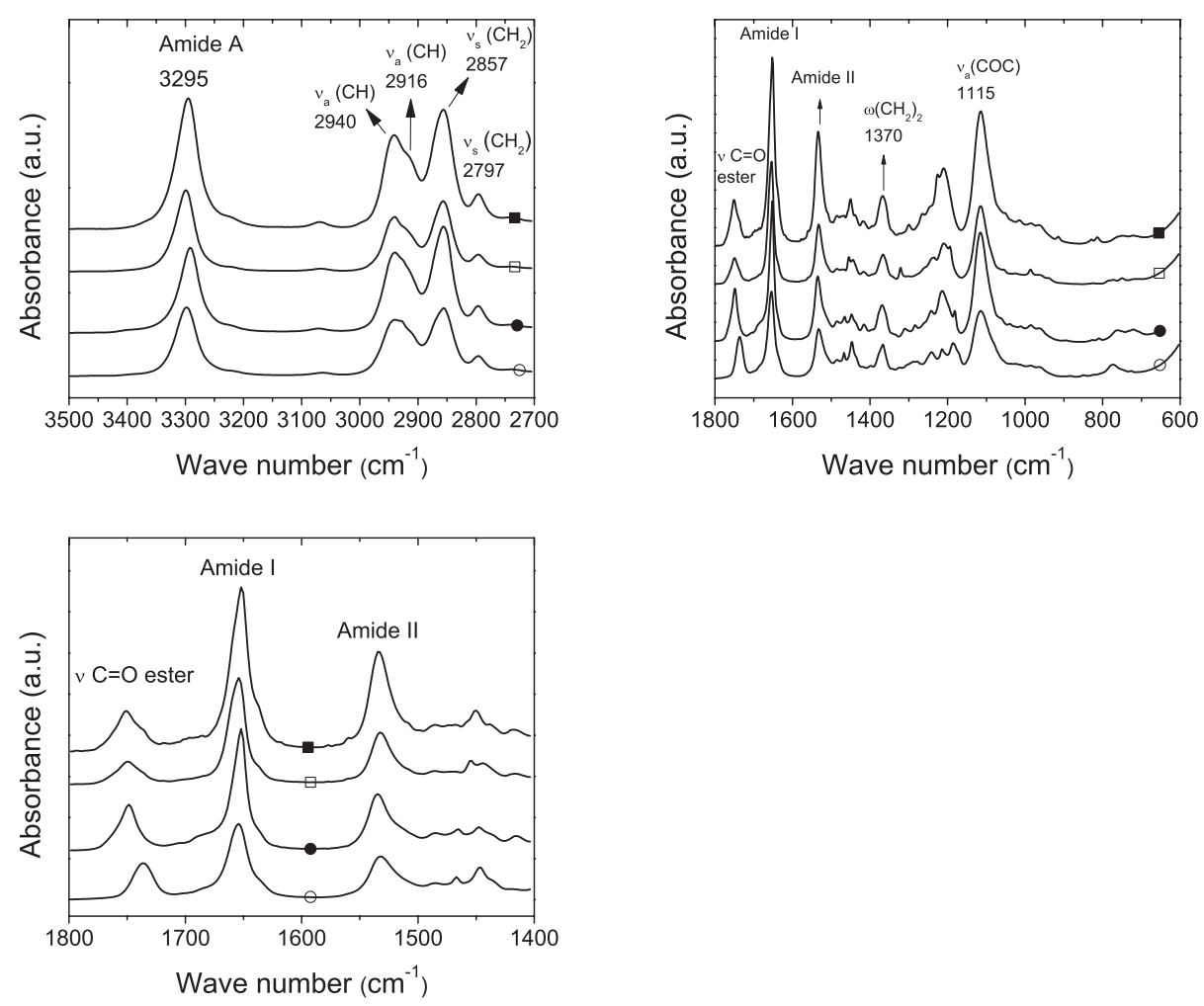

Figure 7.1: FT-IR spectra of segmented poly(ether ester amide)s ( $\boldsymbol{\square}) \mathrm{PTHF}_{1000}-\mathrm{Gly}-$ $\mathrm{OXA}_{2} 2$-Gly (4), (口) $\mathrm{PTHF}_{1000}$-Gly-OXA 2 -Gly (5), (•) $\mathrm{PTHF}_{1000}$-Gly$\mathrm{OXA}_{2} 6$-Gly (6a) and (O) $\mathrm{PTHF}_{1000}-\beta$ Ala-OXA $26-\beta$ Ala (7) at $50{ }^{\circ} \mathrm{C}$.

(amide $\mathrm{I}, \nu \mathrm{C}=\mathrm{O}$ amide, $\mathrm{H}$-bonded ordered), $\sim 1530 \mathrm{~cm}^{-1}$ (Amide II, $\nu \mathrm{C}-\mathrm{N}+\delta \mathrm{N}-\mathrm{H}$ ) (Table 7.2)

For all polymers, the $\mathrm{N}-\mathrm{H}$ and $\mathrm{C}=\mathrm{O}$ stretching vibrations appear as sharp bands at 3295 and $1650 \mathrm{~cm}^{-1}$, respectively. This indicates that the bisoxalamide segments in the polymers are highly ordered and strong hydrogen bonds are formed between the oxalamide groups. Importantly, the ester $\mathrm{C}=\mathrm{O}$ stretching vibration band of the glycine $(\mathbf{4}, \mathbf{5}$ and $\mathbf{6 a})$ and $\beta$-alanine (7) moieties in the segmented poly(ether ester amide)s are found at 1746 and $1736 \mathrm{~cm}^{-1}$, respectively, indicative of non-hydrogen bonded ester groups. These wave numbers are similar to those found for the monomers $\mathbf{2 a - c}$ and $\mathbf{3}$ and indicative of a similar crystalline structure of the monomer and the hard segments in the polymer ${ }^{32}$. Moreover, this indicates that the ester carbonyl groups are spatially tilted away from the oxalamide plane. The higher wave number of the 
glycine ester carbonyl compared to the $\beta$-alanine ester carbonyl vibration band is likely due to rotation of the former group into a more a-polar surrounding.

The amide II band, which is especially sensitive to a specific crystalline structure resulting from the different chain conformation, like the $\alpha$ - or $\gamma$-crystalline structures of nylons, is located at $\sim 1532 \mathrm{~cm}^{-1}$ for all four polymers. Previous research on segmented poly(ether amide)s with bisoxalamide hard segments showed a similar position of the amide II band for spacer lengths of 2 and 4 methylene groups, but this position shifted to $\sim 1520 \mathrm{~cm}^{-1}$ for bisoxalamides with spacer lengths of 6 methylene groups and higher ${ }^{30}$.

Higher wave numbers for bisoxalamide segments with decreasing spacer length can be attributed to increasing chain distortions and hence deviations from the fully extended zig-zag conformation. The amide II position of the segmented poly(ether ester amide)s with bisoxalamide segments having spacer lengths of 6 methylene groups is located at $\sim 1532 \mathrm{~cm}^{-1}$, whereas the amide II position of the corresponding segmented poly(ether amide) is found at a wave number of $1520 \mathrm{~cm}^{-1}$. Apparently, the glycine and $\beta$-alanine ester groups induce a tilting of the oxalamide groups from a fully extended planar zig-zag conformation thereby shifting the amide II band to higher wave numbers.

Table 7.2: Characteristic infrared bands $\left(\mathrm{cm}^{-1}\right)$ of segmented poly(ether ester amide)s 4-7.

\begin{tabular}{|c|c|c|c|c|}
\hline & Amide A & $\nu \mathrm{C}=\mathrm{O}$ & Amide I & Amide II \\
\hline $\mathrm{PTHF}_{1000}-\mathrm{Gly}_{-} \mathrm{OXA}_{2} 2-$ Gly (4) & 3295 & 1751 & 1652 & 1534 \\
\hline PTHF $_{1000}-$ Gly-OXA 24 -Gly (5) & 3299 & 1749 & 1654 & 1532 \\
\hline $\mathrm{PTHF}_{1000}-\mathrm{Gly}_{-} \mathrm{OXA}_{2} 6$-Gly (6a) & 3292 & 1749 & 1652 & 1534 \\
\hline $\mathrm{PTHF}_{1000}-\beta$ Ala-OXA $26-\beta$ Ala $(7)$ & 3298 & 1736 & 1654 & 1532 \\
\hline
\end{tabular}

With temperature dependent FT-IR the effect of temperature on the extent of hydrogen bonding and crystallinity of the hard segment was studied. The N-H stretching vibration band and ester and amide $\mathrm{C}=\mathrm{O}$ stretching vibration bands of $\mathrm{PTHF}_{1000^{-}}$ Gly-OXA 2 6-Gly (6a) at different temperatures are depicted in Figure 7.2. Between 120 and $140{ }^{\circ} \mathrm{C}$, the hydrogen bonded amide $\mathrm{N}-\mathrm{H}$ vibration band shifts from 3292 to $3333 \mathrm{~cm}^{-1}$ and broadens, indicating that the strength of the hydrogen bonds decreases. In addition, a new band at $3400 \mathrm{~cm}^{-1}$ characteristic of free $\mathrm{N}-\mathrm{H}$ bonds arises. Melting of the hard segments is also reflected by the strong decrease of the H-bonded ordered amide $\mathrm{C}=\mathrm{O}$ stretching vibration band at $1652 \mathrm{~cm}^{-1}$ and the appearance of the non $\mathrm{H}$-bonded amide $\mathrm{C}=\mathrm{O}$ peak at $1686 \mathrm{~cm}^{-1}$. The ester $\mathrm{C}=\mathrm{O}$ stretching vibration at 1749 $\mathrm{cm}^{-1}$ only slightly broadens and decreases in intensity as expected for non-ordered and 
(a)

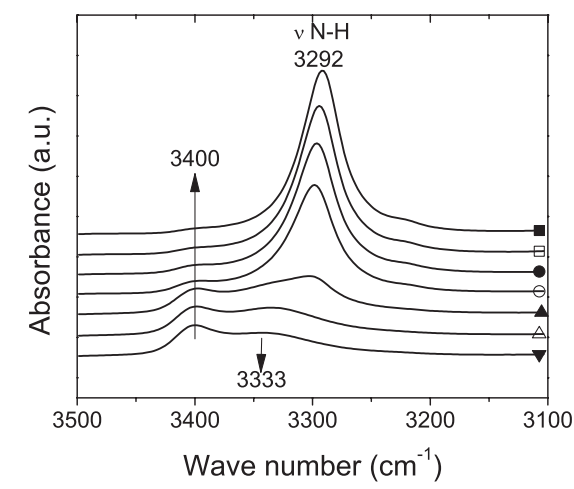

(b)

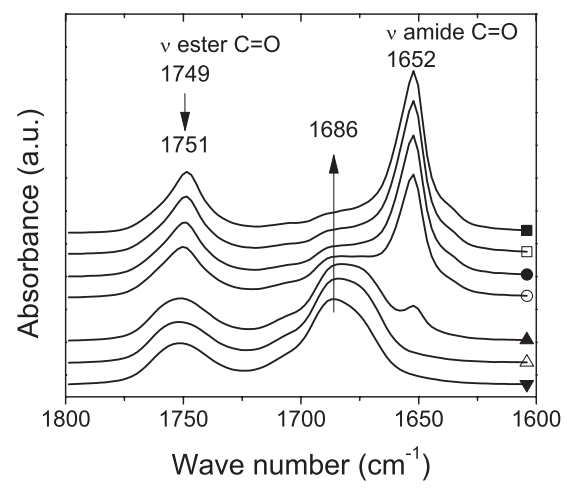

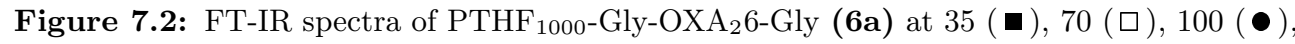
$120(\mathrm{O}), 140(\boldsymbol{\Delta}), 170(\Delta)$ and $200{ }^{\circ} \mathrm{C}(\boldsymbol{\nabla})$ for $(\mathrm{a})$ the $\mathrm{N}-\mathrm{H}$ stretching vibration band and (b) the ester and amide $\mathrm{C}=\mathrm{O}$ strechting vibration bands.

non hydrogen-bonded ester groups. Similar structural characteristics were observed in the FT-IR spectra of the segmented poly(ether ester amide)s $\mathbf{4}, \mathbf{5}$ and $\mathbf{7 .}$

By deconvolution of the amide $\mathrm{C}=\mathrm{O}$ stretching vibration band, the hard segment crystallinity can be determined from the ratio of the area of the hydrogen bonded ordered phase at $1652 \mathrm{~cm}^{-1}$ to the total area. For the polymers comprising Gly$\mathrm{OXA}_{2} 6$-Gly hard segments 6a-c, the hard segment crystallinity at room temperature ranged from 73 to $85 \%$, while this value was between 95 and $100 \%$ for polymers $\mathrm{PTHF}_{1000}$-Gly-OXA 2 -Gly (4), $\mathrm{PTHF}_{1000}$-Gly-OXA $_{2} 4$-Gly (5) and PTHF 1000 - $\beta$ ala$\mathrm{OXA}_{2} 6$ - $\beta$ Ala (7). The hard segment crystallinity of these polymers as a function of the temperature is depicted in Figure 7.3. By increasing the $\mathrm{M}_{\mathrm{n}}$ of the polytetrahydrofuran and thus decreasing the hard segment content, the change in crystallinity, related to melting of the crystals, shifts to slightly lower temperatures (Figure 7.3a). This can be explained by the solvent effect proposed by Flory ${ }^{34}$. Upon dilution of the crystallizable hard segments by increasing the molar fraction of the soft segment, the size of the crystals will become smaller and hence their melting temperature decreases. The transitions found appeared more pronounced upon changing the number of methylene groups between the oxalamide moieties. Increasing the number of methylene groups shifted the transition to lower temperatures. Changing the glycine moiety for $\beta$ alanine however shifted the transition to a higher termperature. Importantly, the transitions take place within a narrow temperature range contrary to the transition of the segmented poly(ether amide) $\mathbf{8}^{30}$. 
(a)

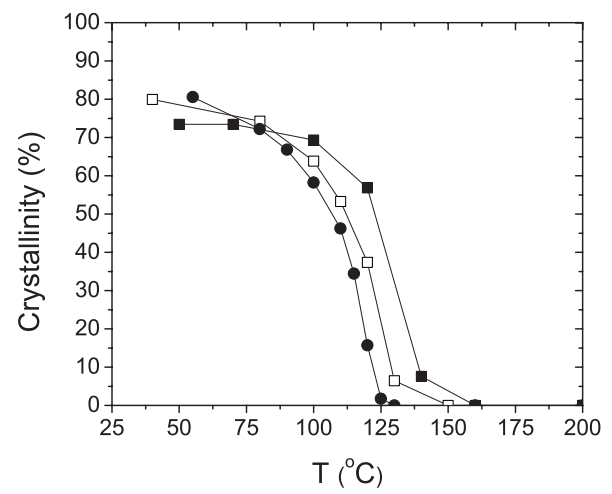

(b)

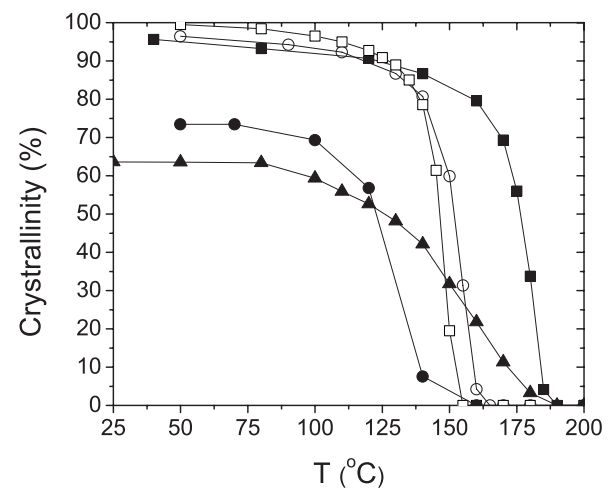

Figure 7.3: Hard segment crystallinity as a function of temperature for (a) (a) $\mathrm{PTHF}_{1000^{-}}$ Gly-OXA 2 6-Gly (6a), ( $\square$ ) $\mathrm{PTHF}_{2000-G l y-O X A} 6$-Gly (6b), (•) $\mathrm{PTHF}_{2900}$ Gly-OXA 26 -Gly (6c). (b) (a) PTHF $1000-$ Gly-OXA 2 -Gly (4), ( $\square$ ) PTHF 1000 -

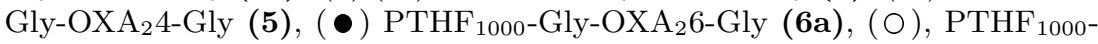
$\beta$ Ala-OXA $26-\beta$ Ala (7) and ( $\Delta)^{P_{T H F}} 1100-\mathrm{OXA}_{2} 6$ (8).

\subsubsection{Thermal properties}

The crystallization and melting temperatures and corresponding enthalpies of the segmented poly(ether ester amide)s were taken from the first cooling scan and the second heating scan as measured by DSC (Table 7.3).

The segmented poly(ether ester amide)s exhibit a glass transition temperature between 68 and $-76^{\circ} \mathrm{C}$, which is close to the glass transition temperature of polytetrahydrofuran of $-86{ }^{\circ} \mathrm{C}^{35}$. This indicates the absence of phase mixing between the hard and the soft segments. The DSC curves depicted in Figure 7.4 show the effect of the soft segment $\mathrm{M}_{\mathrm{n}}$ on the thermal properties. PTHF $1000^{-G l y-O X A_{2} 6-G l y ~(6 a) ~ h a s ~ a ~}$ melting transition at $119{ }^{\circ} \mathrm{C}$ and a crystallization transition at $99{ }^{\circ} \mathrm{C}$. Increasing the polytetrahydrofuran $\mathrm{M}_{\mathrm{n}}$ from $2.0 \times 10^{3}$ to $2.9 \times 10^{3} \mathrm{~g} \cdot \mathrm{mol}^{-1}$, results in an additional thermal transition which is attributed to crystallization of the soft polytetrahydrofuran phase. The melting temperature increases from -9 to $-5{ }^{\circ} \mathrm{C}$ and the crystallization temperature increases from -43 to $-32{ }^{\circ} \mathrm{C}$ with increasing polytetrahydrofuran $\mathrm{M}_{\mathrm{n}}$. Contrary, the melting temperature of the bisoxalamide phase decreases from 119 to $111{ }^{\circ} \mathrm{C}$ as the polytetrahydrofuran $\mathrm{M}_{\mathrm{n}}$ increases and thus the hard segment content decreases. 
(a)

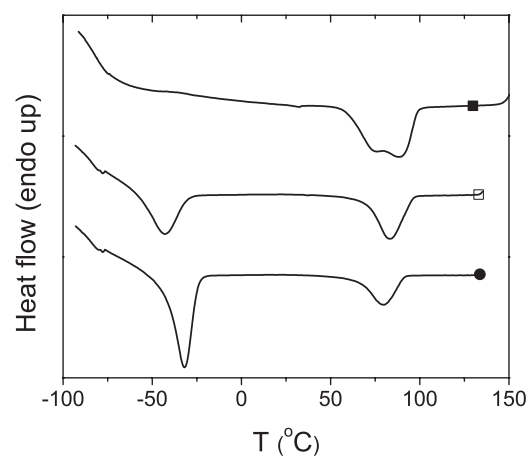

(b)

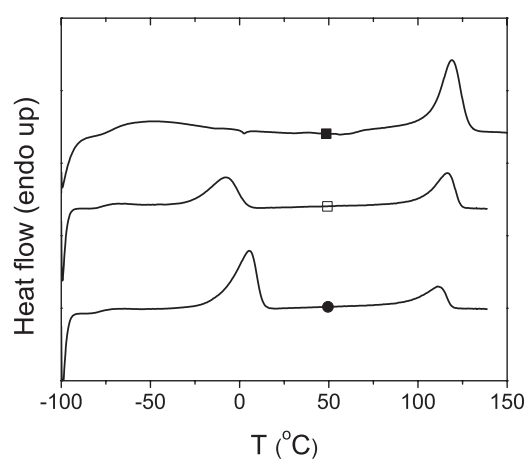

Figure 7.4: DSC cooling curves (a) and second heating curves (b) of segmented poly(ether ester amide)s ( ) PTHF $_{1000}$-Gly-OXA 2 6-Gly (6a), ( $\square$ ) $\mathrm{PTHF}_{2000}$-Gly-OXA 2 Gly (6b) and (•) $\mathrm{PTHF}_{2900}$-Gly-OXA 2 6-Gly (6c).

The effect of the number of methylene units separating the bisoxalamide moieties in the hard segment on the polymer thermal properties is depicted in Figure 7.5. Segmented poly(ether ester amide)s comprising glycine based bisoxalamide hard segments $\mathbf{4}, \mathbf{5}$ or 6a show one melting and crystallization transition attributed to the bisoxalamide hard segment crystals. Increasing the number of methylene groups between two oxalamide groups from 2 to 6 decreases the melting temperature from 171 to $119{ }^{\circ} \mathrm{C}$. The melting temperature of the polymer comprising the $\beta$-alanine based hard segment ( 7$)$ is found at $142{ }^{\circ} \mathrm{C}$, which is much higher than that of its glycine analogue $6 \mathbf{a}\left(119{ }^{\circ} \mathrm{C}\right)$. This may be explained by a better packing of the $\beta$-alanine end groups in the crystal, similarly as observed for the bisester-bisoxalamide monomers Gly-OXA 26 -Gly (2c) $\left(181{ }^{\circ} \mathrm{C}\right)$ and $\beta$ Ala-OXA 26 - $\beta$ Ala (3) $\left(196{ }^{\circ} \mathrm{C}\right)^{32}$.

The degree of hard segment crystallinity is calculated by using the melting enthalpies of the monomers ${ }^{32}$. For all polymers, the crystallinity is higher than $85 \%$ and are comparable to the values determined by FT-IR (Table 7.3). The supercooling effect, the difference between the melting temperature and the crystallization onset, is for all polymers lower than $20^{\circ} \mathrm{C}$. This indicates fast crystallization of the hard segments, which is favorable for processing.

The first cooling scan and the second heating scan of the segmented poly(ether ester amide)s $\mathbf{6 a}$ and $\mathbf{7}$ and the segmented poly(ether amide) $\mathbf{8}$, all having a bisoxalamide hard segment with a spacer length of 6 methylene groups, are presented in Figure 7.6. The structural difference between polymers $\mathbf{6 a}$ and $\mathbf{7}$ and polymer $\mathbf{8}$ is the presence 
(a)

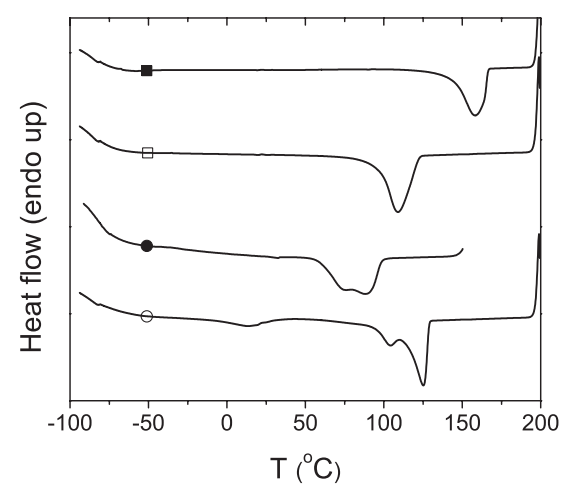

(b)

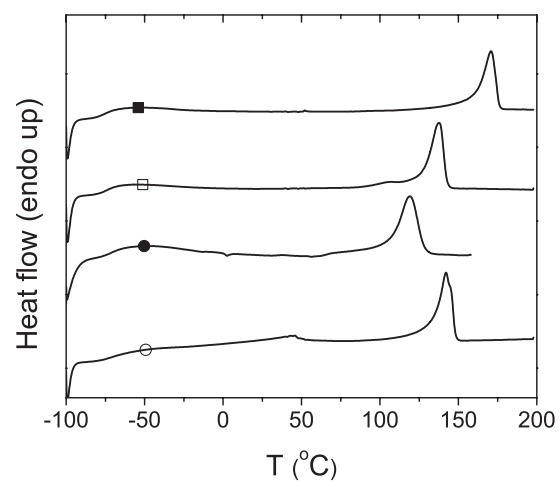

Figure 7.5: DSC cooling curves (a) and second heating curves (b) of segmented poly(ether ester amide)s PTHF 1000 -Gly-OXA 2 -Gly (4), ( $\square)$ PTHF $_{1000-G l y-O X A_{2} 4-G l y}$ (5), (•) $\mathrm{PTHF}_{1000}-$ Gly-OXA 26 -Gly (6a), (O) and $\mathrm{PTHF}_{1000}-\beta$ Ala-OXA 26 $\beta$ Ala (7).

(a)

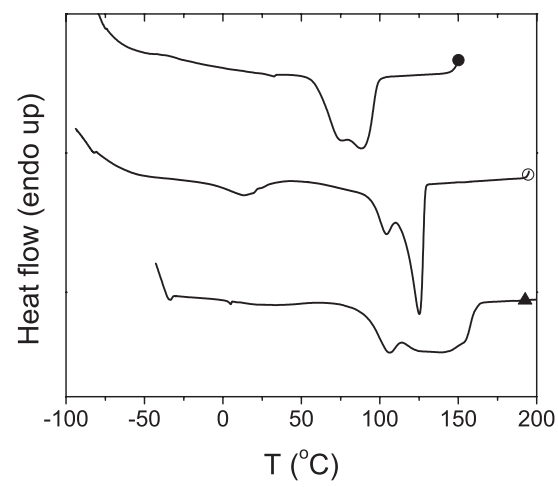

(b)

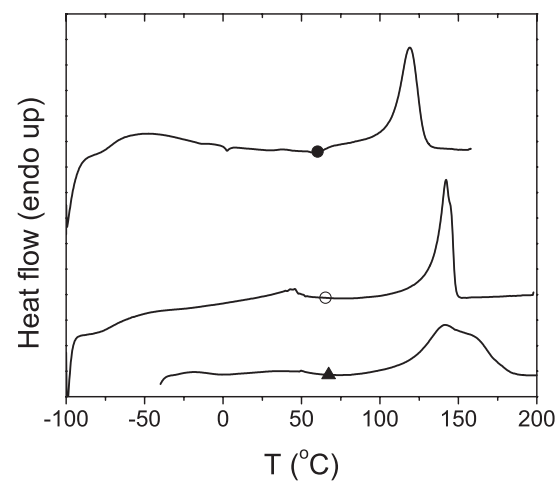

Figure 7.6: DSC cooling curves (a) and second heating curves (b) of segmented poly(ether es-

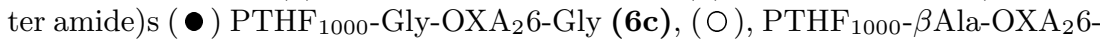
$\beta$ Ala (7) and ( $\mathbf{\Lambda}) \mathrm{PTHF}_{1100-}-\mathrm{OXA}_{2} 6$ (8).

of an ester group between the polytetrahydrofuran segment and the bisoxalamide segment (Scheme 7.1). The thermal transitions of the segmented poly(ether ester amide) $\mathbf{8}$ are broad and consist of multiple peaks, suggesting that different crystal structures and/or crystal thicknesses are present ${ }^{30,31}$. On the contrary, the segmented poly(ether ester amide)s $\mathbf{6 a}$ and $\mathbf{7}$ display sharp thermal transitions. Probably, the bisoxalamide hard segments in $\mathbf{8}$ are able to form different crystal structures, whereas the incorporation of additional ester groups leads to crystallization of the bisoxalamide 
segments in a single form. It is noted that the model compound also showed multiple melting endotherms, whereas the monomers (2c and $\mathbf{3})$ of the segmented poly(ether ester amide)s only showed a sharp single melting endotherm ${ }^{32}$.

The thermal stability of the segmented poly(ether ester amide)s 4-7 under nonoxidative conditions was investigated by thermal gravimetric analysis (TGA). The segmented poly(ether ester amide)s are stable up to $\sim 390{ }^{\circ} \mathrm{C}$ (Table 7.3 ). For all polymers, the decomposition temperatures are considerably higher than the melting temperature, which is important for processing of the material.

\subsubsection{Morphology}

In previous research, we proposed that the bisoxalamide hard segments in segmented poly(ether amide) (8) forms fiber-like nano-crystals as depicted in Figure 7.7. It was shown that the long direction of the crystals is the direction of the hydrogen bonds (a-direction).

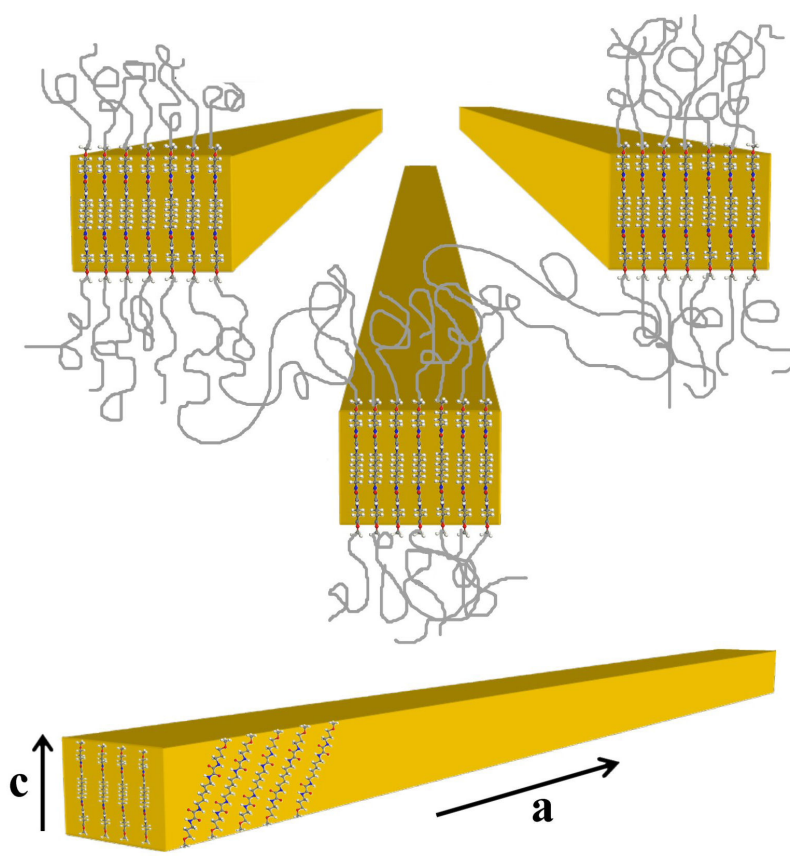

Figure 7.7: Proposed structural model of the segmented poly(ether amide) comprising bisoxalamide hard segments (8). 


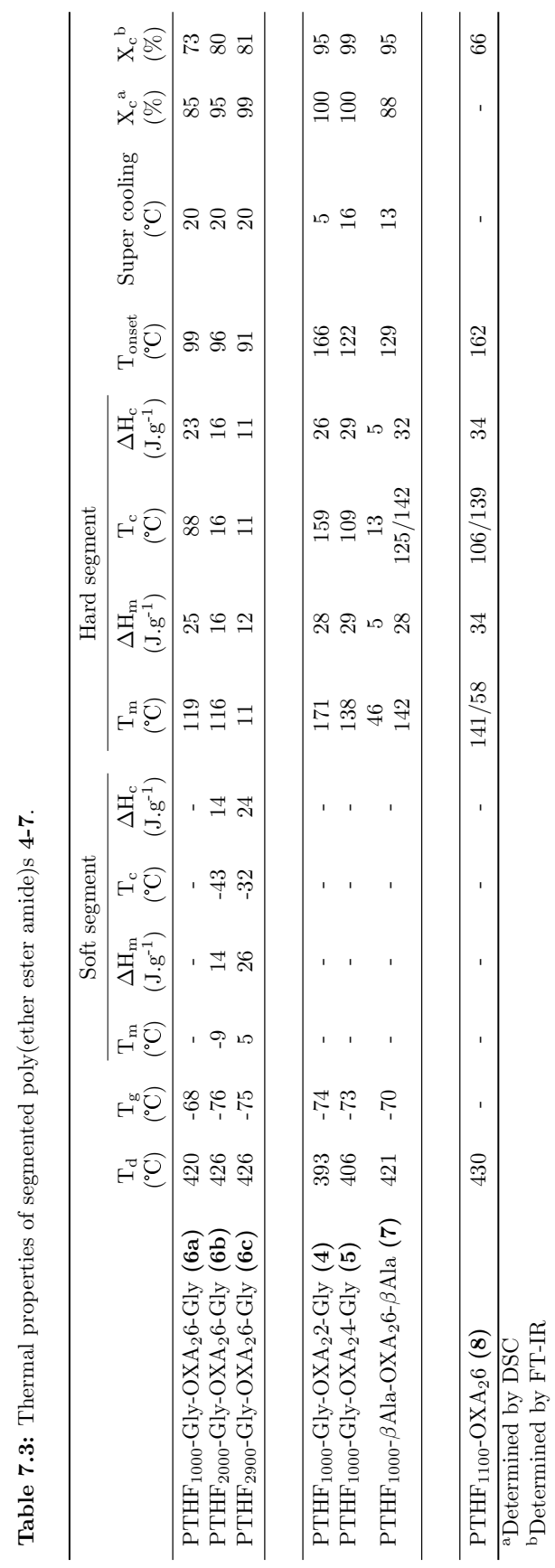


The segmented poly(ether ester amide)s comprising glycine or $\beta$-alanine extended bisoxalamide hard segments (4-7) are highly phase separated into relatively pure amide and polyether domains. FT-IR measurements revealed that the bisoxalamide based hard segments are highly ordered and the hydrogen bonds are solely formed between the oxalamide groups. This already indicates that the bisoxalamide crystals are formed by self-assembly of the oxalamide groups into hydrogen bonded sheets and subsequent stacking of the hydrogen bonded sheets. The crystalline structure of the hard segments likely resemble the crystalline structure of the monomers $\mathbf{2 a - c}$ and $\mathbf{3}$ based on X-ray diffraction and FT-IR measurements (Figure 7.8) ${ }^{32}$. These monomers form hydrogen bonded sheets by stacking of the bisoxalamide units forming like-to-like amide-amide hydrogen bonds with a hydrogen bonding distance of $\sim 5 \AA$ ( $\boldsymbol{a}$-direction). Moreover, the glycine and $\beta$-alanine carbonyl ester groups are spatially tilted away from the oxalamide plane. The distance between the hydrogen bonded sheets was $\sim 10$ $\AA$ for all compounds (b-direction).

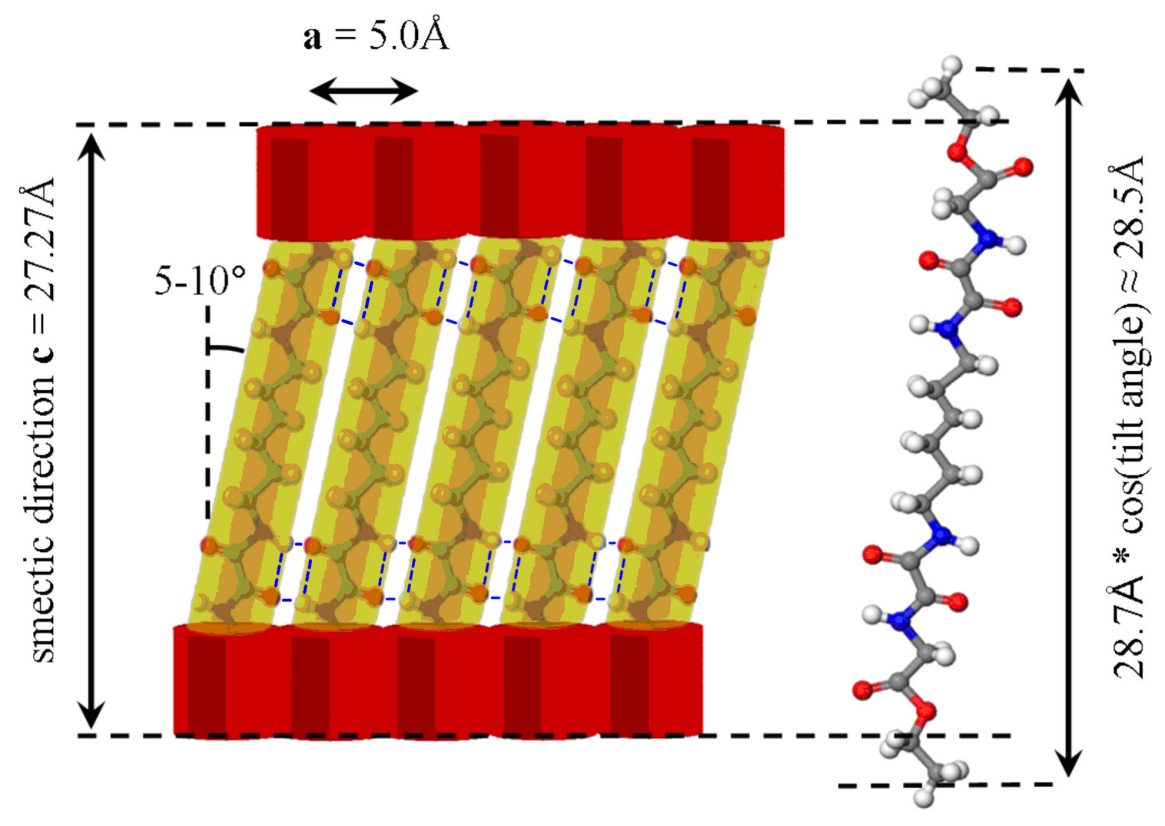

Figure 7.8: Sketch of the crystalline structure of model compound Gly-OXA 26 -Gly $(\mathbf{2 c})^{32}$. 
To obtain more insight in the crystalline structure of the hard segments in the segmented poly(ether ester amide)s, the materials were further investigated using AFM and X-ray diffraction techniques.

\section{Atomic force microscopy}

To illustrate the highly phase separated structure of the segmented poly(ether ester amide)s, the morphology was visualized with atomic force microscopy (AFM) (Figure 7.9) The results reveal a morphology characterized by long fiber-like nanocrystals in a soft polymer matrix. A similar morphology was shown in previous research for analogous bisoxalamide based segmented poly(ether amide)s ${ }^{31}$. The AFM measurements confirm the proposed fiber-like model as depicted in Figure 7.7.

Because the AFM tip has a radius of $8 \mathrm{~nm}$, an accurate determination of the fiber diameter $(\leq 3 \mathrm{~nm})$ was not possible. The length of the crystals is up to several hundreds of nanometers. However, the full length of the crystals cannot be determined since only the surface morphology of the sample is scanned.

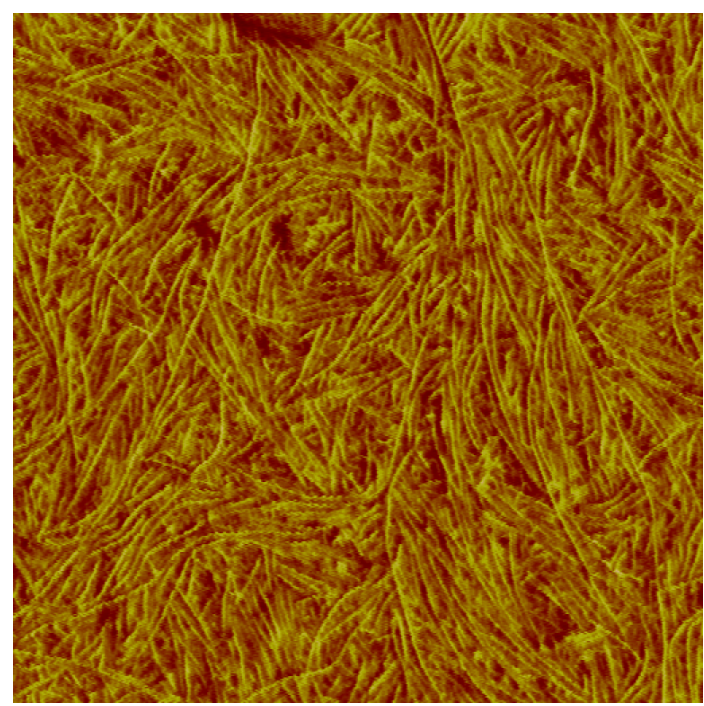

Figure 7.9: Phase image of $\mathrm{PTHF}_{1000}-\beta \mathrm{Ala}_{\mathrm{O}} \mathrm{OXA}_{2} 6-\beta \mathrm{Ala}(\mathbf{7})$ (image size: $1 \times 1 \mu \mathrm{m}$ ).

\section{WAXD}

The diffraction peaks observed for the bisoxalamide monomers are almost absent from the curves of the corresponding copolymers and only a broad amorphous halo originating from the PTHF phase is visible (Figure 7.10). This can be explained by the small crystal thickness along the $\boldsymbol{c}$-direction. Moreover, since only the 200 
peak shows up in the WAXS curves of the polymers, it can be suggested that the small dimensions of the fibers are in the $\boldsymbol{b} \boldsymbol{c}$-plane while the $\boldsymbol{a}$-parameter is parallel to the long fibrillar axis. However, the diffraction in the $\boldsymbol{b}$-direction, i.e. the direction of stacking of the hydrogen bonded sheets, is weak in the monomer diffractogram and therefore presumably not visible in the X-ray pattern of the polymer. Similar conclusions were drawn from the X-ray diffraction data of the segmented poly(ether amide) (8) ${ }^{30}$. The Raman spectroscopy measurements on Gly-OXA 26 -Gly $\mathbf{2 c}$ and $\beta$ Ala-OXA 26 - $\beta$ Ala 3 model compounds (data not shown here) indicate that the long direction of the crystals is the direction of beta-sheets, i.e. the $\boldsymbol{a}$-direction.

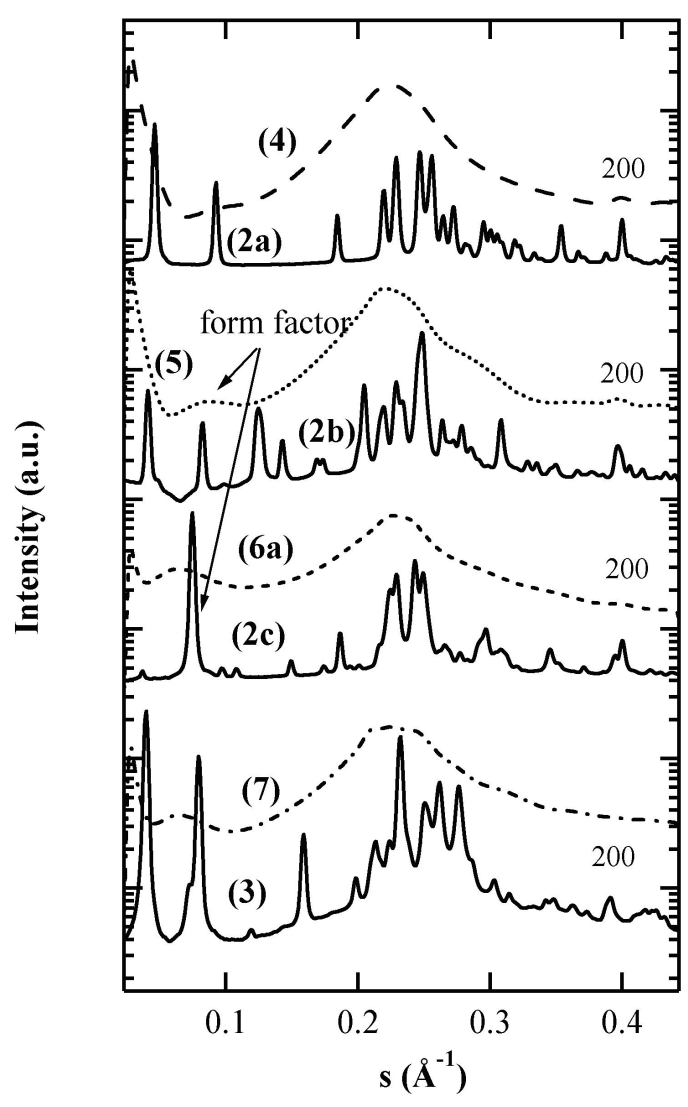

Figure 7.10: WAXD curves of bisester-bisoxalamide monomers and corresponding copolymers of Gly-OXA 2 2-Gly (2a) and PTHF $1000-$ Gly-OXA 2 -Gly (4), Gly$\mathrm{OXA}_{2} 4$-Gly (2b) and PTHF 1000 -Gly-OXA 2 -Gly (5), Gly-OXA 26 -Gly (2c) and $\mathrm{PTHF}_{1000}-$ Gly-OXA $26-$ Gly (6a) and $\beta$ Ala-OXA $26-\beta$ Ala (3) and $\mathrm{PTHF}_{1000}-\beta$ Ala-OXA $26-\beta$ Ala (7). 


\section{SAXS}

The SAXS curves of all segmented poly(ether ester amide)s 4-7 show a scattering maximum indicative for the presence of phase separated domains. Based on the fiber structure observed with AFM the interpretation of the SAXS curves was performed using a 2D model (Figure 7.11a) ${ }^{31}$.

(a)

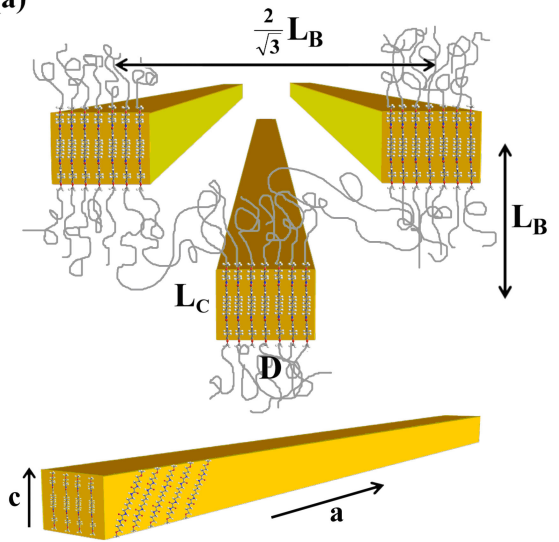

(b)

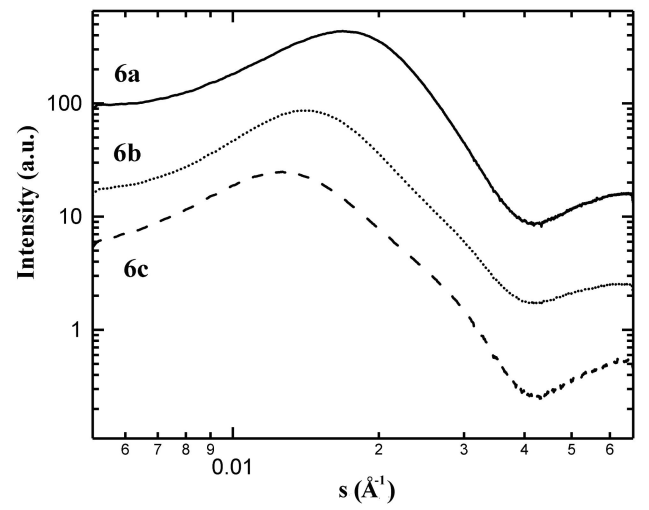

Figure 7.11: (a) Fibrillar crystal model used for interpretation of the SAXS data. (b) SAXS intensities corresponding to the segmented poly(ether ester amide)s consisting of Gly-OXA 26 -Gly (2c) hard segments and PTHF soft segments with varying lengths (6a-c).

It is assumed that the sample contains fiber-like crystals having a virtually infinite length along the fiber axis. The long spacing $\left(\mathrm{L}_{\mathrm{B}}\right)$, crystal $\left(\mathrm{L}_{\mathrm{C}}\right)$ and amorphous domain thickness $\left(\mathrm{L}_{\mathrm{a}}\right)$ are all derived from the SAXS curves (Figure 7.11b). The $\mathrm{L}_{\mathrm{B}}$ is determined from the position of the Bragg peak whereas the crystalline domain thicknesses along the chain direction $\left(\mathrm{L}_{\mathrm{c}}\right)$ was calculated from the position of the form factor approximated by the following function:

$$
A+\frac{1}{s^{\mathrm{n}}}\left(\frac{\sin \left(\pi \times s \times \mathrm{E}_{\mathrm{c}}\right)}{\left(\pi \times s \times \mathrm{E}_{\mathrm{c}}\right)}\right)^{2}
$$

In which $\mathrm{A}$ is a constant. 
The crystal dimension D was calculated as:

$$
D=\frac{\Theta_{\mathrm{vol}} \times \frac{2}{\sqrt{3}} \times L_{\mathrm{B}}^{2}}{L_{\mathrm{c}}}
$$

where

$$
\Theta_{\mathrm{vol}}=\frac{S_{\text {crystalline core }}}{S_{\text {lamellar surface }}}
$$

The relation between $\mathrm{L}_{\mathrm{c}}$ and $\mathrm{L}_{\mathrm{B}}$ can be extracted from the corresponding volume ratio:

$$
\frac{\frac{M_{\text {bisoxalamide }}}{\rho_{\text {bisoxalamide }}}}{\frac{M_{\text {bisoxalamide }}}{\rho_{\text {bisoxalamide }}}+\frac{M_{\mathrm{PTHF}}}{\rho_{\mathrm{PTHF}}}}=\frac{L_{\mathrm{c}} \times D}{\frac{2}{\sqrt{3}} \times L_{\mathrm{B}}^{2}}
$$

In equation 8.2-4, $\theta_{\mathrm{vol}}$ is the crystalline volume fraction, $\rho$ is the density (0.982 and 1.21 g. $\mathrm{cm}^{-3}$ for amorphous PTHF and bisoxalamide segments, respectively), $\mathrm{S}_{\text {crystal core }}$ is the surface per crystal core and $\mathrm{S}_{\text {lamellar surface }}$ is the total surface of the $2 \mathrm{D}$ lattice formed by the fibrils assuming hexagonal packing of the crystalline fibers.

The long spacing $\left(\mathrm{L}_{\mathrm{B}}\right)$, crystal dimensions $\left(\mathrm{L}_{\mathrm{c}}\right.$ and $\left.\mathrm{D}\right)$ and amorphous layer thickness $\left(\mathrm{L}_{\mathrm{a}}\right)$ of the segmented poly(ether ester amide)s are listed in Table 7.4. The $\mathrm{L}_{\mathrm{B}}$ and the $\mathrm{L}_{\mathrm{a}}$ increase with the increase of the $\mathrm{M}_{\mathrm{n}}$ of the PTHF segment length from $1.0 \times 10^{3}$ to $2.9 \times 10^{3}$ g. $\mathrm{mol}^{-1}$ (6a-c), whereas the crystal thickness $\mathrm{L}_{\mathrm{c}}$ remains constant. On the other hand, $\mathrm{L}_{\mathrm{a}}$ differs significantly for the hard blocks with different end groups (for example sample $\mathbf{6 a}$ and $\mathbf{7}$ ). As far as the crystal thickness is concerned it can be shown, that $\mathrm{L}_{\mathrm{c}}$ increases with the spacer length between oxalamide groups. Therefore the crystal morphology is mainly determined by the structure of the hard segment. For all copolymers, the value of $\mathrm{L}_{\mathrm{c}}$ is somewhat larger than the estimated hard block length, which indicates that the crystalline core in the copolymer structure also partially includes the ester groups.

When the length of the crystalline stem is calculated by dividing $\mathrm{L}_{\mathrm{c}}$ by cosine of the 
tilt angle, one can see that copolymers $\mathbf{6 a}$ (glycine substituted bisoxalamide) and $\mathbf{7}$ ( $\beta$-alanine substituted bisoxalamide) exhibit similar values of the stem length $(\sim 25 \AA)$ while their melting temperatures, $119{ }^{\circ} \mathrm{C}$ and $142{ }^{\circ} \mathrm{C}$, respectively, differ strongly.

These differences become even more clear, when the poly(ether amide) (8) is considered, which has the smallest $\mathrm{L}_{\mathrm{c}}$ of the $\mathrm{OXA}_{2} 6$ samples, while it reveals a melting temperature as high as $\mathbf{7}$ ( $\beta$-alanine substituted bisoxalamide). Therefore the $\mathrm{L}_{\mathrm{c}}$ is not the only parameter determining the melting temperature, but the arrangement of the hard block inside the unit cell (i.e. the chain tilt and possibly the difference in the H-bonding energy) are also important.

Table 7.4: Long spacings $\left(\mathrm{L}_{\mathrm{B}}\right)$, crystalline lamellar thicknesses $\left(\mathrm{L}_{\mathrm{c}}\right.$ and $\left.\mathrm{D}\right)$ and amorphous lamellar thicknesses $\left(\mathrm{L}_{\mathrm{a}}\right)$ of segmented poly(ether ester amide)s 4-7.

\begin{tabular}{|c|c|c|c|c|c|c|c|}
\hline & $\begin{array}{l}\mathrm{L}_{\mathrm{B}} \\
(\AA)\end{array}$ & $\begin{array}{c}\mathrm{L}_{\mathrm{c}} \\
(\AA)\end{array}$ & $\begin{array}{c}\mathrm{D} \\
(\AA)\end{array}$ & $\begin{array}{c}\mathrm{L}_{\mathrm{a}} \\
(\AA)\end{array}$ & $\begin{array}{c}\text { Chain } \\
\text { tilt } \\
\left({ }^{\circ}\right)\end{array}$ & $\begin{array}{c}\text { Stem } \\
\text { length }^{\mathrm{a}} \\
(\AA)\end{array}$ & $\begin{array}{l}\text { Hard block } \\
\text { length } \\
(\AA)\end{array}$ \\
\hline $\mathrm{PTHF}_{1000}$-Gly-OXA 26 -Gly (6a) & 57.5 & 24 & 32 & 33.5 & $\sim 5-10$ & 24 & 18.75 \\
\hline $\mathrm{PTHF}_{2000}$-Gly-OXA 2 6-Gly (6b) & 71.4 & 24 & 27 & 47.4 & $\sim 5-10$ & 24 & 18.75 \\
\hline $\mathrm{PTHF}_{2900}$-Gly-OXA 6 6-Gly (6c) & 79.0 & 24 & 24 & 55.0 & $\sim 5-10$ & 24 & 18.75 \\
\hline $\mathrm{PTHF}_{1000}$-Gly-OXA 2 2-Gly (4) & 49.8 & 14.3 & 29 & 35.5 & $\sim 5-10$ & 14.5 & 13.75 \\
\hline PTHF $_{1000}$-Gly-OXA 2 -Gly (5) & 52.6 & 17.4 & 32 & 35.2 & $\sim 5-10$ & 17.6 & 16.25 \\
\hline $\mathrm{PTHF}_{1000-} \beta$ Ala-OXA $26-\beta$ Ala (7) & 73.0 & 22.9 & 50 & 50.1 & $\sim 28$ & 25 & 18.75 \\
\hline $\mathrm{PTHF}_{1100}-\mathrm{OXA}_{2} 6$ (8) & 75.5 & 16.5 & 63 & 59 & $\sim 25$ & 18 & 18.75 \\
\hline
\end{tabular}

\section{Temperature dependent WAXS/SAXS}

Temperature-dependent WAXS and SAXS measurements were performed to obtain information on the evolution of the phase separated morphology upon heating. Figure 7.12 shows the results of such measurements for the segmented poly(ether ester amide)s with different soft segment lengths (6a-c). Below $0{ }^{\circ} \mathrm{C}$, the $(020)$ and $(110)$ peaks of polytetrahydrofuran crystals are clearly seen for the copolymers with polytetrahydrofuran $\mathrm{M}_{\mathrm{n}}$ 's of $2.0 \times 10^{3}$ and $2.9 \times 10^{3} \mathrm{~g} \cdot \mathrm{mol}^{-1}$. Moreover, the PTHF peaks are much stronger for copolymer 6c, indicating that crystallinity of the soft block rapidly increases with its length.

These SAXS/WAXS results are in agreement with DSC measurements. The main SAXS interference maximum and the form factor of the bisoxalamide crystals located 
(a)

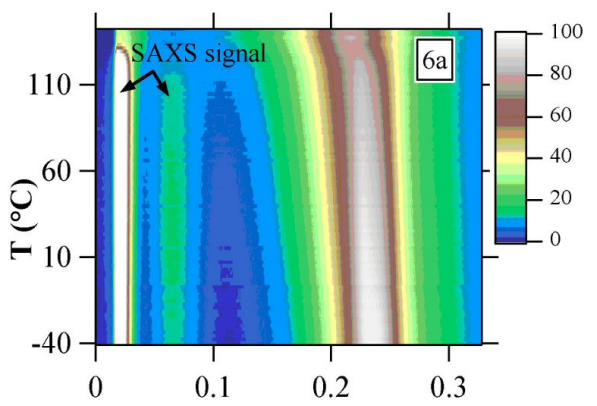

(c)

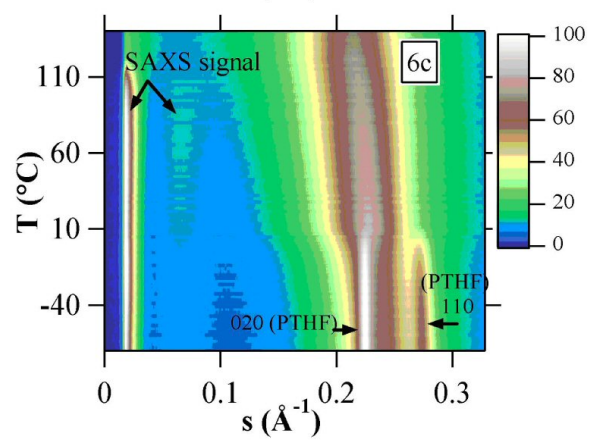

(b)

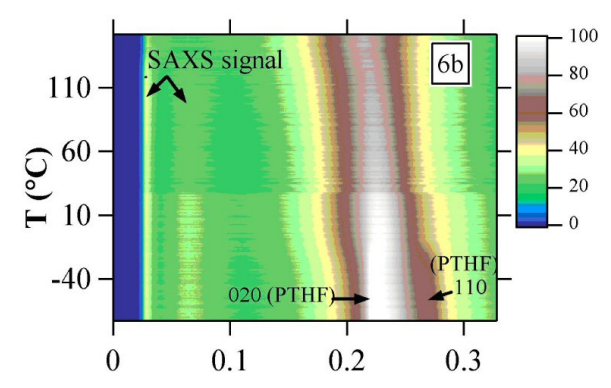

Figure 7.12: Results of combined SAXS/WAXS measurements performed during heating for segmented poly(ether ester amide)s with polytetrahydrofuran molecular weights of (a) $1.0 \times 10^{3}$ g.mol ${ }^{-1}$ (6a), (b) $2.0 \times 10^{3}$ g.mol ${ }^{-1}$ (6b) and (c) $2.9 \times 10^{3}$ g. $\mathrm{mol}^{-1}(6 \mathrm{c})$.

at $\sim 0.07 \AA^{-1}$ disappear above the copolymers melting temperature indicating a transition to the homogeneous melt.

\subsubsection{Dynamic mechanical properties}

Dynamic mechanical properties were studied using DMA and the storage modulus and loss modulus as a function of the temperature are depicted in Figure 7.13.

The glass transition temperatures range from -65 to $-75{ }^{\circ} \mathrm{C}$ and correspond well to the glass transition temperatures measured by DSC. The crystallization of the polytetrahydrofuran with molecular weights of $2.0 \times 10^{3}$ and $2.9 \times 10^{3}$ g.mol ${ }^{-1}$ is reflected by the presence of a shoulder in the storage modulus prior to the start of the rubber 
(a)

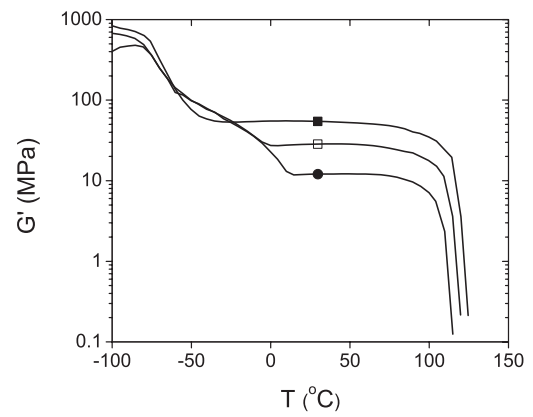

(c)

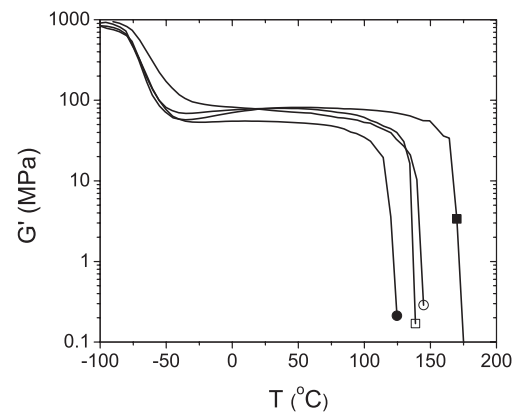

(b)

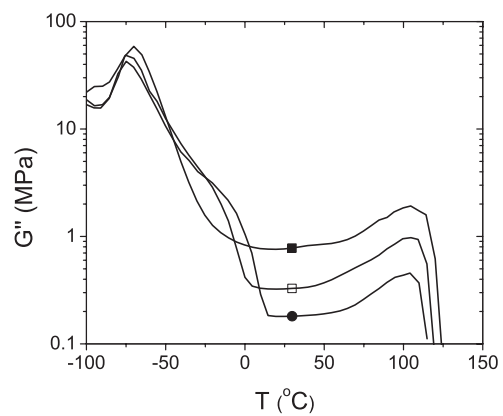

(d)

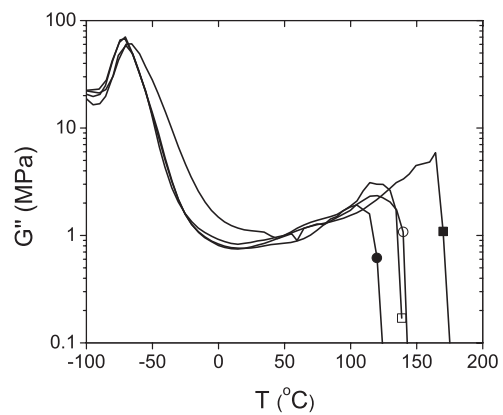

Figure 7.13: Storage modulus and loss modulus as a function of temperature for segmented poly(ether ester amide)s (a-b) ( $\mathbf{a})$ PTHF $_{1000}-G_{l y-O X A} 6$-Gly (6a), ( $\square$ )

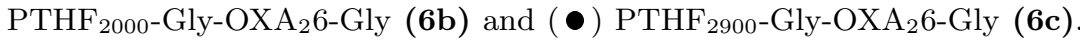

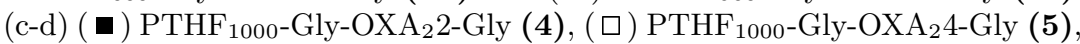
(•) $\mathrm{PTHF}_{1000}-$ Gly-OXA $26-G l y(6 a)$ and (O) $\mathrm{PTHF}_{1000}-\beta$ Ala-OXA $26-\beta$ Ala (7).

plateau. For all polymers, this plateau is broad and remains constant up to the flow temperature, which is typical for segmented block copolymers with uniform hard segments. By increasing the molecular weight of the polytetrahydrofuran, the storage modulus at $25^{\circ} \mathrm{C}$ decreases from 54 to $12 \mathrm{MPa}$ due to a decreasing hard segment content (Figure 7.13a). Whereas PTHF $1000-$ Gly-OXA 26 -Gly (6a) has a storage modulus of 54 MPa, PTHF 1000 -Gly-OXA 2 2-Gly (4), PTHF 1000 -Gly-OXA 2 4-Gly (5) and PTHF $1000^{-}$ $\beta$ Ala-OXA 2 6- $\beta$ Ala (6a) have higher moduli in between 77 and $79 \mathrm{MPa}$. Possibly, the lower stiffness of polymer $\mathbf{6 a}$ is due to the lower hard segment crystallinity as measured by FT-IR and DSC. When the hard segment starts to melt, the polymer softens and as a result the modulus drops. By increasing the $\mathrm{M}_{\mathrm{n}}$ of the soft segment $\mathbf{6 a - c}$, the flow temperature decreases from 122 to $112{ }^{\circ} \mathrm{C}$ (6a-c). Increasing the spacer length between the oxalamide groups from 2 to 6 methylene groups results in a decrease of 
the flow temperature from 170 to $122{ }^{\circ} \mathrm{C}$. Changing the glycine ester into a $\beta$-alanine ester keeping the spacer length constant increases the flow temperature from 122 to $143{ }^{\circ} \mathrm{C}$.

Table 7.5: Dynamic mechanical properties of segmented poly(ether ester amide)s 4-7.

\begin{tabular}{|c|c|c|c|c|c|c|c|}
\hline & \multicolumn{2}{|c|}{ Content $^{\mathrm{a}}$} & \multirow[b]{2}{*}{$\begin{array}{l}\mathrm{X}_{\mathrm{c}}^{\mathrm{b}} \\
(\%)\end{array}$} & \multirow[b]{2}{*}{$\begin{array}{l}\mathrm{X}_{\mathrm{c}}{ }^{\mathrm{c}} \\
(\%)\end{array}$} & \multirow[b]{2}{*}{$\begin{array}{l}\mathrm{T}_{\mathrm{g}} \\
\left({ }^{\circ} \mathrm{C}\right)\end{array}$} & \multirow[b]{2}{*}{$\begin{array}{l}\mathrm{G}_{25^{\circ} \mathrm{C}}^{\prime} \\
(\mathrm{MPa})\end{array}$} & \multirow[b]{2}{*}{$\begin{array}{l}\mathrm{T}_{\text {flow }} \\
\left({ }^{\circ} \mathrm{C}\right)\end{array}$} \\
\hline & $\begin{array}{l}\text { Hard segment } \\
\quad(\text { wt } \%)\end{array}$ & $\begin{array}{c}\text { Soft segment } \\
(\mathrm{wt} \%)\end{array}$ & & & & & \\
\hline PTHF $_{1000}$-Gly-OXA 26 -Gly (6a) & 74.6 & 25.4 & 85 & 73 & -70 & 55 & 112 \\
\hline PTHF $_{2000}$-Gly-OXA 2 6-Gly (6b) & 85.5 & 14.5 & 95 & 80 & -75 & 28 & 117 \\
\hline PTHF $_{2900}$-Gly-OXA 2 6-Gly (6c) & 89.5 & 10.5 & 99 & 81 & -75 & 12 & 112 \\
\hline $\mathrm{PTHF}_{1000}-\mathrm{Gly}_{\mathrm{O}} \mathrm{OXA}_{2} 2$-Gly (4) & 77.8 & 22.2 & 100 & 95 & -70 & 79 & 170 \\
\hline $\mathrm{PTHF}_{1000}$-Gly-OXA 24 -Gly (5) & 76.2 & 23.8 & 100 & 99 & -70 & 79 & 137 \\
\hline $\mathrm{PTHF}_{1000}-\beta$ Ala-OXA $26-\beta$ Ala (7) & 73.1 & 26.9 & 88 & 95 & -65 & 77 & 143 \\
\hline $\mathrm{PTHF}_{1100}-\mathrm{OXA}_{2} 6$ (8) & 81.1 & 18.9 & - & 66 & -70 & 48 & 160 \\
\hline
\end{tabular}

${ }^{a}$ The ester groups are included in the calculation of the hard segment content.

${ }^{\text {a }}$ Determined by DSC

${ }^{\mathrm{b}}$ Determined by FT-IR

\subsubsection{Mechanical properties}

The mechanical properties of the segmented poly(ether ester amide)s were evaluated by tensile testing dumbbells (ISO37 s2) cut from compression molded bars and are reported in Table 7.6. Typical stress-strain curves are presented in Figure 7.14 and Figure 7.15 .

The deformation of segmented thermoplastic elastomers with uniform hard segments was found to take place in steps ${ }^{16,25}$. Non-oriented samples consist of fiber-like nanocrystals randomly distributed in a soft polymer matrix. At low strains, below the yield point, the crystals orient parallel to the stretching direction. At these low strains, hardly any orientation of the soft segment is observed. Above the yield point, a different deformation mechanism sets in. The crystals break up in smaller fragments and become oriented parallel to the stretching direction. Upon further elongation, the soft segments also orient in the direction of the deformation. Finally, the hard segment crystals prevent chain slippage of the soft segments and hence failure of the sample. 
The E-modulus was determined at small deformations where the stress increases linearly with strain. The E-modulus of PTHF-Gly-OXA 2 6-Gly (6a-c) increases as the soft segment $M_{n}$ decreases and thus the hard segment content increases. According to Wegner ${ }^{2}$, the logarithm of the modulus of a segmented copolymer follows a linear relationship with crystalline volume fraction. Since the degrees of crystallinity of the hard phase in polymers 6a-c are comparable and the density of the hard segment crystal is similar, the volume fraction is linear with the weight fraction. Plotting the logarithm of the E-modulus against the hard segment weight fraction confirms the linear relationship (Figure 7.14b). Above the yield point, the material is permanently deformed. By increasing the polytetrahydrofuran molecular weight, the yield stress decreases and the yield strain increases. Polymer 6a displays a distinct yield point whereas this is less pronounced for $\mathbf{6 b}$-c. A distinct yield point indicates a long-range hard segment connectivity and a well percolated hard phase throughout the soft polymer matrix ${ }^{4-6}$. The strain at break for all three polymers is higher than 1000 $\%$. The upsweep in the stress-strain curves at higher strains is caused by a strain hardening effect. For polymers $\mathbf{6 b}$-c the strain hardening is caused by strain induced crystallization of the polytetrahydrofuran soft segments and as a result the stress at break is higher at increasing polytetrahydrofuran $M_{n}$.

(a)

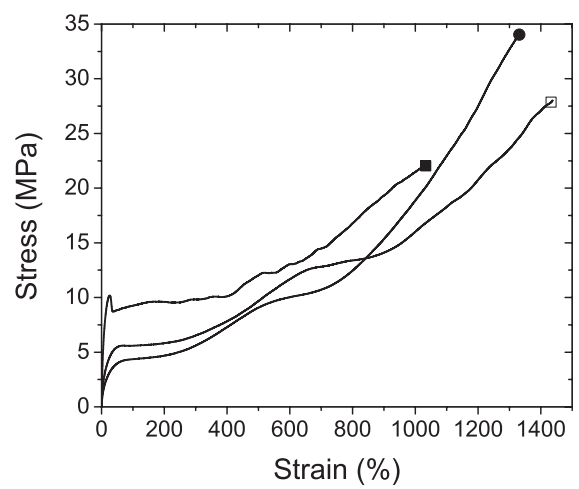

(b)

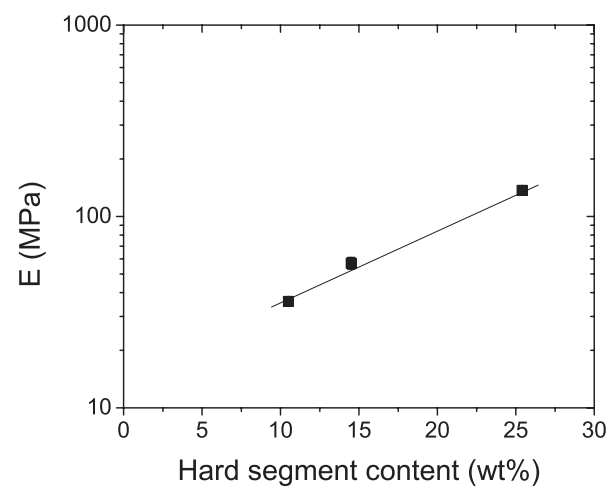

Figure 7.14: (a) Stress-strain curves for segmented poly(ether ester amide)s ( $\mathbf{\square}) \mathrm{PTHF}_{1000^{-}}$ Gly-OXA 26 -Gly (6a), (口) PTHF $_{2000}$-Gly-OXA 2 -Gly (6b) and $\mathrm{PTHF}_{2900}$-Gly-OXA 6 -Gly (6c). (b) E-modulus as a function of hard segment content. 
The stress-strain curves of the segmented poly(ether ester amide)s PTHF $1000-\mathrm{Gly}$ $\mathrm{OXA}_{2} 6$-Gly (6a) and $\mathrm{PTHF}_{1000}-\beta$ Ala-OXA 26 - $\beta$ Ala (7) and the corresponding segmented poly(ether amide) $\mathrm{PTHF}_{1100}-\mathrm{OXA}_{2} 6$ (8) are depicted in Figure 7.15. All polymers show a pronounced yield point followed by necking and strain hardening. Interestingly, the copolymer with the $\beta$-alanine based hard segments (7) shows a more pronounced strain hardening effect than the copolymers with the glycine based hard segment (6a) and as a consequence the fracture stress of this polymer is higher. The mechanical behavior of copolymer $\mathbf{7}$ is comparable to the mechanical behavior of the analogous segmented poly(ether amide) $\mathbf{8}$. The glycine based segmented copolymers 4 and $\mathbf{5}$ reveal a similar strain hardening effect as copolymer $\mathbf{6 a}$.

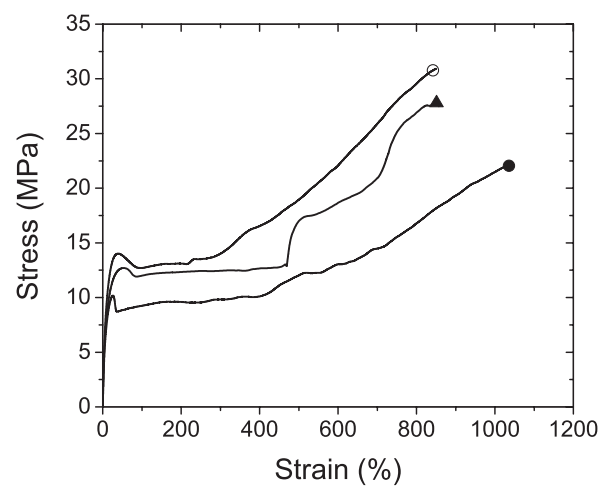

Figure 7.15: Stress-strain curves for segmented poly(ether ester amide)s $(\bullet) \mathrm{PTHF}_{1000}-\mathrm{Gly}-$ $\mathrm{OXA}_{2} 6$-Gly (6a), (O) $\mathrm{PTHF}_{1000}-\beta$ Ala-OXA $26-\beta$ Ala (7) and ( $\left.\mathbf{\Delta}\right) \mathrm{PTHF}_{1100^{-}}$ $\mathrm{OXA}_{2} 6(8)$.

The difference observed in strain hardening is thought to be a result of the bisoxalamide crystal structure. At high strains, the fiber-like nano-crystals break up in smaller fragments and bisoxalamide hard segments become oriented parallel to the stretching direction. Moreover, the soft segment is also oriented in the tensile direction. The hard segment crystals prevent chain slippage of the soft segments and hence failure of the sample. Copolymer $\mathbf{7}$, with the $\beta$-alanine based segment, shows more pronounced strain hardening compared to the glycine based copolymers 6 a suggesting more resistance of chain slippage and thus more resistance of disruption of the crystalline structure. To obtain more insight in the strengths of the hard segment crystalline structure, the compression set of the polymers was measured. 

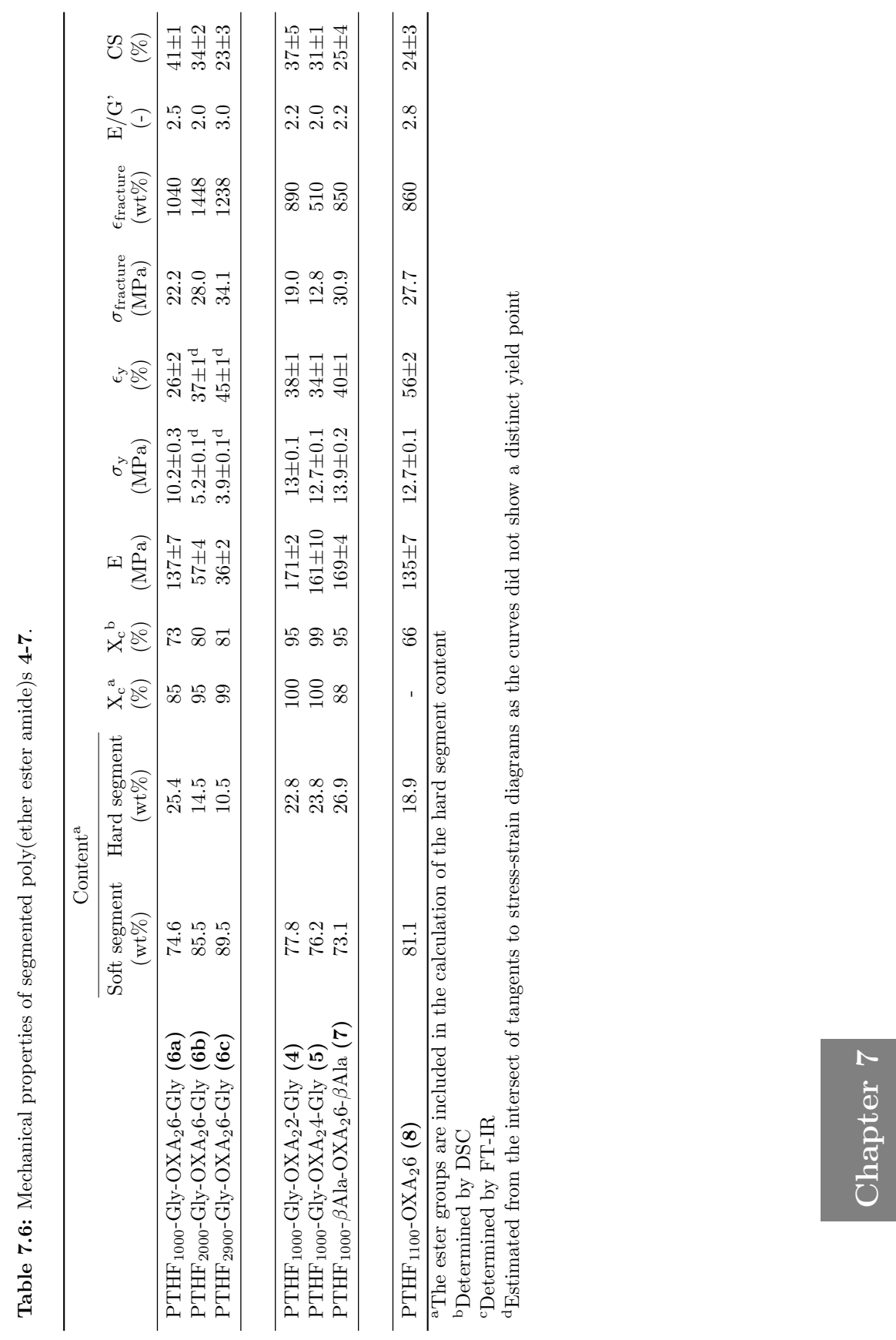
The compression set test is a standard method to measure the elasticity of a thermoplastic elastomer. Ideal elastomers show a perfect recovery after compression, CS $=0$ $\%$, which means no visco-elastic and plastic deformation occur during compression. However, segmented block copolymers are held together by chain entanglements and other physical interactions and complete elastic recovery is hardly observed. During compression, the hard segment crystal disrupts and the material deforms plastically due to permanent flow of the polymer chains, which leads to a permanent set (CS > $0 \%$ ). The compression set thus provides information on the rigidity of the crystals. The CS values of the copolymer with $\beta$-alanine based hard segments 7 and segmented poly(ether amide) 8 are 25 and $24 \%$, respectively, whereas the CS of polymer with the glycine based hard segments $\mathbf{6 a}$ is found to be $41 \%$, which is considerably higher. This confirms that the hard segment crystals formed by the glycine hard segment are weaker compared to those formed by the $\beta$-alanine based hard segment or the bisoxalamide hard segment in the segmented poly(ether amide) 8 .

\subsection{Conclusions}

Segmented poly(ether ester amide)s were prepared by melt polycondensation of $\alpha, \omega-$ hydroxyl end functionalized polytetrahydrofuran and bisester-bisoxalamides with spacer lengths of 2,4 or 6 methylene groups and glycine- or $\beta$-alanine ethyl ester functional groups. All segmented copolymers appear to be highly phase separated materials with a broad temperature independent rubber plateau starting at low temperatures. FT-IR revealed strongly hydrogen bonded and highly ordered bisoxalamide segments with hydrogen bonds formed between the oxalamide groups. The hard segment crystallinities were in between 73 and $99 \%$. The melting transition of the glycine based hard segment increased from 119 to $170{ }^{\circ} \mathrm{C}$ with decreasing spacer length from 6 to 2 methylene groups. Moreover, changing the glycine ester group into a $\beta$-alanine ester group, Gly-OXA 26 -Gly to $\beta$ Ala-OXA 26 - $\beta$ Ala, led to an increase of the melting transition of the hard segments from 119 to $141{ }^{\circ} \mathrm{C}$. The polymers have an elastic modulus in a range between 139 and $170 \mathrm{MPa}$, yield stresses between the 10.2 and $13.9 \mathrm{MPa}$ and strains at break higher than $800 \%$. Whereas the fracture stress of the $\beta$-alanine based segmented poly(ether ester amide) was $31 \mathrm{MPa}$, the fracture stress of the glycine based copolymers was not higher than $22 \mathrm{MPa}$. The differences in thermal and mechanical properties between the copolymers comprising $\beta$-alanine or glycine based hard segments is related to a difference in the crystal 
structure of the hard segment. Compared to the corresponding segmented poly(ether amide), PEA, the segmented poly(ether ester amide)s, PEEA's, have narrower melting transitions at lower temperatures. The mechanical behavior of the PEEA with the $\beta$-alanine based hard segment is comparable to that of PEA, whereas the mechanical properties are significantly decreased when a glycine ester unit is introduced in the hard segment.

\subsection{References}

[1] Fakirov, S. Handbook of condensation thermoplastic elastomers; Wiley-VCH: Weinheim, 2005.

[2] Holden, G.; Legge, N. R.; Quirk, R. P.; Schroeder, H. E. Thermoplastic elastomers, 2nd ed.; Hanser Publishers: Munich, 1996.

[3] Cella, R. J. J Polym Sci: Symp No 47 1973, 42, 727-740.

[4] Das, S.; Cox, D. F.; Wilkes, G. L.; Klinedinst, D. B.; Yilgor, I.; Yilgor, E.; Beyer, F. L. J Macromol Sci Phys 2007, 46, 853-875.

[5] Das, S.; Yilgor, I.; Yilgor, E.; Inci, B.; Tezgel, O.; Beyer, F. L.; Wilkes, G. L. Polymer 2007, 48, 290-301.

[6] Das, S.; Yilgor, I.; Yilgor, E.; Wilkes, G. L. Polymer 2008, 49, 174-179.

[7] Yilgor, I.; Yilgor, E. Polym Rev 2007, 47, 487-510.

[8] Eisenbach, C. D.; Stadler, E. Macromol Chem Phys 1995, 196, 1981-1997.

[9] Fu, B.; Macknight, W. J.; Schneider, N. S. Rubber Chem Technol 1986, 59, 896-911.

[10] Harrell, L. L. Macromolecules 1969, 2, 607-612.

[11] Miller, J. A.; Lin, S. B.; Hwang, K. K. S.; Wu, K. S.; Gibson, P. E.; Cooper, S. L. Macromolecules 1985, 18, 32-44.

[12] Ng, H. N.; E., A. A.; Seymour, R. W.; Cooper, S. L. Polymer 1973, 14, 255-261.

[13] Niesten, M. C. E. J.; Feijen, J.; Gaymans, R. J. Polymer 2000, 41, 8487-8500.

[14] Biemond, G. J. E.; Feijen, J.; Gaymans, R. J. Polym Eng Sci 2008, 48, 1389-1400.

[15] Shirasaka, H.; Inoue, S.; Asai, K.; Okamoto, H. Macromolecules 2000, 33, 27762778.

[16] Versteegen, R. M.; Kleppinger, R.; Sijbesma, R. P.; Meijer, E. W. Macromolecules 2006, 39, 772-783.

[17] Biemond, G. J. E.; Feijen, J.; Gaymans, R. J. J Appl Polym Sci 2007, 105, 951-963. 
[18] Bouma, K.; Wester, G. A.; Gaymans, R. J. J Appl Polym Sci 2001, 80, 1173-1180.

[19] Gaymans, R. J.; Dehaan, J. L. Polymer 1993, 34, 4360-4364.

[20] Husken, D.; Krijgsman, J.; Gaymans, R. J. Polymer 2004, 45, 4837-4843.

[21] Krijgsman, J.; Husken, D.; Gaymans, R. J. Polymer 2003, 44, 7043-7053.

[22] Krijgsman, J.; Husken, D.; Gaymans, R. J. Polymer 2003, 44, 7573-7588.

[23] Niesten, M. C. E. J.; Bouma, K.; Gaymans, R. J. Polymer 1998, 39, 93-98.

[24] Niesten, M. C. E. J.; Gaymans, R. J. Polymer 2001, 42, 6199-6207.

[25] Niesten, M. C. E. J.; Harkema, S.; van der Heide, E.; Gaymans, R. J. Polymer 2001, 42, 1131-1142.

[26] Niesten, M. C. E. J.; Tol, R.; Gaymans, R. J. Polymer 2001, 42, 931-939.

[27] van der Schuur, M.; Gaymans, R. J. J Polym Sci Part A Polym Chem 2006, 44, 4769-4781.

[28] van der Schuur, M.; Feijen, J.; Gaymans, R. J. Polymer 2005, 46, 4584-4595.

[29] van der Schuur, M.; Feijen, J.; Gaymans, R. J. Polymer 2005, 46, 4584-4595.

[30] Sijbrandi, N. J.; Kimenai, A. J.; Mes, E. P. C.; Broos, R.; Dijkstra, P. J.; Feijen, J. Chapter 3, this thesis; University of Twente, 2011.

[31] Sijbrandi, N. J.; Kimenai, A. J.; Mes, E. P. C.; Broos, R.; Bar, G.; Rosenthal, M.; Odarchenko, Y.; Ivanov, D. A.; Dijkstra, P. J.; Feijen, J. Chapter 4, this thesis; University of Twente, 2011.

[32] Sijbrandi, N. J.; Kimenai, A. J.; Mes, E. P. C.; Broos, R.; Bar, G.; Rosenthal, M.; Odarchenko, Y.; Ivanov, D. A.; Dijkstra, P. J.; Feijen, J. Chapter 6, this thesis; University of Twente, 2011.

[33] Meier, R. J. Vib Spectrosc 2005, 39, 266-269.

[34] Flory, P. J. Trans Faraday Soc 1955, 51, 848-857.

[35] Mark, H. F. Encyclopedia of polymer science and technology, 3rd ed.; WileyInterscience: New York, 2001. 


\title{
Chapter 8
}

\section{The effect of molecular orientation in electrospun fibers of a segmented poly(ether amide) with uniform bisoxalamide hard segments on its mechanical properties}

\author{
N.J. Sijbrandi ${ }^{a}$, K.O. van der werf $f^{b}$, M.L. Bennink ${ }^{b}$, V. Subramaniam ${ }^{b}$, A.T.M. Lenferink ${ }^{c}$, \\ C. Otto ${ }^{c}$, P.J. Dijkstra ${ }^{a}$, J. Feijen ${ }^{a}$

\begin{abstract}
${ }^{a}$ Department of Polymer Chemistry and Biomaterials, MIRA Institute for Biomedical Technology and Technical Medicine, Faculty of Science and Technology, University of Twente, P.O. Box 217, 7500 AE Enschede, The Netherlands

${ }^{\mathrm{b}}$ Nanobiophysics, MESA+ Institute for Nanotechnology, University of Twente, P.O. Box 217, 7500 AE Enschede, Netherlands University of Twente, P.O. Box 217, 7500 AE Enschede, Netherlands
\end{abstract} \\ ${ }^{\mathrm{c}}$ Medical Cell BioPhysics, MIRA Institute for Biomedical Technology and Technical Medicine,
}

\begin{abstract}
A segmented poly(ether amide) composed of polytetrahydrofuran $\left(\mathrm{M}_{\mathrm{n}}=1.1 \times 10^{3}\right.$ g.mol ${ }^{-1}$ ) soft segments and uniform bisoxalamide hard segments was electrospun into fibers with diameters ranging from 150 to $2000 \mathrm{~nm}$ from a chloroform/formic acid solution $(9 / 1 \mathrm{v} / \mathrm{v})$. Polarized Raman microspectroscopy on single electrospun PEA fibers revealed significant molecular orientation of the polytetrahydrofuran and bisoxalamide segments along the fiber axis. The degree of molecular orientation of the bisoxalamide segments appeared independent on the fiber diameter. On the other hand, the degree of molecular orientation of the polytetrahydrofuran segments was significantly higher for fibers with diameters $<400 \mathrm{~nm}$ than for thicker fibers indicating alignment and extension of polytetrahydrofuran chains. The tensile properties of single electrospun PEA fibers as determined with atomic force microscopy revealed that the E-modulus and tensile strength at $50 \%$ strain ranged from 40 to $2000 \mathrm{MPa}$ and 10 to $180 \mathrm{MPa}$, respectively, depending on the fiber diameter. The stiffness and tensile strength of the fibers increased rapidly with decreasing fiber diameters for fibers with diameters smaller than $\sim 700 \mathrm{~nm}$, whereas the ductility decreased. The improvement in mechanical properties of fibers with decreasing diameters is thus correlated to a concurrent increase in the extension of the polytetrahydrofuran segments present.
\end{abstract}




\subsection{Introduction}

Segmented poly(ether amide)s based on polytetrahydrofuran soft segments and uniform bisoxalamide hard segments are highly phase separated thermoplastic elastomers ${ }^{1,2}$. These materials combine the physical characteristics of an elastomer and the processability of a thermoplastic as a result of their phase separated morphology ${ }^{3,4}$. The uniform bisoxalamide hard segments are strongly hydrogen bonded and highly ordered, forming fiber-like nano-crystals which are randomly dispersed in the amorphous polytetrahydrofuran matrix. The crystals act as physical crosslinks providing the material dimensional stability, stiffness and strength, whereas the polymer matrix contributes to the flexibility and extensibility of the polymer.

Electrospinning is a versatile and relatively simple processing technique through which micro- to nanosized fibers can be generated. Oriented and non-woven fiber mats can be fabricated using this technique providing materials with interesting characteristics such as a very large surface area, a small pore size and a high porosity. Moreover, fibers with diameters ranging from hundreds of micrometers to as small as tens of nanometers can be prepared ${ }^{5-7}$. Electrospinning of polymer solutions is an extremely rapid process that includes the stretch of the polymer jet and the evaporation of the solvent within milliseconds. The rapid solidification may affect the crystallization process and generally results in less-developed crystal structures. Otherwise, in the polymer jet high elongation and shear forces capable of aligning the macromolecular chains along the fiber axis result in a high degree of molecular orientation in the fiber $^{8-14}$. The morphological changes resulting from the electrospinning process affect the mechanical properties of the fibers and hence the bulk mechanical properties of oriented or non-woven fibermats.

Conventional mechanical testing set-ups are not suitable for mechanical characterization of fibers with sub-micron diameters. Therefore, new mechanical testing methods have been developed which can be classified by three basic methods, namely; nanotensile testing, atomic force microscopy (AFM) based two and three-point bending or indentation tests ${ }^{15,16}$. Of these three methods, nano-tensile testing is the most effective method of determining the mechanical properties such as the E-modulus, yield stress and fracture properties. Using AFM cantilevers ${ }^{17-21}$ or the commercial NanoBionix nano-tensile tester (NanoBionix, MTS, USA) ${ }^{22}$ the tensile properties of single fibers have been studied. 
A commonly observed phenomenon in the mechanical properties of single electrospun fibers is the large increase in E-modulus and tensile strength when the fiber diameter is below a critical value ${ }^{12,23-27}$. However, this size effect is poorly understood and systematic studies to correlate the fiber diameter and fiber morphology to the mechanical properties are limited. Arinstein et $a l^{23}$ measured an abrupt increase in the E-modulus of electrospun nylon-6,6 fibers with diameters smaller than $\sim 500 \mathrm{~nm}$. The authors proposed that the reinforcing phenomenon is attributed to the supramolecular orientation of the amorphous phase. Lim et al ${ }^{26}$ explained the increased E-modulus and tensile strength of electrospun poly( $\varepsilon$-caprolactone) fibers with diameters smaller than $\sim 500 \mathrm{~nm}$ by visualizing the changes in the crystalline morphology with AFM. Fibers with small diameters exhibited both fibrillar and aligned structures with amorphous regions consisting of extended tie molecules. On the other hand, fibers with larger diameters only consisted of misaligned lamellae with amorphous regions consisting of relaxed tie molecules. The fibrillar structures with alternating crystalline and extended amorphous tie molecules showed a higher resistance in axial force than the lamellar structures consisting of relaxed amorphous molecules.

In this paper, we present the effect of molecular orientation in segmented poly(ether amide)s (PEA) on the mechanical properties of single electrospun fibers with diameters ranging from 150 to $2000 \mathrm{~nm}$. The PEA was composed of polytetrahydrofuran $\left(\mathrm{M}_{\mathrm{n}}=\right.$ $1.1 \times 10^{3}$ g. $\mathrm{mol}^{-1}$ ) soft segments and uniform hydrogen bonding bisoxalamide segments. The molecular orientation in these single electrospun PEA fibers was determined with polarized Raman microspectroscopy. Tensile tests on single electrospun PEA fibers were performed using atomic force microscopy. 


\subsection{Experimental}

\subsubsection{Materials}

Diethyl oxalate, bis(3-aminopropyl) polytetrahydrofuran $\left(\mathrm{M}_{\mathrm{n}}=1.1 \mathrm{x} 10^{3} \mathrm{~g} \cdot \mathrm{mol}^{-1}\right)$, 1,6-diaminohexane, 1,1,1,3,3,3-hexafluoro-2-propanol (HFIP), deuterated chloroform $\left(\mathrm{CDCl}_{3}-\mathrm{d}_{1}\right)$ and formic acid (puriss. P.a. $\sim 98 \%$ ) were purchased from Aldrich (Zwijndrecht, The Netherlands). Irganox1330 was kindly provided by Ciba (Geigi, Switzerland). HPLC-quality chloroform was purchased from Lab-Scan (Gliwice, Poland). Polydimethylsiloxane (PDMS, Sylgard 184) for device preparation was purchased from DOW Corning (USA). Diethyl ether and tetrahydrofuran were obtained from Biosolve (Valkenswaard, The Netherlands) and chloroform was purchased from Merck (Darmstadt, Germany). All materials were used as received.

\subsubsection{Synthesis}

\section{Bis(ethyl 2-(aminopropyl) oxo acetate) polytetrahydrofuran (2)}

Diethyl oxalate (132.75 g, $0.92 \mathrm{~mol}$ ) was added to a solution of bis(3-aminopropyl) polytetrahydrofuran (1) (250.00 g, $0.23 \mathrm{~mol})$ in $500 \mathrm{ml}$ of THF at room temperature. Subsequently, the mixture was stirred at room temperature for $16 \mathrm{~h}$. The solvent was removed at reduced pressure. The excess of diethyl oxalate was removed by vacuum distillation $(\sim 0.1 \mathrm{mbar})$ at $70{ }^{\circ} \mathrm{C}$ for $16 \mathrm{~h}$. The product was obtained as a viscous yellow/orange liquid in a yield of $98 \%$. ${ }^{1} \mathrm{H} \mathrm{NMR}\left(300 \mathrm{MHz}, \mathrm{CDCl}_{3}-\mathrm{d}_{1}\right) \delta=7.73$ (bt, $2 \mathrm{H}, \mathrm{OCOCONH}$ ), 4.27 (q, $4 \mathrm{H}, \mathrm{CH}_{3} \mathrm{CH}{ }_{2} \mathrm{O}$ ), 3.48 (t, $4 \mathrm{H}, \mathrm{NHCH}_{2} \mathrm{CH}_{2} \mathrm{CH}_{2} \mathrm{O}$ ), 3.27-3.45 (m, 54H, OCH $\left.{ }_{2} \mathrm{CH}_{2}\right), 3.27-3.45$ (q, $\left.4 \mathrm{H}, \mathrm{NHCH}_{2} \mathrm{CH}_{2} \mathrm{CH}_{2} \mathrm{O}\right), 1.76$ (m, 4H, $\left.\mathrm{NHCH}_{2} \mathrm{CH}_{2} \mathrm{CH}_{2} \mathrm{O}\right), 1.50-1.65\left(\mathrm{~m}, 54 \mathrm{H}, \mathrm{OCH}_{2} \mathrm{CH}_{2}\right), 1.31$ (t, $6 \mathrm{H}, \mathrm{CH}_{3} \mathrm{CH}_{2} \mathrm{O}$ ).

\section{Segmented poly(ether amide) (PEA) (3)}

Bis(ethyl 2-(aminopropyl) oxo acetate) polytetrahydrofuran (2) (90.00 g, 0.069 mol) and 1,6-diaminohexane $(7.04 \mathrm{~g}, 0.069 \mathrm{~mol})$ were placed in a polymerization tube. To this mixture was added Irganox1330 (1 wt\% of the total mass). The mixture was heated to $190{ }^{\circ} \mathrm{C}$ under a nitrogen flow. After $1 \mathrm{~h}$, the pressure was slowly reduced to $\sim 20$ mbar to distill off the ethanol. Subsequently, the pressure was reduced to $\sim 0.08$ mbar in the following $2 \mathrm{~h}$. The reaction mixture was then cooled to room temperature under vacuum. The polymer was dissolved in $500 \mathrm{ml}$ of chloroform at $50{ }^{\circ} \mathrm{C}$ and subsequently precipitated in $4 \mathrm{~L}$ of diethyl ether. The polymer was filtered and dried at $60{ }^{\circ} \mathrm{C}$ at 
reduced pressure. The product was obtained as a yellow transparent elastic solid in a yield of $95 \%$. ${ }^{1} \mathrm{H} \mathrm{NMR}\left(300 \mathrm{MHz}, \mathrm{CDCl}_{3}-\mathrm{d}_{1}\right) \delta=7.83\left(\mathrm{bt}, 2 \mathrm{H}, \mathrm{OCH}_{2} \mathrm{CH}_{2} \mathrm{CH}_{2} \mathrm{NHCO}\right.$ ), 7.48 (bt, $2 \mathrm{H}, \mathrm{CONHCH} \mathrm{CH}_{2} \mathrm{CH}_{2}$ ), 3.46 (t, $4 \mathrm{H}, \mathrm{OCH}_{2} \mathrm{CH}_{2} \mathrm{CH}_{2} \mathrm{NH}$ ), 3.30-3.44 (m, 54H, OCH ${ }_{2} \mathrm{CH}_{2}$ ), 3.30-3.44 (m, $4 \mathrm{H}, \mathrm{OCH}_{2} \mathrm{CH}_{2} \mathrm{CH}_{2} \mathrm{NH}$ ), 3.26 (q, $4 \mathrm{H}, \mathrm{CONHCH}_{2} \mathrm{CH}_{2} \mathrm{CH}_{2}$ ), $1.79\left(\mathrm{~m}, 4 \mathrm{H}, \mathrm{OCH}_{2} \mathrm{CH}_{2} \mathrm{CH}_{2} \mathrm{NH}\right), 1.60-1.70\left(\mathrm{~m}, 54 \mathrm{H}, \mathrm{OCH}_{2} \mathrm{CH}_{2}\right), 1.60-1.50(\mathrm{~m}, 4 \mathrm{H}$, $\left.\mathrm{CONHCH}_{2} \mathrm{CH}_{2} \mathrm{CH}_{2}\right), 1.33\left(\mathrm{~m}, 4 \mathrm{H}, \mathrm{CONHCH}_{2} \mathrm{CH}_{2} \mathrm{CH}_{2}\right.$ ).

\subsubsection{Methods}

\section{NMR}

${ }^{1} \mathrm{H}$ NMR (300 MHz) spectra were recorded on a Varian Inova Nuclear Magnetic Resonance Spectrometer using $\mathrm{CDCl}_{3}-\mathrm{d}_{1}$ as solvent.

\section{GPC}

The GPC setup consisted of a Perkin Elmer series 200 binary pump, a Perkin Elmer series 200 autosampler, a Shimadzu CTO-AVP column oven, and a Shimadzu RID-10A refractive index detector. The eluent was $\mathrm{CHCl}_{3} / \mathrm{HFIP}(95 / 5 \mathrm{v} / \mathrm{v})$. The flow was set at $1 \mathrm{ml} \cdot \mathrm{min}^{-1}$. The injection volume was $200 \mu \mathrm{L}$. The separation was performed on two PL Mixed-D columns $(300 \times 7.5 \mathrm{~mm})$ from Polymer Laboratories Ltd., packed with $5 \mu \mathrm{m}$ particles. The temperature of the columns was set at $30{ }^{\circ} \mathrm{C}$. Approximately $120 \mathrm{mg}$ of sample was weighed in a $50 \mathrm{ml}$ vial. To this vial $2 \mathrm{ml}$ of HFIP was added and the solution was allowed to stand for $2 \mathrm{~h}$. Next, $38 \mathrm{ml}$ of warm $\left(\sim 35^{\circ} \mathrm{C}\right)$ HPLC-quality chloroform was added and mixed thoroughly. Prior to injection, the sample solution was filtered through a Millex-LCR $0.45 \mu \mathrm{m}$ filter (Millipore). The system was calibrated with 14 narrow polystyrene standards (Polymer Laboratories) with MW ranging from $5.8 \times 10^{2}$ to $1.0 \times 10^{6}$ g. $\mathrm{mol}^{-1}$. The standards were dissolved in $\mathrm{CHCl}_{3} / \mathrm{HFIP}(95 / 5 \mathrm{v} / \mathrm{v})$. Because the $\mathrm{K}$ and $\alpha$ values of the samples are not known and a viscometer was not available, no universal calibration could be performed. The reported molecular weights should, therefore, be regarded as PS-equivalent molecular weights. A calibration curve that is virtually linear over a broad molecular weight range was obtained. However, the highest molecular weights tested $\left(6.75 \times 10^{5}\right.$ g.mol ${ }^{-1}$, $8.41 \times 10^{5} \mathrm{~g} \cdot \mathrm{mol}^{-1}$, and $1.0 \times 10^{6} \mathrm{~g} \cdot \mathrm{mol}^{-1}$ ) elute near or in the exclusion limit of the column, causing an upward curvature at the high MW end. 


\section{Electrospinning}

All electrospinning experiments were performed using a setup schematically depicted in Figure 8.1. A solution of PEA in chloroform/formic acid (9/1 v/v, 0.075 g.ml-1) was transferred to a $20 \mathrm{ml}$ syringe which was connected to a syringe pump (KDS 100, KD Scientific). The spinning solution was pushed through a silicon tube (Nalgene $50,1.6 \mathrm{~mm}$ ID $\times 3.1 \mathrm{~mm}$ OD, Rochester, NY, USA) into a blunt steel needle $(22 \mathrm{G}$ 1.25 ", $0.7 \mathrm{~mm} 1 \mathrm{D} \times 30 \mathrm{~mm}$ length) at a constant speed of $0.3 \mathrm{ml}^{-\mathrm{h}^{-1}}$. The needle was attached to the electrode of a high voltage supply (Gamma High Voltage Research Inc., USA). A grounded piece of aluminum foil $\left(10 \times 10 \mathrm{~cm}^{2}\right)$ was placed at a $20 \mathrm{~cm}$ distance from the needle to collect the fibers. A continuous production of electrospun fibers was obtained at $25 \mathrm{kV}$.

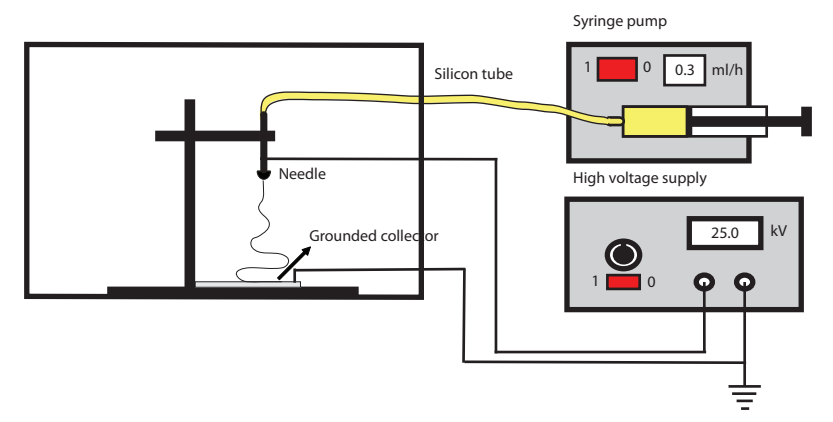

Figure 8.1: Schematic representation of the electrospinning setup.

\section{SEM}

The morphology and diameter of the electrospun polymer fibers was determined from SEM measurements (Leo Gemini 1550 FEG-SEM, Oberkochen, Germany). No sputter coating was applied on the sample before imaging.

\section{AFM imaging}

Atomic force microscopy images of the electrospun PEA fibers were obtained in tapping mode using V-shaped $\mathrm{Si}_{3} \mathrm{~N}_{4}$ cantilevers (coated sharp, micro-levers MSCT-AUHW, type $\mathrm{F}$, spring constant $\mathrm{k}=0.5 \mathrm{~N} . \mathrm{m}^{-1}$, Veeco, Cambridge, UK). A tapping frequency of $\sim 120 \mathrm{kHz}$ and a tapping amplitude of $\sim 100 \mathrm{~nm}$ were used. Samples were prepared by electrospinning PEA fibers from a solution of PEA in chloroform/formic acid (9/1 $\mathrm{v} / \mathrm{v}, 0.075$ g. $\mathrm{ml}^{-1}$ ) on a glass substrate. 


\section{DSC}

Thermal analysis was carried out using a Perkin-Elmer Pyris 1. Calibration was carried out with pure indium. Samples (5-10 mg) were heated from -100 to $200{ }^{\circ} \mathrm{C}$ at a rate of $20{ }^{\circ} \mathrm{C} \cdot \mathrm{min}^{-1}$. The melting $\left(\mathrm{T}_{\mathrm{m}}\right)$ temperature was obtained from the peak maximum and the melt $\left(\Delta \mathrm{H}_{\mathrm{m}}\right)$ enthalpy was determined from the area under the curve.

\section{Polarized Raman microspectroscopy}

Polarized Raman measurements were carried out using a confocal Raman microspectrometer similar to the setup described by Pully et al ${ }^{28}$. The $647.1 \mathrm{~nm}$ excitation light from a Krypton ion laser light source (Innova 90-K; Coherent Inc., Santa Clara, CA) was focused through a 40x/0.95 NA objective (Zeiss W-Plan Apochromat; Carl Zeiss MicroImaging GmbH, Gottingen, Germany) onto single fibers. The laser intensity was $35 \mathrm{~mW}$ and the gain was set at 4 . A single spectrum resulted after integration of 100 measurements each second.

The incident beam was polarized along the X-direction, which was also the fiber direction (Figure 8.2). The fiber was rotated $90^{\circ}$ to allow polarization of the incident beam in the Y-direction. The emitted beam was analyzed using a polarizer, which was placed before the analyzer. In this way a total of four Raman spectra were acquired with polarization geometries $\mathrm{X}|\mathrm{X}, \mathrm{X}| \mathrm{Y}, \mathrm{Y} \mid \mathrm{X}$ and $\mathrm{Y} \mid \mathrm{Y}$, using the notation "incident polarization|emitted polarization". Identical experiments were performed on non-oriented and oriented polymer films (30 min after being stretched to failure) with a thickness of $0.4 \mu \mathrm{m}$. In these experiments, the stretching direction was similar to the X-direction.

The molecular orientation was quantified by calculating the qualitative orientation parameter, $\mathrm{P}_{\text {qual }}$, using equation $8.1^{29}$.

$$
P_{\text {qual }}=\frac{I_{\mathrm{Y} \mid \mathrm{X}}}{I_{\mathrm{X} \mid \mathrm{X}}}
$$

In which $I_{\mathrm{Y} \mid \mathrm{X}}$ and $I_{\mathrm{X} \mid \mathrm{X}}$ are the intensities of the amide $\mathrm{I}$ vibration band at $1675 \mathrm{~cm}^{-1}$, amide II vibration band at $1550 \mathrm{~cm}^{-1}$ and $\nu \mathrm{C}-\mathrm{O}-\mathrm{C}$ vibration band at $1117 \mathrm{~cm}^{-1}$ peaks in the $\mathrm{Y} \mid \mathrm{X}$ and $\mathrm{X} \mid \mathrm{X}$ spectra, respectively. 


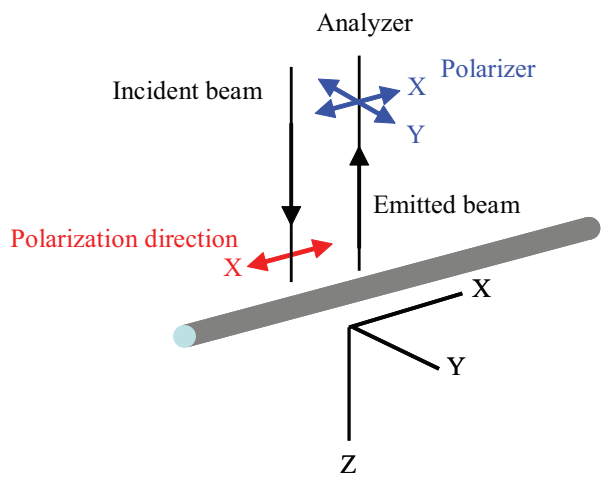

Figure 8.2: Coordinate system used for the recording of polarized Raman spectra of electrospun PEA fibers. The incident beam is polarized in the $\mathrm{X}$-direction or Y-direction (by rotating the sample $90^{\circ}$ ).

\subsubsection{Nano-tensile testing of electrospun fibers using AFM}

\section{Preparation of PDMS substrates}

Poly(dimethyl siloxane) (PDMS) molds were prepared using Sylgard 184 silicone elastomer. The prepolymer was mixed with the curing agent in a 10:1 weight ratio as specified by the manufacturer. After $10 \mathrm{~min}$ of stirring and $40 \mathrm{~min}$ of degassing in a vacuum oven, the mixture was poured onto a pre-patterned silicon wafer with parallel channels and cured at $70{ }^{\circ} \mathrm{C}$ overnight. The width and depth of the channels on the pre-patterned silicon wafer were 250 and $300 \mu \mathrm{m}$, respectively. After curing the PDMS layer was peeled off the silicon wafer.

\section{Sample preparation}

For the mechanical tests, samples with fibers suspending microchannels were prepared. Sample preparation was carried out according the procedure schematically outlined in Figure 8.3a. A few drops of Araldite ${ }^{\circledR}$ (Araldite 2011, Vantico, Basel, Switzerland), mixed for $5 \mathrm{~min}$, were deposited on a glass slide and the PDMS substrate with microchannels was pressed onto the substrate. After $2 \mathrm{~h}$, the Araldite was cured and the PDMS was peeled off affording microchannels. In the next step, a very thin layer of fresh Araldite, mixed for 5 min, was carefully deposited on top of the Araldite dikes and immediately the glass slide was held under the electrospinning jet to collect the fibers. Only a few seconds were needed to collect enough fibers which were suitable for tensile testing (Figure 8.3b). The Araldite was at least cured for $24 \mathrm{~h}$ before measurement. 
(a)
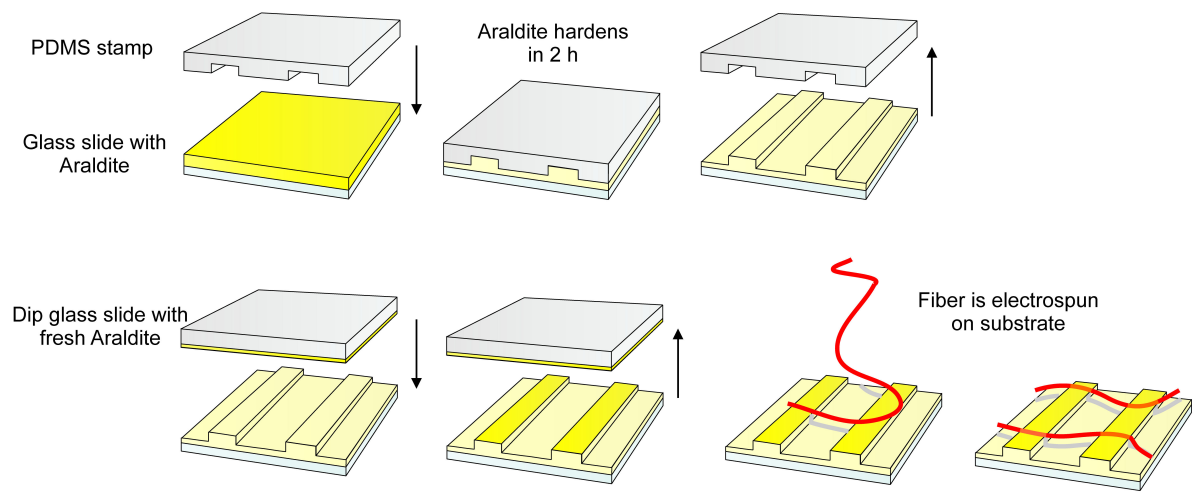

Channel dimensions: width $=250 \mu \mathrm{m}$, depth $=300 \mu \mathrm{m}$

(b)

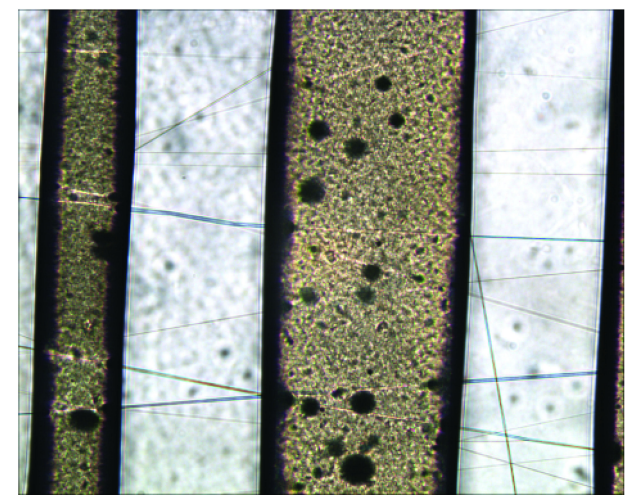

Figure 8.3: (a) Schematic drawing of preparation of a substrate with microchannels and deposition of electrospun fibers. (b) Optical microscope image with electrospun PEA fibers suspended over two parallel channels. Lighter areas are the channels and darker areas are the dikes. 


\section{Nano-tensile testing of single fibers}

Nano-mechanical tensile tests on single electrospun fibers were performed on a homebuilt AFM combined with an optical microscope. A schematic drawing of the set-up is presented in Figure 8.4a. The sample was placed above the microscope objective on the sample plate and a modified cantilever (NanoWorld Pointprobe, spring constant $\mathrm{k}=35 \mathrm{~N} . \mathrm{m}^{-1}$, Nanoworld, Wetzlar, Germany) was placed in the channel. The cantilever contained a Pt pillar on its back, which was grown by a focused ion beam instrument (FIB) (FEI, NOVALAB 600 dual beam machine, Eindhoven, the Netherlands) (Figure 8.4c-d). The Pt pillar on the back of the cantilever prevented the fiber from sliding off the cantilever during elongation. A calibrated piezo tube (Micros, Piezosystem Jena, Jena, Germany) was connected to the sample plate. The piezo tube can extend in the Z-direction over a maximum distance of $400 \mu \mathrm{m}$ at a preset rate. After placing the cantilever underneath the fiber in the middle of the channel, the sample plate was moved downward by the piezo in order to stretch the fiber (Figure 8.4a). The force applied to the fiber was determined from the deflection of the cantilever.

(a)
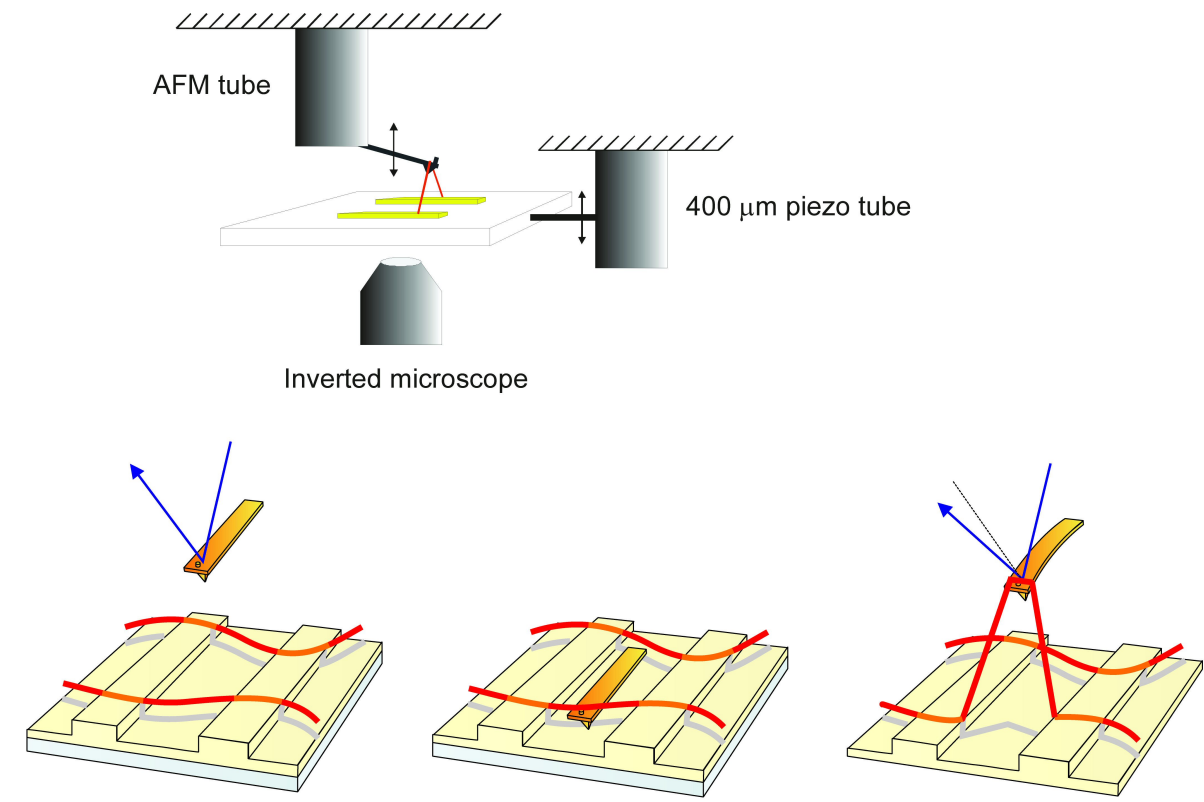
(b)

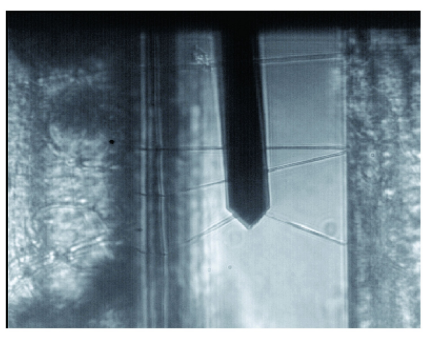

(c)

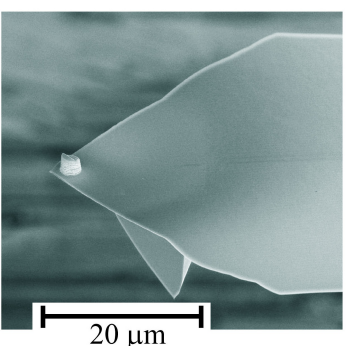

(d)

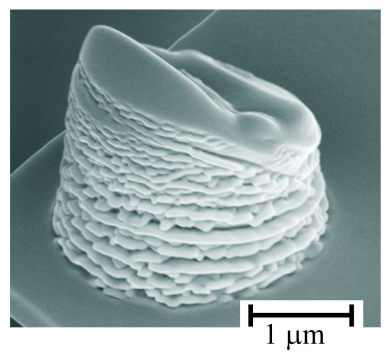

Figure 8.4: (a) Schematic drawing of the tensile experiment, (b) Optical microscope image illustrating the stretching of a fiber using an AFM cantilever with a pillar on the back. Lighter area in the middle of the image is a channel across which the fibril is suspended. Darker areas are the araldite dikes to which the fibril is attached. (c-d) SEM images of a Pt pillar (2 $\mu \mathrm{m}$ diameter and 3-5 $\mu \mathrm{m}$ height) that was grown on the back of an AFM cantilever.

A typical deflection-Z-displacement curve of a single tensile cycle of $400 \mu \mathrm{m}$ is shown in Figure 8.5b. The force measured is:

$$
\begin{aligned}
& F_{\text {fiber }}=\frac{F_{\text {vert }}}{2 \times \cos \alpha} \\
& \tan \alpha=\frac{2 Z}{W}
\end{aligned}
$$

In which $\mathrm{W}$ is the length of the fiber between the two fixed ends and $\mathrm{Z}$ is the displacement of the piezo tube. The cosine of this angle is the ratio between the force measured $\left(\mathrm{F}_{\mathrm{vert}}\right)$ and the force on the fiber $\left(\mathrm{F}_{\text {fiber }}\right)$.

The length of the fiber (L) can be expressed as:

$$
L=2 \sqrt{\left(\frac{W}{2}\right)^{2}+Z^{2}}=\sqrt{W^{2}+4 Z^{2}}
$$


The stress $(\sigma)$ and the strain $(\varepsilon)$ were calculated using equations 8.4 and 8.5, respectively.

$$
\begin{aligned}
& \sigma=\frac{F_{\text {fiber }}}{A}=\frac{2 D_{\text {vert }} \times B \times k}{\pi \times d^{2} \times \sin \alpha} \\
& \epsilon=\frac{L-L_{0}}{L_{0}}=\frac{\sqrt{W^{2}-4 Z^{2}}-W}{W}=\sqrt{1+\frac{4 Z^{2}}{W^{2}}}-1
\end{aligned}
$$

in which $\mathrm{D}_{\text {vert }}$ is the calibrated deflection signal of the cantilever, B is the deflection sensitivity, $\mathrm{k}$ is the spring constant of the cantilever and $\mathrm{d}$ is the diameter of the fiber. The E-modulus of the fibers was determined from the slope of the stress-strain curves at strains between 1 and $2 \%$.

(a)

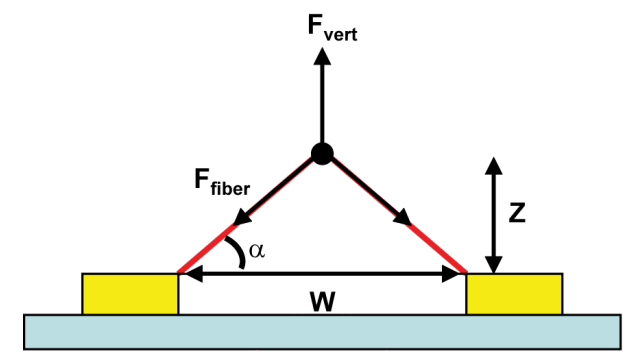

(b)

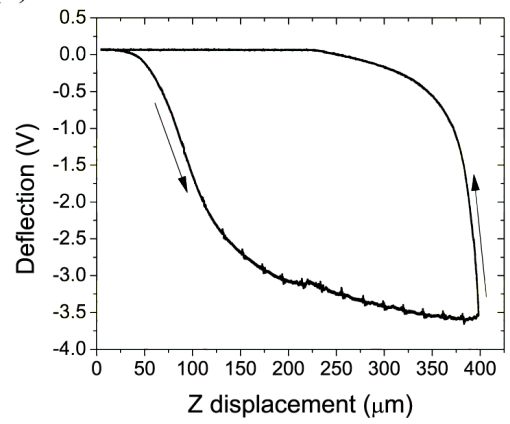

(c)

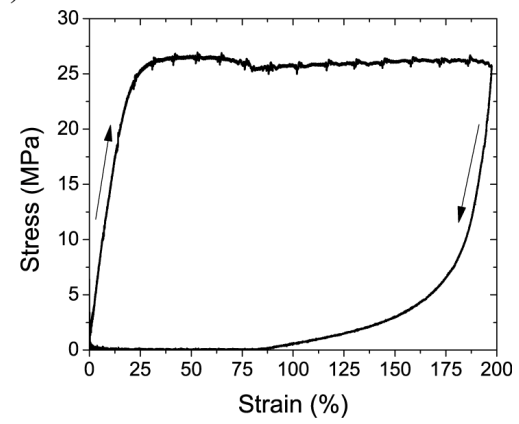

Figure 8.5: (a) Fiber geometry during tensile testing. (b) A typical deflection-Z movement curve for a single tensile cycle of $400 \mu \mathrm{m}$, (c) corresponding stress-strain curve determined from the deflection- $\mathrm{Z}$ movement data using equations 8.2-6. 


\subsection{Results and Discussion}

\subsubsection{Synthesis and characterization}

The segmented poly(ether amide) (PEA) used consists of polytetrahydrofuran $\left(\mathrm{M}_{\mathrm{n}}\right.$ $=1.1 \times 10^{3}$ g. $\left.\mathrm{mol}^{-1}\right)$ soft segments and uniform bisoxalamide hard segments. The polymer selected for this study comprises bisoxalamide hard segments with a spacer length of 6 methylene groups between oxalamide groups and was prepared by a polycondensation reaction as reported previously (Scheme 8.1) ${ }^{1}$. The polymer is a yellow elastic transparent material and GPC analysis revealed a molecular weight of $6.3 \times 10^{4}$ g.mol ${ }^{-1}$ with a PDI of 4 relative to polystyrene standards.

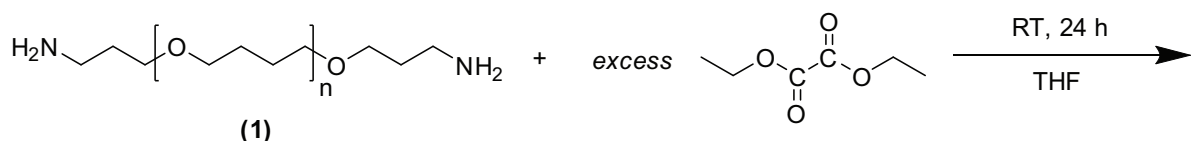

(1)

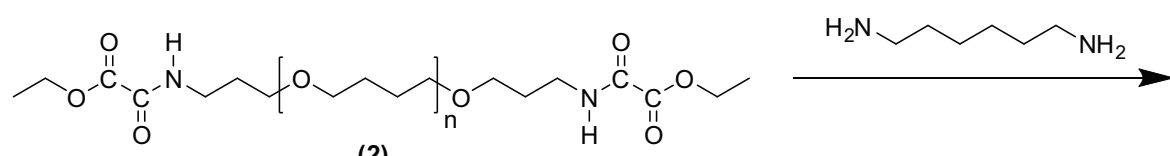

(2)<smiles>CC(C)(C)CCCNC(=O)C(=O)NCCCCCCNC(=O)C(=O)NCCCOC(C)(C)CCCOC1CCCCC1</smiles>

(3)

Scheme 8.1: Synthesis of the segmented poly(ether amide) consisting of polytetrahydrofuran soft segments and uniform bisoxalamide hard segments.

\subsubsection{Electrospinning}

Electrospinning a solution of the PEA in chloroform at a concentration of $0.075-0.100$ g. $\mathrm{ml}^{-1}$, a voltage between $20-25 \mathrm{kV}$, a collector distance of $20 \mathrm{~cm}$ and a flow rate between 1.5 and $2.0 \mathrm{ml} . \mathrm{h}^{-1}$ afforded beadless fibers (Figure 8.6a-b). The spun fibers had an average diameter of $2.86 \pm 0.36 \mu \mathrm{m}$ as determined from SEM images. The surface of the fibers was porous, a morphology often observed when a low boiling point solvent is applied. This phenomenon is ascribed to phase separation of the solution 
into a polymer rich and a solvent rich phase ${ }^{30-32}$. As a consequence, pores are formed upon evaporation of solvent from the solvent rich phase during electrospinning.

The fiber diameter and morphology of electrospun fibers are highly influenced by the conductivity and dielectric constant of the solution. By increasing these values, the electrospinning jet can carry more charges and due to repulsion between similar charges, the jet stretches more and consequently the fiber diameter decreases. To increase the charge carrying capacity of the solution, mixtures of chloroform and formic acid were tested. Electrospinning of a solution of the PEA in a $9 / 1 \mathrm{v} / \mathrm{v}$ mixture of chloroform and formic acid at a concentration of $0.075 \mathrm{~g} \cdot \mathrm{ml}^{-1}$, a voltage of $25 \mathrm{kV}$, a collector distance of $20 \mathrm{~cm}$ and a flow rate of $0.3 \mathrm{ml} \cdot \mathrm{h}^{-1}$ offered continuous production of beadless fibers with diameters ranging from 150 to $2000 \mathrm{~nm}$ with relatively smooth surfaces (Figure 8.6c-d). Some split and ribbon-type fibers were also observed. These electrospun fibers were collected on glass substrates containing micro-channels (Figure 8.3a).

(a)

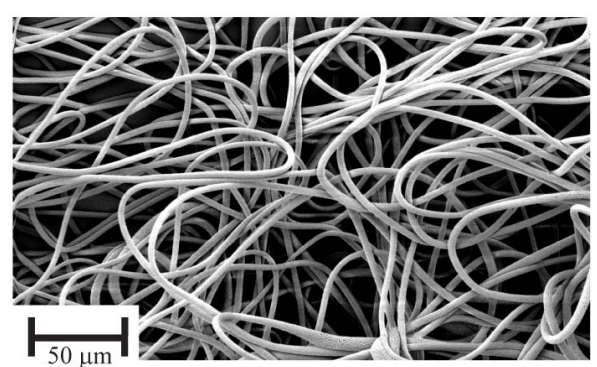

(c)

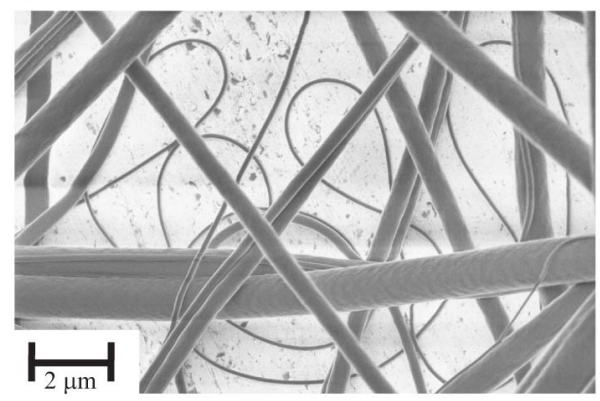

(b)

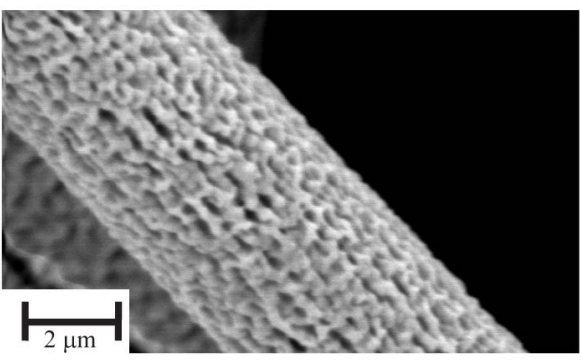

(d)

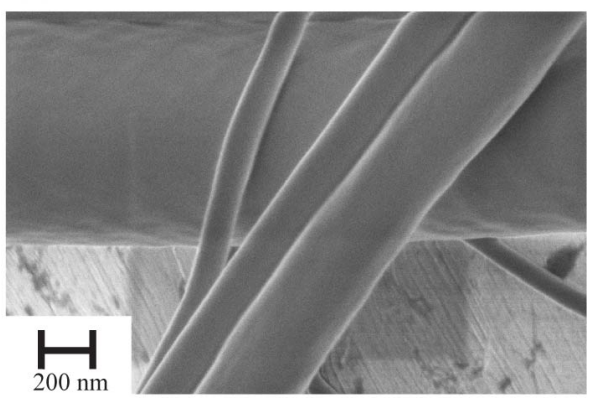

Figure 8.6: SEM images of fibers electrospun from (a-b) a solution of the PEA in chloroform at a concentration of $0.075 \mathrm{~g} \cdot \mathrm{ml}^{-1}$, a voltage of $20 \mathrm{kV}$, a collector distance of $20 \mathrm{~cm}$ and a flow rate of $1.5 \mathrm{ml} \cdot \mathrm{h}^{-1}$ (c-d) a solution of the PEA in a $9 / 1 \mathrm{v} / \mathrm{v}$ mixture of chloroform and formic acid at a concentration of 0.075 g.ml ${ }^{-1}$, a voltage of $25 \mathrm{kV}$, a collector distance of $20 \mathrm{~cm}$ and a flow rate of $0.3 \mathrm{ml} . \mathrm{h}^{-1}$. 


\subsubsection{Atomic force microscopy}

Imaging the surface of an electrospun PEA fiber revealed no pronounced crystalline morphology, although some fiber-like crystals can be recognized in the phase image (Figure 8.7b). Probably, the rapid evaporation of solvent from the polymer jet and the high elongation and shear forces that are experienced during electrospinning, prevent the development of a fiber-like crystalline structure as observed in polymer films ${ }^{2}$.

(a)

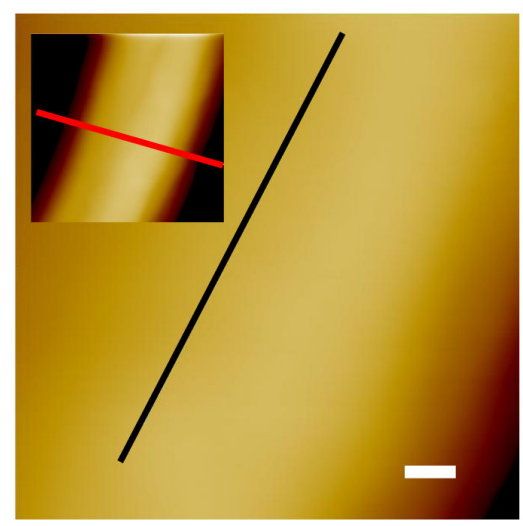

(c)

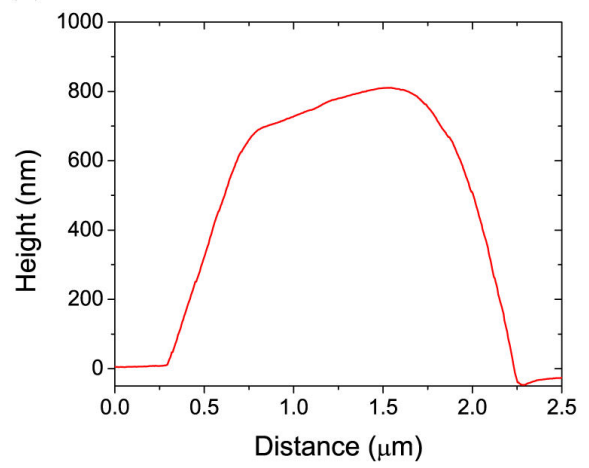

(b)

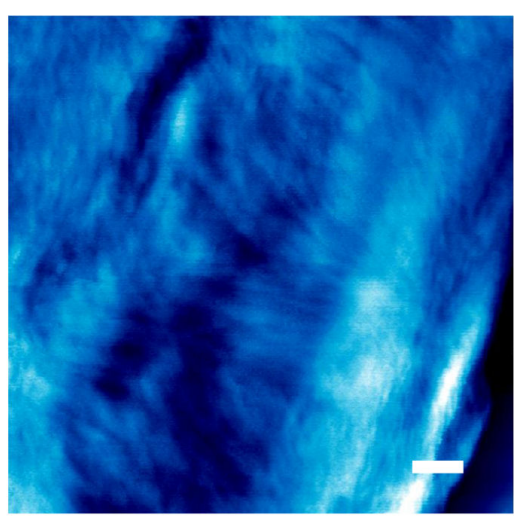

(d)

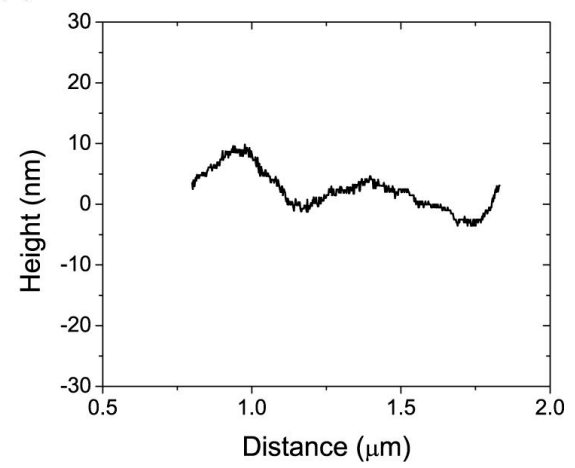

Figure 8.7: Tapping mode AFM height image (a) and phase image (b) of a single electrospun PEA fiber (electrospun from a chloroform/formic acid solution $(9 / 1 \mathrm{v} / \mathrm{v})$ ) on a glass slide (image size $1 \times 1 \mu \mathrm{m}$, bar $=100 \mathrm{~nm}$ ). Cross-sections perpendicular to the fiber axis (c) and parallel to the fiber axis (d). 


\subsubsection{Differential scanning calorimetry}

The crystallization behavior of electrospun fibers and compression molded films were studied using differential scanning calorimetery (Figure 8.8). It should be noted that electrospun fiber samples consisted of fibers with diameters ranging from 150 to 2000 $\mathrm{nm}$ and thus no correlation between the fiber diameter and crystallinity could be made.

In previous research it was shown that the segmented poly(ether amide) with uniform bisoxalamide hard segments had a broad melting transition ${ }^{1}$. This transition, resulting from the melting of bisoxalamide crystals, consisted of multiple peaks suggesting that different crystal structures and/or crystal thicknesses are present. Similar to compression molded films electrospun fiber samples exhibited a broad melting transition between $\sim 110$ and $180{ }^{\circ} \mathrm{C}$. The maximum in the melting transition of the compression molded film is found at $144{ }^{\circ} \mathrm{C}$, whereas this maximum is shifted to $159{ }^{\circ} \mathrm{C}$ for the electrospun fiber sample. The shift of the main melting transition to a higher temperature suggests that the amount of bisoxalamide crystals with a higher degree of perfection or a more stable crystalline structure is higher in the electrospun PEA fibers than in compression molded films. The melting enthalpies of the compression

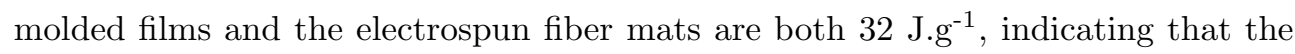
crystallinity is similar for the compression molded films and the electrospun fibers samples.

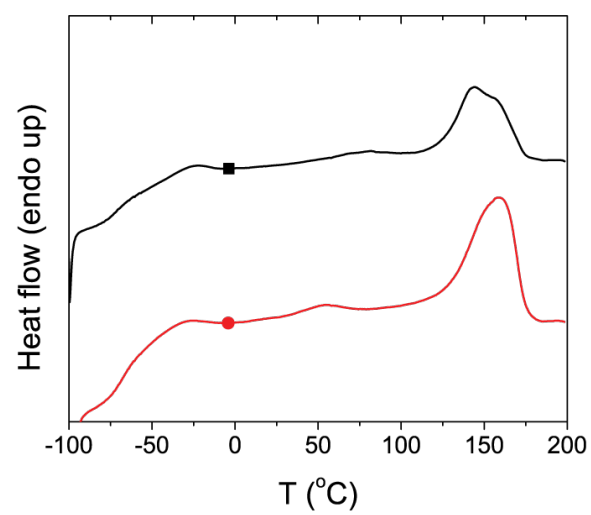

Figure 8.8: DSC heating scans of a $(\boldsymbol{\square})$ compression molded film and a $(\bullet)$ random sample of electrospun fibers with diameters ranging from 150-2000 nm. 


\subsubsection{Polarized Raman microspectroscopy}

The molecular orientation of the polytetrahydrofuran and bisoxalamide segments in the electrospun fibers, oriented and non-oriented films were subsequently studied by polarized Raman microspectroscopy. In this technique, a microscope is used to focus the laser beam on the sample and enables recording of Raman spectra of single electrospun PEA fibers with diameters larger than $200 \mathrm{~nm}$.

The polarized Raman spectra of the non-oriented and oriented PEA films are presented for the Raman shift regions $600-1800$ and $2600-3500 \mathrm{~cm}^{-1}$ in figures Figure $8.9 \mathrm{a}-$ $\mathrm{b}$ and Figure 8.9c-d, respectively. A total of four Raman spectra were acquired with polarization geometries $\mathrm{X}|\mathrm{X}, \mathrm{X}| \mathrm{Y}, \mathrm{Y} \mid \mathrm{X}$ and $\mathrm{Y} \mid \mathrm{Y}$, using the notation "incident polarization|emitted polarization" (see section 8.2.3). Characteristic Raman peaks are found at $3291(\nu \mathrm{N}-\mathrm{H}), 1675$ (Amide I, $\nu \mathrm{C}=\mathrm{O}$ ), 1547 (Amide II, $\nu \mathrm{C}-\mathrm{N}+\delta \mathrm{N}-\mathrm{H}$ ) and $1117 \mathrm{~cm}^{-1}(\nu \mathrm{C}-\mathrm{O}-\mathrm{C})^{33-39}$. Interestingly, a high intensity of the amide II band in the Raman spectra of oxalamides was observed ${ }^{33}$.

The Raman spectra of the non-oriented film with different polarization geometries overlap almost perfectly, indicating that this film is isotropic (Figure 8.9a-b). On the other hand, when the film was stretched to failure major differences in the $\mathrm{X} \mid \mathrm{X}$ (x-direction parallel to the stretching direction) and $\mathrm{Y} \mid \mathrm{X}$ spectra (y-direction perpendicular to the stretching direction) were observed (Figure 8.9c-d). The N$\mathrm{H}$ and $\mathrm{C}=\mathrm{O}$ stretching vibration bands at 3291 and $1675 \mathrm{~cm}^{-1}$, respectively, show perpendicular polarization as the intensity of these bands are stronger in the $\mathrm{Y} \mid \mathrm{X}$ spectra than in the $\mathrm{X} \mid \mathrm{X}$ spectra. Contrary, the amide II band at $1547 \mathrm{~cm}^{-1}$, mainly attributable to $\mathrm{C}-\mathrm{N}$ stretching and N-H in-plane bending, shows parallel polarization. These results clearly indicate that the bisoxalamide segments are oriented parallel to the stretching direction and the crystals, formed by stacking of bisoxalamide segments, are oriented perpendicular to the stretching direction. The C-O-C stretching vibration band at $1117 \mathrm{~cm}^{-1}$ shows weak polarization in the stretching direction i.e. the polytetrahydrofuran chains are slightly oriented in the stretching direction of the film. It is noted that the measurements were performed $\sim 30$ minutes after stretching the film, which presumably allowed relaxation of the polytetrahydrofuran chains to their original state. 
(a)

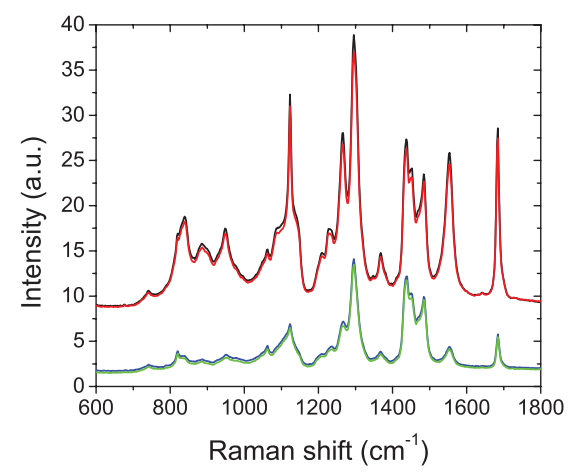

(c)

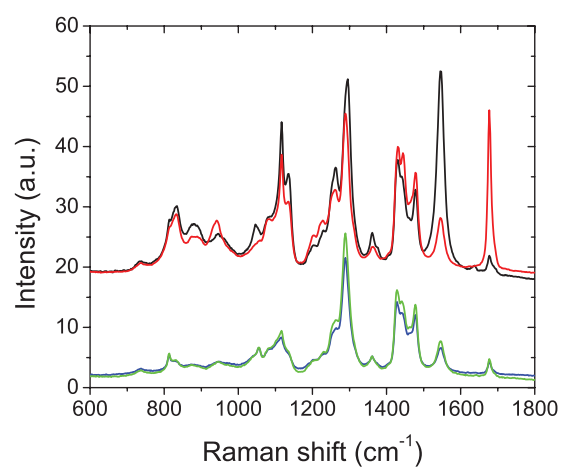

(b)

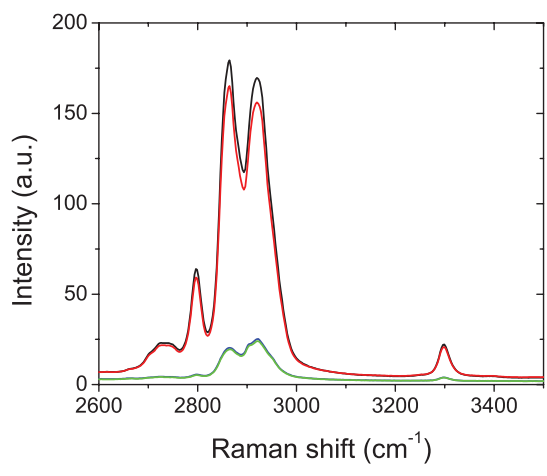

(d)

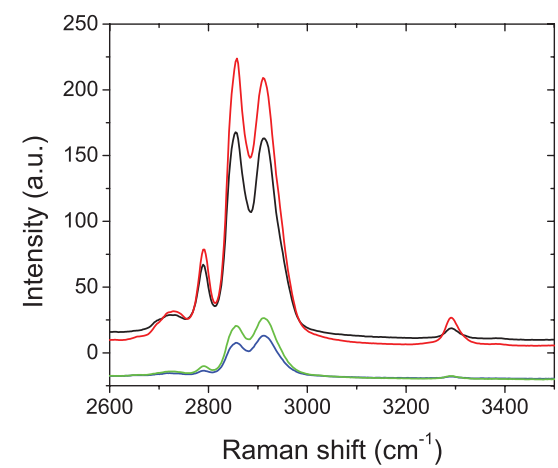

Figure 8.9: Polarized Raman spectra of a (a-b) non-oriented PEA film and an (c-d) oriented PEA film stretched to failure for the Raman shift regions $600-1800 \mathrm{~cm}^{-1}$ and 2600-3500 $\mathrm{cm}^{-1}$. Polarization geometries (-) X|X, (一) $\mathrm{Y}|\mathrm{X},(-) \mathrm{X}| \mathrm{Y},(-)$ $\mathrm{Y} \mid \mathrm{Y}$.

The polarized Raman measurements are in agreement with the general morphological model of deformation of segmented thermoplastic elastomers ${ }^{40,41}$. Non-oriented polymers display a morphology in which fiber-like nano-crystals are randomly dispersed in a soft polymer matrix. At high strains, these crystals are broken up and oriented perpendicular to the stretching direction. The soft segments are oriented in the stretching direction. After releasing the stress, the hard segment crystals remain oriented whereas the soft segments relax to their original state.

The polarized Raman spectra of single electrospun PEA fibers with diameters of 321 and $913 \mathrm{~nm}$ are presented in figures Figure 8.10a-b and Figure 8.10c-d, respectively. Both fibers show significant differences in the $\mathrm{X} \mid \mathrm{X}$ spectra ( $\mathrm{x}$-direction parallel to the 
(a)

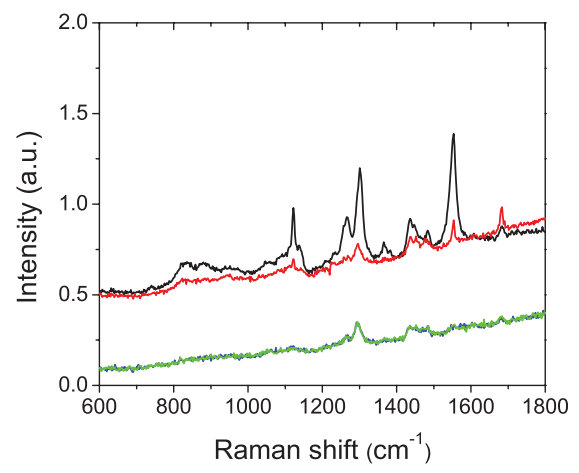

(c)

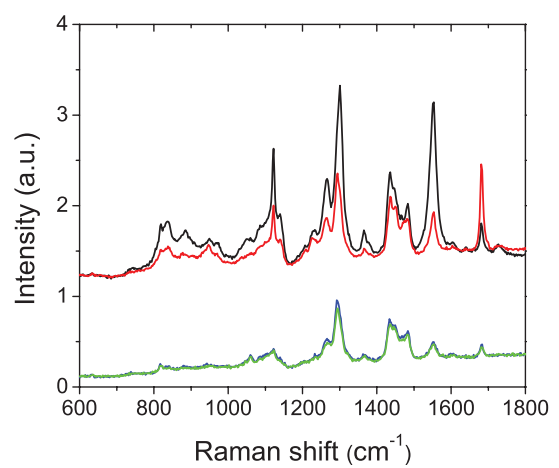

(b)

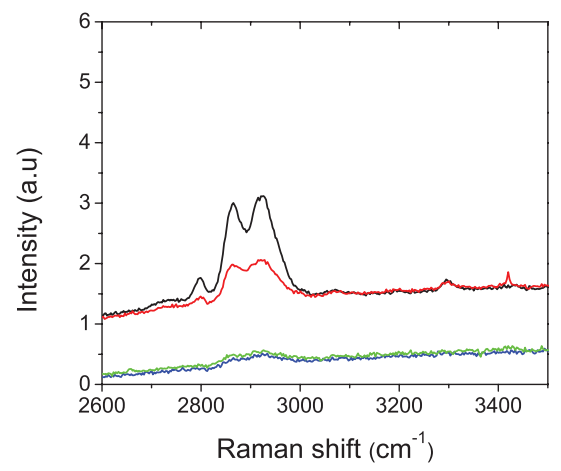

(d)

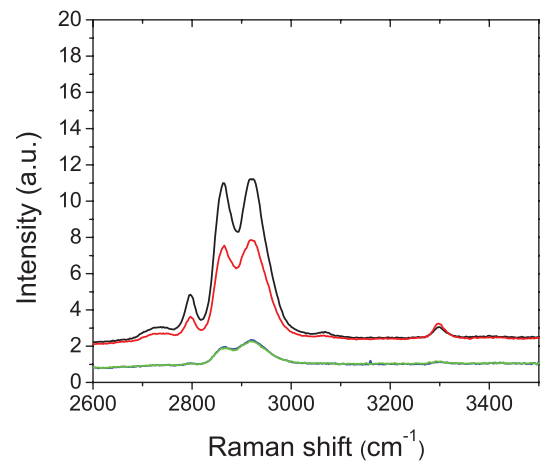

Figure 8.10: Polarized Raman spectra of a single electrospun fiber with a diameter of (a-b) $321 \mathrm{~nm}$ and (c-d) $913 \mathrm{~nm}$ for the Raman shift regions of $600-1800 \mathrm{~cm}^{-1}$ and 2600-3500 $\mathrm{cm}^{-1}$. Polarization geometries (-) X|X, (一) $\mathrm{Y}|\mathrm{X},(-) \mathrm{X}| \mathrm{Y},(-)$ $\mathrm{Y} \mid \mathrm{Y}$.

fiber axis) and $\mathrm{Y} \mid \mathrm{X}$ spectra (y-direction perpendicular to the fiber axis) indicating molecular orientation in the fibers. Similarly as observed for the stretched film, the intensity of the amide I band at $1675 \mathrm{~cm}^{-1}$ is stronger in the $\mathrm{Y} \mid \mathrm{X}$ spectra than in the $\mathrm{X} \mid \mathrm{X}$ spectra indicating orientation perpendicular to the fiber axis, whereas the amide II band at $1547 \mathrm{~cm}^{-1}$ displays parallel orientation in the fiber direction. Since the amide $\mathrm{I}$ is associated with the $\mathrm{C}=\mathrm{O}$ stretching vibration and the amide II band has a major contribution from $\mathrm{C}-\mathrm{N}$ stretching, these results clearly show that the bisoxalamide segments are oriented parallel to the fiber axis. Consequently, the crystals formed by stacking of the bisoxalamide segments are oriented perpendicular to the fiber axis. 
The degree of molecular orientation $\left(\mathrm{P}_{\text {qual }}\right)$ of the amide groups using equation 1 (Table 8.1) afforded similar values indicating that the degree of orientation of the bisoxalamide hard segments is independent on the fiber diameter.

A much stronger C-O-C stretching vibration at $1117 \mathrm{~cm}^{-1}$ was found in the $\mathrm{X} \mid \mathrm{X}$ spectra compared to the $\mathrm{Y} \mid \mathrm{X}$ spectra of the fibers. The $\mathrm{P}_{\text {qual }}$ of the $\mathrm{C}-\mathrm{O}-\mathrm{C}$ stretching vibration is significantly higher for the thin fibers than for the thick fibers (Table 8.1). This indicates that by decreasing the fiber diameter, the polytetrahydrofuran segments become more oriented in the fiber direction and hence are more extended. Thinner fiber are subjecte to stronger bending instabilities and experience a longer jet path which is synonymous with a more intense action of elongation force and thus a higher degree of macromolecular orientation ${ }^{42-44}$.

Table 8.1: Qualitative orientation parameter $\left(\mathrm{P}_{\text {qual }}\right)$ from polarized Raman spectra.

\begin{tabular}{lccc}
\hline & \multicolumn{3}{c}{$\mathrm{P}_{\text {qual }}$} \\
& Amide I & Amide II & $\nu$ C-O-C \\
\hline Non-oriented film & 0.10 & 0.07 & 0.06 \\
Oriented film & 0.92 & 0.74 & 0.23 \\
Fiber - 321 nm & 0.55 & 0.78 & 0.74 \\
Fiber - 321 nm & 0.42 & 0.72 & 0.67 \\
Fiber - 321 nm & 0.59 & 0.82 & 0.67 \\
Fiber - 321 nm & 0.64 & 0.73 & 0.47 \\
Fiber - 321 nm & 0.23 & 0.61 & 0.39 \\
Fiber - 321 nm & 0.50 & 0.63 & 0.39 \\
\hline
\end{tabular}

\subsubsection{Mechanical properties of single electrospun PEA fibers}

The tensile properties of the single electrospun PEA fibers were evaluated using an AFM based tensile tester (see section 8.2.4, Figure 8.4). After selecting a fiber that perpendicular crossed the microchannel, the cantilever was positioned under the fiber in the middle of the channel. The tensile experiments were carried out using a piezo tube connected to the microscope table over a distance of $400 \mu \mathrm{m}$ at a rate of $3 \mu \mathrm{m} . \mathrm{s}^{-1}$. Typical stress-strain curves of single electrospun PEA fibers with diameters of 214, 512 and $960 \mathrm{~nm}$ are presented in Figure 8.11b. The stress-strain curve of the $2 \mathrm{~mm}$ thick compression molded dumbbell is included in this graph ${ }^{2}$.

The maximum strain that can be applied with the tensile testing set-up is $\sim 235 \%$, which appeared sufficient to cause sample failure of fibers with diameters $<400 \mathrm{~nm}$. 
(a)

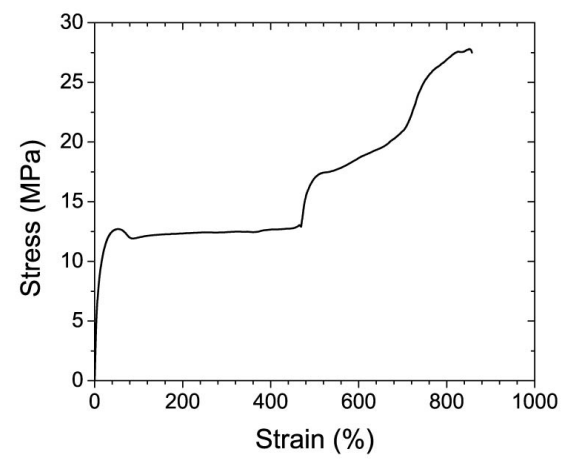

(c)

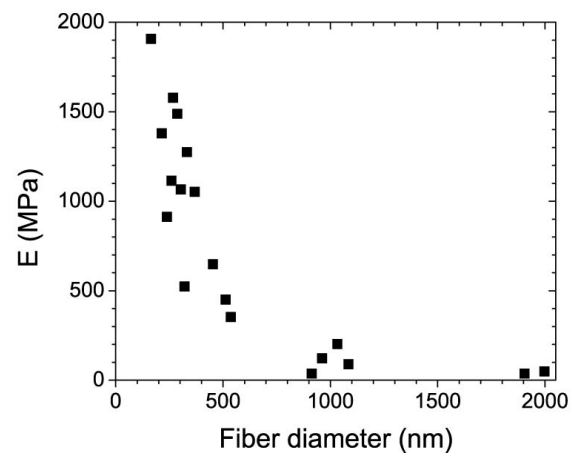

(b)

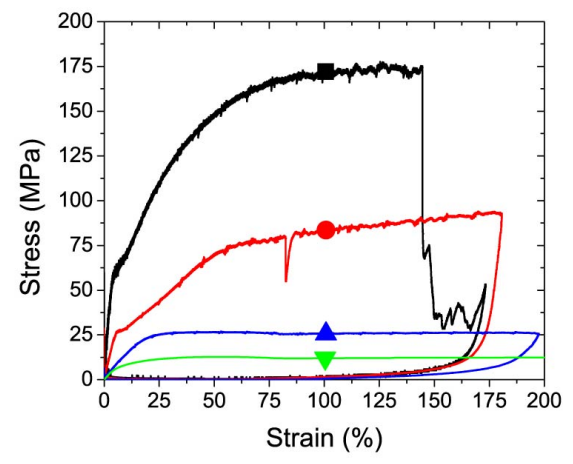

(d)

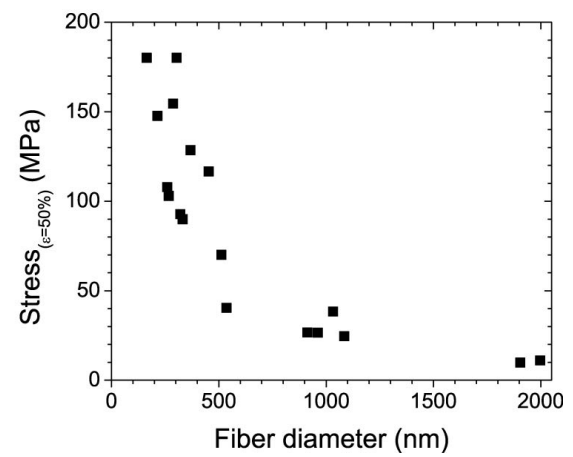

Figure 8.11: Stress-strain curve of (a) a $2 \mathrm{~mm}$ thick compression molded dumbbell, (b) single electrospun PEA fibers with diameters of $(\boldsymbol{\square}) 214 \mathrm{~nm},(\bullet) 512 \mathrm{~nm}$, ( $\Delta$ ) $961 \mathrm{~nm}$ and $(\boldsymbol{\nabla})$ the compression molded dumbbell. (c) E modulus as a function of fiber diameter, (d) Stress at $50 \%$ strain as a function of fiber diameter. The relative error in the E-modulus and tensile strength is $\sim 36 \%$ and is derived from the error in the fiber diameter $(\sim 3 \%)$, the width of the fiber $(\sim 3 \%)$, the spring constant of the cantilever $(\sim 10 \%)$, the deflection sensitivity $(\sim 10 \%)$, and the deflection $(\sim 10 \%)$.

On the other hand, fibers with larger diameters did not break and consequently no ultimate tensile properties could be determined. The fibers with diameters $>900 \mathrm{~nm}$ showed a pronounced yield point followed by necking similar as observed for the $2 \mathrm{~mm}$ thick dumbbell shaped sample. This indicates that fibers with diameters exceeding $900 \mathrm{~nm}$ the bisoxalamide crystals are interconnected. By decreasing the fiber diameter from 2000 to $150 \mathrm{~nm}$, the E-modulus and tensile strength increase from 40 to 2000 $\mathrm{MPa}$ and 10 to $180 \mathrm{MPa}$, respectively. The stiffness and tensile strength of the fibers increase rapidly with decreasing fiber diameters smaller than $\sim 700 \mathrm{~nm}$ as illustrated 
in Figure 8.11c and d, respectively.

This change in mechanical properties can be correlated with the macromolecular orientation in the fiber. Polarized Raman microspectroscopy reveals a higher degree of molecular orientation of the polytetrahydrofuran segments for fibers with diameters $<400 \mathrm{~nm}$ than for thicker fibers i.e. polytetrahydrofuran segments are more extended in thin fibers. Consequently, thin fibers show a higher resistance in axial force and hence have a higher E-modulus and tensile strength

A higher degree of macromolecular orientation and hence an increase of the E-modulus and tensile strength for fibers with small diameters is in line with the fiber diameter effect for electrospun poly( $\epsilon$-caprolactone) as measured by Lim et $a l^{26}$. The authors explained the change in mechanical properties by visualizing changes in the crystalline morphology with AFM. Fibers with small diameters exhibited both fibrillar and aligned structures with amorphous regions consisting of extended tie molecules. On the other hand, Fibers with larger diameters only consisted of misaligned lamellae with amorphous regions consisting of relaxed tie molecules. The fibrillar structures with alternating crystalline and extended amorphous tie molecules showed a higher resistance in axial force than the lamellar structures consisting of relaxed amorphous molecules.

\subsection{Conclusions}

The effect of molecular orientation on the mechanical properties of single electrospun fibers based on a segmented poly(ether amide) comprising polytetrahydrofuran segments $\left(1.1 \times 10^{3}\right.$ g. $\left.\mathrm{mol}^{-1}\right)$ and uniform bisoxalamide segments was investigated. By electrospinning a solution of the PEA in a $9 / 1 \mathrm{v} / \mathrm{v}$ chloroform/formic acid solvent fibers were obtained having diameters in the range of 150 to $2000 \mathrm{~nm}$. The molecular orientation of the polytetrahydrofuran and the bisoxalamide segments in single electrospun fibers was investigated using polarized Raman microspectroscopy. Both segments appeared to be oriented in direction of the fiber axis. For fibers with diameters $<400$ $\mathrm{nm}$ the degree of molecular orientation the polytetrahydrofuran chains is higher than for fibers with diameters larger than $900 \mathrm{~nm}$, whereas the degree of orientation of the bisoxalamide segments is similar. The mechanical properties of single electrospun PEA fibers were investigated using an AFM. The E-modulus and the tensile strength at 50 $\%$ strain of the electospun PEA fibers ranged from 40 to $2000 \mathrm{MPa}$ and 10 to $180 \mathrm{MPa}$ 
and increased rapidly for fibers with diameters below $\sim 700 \mathrm{~nm}$ while the ductility of the fibers decreased. This behavior is explained by the increased extension of the polytetrahydrofuran chains in the direction of the fiber axis when the diameter of the fiber decreases. This research clearly shows that electrospinning strongly influences the molecular orientation and hence the mechanical properties of the segmented poly(ether amide) especially when the diameter of the fibers are below $\sim 700 \mathrm{~nm}$.

\subsection{References}

[1] Sijbrandi, N. J.; Kimenai, A. J.; Mes, E. P. C.; Broos, R.; Dijkstra, P. J.; Feijen, J. Chapter 3, this thesis; University of Twente, 2011.

[2] Sijbrandi, N. J.; Kimenai, A. J.; Mes, E. P. C.; Broos, R.; Rosenthal, G., M. Bar; Odarchenko, Y.; Ivanov, D. A.; Dijkstra, P. J.; Feijen, J. Chapter 4, this thesis; University of Twente, 2011.

[3] Fakirov, S. Handbook of condensation thermoplastic elastomers; Wiley-VCH: Weinheim, 2005.

[4] Holden G, Q. R. S. H., Legge NR Thermoplastic elastomers, 2nd ed.; Hanser Publishers: Munich, 1996.

[5] Greiner, A.; Wendorff, J. H. Angew Chem Int Ed 2007, 46, 5670-5703.

[6] Huang, Z. M.; Zhang, Y. Z.; Kotaki, M.; Ramakrishna, S. Composites Sci Technol 2003, 63 .

[7] Li, D.; Bellan, L. M.; Craighead, H. G.; Frey, M. W. Polymer 2006, 47, 6208-6217.

[8] Bellan, L. M.; Craighead, H. G. Polymer 2008, 49, 3125-3129.

[9] Bianco, A.; Iardino, G.; Manuelli, A.; Bertarelli, C.; Zerbi, G. ChemPhysChem 2007, 8, 510-514.

[10] Dersch, R.; Liu, T.; Schaper, A. K.; Greiner, A.; Wendorff, J. H. J Polym Sci Part A Polym Chem 2003, 41, 545-553.

[11] Kongkhlang, T.; Tashiro, K.; Kotaki, M.; Chirachanchai, S. J Am Chem Soc 2008, 130, 15460-15466.

[12] Li, D.; Xia, Y. Adv Mater 2004, 16, 1151-1170.

[13] Liu, L. Q.; Tasis, D.; Prato, M.; Wagner, H. D. Adv Mater 2007, 19, 1228-1233.

[14] Yoshioka, T.; Dersch, R.; Tsuji, M.; Schaper, A. K. Polymer 2010, 51, 2383-2389.

[15] Bazbouz, M. B.; Stylios, G. K. J Polym Sci Part B Polym Phys 2010, 48, 1719-1731.

[16] Tan, E. P. S.; Lim, C. T. Composites Sci Technol 2006, 66, 1099-1108. 
[17] Carlisle, C. R.; Coulais, C.; Namboothiry, M.; Carroll, D. L.; Hantgan, R. R.; Guthold, M. Biomaterials 2009, 30, 1205-1213.

[18] Hwang, K. Y.; Kim, S. D.; Kim, Y. W.; Yu, W. R. Polym Test 2010, 29, 375-380.

[19] Tan, E. P. S.; Goh, C. N.; Sow, C. H.; Lim, C. T. Appl Phys Lett 2005, 86, 1-3.

[20] Van Der Rijt, J. A. J.; Van Der Werf, K. O.; Bennink, M. L.; Dijkstra, P. J.; Feijen, J. Macromol Biosci 2006, 6, 699-702.

[21] Zussman, E.; Burman, M.; Yarin, A. L.; Khalfin, R.; Cohen, Y. J Polym Sci Part B Polym Phys 2006, 44, 1482-1489.

[22] Tan, E. P. S.; Ng, S. Y.; Lim, C. T. Biomaterials 2005, 26, 1453-1456.

[23] Arinstein, A.; Burman, M.; Gendelman, O.; Zussman, E. Nature Nanotechnology 2007, 2, 59-62.

[24] Chew, S. Y.; Hufnagel, T. C.; Lim, C. T.; Leong, K. W. Nanotechnology 2006, 17, 3880-3891.

[25] Jaeger, D.; Schischka, J.; Bagdahn, J.; Jaeger, R. J Appl Polym Sci 2009, 114, $3774-3779$.

[26] Lim, C. T.; Tan, E. P. S.; Ng, S. Y. Appl Phys Lett 2008, 92.

[27] Wong, S. C.; Baji, A.; Leng, S. Polymer 2008, 49, 4713-4722.

[28] Pully, V.; Lenferink, A.; Otto, C. J Raman Spectrosc 2010, 42, 167-173.

[29] Frisk, S.; Ikeda, R. M.; Chase, D. B.; Rabolt, J. F. Appl Spectrosc 2004, 58, 279-286.

[30] Bognitzki, M.; Czado, W.; Frese, T.; Schaper, A.; Hellwig, M.; Steinhart, M.; Greiner, A.; Wendorff, J. H. Adv Mater 2001, 13, 70-72.

[31] Dayal, P.; Liu, J.; Kumar, S.; Kyu, T. Macromolecules 2007, 40, 7689-7694.

[32] Megelski, S.; Stephens, J. S.; Bruce Chase, D.; Rabolt, J. F. Macromolecules 2002, 35, 8456-8466.

[33] Desseyn, H. O.; Clou, K.; Keuleers, R.; Miao, R.; Van Doren, V. E.; Blaton, N. Spectrochim Acta Part A 2001, 57, 231-246.

[34] Desseyn, H. O.; Perlepes, S. P.; Clou, K.; Blaton, N.; Van der Veken, B. J.; Dommisse, R.; Hansen, P. E. J Phys Chem A 2004, 108, 5175-5182.

[35] Desseyn, H. O.; Vanderveken, B. J.; Herman, M. A. Spectrochim Acta Part A 1977, 33, 633-641.

[36] Nyquist, R. A.; Chrisman, R. W.; Putzig, C. L.; Woodward, R. W.; Loy, B. R. Spectrochim Acta Part A 1979, 35, 91-98.

[37] Matsui, Y.; Kubota, T.; Tadokoro, H.; Yoshihara, T. J Polym Sci, Part A: Polym Chem 1965, 3, 2275-2288.

[38] Odziemkowski, M.; Krell, M.; Irish, D. J Electrochem Soc 1992, 139, 3052-3063. 
[39] Schaufel, R. Trans NY Acad Sci 1967, 30, 69.

[40] Niesten, M.; Harkema, S.; van der Heide, E.; Gaymans, R. J. Polymer 2001, 42, 1131-1142.

[41] Versteegen, R. M.; Kleppinger, R.; Sijbesma, R. P.; Meijer, E. W. Macromolecules 2006, 39, 772-783.

[42] Yarin, A. L.; Koombhongse, S.; Reneker, D. H. J Appl Phys 2001, 89, 3018-3026.

[43] Reneker, D. H.; Yarin, A. L.; Fong, H.; Koombhongse, S. J Appl Phys 2000, 87, 4531-4547.

[44] Reneker, D. H.; Yarin, A. L. Polymer 2008, 49, 2387-2425. 


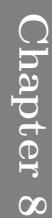




\section{Summary}

Thermoplastic elastomers (TPEs) are melt-processable materials with rubber-like properties. The main difference between TPEs and conventional rubbers is the type of crosslinking of the elastomeric phase. Conventional rubbers contain chemical crosslinks, while the crosslinks in TPEs are physical of nature. These physical crosslinks are thermo-reversible leading to facile processing of TPEs and the ability to recycle scrap. This provide TPEs important economical and environmental advantages over conventional rubbers.

Segmented block copolymers consisting of alternating elastomeric soft segments and rigid hard segments belong to the family of thermoplastic elastomers. The hard segments form rigid domains acting as thermo-reversible crosslinks for the soft elastomeric phase. By using uniform and symmetrical hydrogen bonding arrays comprising carbamate (urethane), urea or amide groups as organizational elements, the phase separated morphology and mechanical properties of segmented block copolymers can be considerably improved.

Oxalamides, diamides of oxalic acid, are interesting hydrogen bonding motifs for use in hard segments. They are conformationally rigid and capable of donating and receiving two hydrogen bonds. Moreover, oxalamides provide nylon type materials (nylon-x,2) properties such as high melting temperatures, high moduli and low solubility in organic solvents. Besides, these attractive physical properties, oxalamides also have attractive economical and environmental aspects.

In this thesis, the synthesis and characterization of segmented poly(ether amide)s based on polytetrahydrofuran (PTHF) soft segments and oxalamide based hard segments are described. To understand the structure-property relations of these polymers, the thermal, physical and mechanical properties have been determined and linked to the phase separated morphology and crystallization of the oxalamide based hard segments.

In chapter 2, an overview of the available literature on segmented poly(ether amide)s is given. The emphasis is on copolymers comprising polydisperse aliphatic and uniform (semi-)aromatic amide based segments. A second topic deals with the conformation and hydrogen bonding characteristics of oxalamide groups. Finally, polyoxalamides are reviewed for their synthesis, thermal properties and crystal structure. 
In chapter 3, the synthesis and characterization of segmented poly(ether amide)s (PEAs) based on flexible PTHF segments $\left(\mathrm{M}_{\mathrm{n}}=1.1 \times 10^{3} \mathrm{~g} \cdot \mathrm{mol}^{-1}\right)$ and uniform rigid oxalamide segments is presented. The amount of oxalamide groups and the spacer length between the oxalamide segments is varied systematically. The polymer having a single oxalamide unit between PTHF blocks is a sticky transparent solid material with a melting temperature around room temperature. FT-IR shows weak hydrogen bonding between the oxalamide units. Uniform hard segments comprising two or three oxalamide groups are strongly hydrogen bonded and highly ordered affording elastic PEAs. The melting temperatures of the bisoxalamide based PEAs increase from 140 to $200{ }^{\circ} \mathrm{C}$ when the number of methylene groups between the two bisoxalamide groups decreased from 10 to 2 . The copolymer with three oxalamide groups in the hard segment has a melting temperature of $220^{\circ} \mathrm{C}$. The thermal transitions are broad and the crystallization transitions sre almost independent on the cooling rate.

The phase separated morphology, temperature dependent behavior and mechanical properties of PEAs containing uniform bis- or trisoxalamide hard segments are investigated in chapter 4 . These polymers appear highly phase separated materials with broad temperature dependent rubber plateaus starting at low temperatures. The oxalamide based hard segments crystallize in fiber-like nano-ribbons, which are randomly dispersed in the amorphous PTHF matrix. Above the melting transition of the bisoxalamide crystals, the materials display a homogeneous melt. The PEAs show a distinct yield point and have an elastic modulus between 121 and $210 \mathrm{MPa}$, a stress at break ranging from 15 to $27 \mathrm{MPa}$ and a strain at break of 150 up to 900 \%. The results demonstrate that alternating copolymers with soft PTHF segments and uniform hard segments containing two or three oxalamide groups are TPEs with good thermal and mechanical properties. Due to the high flow temperature of the PEA with three oxalamide groups in the hard segment, melt processing of these materials becomes difficult. Therefore, incorporation of two oxalamide groups in the hard segment to prepare these polymers seems to be the optimum balance between the material properties and processability.

In chapter 5, low molecular weight bisoxalamide based PEAs either with PTHF or oxamic acid ethyl ester end groups $\left(\mathrm{OXA}_{2} 6\right)$ are described. These polymers are prepared by melt polycondensation of an $\alpha, \omega$-amine end functionalized PTHF $\left(\mathrm{M}_{\mathrm{n}}\right.$ $=1.1 \times 10^{3}$ g. $\mathrm{mol}^{-1}$ ) and a bisoxalamide precursor applying different molar feed. All polymers have low glass transition temperatures and hence have extended rubber plateaus with moduli ranging from 57 to $85 \mathrm{MPa}$ up to the flow temperatures ranging 
from 140 to $160{ }^{\circ} \mathrm{C}$. The PEAs with PTHF end groups have two melting transitions, corresponding to melting of crystallized PTHF end groups as well as melting of the crystallized bisoxalamide phase. By increasing the molecular weight of the polymer, the melting temperature of the PTHF endgroup decreases from 15 to $-18{ }^{\circ} \mathrm{C}$. The bisoxalamide crystal display a broad melting traject between 90 and $190{ }^{\circ} \mathrm{C}$ independent on the molecular weight. Polymers having $\mathrm{OXA}_{2} 6$ end groups display only one broad melting transition ranging from $80-190{ }^{\circ} \mathrm{C}$. Increasing the molecular weight reveals a brittle to ductile transition at a molecular weight of $\sim 15 \times 10^{3}$ g.mol ${ }^{-1}$.

Chapter 6 describes the synthesis and characterization of bisester-bisoxalamides, which are structural units to be used as hard segments in TPEs. These compounds are prepared by reacting in a first step $\alpha, \omega$-diamines with lengths of 2, 4 and 6 methylene groups with an excess of diethyl oxalate. Subsequently, the amide-esters are reacted with (pseudo) amino acid esters, glycine and $\beta$-alanine ethyl ester, affording the bisester-bisoxalamides. The compounds are used as model compounds to elucidate the crystallization behavior of the corresponding segmented poly(ether ester amide)s (PEEAs). A qualitative model based on FT-IR and X-ray diffraction reveals that all compounds form hydrogen bonded sheets by stacking of the bisoxalamide units forming like-to-like amide-amide hydrogen bonds with a hydrogen bonding distance of $\sim 5 \AA$. Moreover, the ester side groups are spatially tilted away from the oxalamide plane. The distance between the hydrogen bonded sheets is for all compounds $\sim 5$ $\AA$.

High molecular weight PEEAs are prepared by melt polycondensation of the bisesterbisoxalamides with $\alpha, \omega$-hydroxyl end functionalized PTHF $\left(\mathrm{M}_{\mathrm{n}}=1.0 \mathrm{x} 10^{3}, 2.0 \times 10^{3}\right.$ and $2.9 \times 10^{3}$ g.mol ${ }^{-1}$ ). The effect of the structure of the bisester-bisoxalamide segment and the length of the soft PTHF block on the thermal, physical and mechanical properties of the PEEAs is discussed in chapter 7. All PEEAs appear to be highly phase separated materials with a broad temperature independent rubber plateau starting at low temperatures. The bisoxalamide hard segments almost completely crystallize in fiber-like nano-crystals, which are randomly dispersed in the PTHF matrix. The crystal structure of the bisester-bisoxalamide monomers are preserved in the PEEAs. The melting transitions of all hard segments are sharp and range from 119 to $170{ }^{\circ} \mathrm{C}$. The PEEAs have an elastic modulus between 139 and $170 \mathrm{MPa}$, a stress at break ranging from 18 to $31 \mathrm{MPa}$ and a strain at break higher than $800 \%$. By changing the glycine ester group into a $\beta$-alanine ester group while keeping the spacer length constant, leads to an increase in the melting transition from 119 to 141 
${ }^{\circ} \mathrm{C}$ and an increase in the fracture stress from 22 to $31 \mathrm{MPa}$. The improved thermal and mechanical properties of the $\beta$-alanine based polymer is related to the crystal packing of the $\beta$-alanine based segment in the copolymer compared to the packing of the hard segments comprising glycine ester groups.

Chapter 8 describes the effect of molecular orientation on the mechanical properties of single electrospun fibers based on PEAs comprising uniform bisoxalamide segments and PTHF segments (as prepared in chapter 3). Electrospun PEA fibers with diameters ranging from 150 to $2000 \mathrm{~nm}$ are successfully produced from a chloroform/formic acid solution (9/1 v/v). Polarized Raman microspectroscopy on single electrospun PEA fibers reveals that both bisoxalamide and PTHF segments are oriented in the direction of the fiber axis. While the molecular orientation of the bisoxalamide segments in single electrospun appears independent on the fiber diameter, the molecular orientation of the PTHF segments for fibers with diameters $<400 \mathrm{~nm}$ is higher than for fibers with diameters $>900 \mathrm{~nm}$. The tensile properties of single electrospun PEA fibers are investigated using an atomic force microscope (AFM). By decreasing the fiber diameter from 2000 to $150 \mathrm{~nm}$, the E-modulus and tensile strength increase from 40 to 2000 $\mathrm{MPa}$ and 10 to $180 \mathrm{MPa}$, respectively. For fibers smaller than $700 \mathrm{~nm}$ the stiffness and tensile strength increased rapidly with decreasing fiber diameter, whereas the ductility decreases. This research clearly shows that electrospinning strongly influences the molecular orientation and hence the mechanical properties of the PEA especially when the diameter of the fibers are below $700 \mathrm{~nm}$. 


\section{Samenvatting}

Thermoplastische elastomeren (TPE's) zijn materialen met rubberachtige eigenschappen die in de smelt kunnen worden verwerkt. Het belangrijkste verschil tussen TPE's en conventionele rubbers is het type van verknoping ("crosslinking") van de elastische fase. Conventionele rubbers bevatten chemische crosslinks, terwijl de crosslinks in TPE's fysisch zijn. Deze fysische crosslinks zijn thermoreversibel met als gevolg dat TPE's goed in de smelt te verwerken zijn en b.v. afval kan worden gerecycled. Dit verschaft TPE's belangrijke economische en milieutechnologische voordelen ten opzichte van conventionele rubbers.

Gesegmenteerde blok-copolymeren bestaande uit alternerende elastische zachte segmenten en rigide harde segmenten behoren tot de familie van thermoplastische elastomeren. De harde segmenten vormen domeinen welke zich gedragen als thermoreversibele crosslinks voor de zachte elastische fase. Door gebruik te maken van uniforme en symmetrische waterstofbrug vormende blokken, bestaande uit b.v. carbamaat, urea of amide groepen als organiserende elementen, kunnen de fase gescheiden morfologie en mechanische eigenschappen van gesegmenteerde blok-copolymeren aanzienlijk worden verbeterd.

Oxalamides, diamides van oxaalzuur, zijn waterstofbrug vormende groepen en komen voor in een enkele conformatie. Bovendien geven oxalamides, nylon-achtige materialen (nylon-x,2) met hoge smelttemperaturen, hoge moduli en goede weerstand tegen organische oplosmiddelen.

Dit proefschrift beschrijft de synthese en eigenschappen van gesegmenteerde poly(ether amide)s gebaseerd op polytetrahydrofuran (PTHF) zachte segmenten en oxalamide gebaseerde harde segmenten. Om de structuur-eigenschap relaties van deze materialen te begrijpen, worden de thermische, fysische en mechanische eigenschappen bepaald en wordt er een verband gelegd tussen de fase gescheiden morfologie en kristallisatie van de oxalamide type harde segmenten.

In hoofdstuk 2 wordt een overzicht gegeven van gesegmenteerde poly(ether amide)s. De nadruk ligt op copolymeren gebaseerd op polydisperse alifatische en uniforme (semi-) aromatische amide segmenten. Daarnaast zijn de conformatie en waterstofbrug vormende eigenschappen van oxalamide groepen beschreven. Tot slot is in dit hoofdstuk een overzicht gegeven van de synthese, thermische eigenschappen en de kristal structuur van polyoxalamides. 
In hoofdstuk 3 wordt de synthese van gesegmenteerde poly(ether amide)s (PEA's) gebaseerd op flexibele PTHF segmenten $\left(\mathrm{M}_{\mathrm{n}}=1.1 \times 10^{3} \mathrm{~g} \cdot \mathrm{mol}^{-1}\right)$ en uniforme rigide oxalamide segmenten beschreven. Het aantal oxalamide groepen en de lengte tussen de oxalamide segmenten is systematisch gevariëerd. Het polymeer met één enkele oxalamide groep tussen de PTHF segmenten is een plakkerig transparant materiaal met een smelttemperatuur rond kamertemperatuur. FT-IR spectra laten een zwakke waterstofbrug vorming zien tussen de oxalamide eenheden. PEA's met uniforme harde segmenten welke twee of drie oxalamide groepen bevatten zijn sterk waterstofbrug gebonden, in hoge mate geordend en elastisch. De smelttemperaturen van de bisoxalamide gebaseerde PEA's, nemen toe van 140 tot $200{ }^{\circ} \mathrm{C}$ met een afnemened aantal methyleen groepen tussen de twee oxalamide groepen. Het copolymeer met drie oxalamide groepen in het harde segment heeft een smelttemperatuur van $220^{\circ} \mathrm{C}$. De thermische overgangen zijn breed en vrijwel onafhankelijk van de afkoelsnelheid.

De fase gescheiden morfologie, het temperatuur afhankelijke gedrag en de mechanische eigenschappen van PEA's met bis- of trisoxalamide gebaseerde harde segmenten zijn beschreven in hoofdstuk 4 . Deze materialen zijn sterk fase gescheiden materialen met brede temperatuur onafhankelijke rubber plateaus. De oxalamide gebaseerde harde segmenten kristalliseren in vezel-achtige nano-kristallen, willekeurig verdeeld in de zachte amorfe matrix. De polymeren geven een homogene smelt boven de smelttemperatuur van de bisoxalamide kristallen. De PEA's hebben een modulus variërend van 121 en $210 \mathrm{MPa}$, een stress bij breuk variërend van 15 tot $27 \mathrm{MPa}$ en een rek bij breuk oplopend van 150 tot $900 \%$. De resultaten tonen aan dat deze alternerende copolymeren met zachte PTHF segmenten en uniforme harde segmenten, TPE's zijn met goede thermische en mechanische eigenschappen. Door de hoge smelttemperatuur van de PEA met drie oxalamide groepen in het harde segment is verwerking van de polymeren in de smelt moeilijk. Samenvattend, polymeren met twee oxalamide groepen in het harde segment leveren een optimale balans tussen materiaal eigenschappen en verwerkbaarheid.

In hoofdstuk 5 worden bisoxalamide gebaseerde PEA's met een laag moleculair gewicht beschreven die PTHF of oxaalzure zuur ethyl ester eindgroepen $\left(\mathrm{OXA}_{2} 6\right)$ bevatten. Deze polymeren zijn bereid via een smeltpolycondensatie van een $\alpha, \omega$-amine eind gefunctionaliseerd PTHF $\left(\mathrm{M}_{\mathrm{n}}=1.1 \times 10^{3} \mathrm{~g} \cdot \mathrm{mol}^{-1}\right)$ en een bisoxalamide door het toepassen van verschillende molaire verhoudingen. Alle polymeren hebben een lage glasovergangstemperatuur en derhalve een breed rubber plateau met moduli variërend van 57 tot $85 \mathrm{MPa}$ en vloeitemperaturen variërend van 140 tot $160{ }^{\circ} \mathrm{C}$. De PEA's met 
PTHF eindgroepen hebben twee smeltovergangen, die overeenkomen met het smelten van gekristalliseerde PTHF eindgroepen alsmede het smelten van de gekristalliseerde bisoxalamide fase. Door een verhoging van het molecuulgewicht van het polymeer daalt de smelttemperatuur van de PTHF eindgroep van 15 tot $-18^{\circ} \mathrm{C}$. De bisoxalamide kristallen laten een breed smelt traject zien onafhankelijk van het molecuulgewicht. Polymeren met $\mathrm{OXA}_{2} 6$ eindgroepen laten alleen brede smeltovergangen zien. De bros naar taai overgang ligt bij een moleculair gewicht van $\sim 15 \times 10^{3}$ g.mol ${ }^{-1}$.

Hoofdstuk 6 beschrijft de synthese en karakterisering van bisester-bisoxalamides, structurele eenheden die gebruikt zijn als harde segmenten in TPE's. Deze verbindingen zijn gemaakt door in een eerste stap $\alpha, \omega$-diamines met lengte van 2, 4 of 6 methyleen groepen te laten reageren met een overmaat diethyloxalaat. De bisester-bisoxalamides zijn vervolgens gemaakt door de gevormde amide-esters verbindingen te laten reageren met de (pseudo) aminozure esters, glycine en $\beta$-alanine ethyl ester. De bisesterbisoxalamides worden gebruikt als model verbindingen om het kristallisatie gedrag van de overeenkomstige gesegmenteerde poly(ether ester amide)s (PEEA's) op te helderen. Een kwalitatief model gebaseerd op FT-IR en X-ray diffractie laat zien dat alle verbindingen zich stapelen in een vlak via oxalamide-oxalamide waterstofbruggen met een waterstofbrug afstand van $\sim 5 \AA$. Bovendien zijn de ester zijgroepen ruimtelijk gekanteld uit het oxalamide vlak. De afstand tussen de waterstofbrug vlakken is voor alle verbindingen $\sim 5 \AA$.

PEEA's met een hoog moleculair gewicht zijn bereid door $\alpha, \omega$-hydroxyl eind gefunctionaliseerde PTHF te condenseren met de bisester-bisoxalamides, in de smelt. Het effect van de structuur van de bisester-bisoxalamide segmenten en de lengte van het zachte PTHF blok op de thermische, fysische en mechanische eigenschappen van de PEEAs wordt besproken in hoofdstuk 7. Alle PEEAs blijken in hoge mate fase gescheiden materialen te zijn met een breed temperatuur onafhankelijk rubber plateau beginnend bij lage temperaturen. De bisoxalamide harde segmenten kristalliseren vrijwel volledig uit in vezel-achtige nano-kristallen, willekeurig verspreid in de PTHF matrix. De kristalstructuur van de bisester-bisoxalamide monomeren blijven bewaard in de PEEA's. De smelt overgangen van alle harde segmenten zijn scherp en variëren van 119 tot $170{ }^{\circ} \mathrm{C}$. De PEEA's beschikken over een elasticiteit modulus tussen de 139 en $170 \mathrm{MPa}$, een stress bij breuk variërend van 18 tot $31 \mathrm{MPa}$ en een rek bij breuk hoger dan $800 \%$. Het vervangen van de glycine ester groep door een $\beta$-alanine ester groep, met gelijke lengte tussen de oxalamide groepen, resulteert in een toename van de smeltovergang van 119 tot $141{ }^{\circ} \mathrm{C}$ en een verhoging van de stress bij 
breuk van 22 tot $31 \mathrm{MPa}$. De betere thermische en mechanische eigenschappen van het $\beta$-alanine gebaseerde polymeer is gerelateerd aan de kristallijne pakking van het $\beta$-alanine gebaseerde segment in het copolymeer ten opzichte van de pakking van de harde segmenten bestaande uit glycine ester groepen.

Hoofdstuk $\mathbf{8}$ is het effect van de moleculaire oriëntatie op de mechanische eigenschappen van één enkele electrogesponnen vezel op basis van PEA's bestaande uit uniforme bisoxalamide segmenten en PTHF segmenten (zoals gesynthetiseerd in hoofdstuk 3). PEA vezels met diameters variërend van 150 tot $2000 \mathrm{~nm}$ zijn electrogesponnen uit een chloroform/mierezuur oplossing $(9 / 1 \mathrm{v} / \mathrm{v})$. Gepolariseerde Raman microspectroscopie op de PEA vezels laat zien dat zowel bisoxalamide als PTHF segmenten zijn georiënteerd in de richting van de vezel as. Terwijl de moleculaire oriëntatie van de bisoxalamide segmenten in één enkele electrosponnen vezel onafhankelijk blijkt te zijn van de vezel diameter, is de moleculaire oriëntatie van de PTHF segmenten voor vezels met een diameter van kleiner dan $400 \mathrm{~nm}$ hoger dan voor vezels met een diameter groter dan $900 \mathrm{~nm}$. De mechanische eigenschappen van electrosponnen PEA vezel zijn gemeten met behulp van een 'atomic force microscope' (AFM). Bij een afnemende diameter (2000 tot $150 \mathrm{~nm}$ ), neemt de E-modulus toe van 40 naar $2000 \mathrm{MPa}$ en de treksterkte neemt toe van 10 naar $180 \mathrm{MPa}$. Dit onderzoek toont duidelijk aan dat de moleculaire oriëntatie een grote invloed heeft op de mechanische eigenschappen van de PEA vezels. 


\section{Overpeinzingen in een dankwoord}

Het is zaterdagmiddag als we ons gereed maken voor een middagje vissen aan het Wad bij Harlingen. De zon schijnt en er staat weinig of geen wind. "Vergeet niet een pet of factor 20 mee te nemen". Bij de zee ben je zonder deze hulpmiddelen gelijk aan één die wellicht nu nog in de zee zwemt. Beter gezegd loopt of wat een kreeft ook maar doet om vooruit te komen in deze wereld. Echter voordat we kunnen beginnen moeten we eerst naar Zurich (Friesland) om aas te halen. Dit echter meer met het vooruitzicht om de middenstand van Zurich te ondersteunen dan met de verdere verwachtingen van de enorme vangsten die we zullen behalen. "De zee geeft en neemt" wordt ergens in een bekend toneelstuk verkondigd, maar hier is het eigenlijk alleen maar het tweede. $\mathrm{Na}$ een drie kwartier komen we aan bij de visgronden en kunnen we beginnen aan het wachten, wachten waarop? "Vissen dat is niks voor mij", zei mijn opa altijd. "Je sitte te wachten op één dyt je noch noait keken hewwe". Terwijl we daar zo zitten en de krabben ons van het dure gekweekte aas afhelpen, valt het op dat de Waddenkust maar weinig ontsierd wordt door het vele afval dat door de zee wordt aangevoerd. De Waddenkust heeft wel veel meer verontreiniging gekend.

Maar nu ik hier sta, is het leuk om alle mensen te bedanken, die me ontzettend hebben geholpen met het tot stand komen van dit boekje. Laat ik het zo doen met het ene oog in gedachten gericht over het Wad naar Terschelling vanwaar jullie komen en zo aan dit dankwoord worden toegevoegd. Het andere oog gericht op het puntje van de hengel want het is zoals mijn opa sège su "je mutte by de les bliefe, wat der oek gebeurd".

$\mathrm{Na}$ enkele overpeinzingen waarin een paar beelden uit het verleden mij zomaar te binnen schieten, wil ik nu beginnen met de mensen te bedanken die de laatste vijf jaren mij hebben geholpen en vooral hebben gesteund bij het doen van het onderzoek en het schrijven van het proefschrift.

Als eerste wil ik mijn assistent-promotor Piet Dijkstra bedanken. Het laatste gedeelte van de werkzaamheden vielen me zwaar. Schrijven was en is mijn hobby niet. Soms was er enige mis communicatie en duurde het allemaal wat langer. Toch ben ik dankzij jouw hulp gekomen bij het resultaat dat er nu ligt. Piet, ontzettend bedankt voor je begeleiding en vooral bij het nakijkwerk dat je moest doen voor dit proefschrift. De tweede man, die ik zeker moet noemen is mijn promotor Jan Feijen. Op details bracht $\mathrm{U}$ verbeteringen aan en gaf $\mathrm{U}$ uw goedkeuring. Bij $\mathrm{U}$ kwam ik zeker met positieve gevoelens weg na een meeting. Niet alleen dat ik bij U mag promoveren, maar het 
was voor mij extra leuk om bij het filmpje, dat we ter ere van uw afscheid hadden gemaakt, ik in uw huid mocht kruipen. Alle goede herinneringen blijven je bij, wat me zeker bij zal blijven zijn de rookwolken en de smaak van uw stevige sigaren.

Zoals menig mossel uit de Waddenzee wordt gevangen en naar Zeeland wordt verscheept, ben ik ook regelmatig gedurende de laatste jaren in Zeeland geweest. In tegenstelling tot de mossel die in een Zeeuwse pan eindigt, heb ik een vruchtbare samenwerking gehad met de mensen van DOW in Terneuzen. In het bijzonder wil ik René Broos bedanken voor al zijn hulp de laatste jaren. René, jouw interesse in en visie op het project heb ik altijd erg plezierig gevonden en zeer gewaardeerd. By the way, René, heb je ooit eens een lijntje in de Westerschelde uitgezet en daar ooit veel meer mee uitgehaald dan er in gegooid....? Edwin Mes is nauw betrokken geweest bij de samenwerking en heeft vele malen de oversteek van Terneuzen naar Enschede gemaakt. Edwin bedankt voor je interesse en de verschillende metingen die je hebt uitgevoerd. Rudy Koopmans wil ik bedanken voor zijn voortdurende interesse in de exploratie van zelf-assemblerende polymeren. Daarnaast bedank ik de volgende DOW mensen voor de vele metingen die in dit proefschift terug te vinden zijn: Ad Kimenai, Brian Dickie, Pascal Pijcke, Hans de Jonge, Chris Torfs en Marlies Totte-Van 't Westeinde.

Another fruitful collaboration I had was with Georg Bar (DOW), Martin Rosenthal, Yaroslav Odarchenko and Dimitri Ivanov (ICSI, Mulhouse). I'm still amazed at the amount of X-ray diffraction measurements and results. A small fraction of all these results can be found in chapters 4,6 and 7 . Thank you guys for everything.

Als afwisseling op het polymeer bakken heb ik in samenwerking met Kees van der Werf en Martin Bennink (NanoBioPhysics groep, Utwente) de mechanische eigenschappen van electrogesponnen vezels bepaald (hoofdstuk 8). Ik wil jullie beide hartelijk bedanken voor de tijd en het werk dat jullie hier in hebben gestopt. Kees, ik vind het bijzonder hoe jij voor elk praktisch probleem altijd weer een oplossing weet te bedenken. In één adem kan ik noemen: Aufried Lenferink en Cees Otto (Medical Cell BioPhysics groep, Utwente) die hebben geholpen met het uitvoeren van de Raman metingen en de discussie van de resultaten.

De mooie AFM plaatjes in mijn proefschrift zijn gemaakt door Hetty ten Hoopen. Hetty, jij weet altijd weer mooie fiber structuren op het beeldscherm te toveren waarvoor mijn dank. Zoals al in menig dankwoord vermeld zou de vakgroep niets zijn zonder Karin Hendriks. Alle administratieve beslommeringen (+ koffiesleutels) zijn in vertrouwde handen bij jou. Voor bestellingen van chemicaliën en andere 
laboratorium benodigdheden kon ik altijd terecht bij de altijd vrolijke Zlata Rekenji. Het onderhoud van apparaten, de veiligheid in de laboratoria en ander lab gerelateerd werk is altijd in goede handen geweest bij Anita Podt en Marc Ankoné, waarvoor bedankt. Met Marc heb ik 3 jaar lang eerstejaars studenten begeleid met de ester synthese. Zodoende hebben we vele waterbakken moeten schoonmaken, scheurende waterslangen vervangen en borrelende oliebaden moeten legen. Ook wil ik graag de overige stafleden van PBM: Dirk Grijpma, André Poot en Johan Engbersen bedanken. $\mathrm{Al}$ hadden we projectmatig niet direct iets met elkaar te maken, jullie kritische noot en vragen tijdens de vakgroepmeetings op maandagochtend gaven wel mede impulsen aan het onderzoek.

Helaas heb ik maar één student mogen begroeten. Er was wellicht weinig interesse vanuit de bachelor- of master hoek voor mijn onderzoek. Iemand die toch de stoute schoenen aantrok, wil ik hier zeker noemen: Gianini Kroes. Gianini veel succes met het verdere verloop van je studie.

Een aparte alinea is er voor de collega's. Buiten het werk hebben we vele activiteiten gehad zoals werkweken, triatlons, zeskampen etc, etc... Mede door al deze activiteiten kijk ik met heel veel plezier terug op mijn periode als AIO. Sytze, wij hebben 4 jaar lang naast elkaar in het lab gestaan en daarnaast zijn we op reis geweest naar Milaan en Barcelona. Dat waren top mid-weekjes en zullen mij nog lang bij blijven. Binnenkort gaan we op herhaling in Edinburgh, zou je daar ook BACO's kunnen bestellen? Ik wil je alvast bedanken voor het paranimf zijn op 1 september. Jos, ook jij hebt jaren met mij in het lab gestaan en was mee naar Milaan, Barcelona en Edinburgh. Daarnaast hebben wij de laatste jaren vaak de elementen van moeder natuur getrotseerd om 's nachts van de stad weer terug naar de campus te fietsen. Ook jij alvast bedankt voor het paranimf zijn op 1 september. Hans, samen hebben we de triatlon en een werkweek georganiseerd, daarnaast hebben we een lange tijd op zondag avond speciaal bier gedronken. Vele activiteiten in de groep zijn door jou geïnitieerd. Waarvoor dank. Mocht je ooit nog een carrière switch overwegen dan kun je altijd nog acteur, schipper, hulp-Sinterklaas of TomTom voor Twente Tours worden. Andries, hoewel onze onderzoeksgebieden ver uit elkaar lagen hebben we samen mede de werkweek naar Gent en Mainz georganiseerd, veel koffie gedronken en Belgisch gersten nat genuttigd. Ook hebben we samen de hoogste sportieve prestaties geleverd; drie maal de poedelprijs in de triatlon, helaas werden deze nooit uitgereikt. Bij één van deze prestaties, welke nog wel een aantal jaartjes zal blijven staan, complementeerde Kim het team. Kim!, je vraagt al maanden of ik het dankwoord al heb geschreven, nu 
is het eindelijk af. Ik wil jou bedanken voor alle vrolijkheid op borrels, zeskampen en andere sociale activiteiten die jij (gewapend met een glas rose rosé in je hand) hebt gebracht. Marloes, we hebben samen de werkweek georganiseerd en tevergeefs geprobeerd om een vlieger op te laten op het strand in Noordwijk aan Zee. Je bent al een tijdje in Australië, maar vaak heb ik jouw kenmerkende lach gemist tijdens koffiepauzes en borrels. Siggi, ik ben erg benieuwd naar de eerste zondag na mijn promotie. Zou deze net zo relaxed zijn als jij hem beschreef? Wij hebben het laatste jaar van het proefschrift schrijven toch wel geleerd wat afzien is. Ik vond het een hele eer om jouw (in dirndl, Mann héééé) te spelen in je promotie filmpje. Janine, ik waardeer erg jouw attentheid van het sturen van vacatures. Ook jouw alertheid is bijzonder, je ziet gelijk wanneer ik een mode trend wil starten door twee verschillende schoenen aan te trekken. Al heb je diezelfde avond wel een kratje bier aan Hans en mij verloren. Erhan, samen hebben wij jaren lang de thermische analyse apparatuur zo goed mogelijk proberen te onderhouden. Ook zat jij in de organiserende commissie van de studie reis naar Gent en Mainz, waarvan vooral de tweede avond in Mainz mij lang zal bij blijven. Erwin, jouw komst betekende 'vers bloed' in een leeglopende groep. Ik moet je veel succes wensen met het beheer van de DSC. Sjoerd, ook jij zat bij het clubje zondagavond speciaal bierdrinkers. Jij was de man van de stevige biertjes op de verkeerde momenten. Martin, de week in Milaan was erg leuk. Also a special thank to my former Indian colleagues, Rani, Arun and Debasish, I enjoyed your presence in and outside the lab. Jung Seok, thanks for being my office mate for four years. Verder moeten in deze alinea ook zeker genoemd worden: Mark P, Rong, Gregory, Chao, Mark ten B, Ingrid, Henriette, Christine, Zheng, Di, Arkadi, Federico, Miguel, Booh Hua, Wei, Yan, Lanti, Bas, Erwin, Sameer, Sri Dewi, Sandra de V, Vincent, Kasia, Hongzhi, Yan, Wei, Sandra T, Federico, Alfredo, Ferry, Federica, Debby, Anne Corine, Wilco, Joost, Sander, Jacob, Gert-Jan, Anita, Jolanda, Suzanne, Kicki en alle andere (voormalige) collega's en studenten van de vakgroepen PBM, BST, BMC, STEP, MTP en ETE.

Tien jaar aan de Calslaan. Met alle verschillende flatmaaltijden van flatgenoten, die gedurende deze tijd langs gekomen zijn in het geheugen, kan het niet anders dan dat ik jullie zeker moet bedanken. Wat zijn er vele goede, kleine, grote, mindere maaltijden gevolgd. Een leven zonder Kip Madras kan ik me niet meer voorstellen.

Tot slot wil ik mijn ouders bedanken. Ook al betwijfel ik of ik jullie precies heb kunnen uitleggen wat ik heb onderzocht, jullie interesse was er niet minder om. Jullie hebben mij altijd gestimuleerd om te studeren en om mij verder te ontwikkelen en als ik ook 
maar ergens hulp bij nodig heb kan ik altijd bij jullie terecht.

Mijn hengel staat nog steeds naast me. Het puntje beweegt heen en weer. Plotseling is er een verhoogde activiteit. Ik kijk om me heen, de wind....? Een verhoogde golfslag....? Zeewier....? De hengel blijft bewegen, ik pak hem voorzichtig tussen de basaltblokken weg, alsof een slachtoffer dat op 30 meter afstand zal voelen. Langzaam haal ik de lijn binnen. Omdat de hengel steeds verder doorbuigt, begin ik te geloven dat er wat anders binnenkomt dan de geijkte laars. Het vieze gezicht van mijn moeder zie ik thuis al verschijnen. "Had dat vieze beest gelaten waar ie thuis hoorde. Dat wil ik niet in mijn keuken en in mijn pan ". Het laatste stukje moet over de basaltblokken omhoog worden geslingerd. Ik buig mij over de vangst heen. Dit is iets waar mijn opa mij altijd al voor waarschuwde: "Gaan toch niet op één sitte te wachten dyt je noch noait sien hewwe". Het blijft bijzonder wat de zee ons geeft. Laat ik deze wel heel bijzondere vangst een heel bijzondere naam geven "Elkenientsje". Ik zet haar terug naar waar zij hoort. Bedankt.

\section{Niels}

September, 2011, Enschede 


\section{Curriculum Vitae}

Niels Sijbrandi is geboren op 20 februari 1982 te Franeker. Na het behalen van zijn VWO diploma aan de Regionale Scholen Gemeenschap Simon Vestdijk te Harlingen in 2000, is hij Chemische Technologie gaan studeren aan de universiteit Twente. In de laatste twee jaar van zijn studie heeft hij zich gespecialiseerd in de richting van materiaalkunde en specifiek op polymeerchemie en technologie. In 2005 heeft hij stage gelopen by Océ Technologies in Venlo, Nederland. De stage opdracht was getiteld: "Styreen-acrylaten als functioneel oplosmiddel voor toner hars". Na deze stage begon hij met afstuderen bij de groep Synthesis and Technology of Engineering Plastics aan de universiteit Twente van dr. R.G. Gaymans onder begeleiding van dr. D. Husken. De afstudeeropdracht had als titel: "Thermoplastic elastomers with definable endblocks". In 2006 behaalde hij zijn universitaire diploma. In de vakgroep Polymer Chemistry and Biomaterials ging hij vervolgens verder werken als assistent in opleiding onder begeleiding van prof. dr. J. Feijen en prof. dr. P.J. Dijkstra. Het promotieonderzoek

was getiteld:" Oxalamides as a hydrogen bonding motif in thermoplastic elastomers". De resultaten van dit onderzoek staan beschreven in dit proefschrift. 
